\title{
PEER INTERACTIONS AMONG UNDER THREE YEARS OLD CHILDREN IN MALAYSIAN CHILDCARE CENTRES: A CASE STUDY APPROACH
}

BY

FARHANA WAN YUNUS

A thesis submitted to the Victoria University of Wellington

in fulfilment of the requirements for the degree of

Doctor of Philosophy

Victoria University of Wellington 
This thesis is dedicated to my parents:

To my father who has taught me that knowledge is priceless.

To my mother who inspires me to love all children like our own. 


\begin{abstract}
Research on infants' and toddlers' peer interactions in childcare centres shows many benefits for children's social competence. With increasing participation of under-three year olds in group-based early childhood services worldwide, there is also growing interest in the role played by childcare adults in supporting children's social competence. In the Malaysian context, where the number of childcare settings is growing rapidly, early childhood research remains limited and is non-existent within the field of understanding the complexity of infants' and toddlers' peer interactions. At the same time there has been a mounting discourse by Malaysian economists promoting the benefits of non-cognitive skills to a country, thus focussing attention on social skills, of which peer interactions are a form. This study opens up this under-researched field in Malaysia through three qualitative case studies - one in each of three childcare centres in the state of Selangor. Each case study involved individual semi-structured interviews with the childcare practitioners, video-recorded observations of the children's peer interactions, and video-stimulated recall interviews. A focus group discussion was conducted too with all of the practitioners after that. The aim of the study was to examine how practitioners perceived peer interactions among children under three years old in their childcare centres, and the kinds of peer interactions that occurred among the children. Drawing on constructs from a range of social constructivist theoretical perspectives, the findings revealed that at the start of the study, the practitioners saw themselves as promoting peer interactions by facilitating group activities and managing interactions between children by responding to their conflicts. The observations of children's peer interactions revealed complex negotiations by the children who were actively creating a sense of belonging and togetherness at their childcare centres like embracing the centre's routines, and responding to the needs of others including through humour and laughter. In the process of these interactions, children exercised their agency and learned the skills of becoming socially competent participants in their centre. Through video-stimulated recall interviews and focus group discussion, the practitioners deepened their thoughts on children's peer interactions and saw peer interactions to be linked with learning around three main themes: learning through play; learning through gaining familiarity with
\end{abstract}


others; and learning about having friends. My findings provide a picture of how the children's peer interactions were understood by largely untrained practitioners, and how the complexity of children's lived experiences remained hidden to the practitioners until they took part in the video-stimulated recall interviews; the latter opened up and deepened the practitioners thoughts about children's peer interactions. This study differs from earlier studies in that it is based in Malaysia where the provision of group-based early childhood care and education services is still a relatively new social and educational endeavour staffed by largely unqualified practitioners. This has implications for future childcare training initiatives in Malaysia.

Keywords: peer interactions, practitioners' perceptions, early childhood education, belonging, togetherness, conflicts, agency, social competence, video-stimulated recall, focus group discussions, qualitative case study. 


\section{ACKNOWLEDGEMENT}

This study would not have been possible without the help of so many people. There are many people to thank. I wish to acknowledge the following people for their support in many different ways:

Firstly, I would like to thank my participants for generously taking part in this study. Without you, this thesis would be non-existent. Your willingness in allowing me into your space is something I will treasure for a lifetime.

This thesis would be non-existent too without the advice and support of my supervisors, Prof. Carmen Dalli and Prof. Vanessa Green. Thank you for your encouragement, patience, scholarly advice and thoughtful recommendations over these years.

My husband, Ahmad Ridza, for his love and support throughout this study and for being the stay-at-home-dad even though he could be doing something else out there. Thank you for believing in me even when I stopped believing in myself.

My parents (Wan Yunus \& Zubaidah), my parents-in-law (Mohd Rozlan \& Raihana) and other family members in Malaysia who sent flying kisses, unconditional love, and unwavering support everyday through video calls. Thank you for your prayers, your faith in me and the innumerable sacrifices you made on my behalf.

My beautiful $\mathrm{PhD}$ babies, Medina and Yasmeen, who were born alongside this thesis. I learn a lot about children's peer interactions from you girls. Thank you for being my finishing goal! I kept on going because of you. If mummy can do it, so can you!

Sincere gratitude goes to the babysitters (you know who you are) for taking care of my girls while I was studying. I know they can be challenging at times and for that I am forever indebted to you. To my friends, thank you for your kind words and motivations.

Finally, terima kasih to Universiti Teknologi MARA for approving my study leave and MARA for funding me during this $\mathrm{PhD}$ programme. I will try my best to make full use of the knowledge I have gained and give back to the society. Thank you everyone. 


\section{TABLE OF CONTENTS}

ABSTRACT .iii

ACKNOWLEDGEMENTS

. $\mathrm{V}$

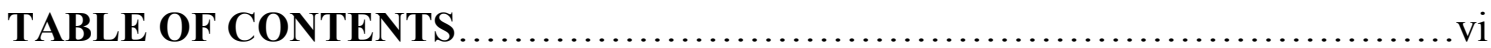

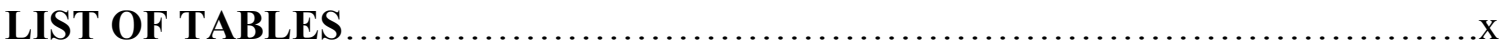

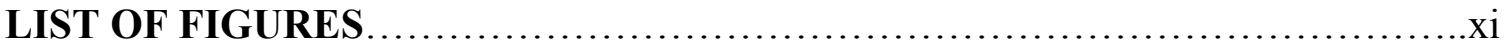

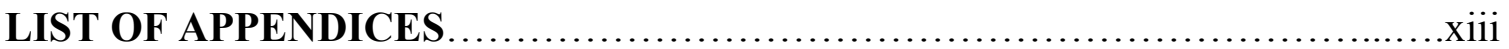

CHAPTER 1. INTRODUCTION ......................................

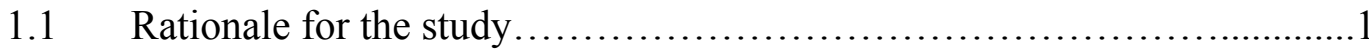

1.2 Context of Early Childhood Care and Education: Policies and Practice in Malaysia ..........................................................6

1.3 Purpose and significance of the study.............................

1.4 The outline of the thesis.......................................... 9

CHAPTER 2. LITERATURE REVIEW .................................. 11

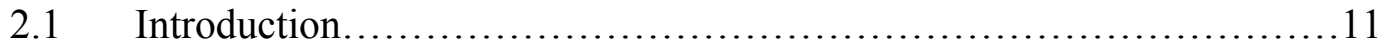

2.2 Children's peer interactions........................................ 12

2.2.1 Definition................................................... 12

2.2.2 Brief history of the study of peer interactions.................13

2.3 The importance of peer interactions among children in ECCE centres.....15

2.3.1 Peer interactions establish a sense of belonging................16

2.3.2 Peer interactions construct togetherness.......................19

2.3.3 Peer interactions create humour and laughter between children...21

2.3.4 Peer interactions establish agency in children..................23

2.3.5 Peer interactions benefit social competence.....................24

2.3.6 Peer interactions develop friendship.........................26

2.3.7 Peer interactions establish peer culture.......................28

2.3.8 Conflicts during interactions................................ 30 
2.4 Adults' roles in children's peer interactions.........................33

2.4.1 Practitioners' perceptions of children's peer interactions..........33

2.4.2 Encouraging and supporting children's peer interactions..........37

2.4.3 Practitioners' role in children's conflicts........................40

2.5 Chapter overview............................................42

CHAPTER 3. THEORETICAL AND METHODOLOGICAL

APPROACH..............................................44

3.1 Research paradigm.............................................44

3.2 Research design.............................................45

3.3 The use of multiple-case study................................46

3.4 Research procedure.........................................48

3.5 Researcher's Role.................................................49

3.6 Selection of childcare centres and participants ......................50

3.7 Data Collection.........................................................

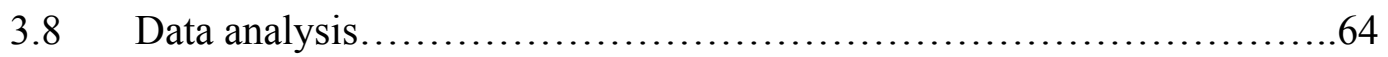

3.8.1 Theoretical constructs...............................67

3.9 Ethical consideration......................................... 71

3.10 Chapter overview.............................................. 73

CHAPTER 4. PRACTITIONERS' PERCEPTIONS OF CHILDREN'S PEER INTERACTIONS ................................................ 74

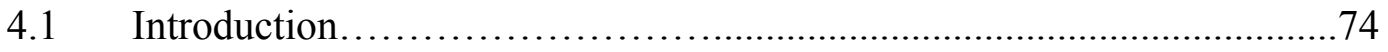

4.2 Promoting peer interactions by facilitating group activities..............75

4.3 Managing peer interactions by responding to children's conflicts........82

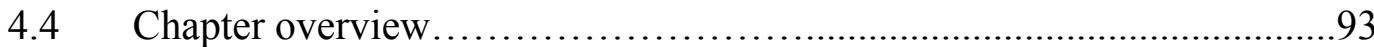

CHAPTER 5. CHILDREN'S INTERACTIONS IN ACTION: CREATING A SENSE OF BELONGING AND TOGETHERNESS..........95

$5.1 \quad$ Introduction........................................................ 95

5.2 Belonging and togetherness as learning to be with peers...............97

5.2.1 Entry strategies.......................................... 97

5.2.2 Becoming one of the group..............................110 
5.3 Belonging and togetherness as embracing the centre's routines.........123

5.4 Togetherness as responding to the need of others.................... 134

5.5 Togetherness as having humour and laughter........................ 142

5.6 Chapter overview..........................................151

CHAPTER 6. WHEN CHILDREN HAVE CONFLICTS ................ 153

$6.1 \quad$ Introduction.................................................... 153

6.2 How conflicts arise ............................................ 154

6.2.1 Possession of objects...................................154

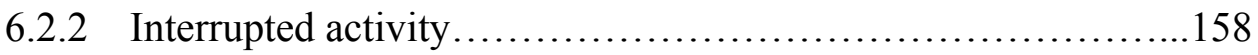

6.2.3 Exploration and curiosity.............................. 162

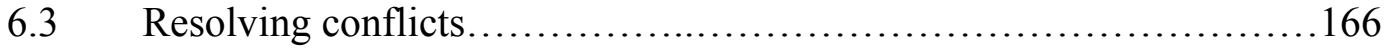

6.3.1 Seeking adult's intervention.............................. 167

6.3.2 Giving in and walking away.............................171

6.3.3 Giving an alternative object............................176

6.4 Chapter overview.......................................... 178

CHAPTER 7. REFLECTING ON PEER INTERACTIONS: PRACTITIONERS' VIEWS USING VIDEO-STIMULATED RECALL AND FOCUS GROUP DISCUSSION..............181

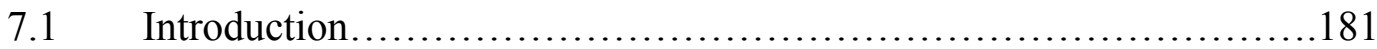

7.2 Learning outcomes of play............................................ 182

7.2.1 Sharing resources.................................... 183

7.2.2 Communicating with peers..............................186

7.2.3 Understanding peers' intentions, needs and emotions...........191

7.3 Learning outcomes of familiarity............................... 195

7.3.1 Making connections...................................196

7.3.2 Gaining confidence.................................. 198

7.3.3 Developing friendships...............................201

7.4 Learning outcomes of having friends............................205

7.4.1 Developing empathy...................................205

7.4.2 Preparation for school..................................208

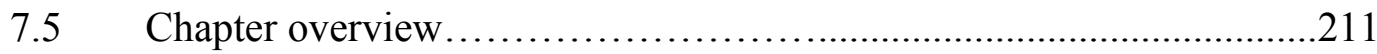




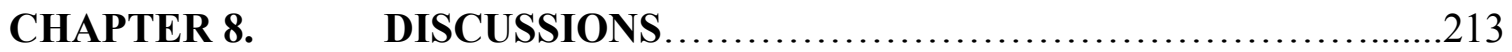

$8.1 \quad$ Overview of the research..........................................213

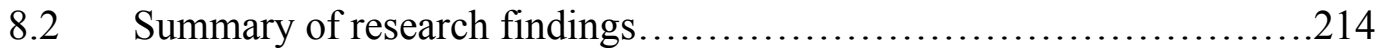

8.2.1 What were the practitioners' perceptions of the children's peer

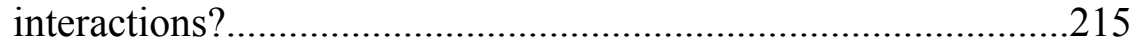

8.2.2 What were the children's peer interactions in the three childcare

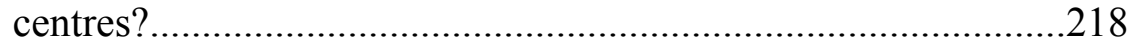

8.2.3 Implications on social competence development and agency....222

8.2.4 Implications on practitioners' trainings and practices............223

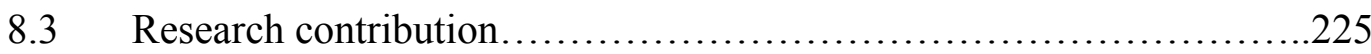

8.3.1 Contributions to the field of children's peer interactions especially under three years olds in Malaysian early childhood education centres...............................................225

8.3.2 Contribution to knowledge about supporting children's peer

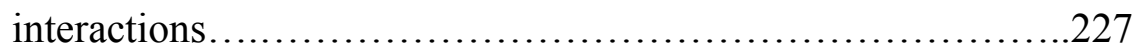

8.3.3 Contribution to good classroom practices......................228

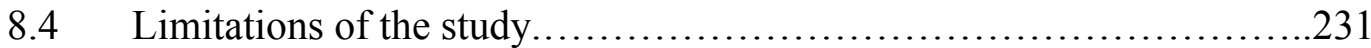

8.5 Areas for future research..........................................232

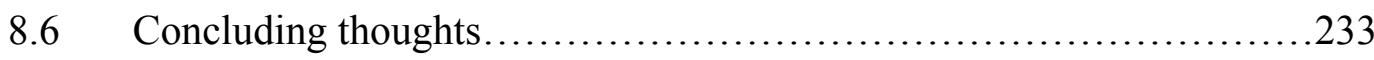

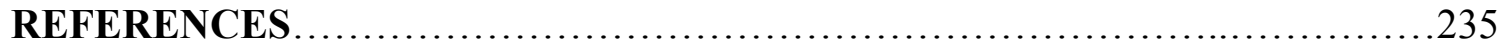

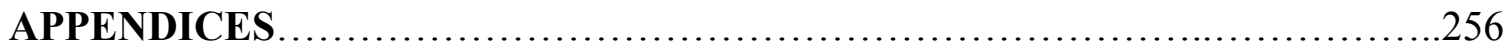




\section{LIST OF TABLES}

Table 1.1: Ratio of a child care provider to a child at a childcare centre.................8

Table 3.1: Key steps in the research procedure.................................48

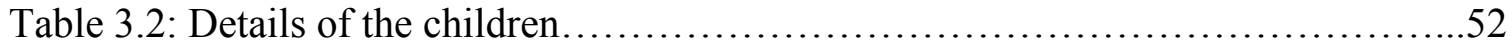

Table 3.3: Practitioners' details...................................................

Table 3.4: Example of each child's observation sessions...........................58

Table 3.5: Research questions and methods..................................61

Table 3.6: Summary of data collected at Sunny Childcare Centre (SCC)..............62

Table 3.7: Summary of data collected at Rainbow Childcare Centre (RCC)............63

Table 3.8: Summary of data collected at Moonbeams Childcare Centre (MCC).........63

Table 3.9: Summary of data collected during focus group discussion..................64 


\section{LIST OF FIGURES}

Figure 2.1: Rose-Krasnor (1997) The Social Competence Prism.......................25

Figure 2.2: The Relational Model (de Waal, 2000).....................................32

Figure 3.1: Data collection methods in each case study ............................62

Figure 5.1: Anna lifts her spoon to Willy's mouth..................................101

Figure 5.2: Dani, Rania and Sam playing with the bead maze together.................105

Figure 5.3: Liza, Omar, Ahmad and Jasmin shouting “Aaaaaaaaaaa”.................107

Figure 5.4: Willy and Ali showing their play-dough creation to each other.............112

Figure 5.5: The children cheering and shouting "Yeay!"...........................114

Figure 5.6: The children jumping and twirling around during the playing of a DVD with

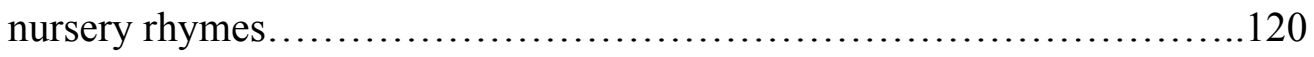

Figure 5.7: Ibrahim, Ahmad and Omar crawling and chasing each other...............122

Figure 5.8: The children putting the dinosaurs into the box.........................131

Figure 5.9: Anna helping Willy ................................................... 135

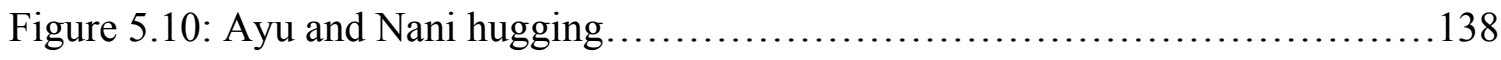

Figure 5.11: Lily hugging Helmi.............................................. 140

Figure 5.12: Zara and Lea looking at each other and laughing.......................144

Figure 5.13: Zara patting Lea.................................................... 144

Figure 5.14: Ali and Anna laughing together after using the puzzle incongruously......146

Figure 5.15: Sharifah touches Omar's back....................................... 148 
Figure 6.1: Roy and Willy pulling the box................................... 156

Figure 6.2: Suzy shouted at Ibrahim........................................ 161

Figure 6.3: Anna and Willy pulling a book.................................... 163

Figure 6.4: Ibrahim was curious about the contents of the red pouch.................164

Figure 6.5: Roy asking for an adult's intervention.............................. 168

Figure 6.6: Ina and Anna having a conflict about a book.......................... 172 


\section{LIST OF APPENDICES}

Appendix A: Manager's information letter and consent form.......................257

Appendix B: Practitioners' information letter and consent form......................261

Appendix C: Parents' information leaflet........................................266

Appendix D: Informed consent form - Parents / Guardian..........................268

Appendix E: Semi-structured interview protocol with individual practitioners.........269

Appendix F: Video-stimulated recall interview protocol.........................272

Appendix G: Focus group ground rules.....................................274

Appendix H: Informed consent form for focus group - practitioners...............276

Appendix I: Ethics Approval from Victoria University of Wellington.................277

Appendix J: Ethics Approval from Economic Planning Unit, Malaysia..................278 


\section{CHAPTER ONE INTRODUCTION}

This thesis is an investigation of very young children's peer interactions in three Malaysian childcare centres. It addresses two research questions:

1. How do practitioners' perceive peer interactions among children under three years old in their childcare centres in Malaysia?

2. What kinds of peer interactions occur among children under three years old in childcare centres in Malaysia?

In this chapter, I discusses my rationale for the study; the early childhood care and education context in Malaysia; the purpose and significance of the study; and the outline of the thesis. I start with the rationale of the study.

\subsection{Rationale for the study}

In Malaysia, the term early childhood care and education (ECCE) refers to education for children from birth to 6 years old. ECCE in Malaysia is divided into two types which are: (i) childcare centres for children from 0 to under 4 years old; and (ii) preschool for children from 4 to 6 years old. My research only looks at children in childcare centres and specifically I looked at children under 3 years old only. The rationale for my study rests on three key motivations.

Firstly, demand for childcare in Malaysia has increased over the years. Statistics show that the number of under 4 years old children enrolled in childcare centres in 2010 was 11,256 children followed by an upsurge to 18,118 children in 2011. There was another high rise in the enrolment of children in 2012, taking the number to 43,262 children,

almost quadrupling 2010 numbers. In 2013, the number of children enrolled in childcare centres increased yet again, totalling of 60,477 children (Education for All 2015, National 
Review: Malaysia, 2014). According to $\mathrm{SSM}^{1}$ and Unicef (2010), this rise in use of childcare centres reflected the rise of economic development in the country and the 58\% rise in the number of female workers aged between 25 to 34 years increase between 2001 and 2008, leading parents to resort to childcare centres to take care of their children while they worked (Chiam, 1999; Rockel \& Craw, 2011). Growing evidence of the benefits of early childhood education also played a part convincing some mothers who were not working to also enrol their children in childcare centres (Chiam, 1999).

As a result of these societal changes, in Malaysia, children under the age of 4 years regularly spend about 9 to 10 hours per day in childcare centres and most of these children attend their centre for five days a week. This means that the children spend most of their waking days at childcare centres where they interact with peers daily. Yet, research on what goes on during these peer interactions, especially for children under the age of three years, is lacking. Also lacking is any research on childcare practitioners' stance towards these young children's peer interactions and on their understanding of the significance of these interactions. The focus of my study is of children under three years old. I chose to put my focus on children under three because I want to gain information on the very young children at the childcare centres who some are still non-verbal and I believe it would be interesting to see how practitioners perceived these very young children's peer interactions with each other when language is limited for them.

The lack of research on peer interactions among under-three year olds in Malaysian childcare settings is not unique to the country. For example, in reviewing research on under-three year olds in early childhood settings, Mathers, Eisenstadt, Sylva, Soukakou, and Ereky-Stevens (2014) identified a number of research gaps, of which early childhood practitioners' perspectives of peer interactions was one (Greve, 2005; Walker, Small, Bigelow, Kirk, Harjusola-Webb, \& Mark, 2004; Woolfolk, 2004). In other words, while there is a considerable amount of research on children's peer interactions among older children, research on how infants' and toddlers' peer interactions and how practitioners respond to them (Buysse, Goldman, \& Skinner, 2003; Kemple, David, \& Hysmith, 1997;

\footnotetext{
${ }^{1}$ SSM stands for Suruhanjaya Syarikat Malaysia or The Companies Commission of Malaysia
} 
Williams, Mastergeorge, \& Ontai, 2010) is very limited and mostly carried out in Western settings. This makes it pertinent to study very young children's peer interactions in an Asian setting (specifically Malaysia) towards closing the research gap.

A second key motivation for my study is that in the current education policy context in Malaysia where the Ministry of Education has the explicit goal of transforming the education system and lifting it to international standards. According to the former Prime Minister of Malaysia, Dato' Seri Mohd Najib bin Tun Haji Abdul Razak, one of the major contribution to Malaysia's economy is education. He further argued that young people need the necessary skills to compete in the labour market (Malaysia Education Blueprint 2013-2025). The current Minister of Education, YB Dr Maszlee Bin Malik has reiterated this view in the Malaysia Education Blueprint Annual Report 2017: "We, Malaysians, realise that education is a major driver of economic growth and has an undeniable impact on the quality of life of individuals" (p. vii). Furthermore, in the Malaysia Economic Monitor, World Bank report, December 2013, it was highlighted that economists have started to learn non-cognitive skills like teamwork, leadership and communication skills which are seen as important for success in the labour market and overall productivity growth. This has led to efforts to strengthen non-cognitive skills in students (Malaysia Economic Monitor December 2013).

In October 2011, the Ministry of Education launched Malaysia Education Blueprint (2013-2025) to prepare Malaysia's students for the needs of the $21^{\text {st }}$ century. The Malaysia Education Blueprint's main focus is on the preschool, primary and secondary school levels of education which encompass students from the age of 4 years to 17 years. The Blueprint does not mention children below the age of 4 years in childcare centres. One possible explanation for this is that childcare centres are not under the responsibility of the Ministry of Education, but are part of the portfolio of the Ministry of Women, Family and Community Development (MoWFCD). This split system for early childhood services means that there are no specific curriculum guidelines for childcare providers (Sham'ah, 2013), making provision for this very young age group a matter of very variable quality. 
Given what is known about the crucial importance of the first few years of a child's life (Barnett, 2011; Belsky, 2006; Campbell \& Ramey, 1995; Chiam, 1999; Dinehart, Katz, Manfra, \& Ullery, 2013) and, within that, the importance of social competence development (e.g., Rose-Krasnor, 1997; Loizou, 2007) from the very early stages of life, it is timely to open up childcare provision in the Malaysian context to systematic research that explores children's experiences in these settings. By focusing on children under the age of three, my study makes a contribution to redressing the limited attention being given to these very young children's education in childcare settings. When children experience quality education and care, they have a better chance of growing into adolescents with better school performance, better cognitive development, lower rates of delinquency (Belsky, 2006; Campbell \& Ramey, 1995; Dinehart, Katz, Manfra, \& Ullery, 2013) and better employment prospects that can increase the economic contribution to the nation (Barnett, 2011; Chiam, 1999; Heckman, 2011). The specific focus of my study on peer interactions - a component of the social skills that are part of the non-cognitive skills mentioned in the World Bank report - further means that my investigation can help build a knowledge base that can contribute to the Malaysian government's stated goals for an education system fit for the $21^{\text {st }}$ century.

The third key motivation for my study came from my personal interest in ECCE, particularly children's peer interactions, and arose through my work and studies as an Educational Psychology lecturer at a public university in Malaysia. Through my role as an educator, I was exposed to a range of reading materials emphasising the impact that our experiences can have on our lives. I was always particularly enthusiastic when teaching my students on the topic of infants and toddlers. I would send my students to visit childcare centres nearby to look at young children's behaviour and ask them to write a report on what they had observed and to link it to a human development topic that they had learned about in the course. I often reflected on the topic of children's development as I read my students' reports and this drove me to become more interested in the subject. 
As time passed and a lot of my friends had babies, they would talk about their children with a recurring topic being their decision to place their children in childcare centres. This topic was a concern to most of these young mothers as they discussed the quality of the centres and what kind of influence the centres might have on their children. This sparked my interest to find out more about the experiences of young children (children under three) in childcare centres and what is really happening there while parents are at work.

An opportunity to pursue my interest arose in 2012, when amid growing concern about ECCE in Malaysia, a strategic decision was made in my faculty to offer a Diploma in Early Childhood Education and to prepare for this by granting scholarships to some qualified lecturers to undertake international postgraduate study in the field of early childhood education. As a beneficiary of one of these scholarships, I chose to pursue an investigation on peer interactions among under three years old children in Malaysian childcare centres. I wanted to focus on the very youngest children, hence why my research looked at children under three years old and not under four years old. While my research is focused on children's peer interactions in Malaysia, I am hopeful that the findings of my study can be useful to childcare centres in other contexts as well and be of interest not only to practitioners at childcare centres but also to parents, teacher training institutions as well as policy makers.

In summary, I see my research examining children's peer interactions among under three years old children in Malaysia as important because: (i) there is a lack of study in Malaysia on under three year old children's peer interactions in childcare settings; (ii) there is a lack of study on how practitioners perceive children's peer interaction in childcare centres; and (iii) in the current educational policy context where Malaysia is putting a strong emphasis on non-cognitive skills and the importance of social competence development, there is no research on how childcare practitioners can support this development through their role in children's peer interactions. 
I provide more information on the Malaysian early childhood education and care policy and practice context in the next section.

\subsection{Context of Early Childhood Care and Education: Policies and Practice in Malaysia}

In Malaysia, childcare centres were first formally instituted in the year 1984, when the government set up a special unit to initiate the formulation of a Childcare Centre Act which to this day is called 'The Childcare Centre Act 1984'. The Childcare Centre Act 1984 was first implemented in Kuala Lumpur on the first of March 1985. A year later, in February 1986, other states in Malaysia implemented the Act as well. The Childcare Centre Act 1984 has been reviewed and has undergone changes since it was implemented to suit the current situation (Early Childhood Care and Education Policy, 2008). As explained in the previous section (see 1.1), the term early childhood care and education (ECCE) refers to education for children from birth to 6 years old. ECCE in Malaysia is broadly divided into two types which are:

a) Childcare centres or Taska in Bahasa Melayu and

b) preschool, which is called Tadika in Bahasa Melayu.

Childcare centres in Malaysia are only for children from 0 to 4 years old while preschool is for children of 4 years old up to 6 years old. At the age of 7 years, children are expected to attend primary school.

Early childhood care and education (ECCE) is not compulsory for children as it is not part of the formal education system and parents can choose whether or not to send their children to childcare and preschool. In Malaysia ECCE is delivered and funded by both government agencies and private organizations. The ECCE programs run by the government are usually located in rural areas whereas many ECCE in the urban areas are run by private organizations (Sham'ah, 2013). As I noted earlier, childcare centres in Malaysia are under the care of the Social Welfare Department in the Ministry of Women, 
Family and Community Development (MoWFCD) while preschools are under the care of the Education Department in the Ministry of Education. All preschools in Malaysia are required to follow the National Preschool curriculum developed by the Ministry of Education (Early Childhood Care and Education Policy, 2008) but there are no specific curriculum guidelines for childcare centres (Sham'ah) and childcare centre providers are free to set up their own curriculum.

In reference to the Child Care Centre Act 1984, updated in November 2012, practitioners in childcare centres have to be at least 18 years old. Additionally, practitioners are required to attend and pass a basic childcare course called 'PERMATA Early Child Care and Education Course' within twelve months after being employed or appointed as a caregiver at a childcare centre (Child Care Centre Act 1984). The PERMATA Early Child Care and Education Course is a programme drawn up by the Social Welfare Department of Malaysia to ensure quality care for children in childcare centres (JKM, 2013). According to statistics, there are 12,272 registered practitioners in Malaysia and of that number, only 6,469 practitioners (just over 50\%), attended and passed the basic childcare course (Education for All 2015, National Review: Malaysia, 2014). From the perspective of my study, the huge gap in the numbers of trained versus untrained practitioners, raises the question of whether childcare practitioners have a good understanding of what children's peer interactions are all about, and whether they are trained enough to suppport the interactions.

Apart from providing guidance on the required age of the caregiver and the requirement to do some compulsory training, the Child Care Centre Act 1984 also laid out the following mandatory ratios of caregivers to children (Table 1.1): 
Table 1.1: Ratio of a child care provider to a child at a child care centre

\begin{tabular}{|l|l|c|c|}
\hline \multicolumn{1}{|c|}{$\begin{array}{c}\text { Category of } \\
\text { children }\end{array}$} & \multicolumn{1}{|c|}{ Age group } & $\begin{array}{c}\text { Number of } \\
\text { children }\end{array}$ & $\begin{array}{c}\text { Number of } \\
\text { caregiver }\end{array}$ \\
\hline \multirow{2}{*}{$\begin{array}{l}\text { Normal children* } \\
(\text { sic) }\end{array}$} & From birth - 1 year & 3 & 1 \\
\cline { 2 - 4 } & Above 1 year - 3 years & 5 & 1 \\
\cline { 2 - 4 } & Above 3 years - 4 years & 10 & 1 \\
\hline \multirow{2}{*}{$\begin{array}{l}\text { Disabled } \\
\text { children* }\end{array}$} & From birth - 1 year & 3 & 2 \\
\cline { 2 - 5 } (sic) & Above 1 year - 3 years & 5 & 3 \\
\cline { 2 - 5 } & Above 3 years - 4 years & 10 & 2 \\
\hline
\end{tabular}

Table source: Child Care Centre Act 1984, Child Care Centre Regulations 2012

*These terminologies are taken directly from the Child Care Centre Regulations 2012

\subsection{Purpose and Significance of the Study}

The primary purpose of this case study was to explore and investigate peer interactions among children under three year olds in a small number of childcare centres in Selangor, Malaysia. This qualitative study was designed to explore how practitioners perceived children's peer interations, and to identify the kinds of peer interactions that occur among under three year olds in Malaysian childcare centres. The findings of this research can help practitioners reflect on their own practices and better understand their potential impact on very young children's peer interactions which may have an effect on the children's later development. At the same time my study responds to the contemporary call by the nation and leaders to highlight the importance of social skills from the early years of life. 


\subsection{The outline of the thesis}

This thesis comprises eight chapters. This chapter serves as an introduction to the thesis and highlights the purpose of the study, the statement of problem, the research questions, the setting of the study, and the significance of this study.

Chapter two provides a review of literature relevant to my study. Literature is presented on: (i) children's peer interactions; (ii) the importance of peer interactions among children in childcare centres; and (iii) adults' roles in children's peer interactions.

Chapter three outlines the theoretical and methodological approach used in this study. This study uses case study methodology and is based on the collection of qualitative data. Data was collected by using semi-structured interviews with the practitioners before the start of the study, video-recorded observations of the children's peer interactions at their childcare centres, video-stimulated recall interviews and focus group discussions with the practitioners again after the completion of the children's observations. The data analysis and ethical considerations are also described in this chapter.

Chapter four discusses the findings on the practitioners' perceptions of children's peer interactions during the semi-structured interviews with individual practitioners. The practitioners mainly talked about promoting peer interactions by facilitating group activities and managing peer interactions by responding to children's conflicts.

Chapter five and six report and discuss the findings obtained from observing the children's peer interactions during their time at their childcare centres. The findings are analysed by looking at the themes identified within the data. The data led me to tell the story of the children creating a sense of belonging and togetherness at their childcare centres as well as what happened when the interactions broke down in conflicts.

Chapter seven revisits the first research question of 'How do practitioners' perceive peer interactions among children under three years old in their childcare centres in Malaysia?' and this time answers the question using data obtained through video-stimulated recall 
interviews and focus group discussion with the practitioners held after I had collected observational data of the children interacting with peers in their childcare centres. In this chapter, the practitioners were more reflective on the topic of children's peer interactions as they were submerged into the topic by watching videos of the children and having a discussion about it with other practitioners in a group.

Chapter eight is the final chapter of this thesis where I review the objectives of this study, summarise the research findings and discuss the contributions and implications of my study. I conclude with some recommendations for future research and some final reflections on my study. 


\section{CHAPTER TWO \\ LITERATURE REVIEW}

\section{$2.1 \quad$ Introduction}

The reality of increased participation in childcare services by under three year olds means that infants' and toddlers' experiences are no longer influenced solely by their immediate family members (White, 2014) but also by practitioners and peers in early childhood education centres. As Katz (2004) has noted, childcare centres can provide children with valuable opportunities for regular interactions with peers because infants attend childcare centres regularly in small groups of same-aged peers. Being at the childcare centres is an opportunity for children to exercise their social competence, of which peer interaction is a part. Many researchers have argued that peer interactions have a significant influence on the children's learning and development (Corsaro, 2003, Bukowski, Buhrmester \& Underwood, 2011) and this suggests that studies of children's peer interactions can contribute to the adults' understanding of the best conditions to support children's learning (Musatti, Mayer, Pettenati \& Picchio, 2017). This in turn can enlighten adults on planning educational practices in ECCE centres.

In this chapter, I discuss studies that have explored peer interactions among children and understandings about a broad range of interaction issues under the headings of: children's peer interactions; the importance of peer interactions among children in ECCE centres; and the adults' roles in children's peer interactions. I begin by explaining what peer interactions are all about and a brief history of how the topic has been studied. 


\subsection{Children's peer interactions}

I have divided this section into two subtopics, which are: (1) the definition and (2) brief history of the study of peer interactions.

\subsubsection{Definition}

Different researchers explain the definition of peer interactions slightly differently. Hay (1985) defined peer interactions between young children as any response made by one child followed by the other child's action. Innocenti, Stowitschek, Rule, Killoran, Striefel, and Boswell (1986) adapted the definition of interactions from a study by Strain, Shores, and Kerr (1976) and divided young children's peer interactions into four categories: positive responses; negative responses; initiation by the target child; and reciprocation by the target child.

Another researcher, Howes (1987b) used the term social interactions and defined it as behaviours that lead to peer acceptance and popularity. These behaviours include play entry, skillful play with peers, sociability, and absence of aggression and hostility. Howes (1987a) further categorized social interactions by childhood stages (infancy, early toddler and late toddler and preschool) reflecting Piaget's (1926) cognitive development and Parten's (1932) play theories, which suggest that children's behaviour and skills change with age. For example, in infancy infants seem to recognize other infants as their social partners and their interactions with each other during this period include smiling, squealing, flapping their arms, touching, leaning on and pulling on the peer. During the early toddler period, children are able to interact in complementary and reciprocal play where they exchange both turns and roles in actions such as hide and seek, run and chase, and offer and receive (Howes, 1987a).

Gonzalez-Mena and Eyer (2012) and Goodfellow (2014) described interactions as the effect that one person has on another like making eye contact with another child, looking at the activity the other child is engaged in, smiling, as well as taking and offering objects to another child. Taken together, peer interaction refers to those responses made by an 
individual that affect another individual or others. As this study looks into young children's peer interactions, the following section provides a more detailed review of research in this area.

\subsubsection{Brief history of the study of peer interactions}

According to Hartup (2008), "peers are necessities, not luxuries" (p. 3). Referring to the phrase, Hartup holds the belief that human beings need each other to develop from as early as infancy (Hartup, 1986). Hartup's interest in children's peer influence began in 1961 after a student in his seminar asked, "Don't children learn things from other children?" Hartup's interest in children's peer interactions led him to observe children in natural settings as well as in laboratories focusing on their individual differences (Hartup 2005). Most of Hartup's (1986; 2005; 2008) research revolved around children's interactions with friends and their influence on each other. In one of his studies, Hartup (1996) shows that "being liked" and "being disliked" are related to social competence and a person's overall development. His evidence demonstrated that friends influence children's cognitive and social scaffolding differently than non-friends, and that having friends benefits children across normative transitions. Results from his research led Hartup (2008) to believe that the influence of peer interactions on other children involves a wide array of social-psychological processes and under a variety of conditions. This means that how peer interactions affect a child very much depends on the child's ecological system (Bronfenbenner, 1979) such as the children's relationship to another, group norms, and cultural and social conditions. Hartup's (2008) theoretical framework incorporates the notion of peer reinforcement and draws also on performance theories (e.g.; Theories of operant learning), social learning theories (e.g., Bandura, 1986) and cognitive theories (e.g., Piaget, 1926; Vygotsky, 1978). At the same time, Hartup (2005) argued that while these theories can help explain children's influence on one another, researchers still do not know for certain what causes what in children's relationships.

Similar to Hartup (1986), Howes (1988) argued that peer interaction is a bridge to the development of social skills. Howes also agreed that children's peer interactions involve various social conditions of the children such as attachment to caregivers and the 
children's experiences. In her now classic monograph, Howes stated that children vary widely in their social experiences with peers and this is due to different childcare arrangements. Howes gave the example of infants who go to childcare centres and remain there with the same group of peers until they begin school versus infants who move to several different childcare centres throughout their childhood. She argued that the more experienced the children are with peers, the better they are at peer interactions.

Howes's (1988) has collected one of the largest data sets on early peer relationships and established a previously unexplored link between young children's peer interactions and social competence later in life. In one of her early studies, she followed 41 children for three years and 233 children for two years to assess predicted sequences and individual differences in the development of social competence with peers. Sociometric measures were used to represent social competence. The study design was both cross-sectional and longitudinal. The results of the study supported Howes's prediction that complementary and reciprocal social play emerged in 1-year-old children while social pretend play emerged when the children were two years old. The study also confirmed her hypothesis that early peer interactions predict later social competence. Nevertheless, her work attracted much debate on the methods including questions about the reliability of the sociometric tests to measure social competence.

Another well-known peer interaction researcher is William Corsaro (1985). Corsaro conducted ethnographic studies for over 30 years on children's peer culture in American and Italian preschool settings. While Corsaro's research is based on sociological theoretical perspectives, he also discusses some ideas from child development, including those of theorists such as Piaget, Vygotsky and Mead. His studies reveal that children create their own unique peer cultures which Corsaro (2012) defined as "the stable sets of routines, artifacts, values and concerns that children produce and share with each other" (p. 489). The highlights of Corsaro's (2002) research on children's peer culture are his findings on play entry, sharing and social participation, friendship, fantasy play, pretend play, role-play and routines. His research concluded that children are very social and rarely participate in solitary play. Instead, Corsaro (2002) found that children liked 
sharing and doing things together. According to Corsaro, children want to gain control of their own lives and share that sense of control with peers. In so doing, children teach each other how to be social, or in other words, they gain social competence.

Research on children's peer interactions remains an important area of study today. Many ECCE scholars have been studying what is going on during children's interactions with their peers at ECCE centres (e.g., Guo \& Dalli, 2016; Shin, 2010; Kemple, 1991; Singer et al., 2012). Nevertheless, there is so much more to learn and understand about children's interactions within their ECCE centres. In the next section, I explored what literature has highlighted about children's peer interactions under the heading of the importance of peer interactions among children in ECCE centres.

\subsection{The importance of peer interactions among children in ECCE centres}

Children as young as two months old show interest in other children (Carta, Greenwood, Luze, Cline, \& Kuntz, 2004), yet for many years, researchers considered infants and toddlers under three year olds as unable to establish interactions with peers (RossettiFerreira, de Moraes, de Oliveira, Campos-de-Carvalho, \& Amorim, 2011). However, a number of studies on children's peer interactions have indeed shown that children younger than three year olds do become involved in quite complex interactions (Brownell, 1990; Goin, 2006; Howes, 1988; Howes \& Matheson, 1992; Whaley \& Rubenstein, 1994; Wittmer, 2012). For example, a study conducted by Aureli and Colecchia (1996) with forty 3-year-olds looked at play behaviour among children who attended childcare compared with children who did not attend childcare. The children were each observed for twenty consecutive minutes during free play for four weeks and both cognitive and social aspects of play were considered. The study revealed that children who went to childcare interacted in a more complex and advanced manner than children who did not go to childcare with the childcare-participant children showing a higher level of symbolic

play with longer interactions between peers. Higher level of symbolic play here refers to 
children carrying out a specific activity, utilizing means to accomplish an activity and completing of an activity through successive steps.

Some researchers claimed that early peer interactions have a unique and important role in children's social and emotional development (Dunn, 2004; Hinde, 1979; Hartup, 1996). Others have specifically linked peer interactions at a young age to children's developing social competence (Aureli \& Colecchia, 1996; Elicker, Ruprecht, \& Anderson, 2014; Kemple, David, \& Hysmith, 1997; Williams, Ontai, \& Mastergeorge, 2010), and specifically to cognitive development and language and literacy development (Williford, Whittaker, Vitiello, \& Downer, 2013). The subsections below summarise some of this literature.

\subsubsection{Peer interactions establish a sense of belonging}

Peer interactions help children to establish a sense of belonging (e.g., Lin, Justice, Paul \& Mashburn, 2016; Wittmer, 2012). Koivula and Hannikainen (2017) define belongingness as relationships among children, which provide a feeling of belonging to a community or a certain environment. According to Over (2016), the need to belong to a certain group requires children to be motivated to interact and engage with the people around them. The concept of belongingness is that positive interactions drive children towards the formation of longer-term bonds. Therefore, it follows that interacting with the same peers many times should be more rewarding than interacting once with many different people (Over).

However, building that sense of belonging is no easy task for anyone and for young children under the age of three, it is especially difficult because their interactions are mainly through physical and non-verbal means (Løkken, 2000). From the social constructivist perspective, children's learning occurs through the many opportunities created by adults as well as peers in the children's community (e.g., Rogoff, 2003; Dockett, Kearney \& Perry, 2012). Children need to eventually learn how to interact within their community (e.g., childcare centres) to have that sense of belongingness with peers (Rogoff, 2003; Hannikainen, 2005). 
Over (2016) has looked at belongingness from the point of view of developmental psychology and social psychology and explains it in terms of the reason 'why' children need to create that sense belonging and the motivations that drive the children to engage in particular behaviours. Over argues that understanding the children's need to belong is critical to understanding their development. She found that children want to seek interactions and affiliation, form and maintain long-term bonds between peers, and belong in a particular group; she also stresses that depriving children of having that sense of belonging will have negative consequences for their wellbeing (House, Landis \& Umberson, 1988; Baumeister \& Leary, 1995).

Guo and Dalli (2016) on the other hand looked at 'how' children create a sense of belonging with their peers through the lens of Lefebvre's (2002) concept of everydayness. Lefebvre argued that everyday life provides an understanding of the complexities of living. This is because the everyday is repetitive but the everyday also changes. By using this concept of everydayness, Guo and Dalli used examples of the everyday experiences of two Chinese immigrant children in an early childhood education centre to consider ways in which they exercised their belongingness. Guo and Dalli linked the concept of belonging with the notion of agency using observational data of two Chinese immigrant children (age 4) in an early childhood education centre in New Zealand gathered over five days by pen and paper and video recordings of everything the children were doing. Guo and Dalli argued that the children used their agency in an unfamiliar sociocultural setting because they wanted to belong. Both children were born in China and spoke fluent Chinese. While there were some other Chinese-speaking children at the centre, English was the main language used. This study concluded that the children used their agency in three key ways: they created a sense of belonging with Chinese-speaking peers through their shared Chinese language; they learned English together; and they actively learned and participated in the everyday patterns of their centre. This study helps us to understand how children promote their agency to learn and behave in their new cultural setting in order to gain a sense of belonging. 
Another study by Koivula and Hannikainen (2017) examines the process through which children build a sense of community at their ECCE centres. According to Koivula and Hannikainen, belongingness not only includes relationships between children, but also belonging to a certain community, in this case, belonging to an ECCE centre. Using ethnographic methods, the researchers collected data about 22 three-and five-year-old children's experiences in their early childhood setting from the beginning of autumn when the children were unfamiliar with each other and over the following 11 months, observing the children's activities, interactions and peer relationships via video recordings, written notes and audio tape recordings. The data were analysed through qualitative content analysis, guided by McMillan and Chavis' (1986) four elements of sense of community and Rogoff's (1998) three planes of sociocultural activity: (i) participatory appropriation; (ii) guided participation; and (iii) apprenticeship. The study revealed that the children's sense of community developed through three stages. In stage one, the children's sense of community grew as they interacted through joint play everyday. In stage two, the children began to form friendships and the use of 'we-talk' began to appear in their interactions. In stage three, the children were seen to establish strong emotional bonding such as the display of physical closeness, sharing and doing things together.

It is important to note that children learn everyday from peer interactions and thus trying to belong in a group is also a learning process for them (Rogoff, 2003). According to Koivula and Hannikainen (2017), the children in their study were slow to develop their sense of community. It took three months to achieve the first stage and another five months to achieve the second stage. They considered that, this slow process needed to be looked into and the involvement of practitioners must be considered (Koivula \& Hannikainen). Practitioners have to give support to the children as they go about their daily lives at the centre, especially in forming that sense of belongingness within their community at the ECCE centre. With the right support and positive environment, children can experience emotional closeness or togetherness with their peers. 


\subsubsection{Peer interactions construct togetherness}

According to Koivula and Hannikainen (2017), the terms belongingness and togetherness have not been clearly distinguished in the literature. While belongingness means the feeling of belonging to a certain group and the relationships or friendship among the members, van Oers and Hannikainen (2001) noted that togetherness does not necessarily include friendship nor does it mean physical closeness. Simply put, togetherness means feelings of emotional interconnectedness that are linked to a person's experience during an activity (van Oers \& Hannikainen). It is important to study children's togetherness in the educational context so that we can get a better understanding of togetherness and its educational value (van Oers \& Hannikainen).

The importance of togetherness can be linked to Vygotsky's (1981) work where he mentioned the importance of affective and social dimensions to a person's learning and development. Although Vygotsky did not use the term 'togetherness', van Oers and Hannikainen (2001) and Goldstein (1999) have argued that the notion of togetherness is embedded in Vygotsky's theory, specifically the Zone of Proximal Development (ZPD). The ZPD refers to the gap between what one knows and what one can get to know with the assistance of more capable others. Vygotsky believed that children could not go far if they had to do the learning on their own and thus they need assistance and interactions with more knowledgeable adults and peers. Looking from the socio-cultural context, the basis of all learning is by acting together during activities (Vygotsky, 1981). According to this perspective, people relate to each other to develop togetherness. There is a desire in people to want to belong together in doing activities (Guo, 2010; Deegan, 1991).

According to Hannikainen and van Oers (1999), the construction of togetherness is grounded in a number of social practices. This includes creating 'we-ness' and connectedness, sharing and verbal communication. De Haan and Singer (2001) and van Oers and Hannikainen (2001) argue that verbal communication (language) is the most important skill in constructing togetherness for people. A study by van Oers and Hannikainen looked at the manifestation of togetherness and the strategies children employ to maintain togetherness. A teacher and four 6-year-old children were involved in 
the study where they needed to compose a story together by looking at coloured pictures provided by the teacher. A qualitative analysis was used to classify the data with the help of Hicks' (1996) theoretical framework which assumes that human activity is a multilayered process with four levels: sociogenetic, discourse genetic, ontogenetic, and microgenetic level. An interesting finding from this research at the microgenetic level is that the joking or 'naughty' language used by the children was effective in creating a group spirit in working on the project together. This joking language started with one child and then became collective. This finding was also found in De Haan and Singer's study where children were observed to use dirty words and imitating nonsense language as a joke. Like van Oers and Hannikainen, De Haan and Singer also agree that language is a very strong element in constructing togetherness in a group.

In De Haan and Singer's (2001) study, they looked at young children's language of togetherness and discussed the verbal strategies used by 2- and 3-year-olds to express and construct a sense of togetherness. This research is a longitudinal case study where Cas (a 3 -year-old boy) was observed and his interactions during free play at his daycare centre were audiotaped for two years. In analyzing the verbal strategies of the children in their study, De Haan and Singer used Brown and Levinson's (1987) theoretical model for analyzing the politeness strategies of adults. The model assumes two basic needs in social interaction: the need for freedom of action and the need to be understood and approved of. Brown and Levinson are interested in the politeness strategies used among adults to reach compromises between these two needs. De Haan and Singer noted that they only adopted the second part of the model, which is the desire to maintain a good relationship with people because this need relates to the themes of togetherness and care. In their model, Brown and Levinson distinguish three general mechanisms by which people express their desire for togetherness: the expression of common ground; the expression of cooperation; and fulfilling the needs and desire of others. By using this model to describe the children's language of togetherness, De Haan and Singer found that children mainly use the expression of common ground to construct togetherness among themselves. They did this by imitating their peers, repeating of nonsense words and referring to sameness. 
While De Haan and Singer (2001) and van Oers and Hannikainen (2001) argue that verbal communication is essential in constructing togetherness - like being able to joke around and using naughty language - I argue that young children who are pre-verbal are also able to construct togetherness by being funny or being naughty. Researchers (e.g., Loizou, 2005; Degotardi \& Pearson, 2014; Cameron, Kennedy and Cameron, 2008; Reddy, 2008) see this behaviour of infants and toddlers as humour.

\subsubsection{Peer interactions create humour and laughter between children}

According to Reddy (2008) and Mireault, Crockenberg, Sparrow, Cousineau, Pettinato and Woodard (2015), humour and laughter begin in infancy (as early as four months) and jokes or teasing bring much joy to children. Looking from the social perspective, humour and laughter among infants and toddlers are important as they can bring children together and allow them to practise their social competence (McGhee, 1989; Loizou, 2005; Reddy, 2008; Engdahl, 2011). McGhee wrote, "the initiation of humour in social interaction is positively related to one's overall level of social competence" (p. 122). This is because humour and laughter can reinforce children's play and prolong the social contact (Engdahl, 2011) as well as strengthen human bonds or relationships (Banas et al., 2010; Mireault \& Reddy, 2016).

Loizou (2005) defines humour as a creative way to make situations funny, which children do by using their bodies and voices. Another definition of humour highlights its socioemotional aspects: "any communication that leads to an emotional experience of amusement, pleasure and/or mirth" (Southam, 2003, p. 28). This definition takes into account the social relationship between people. Laughter on the other hand is more physical and is defined as "an authentic biologically-based emotional response" (Mireault \& Reddy, 2016, p. 2).

According to Mireault and Reddy (2016), humour is first and foremost a social act. It is what people do with other people and thus it is an act of communication (Angeleri \& Airenti, 2014; Mireault \& Reddy, 2016). Infants are capable of telling jokes. By 6 months of age, infants can initiate humourous interactions such as clowning and teasing, mostly 
with their close caregivers (Reddy, 1991; Mireault \& Reddy, 2016). Much research has been done on children's humour and laughter (e.g., McGhee, 1979; Johnson \& Mervis, 1997; Loizou, 2005; Reddy, 2008; Bergen, 2001). Building upon Vygotskian (1987) theory that social interactions influence social cognition, humourous interactions with peers can provide opportunities for children to observe and manipulate everyday incongruities, which can enhance the children's social competence (Mercer, 2000; Rogoff, Mistry, Goncu \& Mosier, 1993). McGhee (1989) points out that the earlier children develop the skills to produce humour, the earlier it can contribute to the children's social development.

A case study by Cameron, Kennedy and Cameron (2008), which employs the methodology of a Day in the Life of a 30-month-old girl, found many instances of humour. The girl's entire waking day was videotaped and all interactions with her family were transcribed and analyzed. The researchers categorized humour into four types: 1) clowning, 2) teasing, 3) jokes and 4) physical play. Additionally, the researchers identified two main clusters of humorous functioning: socio-emotional functioning; and cognitive and linguistic functioning. From the socio-emotional perspective, humour was seen as an enjoyment and pleasure for the child, a source of satisfaction in shared meaning with others, exploring the power of persuasion, seeking positive consensus in the humorous act, and gaining attention from others that leads to further interactions with others. Cameron et al. found that when children use humour in their interactions, it establishes warm connections with others. Apart from that, Mercer (2000) pointed out that telling a joke requires the audience to know that they are involved in a joke. Thus, humour is also seen as an act to negotiate social situations because children learn rules of social discourse. While Cameron's et al. study looked at a child's interaction with her family members, similar findings were reported in a study where young children interacted humorously with non-family members at ECCE centres (e.g., Loizou, 2005; Reddy, 2008). 
Loizou (2005) looked at how six infants (aged between 15 to 22 months) in a childcare centre demonstrated their ability to produce and appreciate humour. Multiple qualitative methods were utilized in this study including observations, video recording, interviewing, journal writing and document reviews. All of the children were observed for a minimum of three hours a week during free play. Upon coding and analyzing the data, the researcher argued that two distinct theories could be used to interpret it, namely the Theory of the Absurd, and the Empowerment theory. The Theory of the Absurd emphasizes the incongruity of an event through funny sounds or gestures, incongruous use of materials and incongruous actions. The Empowerment Theory on the other hand describes children's involvement in humorous activities that empower them and make them feel superior to their caregivers. The findings of this study complement McGhee's (1989) idea of humour being an incongruity. Children are aware of the ways certain things work and what is expected of them and thus they use their existing knowledge, or schemata, to misuse things or materials in order to create incongruities. The finding also supports Chaney's (1993) idea that children under two are capable of producing their own jokes, thus supporting the view that young children can appreciate as well as produce different types of humorous events and create incongruities based on their schemata.

\subsubsection{Peer interactions establish agency in children}

According to Guo and Dalli (2016), the notion of agency is being used frequently in early childhood policies, which means that agency is looked at as an educational aspiration. Many researchers agree that agency is an aspect of learning (e.g. Turunen \& Perry, 2013; Van Nijnatten, 2010) because they viewed agency as children's capacity to act and construct their own life. Other researchers like Nsamenang (2008) viewed agency as internally driven in a child to have an effect to the outside world or, in other words, children's natural disposition to participate and be active in any situation such as making decisions with whom to play and what to play. Because of the many ways of looking at agency, Guo and Dalli defined agency as 'a phenomenon of children's autonomy and capacity to learn' (p. 255). The researchers also noted that children are active and capable constructers of their contexts, which indicated that children are in control of their actions. 
Furthermore, Guo and Dalli (2016) and Nsamenang (2008) viewed agency to be linked to children's capacity in creating a sense of belonging with others. This means, when children are in an ECCE centre, they use their agentic skills to interact with peers and to create that bond between them. In their study of immigrant children (as explained earlier in this chapter), Guo and Dalli found that the children in their study were actively using their agency during peer interactions because they wanted to belong. Thus, it can be said that peer interactions establish or drive children to use their agency when they interact with peers.

\subsubsection{Peer interactions benefit social competence}

As I have noted already, key researchers who have recognized children's peer interactions to be associated with social competence include Hartup (1986), Howes (1988) and Corsaro (1985). In a study by Howes and Matheson (1992), they found that the earlier that children engaged in peer play, the more prosocial and less aggressive the children were towards their peers. This is an important finding in light of studies which show that (i) children who have problems getting on with peers may develop poor social competence later on in their life (Greve, 2005; Williams, Ontai, et al., 2010), and that (ii) children learn the rules and skills needed to maintain social relationship when they interact with peers (Whaley \& Rubenstein, 1994). Researchers have further noted that peer interactions at a very young age predict positive social relationships and language development later in school (Booren, Downer, \& Vitiello, 2012; Burger, 2010; O'Connor \& McCartney, 2007). In other words, poor relationships with peers at a young age are related to emotional and mental health problems, dropping out of school, delinquency and mental health problem (Manaster \& Jobe, 2012).

There have been a lot of definitions of social competence in the literature. For example, White (1959) defined social competence as "an organism's capacity to interact effectively with its environment" (p. 297) while Oppenheimer (1989) noted social competence to be "the ability to engage effectively in complex interpersonal interaction and to use and understand people effectively" (p. 45). Howes (1987b) defined social competence as "behaviour that reflects successful social functioning" (p. 253). Other 
researchers, Rubin and Rose-Krasnor (1992) defined social competence as "the ability to achieve personal goals in social interaction while simultaneously maintaining positive relationships with others over time and across situations" (p. 285). In general, across literature children's social competence has been characterized as the ability to engage in satisfying interactions and activities with adults and peers (Katz \& McClellan, 1997; Fabes, Gaertner \& Popp, 2006; Campbell, Denham, Howarth, Jones, Whittaker, Williford \& Darling-Churchill, 2016). The definition given by Rubin and Rose-Krasnor's (1992) draws attention to the balance between meeting personal needs and those of others. In 1997, Rose-Krasnor developed The Social Competence Prism (see Figure 2.1) to explain the different ways that social competence has been studied and how these studies can be combined into a holistic theoretical framework that could explain social competence.

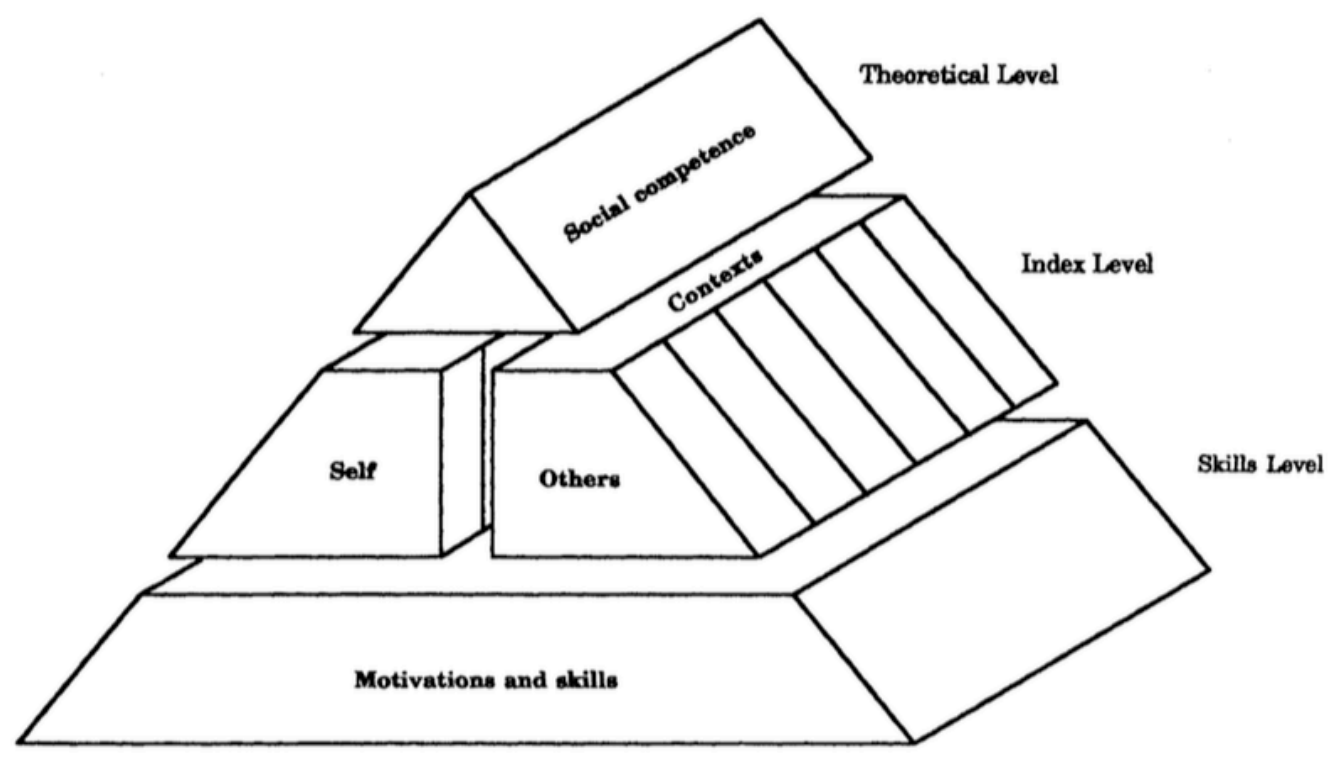

Figure 2.1: Rose-Krasnor (1997) The Social Competence Prism

The Social Competence Prism presents three levels of analysis typically applied in studies of social competence. The topmost level is the theoretical level, in which social competence is considered to be about "effectiveness in interactions". The index level of the prism consists of studies that use measures for components of social competence for example, relationships, group status and social-efficacy. It is divided into two domains: the self and others. The Self Domain consists of "aspects of social competence in which 
the individual's own needs take priority" while the Others Domain "includes aspects of competence which involve interpersonal connectedness" (Rose-Krasnor, 1997, p. 119). The skills level at the bottom includes skills associated with social competence like cognitive, social and emotional abilities and motivations that reside within an individual. In other words, here the focus of study is on an individual's behaviours and motivations as the elements that combine together to create competence during interactions, relationships and in establishing group status. The prism above clearly shows that social competence is understood to incorporate a balance of the self and others. Being in an ECCE centre with peers requires children to have that balance between the self and others (Epstein, 2009; Fabes, Gaertner \& Popp, 2006). It is clear that, early social competence develops in the context of social interaction (Spegman \& Houck, 2005).

\subsubsection{Peer interactions develop friendship}

Many researchers have come to notice the developing friendship between young children through their interactions with one another (e.g., Carter \& Nutbrown, 2016; Shin, 2010; Dunn, 2004; Howes, 1996). According to Carter and Nutbrown the study of friendship has been the focus of research since the 1940s. Howes, Droege and Philipsen (1992) noted that friendships are "opportunities for children to participate in collaborative, intimate personal relationships" (p. 119). Through these collaborative activities and interactions with peers, children become aware of their relationships with peers (Corsaro, 1985). Psychological and sociological perspectives suggest that children's friendship contribute to children's social competence (Carter \& Nutbrown, 2016; Howes, Hamilton \& Philipsen, 1998; Campbell, Lamb \& Hwang, 2000). A lot of definitions have been given to the word 'friendship' but nearly all of the definitions agree that spending time together, peer preference and familiarity are keys in a positive friendship (Shin \& Partyka, 2017; Carter \& Nutbrown, 2016; Shin, 2010; Howes, 1996; Bukowski, Newcomb \& Hartup, 1996; Whaley \& Rubenstein, 1994).

Writing in the early 1990s, Whaley and Rubenstein (1994) argued that while there was a vast amount of research on peer interactions among school-aged children and adolescents, little research could be found focused on children aged under three years. In response, 
Whaley and Rubenstein conducted a qualitative research project to study how a group of toddlers interacted with one another and focused on their friendship. The toddlers were followed and videotaped for over 10 months as they went about their daily lives in their ECCE centres and data from the videotapes were coded by using Rizzo's (1988) dimensions of friendship. Using an interpretive framework to describe the characteristics of the friendship formed between the toddlers, Whaley and Rubenstein reported that the toddlers showed 5 of 8 behaviours on the dimensions of friendship scale used by Rizzo for first grade (6 years old) students. The five behaviours were: helping, intimacy, loyalty, sharing and similarity. Thus, the data showed toddlers form friendship quite similarly to how older children form friendship. However, as in the case for young children, their interactions were most often exhibited in non-verbal ways (Whaley \& Rubenstein, 1994; Howes, 1996; Shin, 2010). Whaley and Rubenstein concluded that the study illustrated that young children can engage in complex peer interactions and are capable of relationships which are more complex than what had been previously thought.

Other researchers argue that children's developing friendship and their capability of complex peer interactions are the result of familiarity with peers (Aureli \& Colecchia, 1996; Howes \& Philipsen, 1992; Hay, Payne \& Chadwick, 2004). According to Parry (2014), Mueller and Brenner (1977) and Ross and Lollis (1989), children's interactions increase over time, with growing familiarity with their peers also resulting in an increase in the number of games played (Whaley \& Rubenstein, 1994). It is also clear that children engage in more interactions with familiar peers than unfamiliar peers, and their social behaviours are more complex when compared to unfamiliar peers (Howes \& Philipsen, 1992; Konstantoni, 2012). This behaviour has been observed in normal developing children as well as children with special education needs. A case study observational approach carried out in eight two-hour periods within one week by Parry examined how social connection and friendship developed between two children (Ray and Isaac) with special education needs in a nursery school in England. The study showed that the two children chose to play with each other over any other peer with the practitioners confirming that Ray and Isaac had known their chosen playmates longer than they had known the others in the group. One of the reasons why children choose 
familiar peers over the others is because they are more comfortable and confident in exercising their social competence with these familiar peers (Parry, 2014; Blandon \& Scrimgeour, 2015). Carter and Nutbrown (2016) and Bukowski, Newcomb and Hartup (1996) also argue that friendship is about mutual interest. A child can be familiar with a peer but friendship would not develop if they do not have any interest in one another. In other words, the children have to like one another and have to like spending time together (Bukowski, Newcomb \& Hartup, 1996). This can be exercised at ECCE centres through everyday interactions with peers.

\subsubsection{Peer interactions establish peer culture}

Other than the developing of friendship, peer interactions among children who meet each other regularly, such as within a childcare centre, can lead to the development of a peer culture (Hay, 1985). The most prominent researcher of children's peer culture is probably Corsaro (1985) whose mainly ethnographic work is centred on young children's free play in Italy and America. By observing children's play, Corsaro (1985) found that children are actively constructing their own peer culture, which differs from the peer culture of adults but still remains connected to the adult world. From a sociological perspective, peer culture is about how children construct their own peer culture and how children interact within groups and make sense of the adults' world (Bagwell \& Schmidt, 2011). Two other basic characteristics about peer culture are that children want to gain control of their lives and secondly, they want to share that sense of control with each other. Corsaro (2003) noted that children always want to be involved in a peer group. When the children did play alone, it did not last long and they soon looked for a peer and did things together. According to Corsaro (1985), children's peer cultures differ from adults' peer cultures because their rituals, values and understandings are unique to the children as a group. Corsaro's findings focused around the routines that allowed children to transform what is unfamiliar to them into something more familiar or something that makes more sense to them. 
From a social constructivist standpoint, children learn about their relationship with peers through activities and interactions with peers (Whaley \& Rubenstein, 1994). Adults who are not aware of the children's culture may misunderstand the children's behaviour and might disrupt the children's learning. Corsaro (2003) gave an example of two preschool girls (Barbara and Betty) who were playing 'zoo' together when another child (Linda) came and wanted to join in the play. Barbara and Betty immediately said no to Linda and Linda resorted to telling the teacher about it. The teacher came and asked the girls to play together but Barbara and Betty insisted that they did not want to share. After that, Barbara and Betty left their play area and went outside together while Linda played with the 'zoo' alone. Corsaro argued that from the children's point of view, they were not being selfish and they were not refusing to share. In fact, "they want to keep sharing what they are already sharing" (Corsaro, 2003, p. 40). Corsaro further argues that children protect their interactive space because they cannot easily suspend their interactions when there is a minor disruption as an adult could easily do. Interactions and play between peers are hard work for children and thus they try to protect their play space from interference because they do not want anyone to 'mess it up'. Insisting children allow another child to play with them may be inappropriate and threatening to the play (Carter \& Nutbrown, 2016).

According to Carter and Nutbrown (2016), Corsaro's (2003) approach to children's peer culture contradicts Paley's (1993) approach. Paley did not allow children in her setting to deny play entry to other children who wanted to join in. Instead, Paley would teach children to be compassionate to their peers and encourage children to play together, suggesting that adults who are aware of the children's peer culture can teach them to be more sensitive to other's needs. Practitioners at ECCE centres have to be mindful of children's peer culture in order to support their social competence more effectively (Carter \& Nutbrown). This awareness will allow practitioners to respond to children's needs appropriately because most children want to belong in a peer group. 


\subsubsection{Conflicts during interactions}

Another benefit from peer interaction is that it enables children to be involved in conflicts. Conflict is defined as, "an occasion when child A does or says something that influences child B, child B resists" (Rourou, Singer, Bekkema, \& De Haan, 2006, p.40). Despite the word conflict having a negative connotation, children can gain valuable skills from conflicts, such as problem solving skills, a chance to understand each other's behaviour, and to exercise skills in compromising and reconciliation which children cannot learn if they are not engaged in peer interactions (Gonzalez-Mena \& Eyer, 2012; Kemple, 1991).

Numerous researchers have pointed out the importance of children's peer conflicts to the development of social competence. For example, children learn social rules and relationships, group formation, cooperation and gain understanding of peers' intentions and feelings when they are involved in conflicts (Brenner \& Mueller, 1982; Hartup, French, Laursen, Johnston, \& Ogawa, 1993; Licht, Simoni, \& Perrig-Chiello, 2008; Shantz, 1987). When children get together, there are bound to be conflicts (Singer, van Hoogdalem, De Haan, \& Bekkema, 2012; van Hoogdalem, Singer, Bekkema, \& Sterck, 2008). This is because conflicting interests among members of the group are a normal social phenomenon for children and even for adults (Licht et al., 2008). However, there are differences in what children fight about and what adults fight about. According to Licht et al., the area of children's conflicts has been studied by researchers but not much attention had been given to the question of what do they fight about? Or what is the motivation behind these conflicts?

Licht et al. (2008) use the word 'motivation' in conflicts to describe an individual child's specific goal during conflicts. The researchers argue that a child's choice of conflict strategy and willingness to compromise or to go on fighting may have different underlying motivations. Yet, not many researches have looked at children's motivations in conflict. A common interpretation of conflicts between children arises because children want to possess objects that are in their peers' hand (e.g., Brenner \& Mueller, 1982; Caplan, Vespo, Pedersen, \& Hay, 1991). However, Licht et al. argue that this interpretation is very broad and does not imply a specific motivation for a child's conflict. 
For example, Rourou et al.'s (2006) study with 96 two- to four-year-old children revealed four common reasons of conflicts which were object-conflicted, territorial or entry conflict, unwanted-action conflicts and content-of-play conflicts. Clearly, Rourou et al. did not imply any specific motivation behind the children's conflicts but instead focused on reasons for the observed conflicts. By contrast, Licht et al. (2008) conducted an exploratory study to identify the motivations underlying conflicts among peers using an inductive naturalistic observation in a longitudinal setting with 28 children between the ages of 8 and 22 months. The children were observed and filmed three times for 30 minutes during free play in their ECCE centre. The first observation took place when the children were 8 months old, 14 months old during the second observation, and 22 months during the third observation. The study identified seven categories of motivation that gave rise to conflicts: interrupted activity; explorations; awoken needs; will to effect; possession; dominance; and contact and sensation seeking. Licht et al. concluded that young children's conflicts are related to more than the possession of an object and careful observation and understanding of this matter is needed in order to fully understand what is going on during a child's conflict.

Another issue that researchers have looked at when they study children's conflict is the resolution strategies children use in conflicts (e.g., Caplan et al., 1991; Singer et al., 2012; van Hoogdalem et al., 2008). A theoretical approach that is relevant in studying children's behaviours during conflict is the Relational Model of de Waal (2000). This approach focuses on the relationship between conflict strategies and the relational interest during the conflict (de Waal, 2000; Killen \& de Waal, 2000; Singer et al., 2012). 

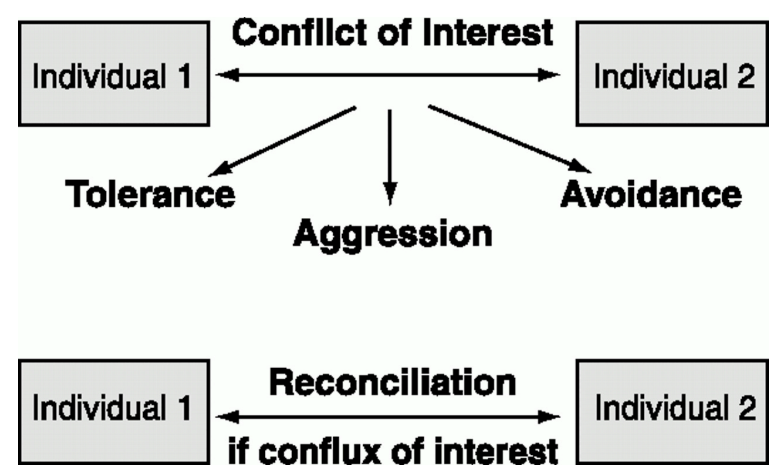

Figure 2.2: The Relational Model (de Waal, 2000)

According to van Hoogdalem et al. (2008), the Relational Model (Figure 2.2) proposed that conflicts should be studied within a social framework. The Relational Model proposed that a conflict might help to define the relationship between peers. According to the Relational Model, there are three ways in which conflicts of interest are settled. They are: tolerance with each other such as sharing and taking turns of an object; avoidance of confrontation; and aggression. While some conflict can result in a more intimate relationship, a conflict can also ruin a relationship (de Waal, 2000; Singer et al., 2012). Aggression during conflicts within a group of family members or peers is constrained by the need to maintain beneficial relationships. When social relationships are valued, one can be seen to reduce the effect of conflict before and after it happens (de Waal). Reconciliation is likely to happen when there is a strong mutual interest in maintaining a relationship.

Young children may have an innate mechanism to protect a valuable relationship (van Hoogdalem et al., 2008). According to Butovskaya, Verbeek, Ljungberg and Lunardini (2000) and Killen and de Waal (2000), children as young as 2 years already show some behaviour of reconciliation after they are involved in a conflict. These behaviours include inviting peers to play, offering objects, hugging and saying apologies. A study by Singer et al. (2012) with two-and three-year-olds at their ECCE centres revealed that as children get older, they value their relationships more. Children were seen to use less physical force in conflicts because it decreased the likelihood they would play together after the conflict. This suggests that children see their relationships as valuable and want to keep 
on playing together even after conflicts. Taken together, these findings suggest that children are socially motivated and that peer conflicts are valuable in developing children's social competence (Caplan et al., 1991; Wheeler, 1994).

\subsection{Adults' roles in children's peer interactions}

The preceding sections clearly illustrate that children-to-children interactions are important and have many benefits to a child's development. However, adults too play an important role in the children's lives. The views practitioners hold about young children in their care can guide the practitioners not only to enable children's experiences but also to constrain them (Salamon \& Harrison, 2015; Salamon, Sumsion, Press, \& Harrison, 2016). While literature says young children are capable of independent learning, it also says children need adults' intervention and involvement in their learning (Salamon \& Harrison). As children spend a great amount of time at ECCE centres, it is important that the practitioners are aware of the peer interaction that is going on between the children, how to support and encourage it, and to be conscious of the connection peer interactions have to social competence. In addition, they need to know what role to play when children's interactions are in dispute (Davis \& Degotardi, 2015; Degotardi \& Pearson, 2009; Williams, Mastergeorge, \& Ontai, 2010)

\subsubsection{Practitioners' perceptions of children's peer interactions}

According to Kemple et al. (1997); Salamon and Harrison (2015) and Williams, Mastergeorge, et al. (2010) practitioners often have their own perceptions about how young children should interact with each other and these are often reflected in how they respond to children's behaviour at their ECCE centres. Practitioners' perceptions thus impact children's engagement with peers. Yet, as Harkness and Super (1997), Hurd and Gettinger (2011), Davis and Degotardi (2015) and more recently, Mussati et al. (2017), have argued, there is still a lack of research on practitioners' perceptions, knowledge and children's experiences with peers in ECCE contexts. 
The limited literature on practitioners' perceptions of children's peer interactions is particularly evident for children aged under three years. While a number of studies have looked at practitioners' perceptions or beliefs of teacher-child interactions at their ECCE centres (e.g., Granger, 2017; Hartz, Williford \& Koomen, 2017; Degotardi, 2010; Berthelsen \& Brownlee, 2007; Mill \& Romano-White, 1999; Berk, 1985), their perceptions of children's interactions with other children have not been investigated.

Similarly to teacher-child interactions, studies of children's peer interactions revealed their positive effects on the children's development - such as their social and cognitive development and the links between these to a variety of long-term outcomes and life skills (Williams et al., 2010). Howes and Lee (2006) reported that in the past, parents and practitioners of young children had little understanding of children's interactions. For fifty years, they were told that children's interactions happened according to Parten's (1932) six stages of play (unoccupied play, solitary play, onlooker play, parallel play, associative play and cooperative play), based on the children's age. An observation at childcare centres in the early 1980s led Howes (1981) to believe that the children interacted with peers beyond Parten's play theories. More recent studies have continued to support this observation showing that children under the age of three are more competent in interactions with peers than what was once thought (Sarafino, 1985). This creates a sound argument for the need to study practitioners' perceptions of children's peer interactions, as this will contribute to informing practitioners about their own knowledge about children's peer interactions and the potential impact their perceptions might have on the children.

As I noted earlier, studies of peer interactions from the perspectives of the practitioners are limited. Most literature of children's peer interactions is from the point of view of researchers who studied children during set-up situations. For example, Hay, Nash and Pedersen (1983) collected video footage of pairs of infants within a playroom and found that the twenty-four infants reacted to the presence of peers by touching them and their toys. In most cases, the peers reciprocated to the touch and the interactions were seen to 
be harmonious. The researchers argued that at 6-month-old, infants are able to influence each other's behaviours. Similarly, a more recent study by Engdahl (2011) focused on how toddlers (17-24-month-old) initiate play, interact and communicate with their peers during free play in a Swedish preschool and showed that the toddlers used multiple strategies to attract the interest of their peers such as showing toys, using verbal and nonverbal cues to invite play, imitation and negotiations during play, to name a few. The researcher also found that not all practitioners at ECCE centres are knowledgeable about young children's interaction competencies. Again, this emphasises the importance of the practitioners' knowledge and the fact that studies that looked at the practitioners' perceptions on children's peer interactions are few in number.

A study that throws light on this focus, even if only indirectly, is that by Degotardi and Davis (2008). This study investigated early childhood practitioners' interpretations of infants' behaviour. Twenty-four practitioners were interviewed and asked to interpret video episodes of selected infants behaviour during play. Findings from the research revealed that the practitioners used a broad range of interpretive statements in describing the infants' behaviours so that while in most cases the responses contained references to non-psychological attributes such as, 'He is sucking his finger' or 'He is kissing teddy', other responses contained descriptions of psychological activities, affective, and motivational inferences, as well as some cognitive references of the children's behaviour. The study suggests that a more careful observation of the children's behaviour could lead the practitioners into giving more in-depth interpretation of the children's behaviour. This could also mean that the practitioners need to be knowledgeable about what is going on during children's peer interactions.

A more recent study by the same researchers related to practitioners' perceptions of children's interactions. Davis and Degotardi (2015) addressed the question of what understanding practitioners expressed about infant social capabilities and peer relationships. In answering the question, the researchers used Super and Harkness' (1986) concept of the developmental niche as their theoretical framework. According to Super and Harkness, "the developmental niche has three major subsystems which operate 
together as a larger system and each of which operates conditionally with other features of the culture" (p. 552). The three subsystems are: (1) the physical and social settings in which the child lives; (2) culturally regulated customs of childcare and child rearing; and (3) psychology of the caretakers. Davis and Degotardi focused on the third subsystem of the developmental niche, which is the psychology of the caregiver, to support their study. Super and Harkness argued that the psychology of the caregivers can influence how they care and teach the children at their ECCE centres. This suggests that the practitioners' understandings of children's interactions can influence the opportunities they provide for the children to engage in peer interactions. By using a case-study design, Davis and Degotardi recruited three early childhood practitioners and interviewed the practitioners on their perspectives of infants' peer relationships with each other. Data analysis revealed three main themes from the interviews: the significance of watching peers, the significance of toys; and the significance of play. The practitioners recognized that by watching peers, infants learn about their social world - like how to go about doing things and carrying out tasks. Watching peers was also regarded as a means to become part of a shared activity and gaining entry into group play through imitation of others' behaviours. Apart from that, the practitioners also perceived toys to be a good tool for interactions because toys can bring children together. Lastly, the practitioners also noted the importance of play for the development of children's social interactions and relationships because while playing together they learn more about what is acceptable and not acceptable to do. Davis and Degotardi concluded that these findings of the practitioners' perceptions suggest that the practitioners had an informed understanding of young children's social and peer relationships.

Another study that indirectly looked at teachers' beliefs and practices regarding children's peer interactions is by Jung (2014). This study looked at children's social competence by using a mixed method approach that involved survey questions distributed to the teachers, and follow-up observations and interviews with selected teachers. The researcher reported that teachers see social competence as having selfcontrol, self-expression, respecting peers' bodies and avoiding conflicts. Jung found that teachers in her study often intervened in the children's conflicts perhaps reflecting the 
teachers' valuing of conflict avoidance as social competence, The teachers emphasized classroom rules and giving solutions to the children whenever the children were in conflict. Jung argues that conflicts should be taken as opportunities or teachable moments because children can learn problem solving on their own if given the chance to do so. Overall, this research emphasizes that children develop social competence through peer interactions. Without interactions, children cannot practise social competence (Jung).

Some researchers have argued that the practitioners' perceptions of social competence very much depend on the practitioners' educational level, working experiences and culture (Han, 2009; Jung, 2014; Mashburn, Hamre, Downer \& Pianta, 2006). For example, a study by Kemple, Hysmith, and David (1996) involving 22 ECCE teachers,

reported the interesting finding that the teachers agreed that social competence was important for children but they also believed that they had little influence in developing it and instead gave more value to academic goals. In other words, the teachers believed social competence should develop naturally through children's interactions with their peers rather than be taught or supported by them. The researchers reported that the teachers' low educational level was connected with lesser commitment to social competence relative to academic goals and with the perception that supporting children's social competence is easy and that parents should influence the childen in their social competence. Taken together, these studies show that what is considered important by practitioners will be the focus of their teaching (Jung, 2014).

\subsubsection{Encouraging and supporting children's peer interaction}

Research cited in the previous section makes the point that practitioners have their own beliefs about how young children should interact with each other and their beliefs may reflect how they support the children's behaviour (Kemple et al., 1997; Williams, Mastergeorge, et al., 2010). However, evidence that practitioners' beliefs are often contradicted by their practice (e.g., Verma \& Peters, 1975; Williams et al., 2010) exists equally as much as evidence that the practitioners' beliefs are consistent with their classroom practice (Caruso, Dunn, \& File, 1992). Arthur, Bochner and Butterfield (1999) and Greve (2005) noted that it is the role of the practitioners in ECCE centres to give 
opportunities for children to interact with peers because children need to be guided in this behaviour but Goodfellow (2014) argued that practitioners might have little knowledge about the best way to support children's peer interactions.

Research shows that practitioners encourage and support children's peer interactions in a variety of ways (Buysse, Goldman, \& Skinner, 2003). For example, Kemple et al. (1997) observed 25 teachers' behaviours when they were involved in children's peer interactions. Each teacher was observed for 30 minutes for three days during the free play period. The study found that teachers used a variety of interventions during children's peer interactions but the teachers' most common practice was to give a lot of rules and commands during children's peer interactions as well as disrupt the interactions by giving punishment or threats for misbehaviour. The teachers were also found to try and facilitate communication and use peer referral strategies to promote peer interactions among young children.

In another study in North Carolina, Buysse et al. (2003) examined teachers' strategies to support friendship among young children in early childhood classes. Twenty-five teachers from nine childcare centres and 213 children ranging in age from 21 to 65 months participated in the study. The teachers were required to answer a questionnaire called 'The Playmates and Friends Questionnaire for Teachers' which was organized into three sections: frequent and occasional playmates, special friends, and the use of various strategies in facilitating friendship formation for individual friendship dyads. The questionnaire was completed by a teacher for an individual child. The results showed three main strategies used by teachers to support young children's friendships: a) allowing children to form friendships on their own without any encouragement or interference from the teachers; b) providing sufficient free play periods in children's daily schedule; and c) giving comments on children's play to support or extend it. Taken together, the findings of this study suggest that two of the frequently used strategies allowing children to form friendships on their own without any encouragement or interference from the teachers; and providing sufficient free play periods in children's daily schedule - represent passive stances in supporting peer interactions among children. 
Buysse et al. argued that to allow children to form friendship on their own may indicate that teachers do not fully understand their role in encouraging and supporting children to form and maintain friendships with their peers. In regards to the second strategy, even though it is considered a passive strategy in this study, allowing opportunities for children to interact with peers and follow their own interests is elsewhere argued to be good for building their social competence (e.g., Epstein, 2009; Jung 2014).

Williams, Mastergeorge, et al. (2010) also provide evidence of the importance of the ECCE practitioners' roles in the development of children's interactions with peers within a study involving thirty-six infants (mean age: 13 months) and eleven practitioners at three childcare centres. Williams, Mastergeorge, et al. (2010) studied the strategies practitioners used to scaffold and guide infants in their interactions with their peers by observing them in the mornings during free play periods for 30 minutes over three days. The study showed that the practitioners used 12 types of social scaffolding in guiding infant peer interactions which then were grouped into three categories: adult-centred; child-centred and group-based strategies. Among these three categories, it was found that infants who received more adult-centred and group-based scaffolding were less sociable with their peers six months later. However, infants who received more child-centred scaffolding showed positively less peer refusal six months later. The researchers concluded that adult-centred scaffolding could limit infants' behaviour towards peers because infants rely on practitioners to facilitate their social opportunities.

It can be seen that practitioners at different childcare centres do things differently with regards to their perceptions of appropriate responses to children's peer interactions. Providing early childhood practitioners with the skills, supports and resources they need to successfully promote children's positive social-emotional development and to work with children with challenging behaviours has been recognized as critical to children's well-being (Green, Malsch, Kothari, Busses \& Brennan, 2012). According to Honig (1982), if practitioners take the time to encourage, support and teach prosocial behaviour, children's interactions can increase and develop. 


\subsubsection{Practitioners' roles in children's conflicts}

According to Chen (2003), conflicts between school children have led researchers to look at conflicts in young children and the responsibility of adults in educating the children about how to negotiate conflicts. Young children's conflicts are brief. It was found that conflicts of children between 2 and 5 year old mostly ended after less than 1 minute (Dawe, 1934; Chen, Fein \& Tam, 1998). Some researchers have indicated that children are capable of solving their own conflicts without adults' intervention (e.g., Majorano, Corsano \& Triffoni, 2015) but adults' assistance is necessary in ensuring children develop competent conflict resolution skills.

According to Chen (2003), there are two main types of conflict intervention by the practitioners at ECCE centres: cessation and mediation strategies. In cessation strategies, practitioners are focused on the external management of the conflict situations. They generate solutions to the children's conflicts without involving them in the conflict resolution. This includes telling children what to do, removing the source of conflict, such as a toy, and separating children who are in conflict with each other. Mediation strategies conversely are interventions focused on helping children resolve their own conflicts. During this intervention, practitioners act as facilitators who assist children regarding their conflict resolution. Identifying problems, generating solutions, implementing agreeable solutions and articulating feelings are some examples of mediation strategies that practitioners use during conflict intervention (Bayer, Whaley, \& May, 1995; Chen, 2003; Clarke, McLaughlin, \& Aspden, 2017).

The use of mediation strategies is strongly recommended in ECCE classrooms. According to DeVries and Zan (1994), conflict and its resolution must be viewed as an important part of learning and development rather than as a problem that needs to be solved. Clarke, McLaughlin and Aspden (2017) noted that conflicts should not be viewed as negative behaviours because conflicts can be learning opportunities for the children in developing their social-emotional skills, how to negotiate, regulate emotions, communication, understanding others' perspectives and finding resolution strategies. Practitioners who use mediating intervention strategies to facilitate children's conflicts 
can help them learn to understand peers' intentions and manage their own needs and intentions as well (Chen, 2003). Facilitating the children's conflict reflects Vygotsky's ZPD theory where adults guide children according to their needs, abilities and development. Unfortunately, Bayer et al. (1995) noted that many practitioners at ECCE centres are more concerned with maintaining peace by abruptly ending children's conflicts themselves rather than taking it an opportunity to guide children into conflict resolution. Looking from the constructivist viewpoint, Arcaro-Mcphee, Doppler, and Harkins (2002) noted that conflict resolution fosters children's development more effectively than a non-constructivist approach. From this perspective, conflicts are viewed as a learning process in which the practitioners play a role of scaffolding children's conflict resolution and encouraging children to create their own conflict resolution (Gloeckler, Cassel \& Malkus, 2014).

Even though conflicts are viewed as learning opportunities for the children, it has been noted across literature that responding to children's peer conflicts can be challenging for ECCE practitioners (Bayer et al., 1995; Clarke et al., 2017). For example, Williams, Mastergeorge, et al. (2010) found that practitioners responded to children's conflicts by stating rules, giving distractions, giving instructions, removing the object of dispute and physically removing the child from peers. This suggests that the practitioners were more concerned with keeping classroom harmony than promoting children's learning and this can cause children to lose opportunities to develop social competence. Due to the fact that the practitioners' role is important in children's conflicts, Clarke et al. conducted a study in New Zealand that looked at practitioners' perspectives during children's conflicts. Thirty-one ECCE practitioners participated in the study where a mixed method approach was used. Data were gathered through focus group interviews and questionnaires with the results revealing that the practitioners took up three key roles during children's conflicts: (1) protecting children physically and emotionally by ensuring their physical safety, identifying, acknowledging and discussing their emotions; (2) advocating for children without prejudicial judgment; and (3) by being role models and coaching the children to develop social-emotional skills like encouraging the children's involvement in social problem skills. Maintaining classroom harmony and 
ending the children's conflicts were perceived as less important to these practitioners in the study. Other practices that the practitioners used were: listening to the children, commenting on what they were doing and questioning them. All of these examples of mediation strategies have been also identified by previous researchers (e.g., Chen, 2003; Gloeckler et al., 2014).

Taken together, the studies discussed in this section demonstrate that children's peer conflicts are natural phenomena which are likely to arise during peer interactions. Current researchers agree that these peer conflicts can present meaningful opportunities for children to be socially competent with their peers but this result is put at risk without the guidance of their ECCE practitioners. The practitioners' roles are important in children's conflict as it can ensure that children learn the skills to resolve conflicts by themselves and become more holistically socially competent.

\subsection{Chapter overview}

The studies reviewed in this chapter have explored a range of aspects of children's peer interactions. Because my study is concerned with children's peer interactions and the practitioners' perceptions of them in their childcare centres, I have focused on studies that throw light on these aspects and highlighted some themes that also emerged within my video data of children's peer interactions. The studies suggested that peer interactions are a building block for children to develop social competence, which can lead to a healthy social-emotional development. Most young children will find peer interactions challenging for them because fitting in with a group of peers is hard work. Through their everyday interactions at their childcare centres, children learn about how to belong, acquire a sense of togetherness, learn about humour and laughter as well as conflict and its resolution. But, young children may not be able to excel in peer interactions on their own and this is where the adults' roles come in. As children spend a lot of time at their ECCE centres everyday, it is pertinent that early childhood practitioners play a role in mediating this important aspect of the children's lives. 
This chapter has also reviewed research on how practitioners perceive children's peer interactions and how practitioners encourage and support young children's peer interactions including the practitioners' roles during children's conflicts. Conflicts in peer interactions are common and can be destructive if not handled with care but the interactions suggest that conflicts should be looked at as learning opportunities for children and an important aspect of becoming socially competent.

In the next chapter, I present the methodological and theoretical approach of the study where I explain the research paradigm, research design, the use of multiple-case study, research procedure, how the childcare centres and participants were selected, how the data were collected, my role as the researcher, how the data were analysed, including the theoretical constructs used in this study, and lastly the ethical considerations of this study. 


\section{CHAPTER THREE}

\section{THEORETICAL AND METHODOLOGICAL APPROACH}

In this chapter I describe and explain the strategies I used to research peer interactions in Malaysian childcare centres and how the early childhood practitioners perceived and responded to them. I outline the research paradigm for my study, the research design, the case study methodology, the research procedures, the participants and setting, my role as the researcher and how the data were collected and analyzed. Additionally, I discuss the theoretical constructs of the study and the ethical considerations of the study.

\subsection{Research paradigm}

According to Guba and Lincoln (1994) and Lincoln, Lynham and Guba (2011), a research paradigm is similar to a world view and represents how the researcher understands the nature of the world within which the research problem is located. It is a set of basic beliefs that guide the researcher in conducting the study. My research sits within a social constructivist worldview. Social constructivism is linked to the interpretive paradigmatic view of knowledge, which holds that there are many ways of looking at any situation. It is thus possible to understand the world as multi-perspectival and as open to interpretation. According to Gray (2009), constructivism assumes that meaning is constructed by individuals rather than discovered by them and social constructivism emphasizes that the multiple realities constructed by individuals are socially influenced.

According to Creswell (2009), this paradigm assumes that individuals try to understand and explore the world where they live and work - which is what my research aims to do. As I acknowledge that a constructivist theoretical paradigm underpins my approach to this research, I also recognize the productive power of the material world as part of the knowledge construction (James, 2000; Prout, 2011; Gallacher, 2016). The constructivist paradigm focuses research on participants, the interactions between participants, the need to recognize and understand social knowledge through critical analysis, as well as the 
need to recognize the active construction and co-creation of such knowledge through human consciousness (Lincoln et al., 2011). The dynamics of this social phenomenon are thus seen to be determined by the research participants' constantly evolving knowledge (Bryman, 2008) and understandings in daily interactions. This means, knowledge is not fixed and there are many perspectives of looking at the world. My role as a researcher is to present the beliefs of the participants in the way that they understand their world.

The focus of my qualitative study was to explore the kinds of peer interactions that occur among children under three year olds in childcare centres and to investigate how practitioners perceived these peer interactions in childcare centres in Malaysia. The underlying assumptions were that under three year old children have particular ways of interacting with their peers, and that practitioners likewise have particular beliefs regarding children's peer interactions among this age group, as well as particular ways of responding to them. From the worldview of social constructivism, meaning is constructed by individuals and thus, this study sought to collect the multiple meanings the practitioners constructed from their perceptions of the under three year olds' peer interactions.

\subsection{Research design}

Merriam (1998) argued that researchers do qualitative studies because they want to understand a phenomenon, a process or the participants' views in their natural settings. Punch (2005) stated that qualitative research is suitable for researchers who want to examine issues in detail and to explore issues that people do not know much about. Thus, a qualitative research design is well suited for this study because its aim is to gain a holistic understanding of participants' experience of the phenomenon of peer interactions among under threes in childcare centres. Inductive analysis is one way of understanding the relationship between theory and data (Bryman, 2008): by searching the data for key ideas and sorting these into categories that built up my thematic analysis, I was able to inductively identify links between my data and a range of theoretical constructs that 
provide insights into how the childcare practitioners in my study viewed their own experiences.

Since the topic of peer interactions among children under three year olds is underresearched in Malaysia, an exploratory study of this phenomenon is appropriate as a way of opening up the field to further study. According to Mutch (2013) and Patton (2002), qualitative researchers find three kinds of data collection useful: in-depth, open-ended interviews; careful, video-recorded observations and the examination of written documents. In seeking answers to the research questions, this study has collected data through video-recorded observations, semi-structured interviews, video-stimulated recall interviews as well as focus group discussions. Video-recorded observations were used to answer the question about the types of peer interactions that occur among children under three years old in three childcare centres in Malaysia, while the semi-structured interviews, video-stimulated recall interviews and focus group discussions were used to find out how practitioners perceived children's peer interactions. The collection of rich data enabled me to gain an understanding of what was going on at the childcare centres. Overall, a qualitative methodology guided the selection of research procedures including the selection of participants, the data gathering strategies, and the analysis of case study data.

\subsection{The use of multiple-case study}

According to Merriam (1998), researchers use case studies when they want to gain meaning and an in-depth understanding of a phenomenon or situation. A case study approach is relevant to researchers who look for answers to how some social phenomenon works (Yin, 2014). Yin (2003) distinguished among three types of case studies: explanatory, descriptive and exploratory. An explanatory case study approach answers research questions that ask 'how' and 'why', particularly where the researcher has little control over the actions of those involved in the study (Yin, 2009). Research questions that ask the question 'what' are more suited to the exploratory case study research approach, while studies that aim to describe a phenomenon are more suited to the descriptive case study approach. In my study, I integrated elements from all three 
types of case study to answer the 'how' and 'what' aspects of my research questions related to how the childcare practitioners perceived children's peer interactions as well as what kind of peer interactions occur among children under three years old in Malaysian childcare centres.

Gray (2009) further pointed out that exploratory studies are beneficial when there is limited knowledge about a situation or phenomenon. This is particularly appropriate for my research because, as noted in chapter one, prior to the research, little has been known about peer interactions among children under the age of three in childcare centres in Malaysia. To explore this issue in depth, I used a multiple-case study design, which used the multiple-site approach to enable the identification of common themes across the study phenomenon, that is: peer interactions at three childcare centres. According to Chmiliar (2010), a researcher may choose cases that are alike in order to analyze findings across similar cases and this was what I did in this study. Three childcare centres were chosen as the study cases, and they were then analyzed as similar cases. Case studies are unique in that they are flexible and multiple data collection methods can be used to gain information (Gray, 2009; Yin 2009). For this study, multiple data collection methods semi-structured interviews, observations, video-stimulated recalls and focus group discussion - were used to gain information to answer the research questions.

According to Nunan and Bailey (2009), case study research is a naturalistic approach that does not involve any kind of treatment, thus enabling contextual conditions within a real life situation to be studied (Yin, 2003). In my study, I have used the real life contextual data as the basis of my inductive data analysis. This enabled me to identify the themes that enabled me to answer each research question. 


\subsection{Research procedure}

Table 3.1 The table below outlines the key steps in the research procedure:

\begin{tabular}{|c|c|}
\hline Steps & Research Procedure \\
\hline Step 1 & $\begin{array}{l}\text { Identified licensed childcare centres in Selangor from an official list held by } \\
\text { the Jabatan Kebajikan Masyarakat Malaysia (Department of Social Welfare } \\
\text { Malaysia, 2013). The first thirty centres on the list were contacted by phone, } \\
\text { email and fax. }\end{array}$ \\
\hline Step 2 & $\begin{array}{l}\text { Waited for feedback from the centres (appendix A). The first three centres } \\
\text { that gave permission to undertake the study were contacted. }\end{array}$ \\
\hline Step 3 & $\begin{array}{l}\text { Entering the field site: Information letters and consent forms were given to the } \\
\text { manager of the childcare centre, practitioners and parents. Consent was } \\
\text { sought from parents on behalf of the children (see appendices A-H) }\end{array}$ \\
\hline Step 4 & $\begin{array}{l}\text { Semi-structured interviews held (appendix E) with the practitioners at Sunny } \\
\text { Childcare Centre first and then Rainbow Childcare Centre and lastly } \\
\text { Moonbeams Childcare Centre. }\end{array}$ \\
\hline Step 5 & $\begin{array}{l}\text { Waited for the parents' consent form (appendix C \& D). The first five forms } \\
\text { that were returned from each centre were used to select children for the study. }\end{array}$ \\
\hline Step 6 & $\begin{array}{l}\text { Observed the selected children's interactions with their peers in their } \\
\text { respective childcare centre. The observations were video-recorded. }\end{array}$ \\
\hline Step 7 & $\begin{array}{l}\text { Watched and selected video episodes for video-stimulated recall interviews } \\
\text { with the practitioners. }\end{array}$ \\
\hline Step 8 & $\begin{array}{l}\text { Conducted video-stimulated recall interviews with the practitioners in each } \\
\text { childcare centre. }\end{array}$ \\
\hline Step 9 & $\begin{array}{l}\text { A focus group discussion with the practitioners was conducted after all of the } \\
\text { data were gained from the three centres. }\end{array}$ \\
\hline Step 10 & Member checking of data \\
\hline Step 11 & \\
\hline
\end{tabular}

The sequence of the research procedure is explained in more details below. 


\subsection{Researcher's role}

In qualitative studies, the researcher is the main instrument for collecting and analysing data (Creswell, 2014; Merriam, 1998). Mistakes and biases can happen when a researcher is familiar with the context and has the background knowledge of the research topic (Merriam, 1998). In conducting this research, it was important that I recognize my own biases and worldviews and I remained aware of the personal and professional biases I might bring into the study. During the initial meeting with each practitioner to discuss what the research was all about, I worked to develop trust and comfort with the practitioners and to build rapport. I visited the centre at least two times before starting the semi-structured interviews to break the ice and to build up rapport and a sense of ease. I was very aware that to start off with, the practitioners might see me as a possibly threatening person as I am a university lecturer. So it was important that I made it clear to the practitioners that I was here to learn. In addition to that, the practitioners were assigned pseudonyms to ensure their confidentiality. I had to take extra care in writing accurately what the participants said in the interviews and to describe their actions and behaviours in detail. In line with this approach, I transcribed the participants' interviews in Bahasa Melayu and had them check the transcriptions. A few weeks after that, the practitioners returned the transcriptions back to me.

During the video-recorded observation of the children's peer interactions, I was a nonparticipant observer. I did not interfere or take part in the activities during the observations. At the start, I was concerned about the possible effect of my presence and the camera on the children. So, before the actual recording started, I tested how the children would react to the camera by visiting the centres with the video equipment and spending time recording them. The children were interested in the camera but after three days when I repeatedly ignored them, the children became quite used to having the camera around and they too ignored me as if I became invisible to them. This is probably because I did not give any response to them and they learned that I was not someone that they could interact with. However, I remained attentive to the children's cues about their comfort and willingness to be observed at all times during the observations and was 
prepared to immediately stop the video recording if I sensed any discomfort from the children. In the event, none of that happened during my study and all of the children seemed to not mind having the camera around. I had to have high tolerance for ambiguity (Merriam, 1998). As a researcher, I needed to untangle ambiguity so that the study could still move forward. Precautions were taken to establish trustworthiness and to uphold ethical considerations to maintain the credibility of my study. I offered pseudonyms for all participants and the research sites and these were accepted.

\subsection{Selection of childcare centres and participants}

This study was conducted in three childcare centres in Selangor. Selangor was chosen as the geographical location for the study because 2010 statistics showed that the highest population by state in Malaysia is in Selangor, totaling 5.46 million people (Department of Statistics, 2010). There are 13 states and 3 federal territories in Malaysia. Statistics show that the third highest level of urbanisation, after the federal territories of Kuala Lumpur and Putrajaya, is in Selangor. Due to the populous nature of this state and rapid urbanisation, there has been a rapid growth in the number of childcare centres (779 centres in 2013) making it appropriate to study childcare centres in Selangor.

The selection of the childcare centres started with the identification of licensed childcare centres in Selangor from an official list held by the Jabatan Kebajikan Masyarakat Malaysia (Department of Social Welfare Malaysia). The first thirty centres on the list were contacted by phone, email as well as fax in the first instance to gauge interest in participating in the study. All of the centres were given pseudonyms for confidentiality. The first centre that sent a positive reply was Sunny Childcare Centre (SCC), which I then contacted and requested to visit to explain what the research was all about. Having explained the aims, background, timescale and the methodology of the project to the centre's manager, consent for the centre to be involved in the study was granted and letters of information and consent forms were sent out to the parents of the children in the centre. After getting all the consents from the practitioners, the study started in the same week with the semi-structured interviews with the practitioners held at an agreed time. 
Following the interviews with the practitioners, and once parental consents were received, observations were carried out of the children's peer interactions using a video recorder. The children were selected for the observation on a 'first-come-first served' basis. In other words, the first five children whose parents returned the consent form were included in the study. After that, video-stimulated recall interviews were held with the practitioners. The selection of the two other centres - Rainbow Childcare Centre (RCC) and Moonbeams Childcare Centre (MCC) and of the practitioner and child participants was done in the same way.

In each case, the video-stimulated recall interviews were held in the evening after the practitioners had finished their working day or on the weekends with the practitioners' agreement. After all of these steps were conducted at each of the three case study centres, I called all of the participating practitioners from the three centres again for a final focus group discussion. I arranged a venue and time on a Saturday morning for this discussion where I paid the practitioners' travel expenses and provided refreshments. All of the practitioners attended the focus group session. More details on the participants are presented in the subsection below.

\section{Participants}

The participants were children under the age of three years in three childcare centres and those practitioners who cared for the under-three year olds. As this study intended to explore peer interactions among under three year olds in Malaysian childcare centres in detail, a small group of participants was chosen as follows:

a) Child participants: children under three years old were identified and only those children that fit the age criteria and whose parents gave consent were observed. All of the children at the centres were given a letter of consent to be taken home to their parents. Consent from the parents was sought on behalf of the children since the children were still too young to give their own formal consent. As noted above, the child participants were selected on the basis of 'first come first served', meaning that the first five children from the three case study centres that returned 
the signed letters from their parents were selected to be in the study and became the focal individuals for this study. Each child was followed as he or she lived their lives at the centre and the observations were taped with a handheld camera two times for 45 minutes on different days. All of the children were assigned pseudonyms to ensure their confidentiality.

Table 3.2 below shows the childcare centres attended by each child, each child pseudonym, their gender and their age.

Table 3.2: Details of the children

\begin{tabular}{|l|l|l|l|l|}
\hline Number & Centre & Child's name & Gender & Age \\
\hline 1 & SCC & Willy & Male & 2.9 years \\
\hline 2 & SCC & Anna & Female & 2.6 years \\
\hline 3 & SCC & Ina & Female & 2.8 years \\
\hline 4 & SCC & Ali & Male & 2.7 years \\
\hline 5 & SCC & Roy & Male & 2.7 years \\
\hline 6 & RCC & Omar & Male & 1.11 year \\
\hline 7 & RCC & Ibrahim & Male & 2.5 years \\
\hline 8 & RCC & Sulaiman & Male & 1.1 year \\
\hline 9 & RCC & Rania & Female & 0.11 months \\
\hline 10 & RCC & Jasmin & Female & 2.1 years \\
\hline 11 & MCC & Nani & Female & 2.3 years \\
\hline 12 & MCC & Ayu & Female & 2.4 years \\
\hline 13 & MCC & Helmi & Male & 2.7 years \\
\hline 14 & MCC & Rafiq & Male & 1.4 years \\
\hline 15 & MCC & Zara & Female & 0.10 months \\
\hline
\end{tabular}


b) Practitioner participants: All of the practitioners who cared for the children under three years old at all of the three childcare centres were invited to participate in the study. All of those invited gave their consent and thus all of the 13 practitioners were included in the study. I made it clear to the practitioners that the study findings would not have any effect on their personal assessment and future career. The practitioners were also aware that they could withdraw from the project before the data collection was complete without having to give reasons or without penalty of any sort. Fortunately, none of the participants changed their mind about being a participant in the study.

Table 3.3: Practitioner details by centre name, age, gender and training background.

\begin{tabular}{|l|l|l|l|l|l|}
\hline No & Centre & Practitioners name & Age & Gender & Description \\
\hline 1 & SCC & Amy & 27 & Female & $\begin{array}{l}\text { Qualified teacher. She } \\
\text { has a Diploma in Early } \\
\text { Childhood Education. } \\
\text { She has been working at } \\
\text { the centre for a year. }\end{array}$ \\
\hline 2 & SCC & Fifi & 21 & Female & $\begin{array}{l}\text { No ECCE training. 3 } \\
\text { years and half of } \\
\text { experience working at } \\
\text { childcare centres. She is } \\
\text { married with a 4-year-old } \\
\text { child. Highest } \\
\text { qualification is secondary } \\
\text { school. }\end{array}$ \\
\hline 3 & RCC & Khalila & 34 & Female & $\begin{array}{l}\text { Qualified teacher with a } \\
\text { Master in Early } \\
\text { Childhood Education; } \\
\text { also the centre manager. } \\
\text { Married with three } \\
\text { children. }\end{array}$ \\
\hline
\end{tabular}




\begin{tabular}{|c|c|c|c|c|c|}
\hline 4 & RCC & Sarah & 22 & Female & $\begin{array}{l}\text { No ECCE training. } \\
\text { Highest qualification is } \\
\text { secondary school. } 8 \\
\text { months of working } \\
\text { experience in ECCE } \\
\text { centre. }\end{array}$ \\
\hline 5 & RCC & Fatimah & 24 & Female & $\begin{array}{l}\text { No ECCE training. } \\
\text { Highest qualification is } \\
\text { secondary school. } 2 \text { years } \\
\text { of working experience in } \\
\text { ECCE centre. }\end{array}$ \\
\hline 6 & $\mathrm{RCC}$ & Maria & 22 & Female & $\begin{array}{l}\text { Some ECCE training. } \\
\text { Highest qualification is } \\
\text { secondary school. } 1 \text { year } \\
\text { and } 8 \text { months of working } \\
\text { at ECCE centre. }\end{array}$ \\
\hline 7 & RCC & Jamilah & 23 & Female & $\begin{array}{l}\text { No ECCE training. } \\
\text { Highest qualification is } \\
\text { secondary school. } 2 \\
\text { months of ECCE } \\
\text { working experience. }\end{array}$ \\
\hline 8 & $\mathrm{RCC}$ & Baiti & 20 & Female & $\begin{array}{l}\text { No ECCE training. } \\
\text { Highest qualification is } \\
\text { secondary school. } 2 \\
\text { months of ECCE } \\
\text { working experience. }\end{array}$ \\
\hline 9 & RCC & Nadia & 21 & Female & $\begin{array}{l}\text { No ECCE training. Has } 3 \\
\text { years of working } \\
\text { experience in the } \\
\text { childcare centre. Highest } \\
\text { qualification is secondary } \\
\text { school. }\end{array}$ \\
\hline 10 & MCC & Rozita & 23 & Female & $\begin{array}{l}\text { Qualified teacher with a } \\
\text { Diploma in Early } \\
\text { Childhood Education. } 5 \\
\text { years of working } \\
\text { experience in ECCE. }\end{array}$ \\
\hline
\end{tabular}




\begin{tabular}{|l|l|l|l|l|l|}
\hline 11 & MCC & Husna & 19 & Female & $\begin{array}{l}\text { No ECCE training. Her } \\
\text { first job at the centre } \\
\text { after finishing secondary } \\
\text { school. 8 months of } \\
\text { ECCE working } \\
\text { experience. }\end{array}$ \\
\hline 12 & MCC & Elina & 19 & Female & $\begin{array}{l}\text { No ECCE training. Her } \\
\text { first job at the centre } \\
\text { after finishing secondary } \\
\text { school. 7 months ECCE } \\
\text { working experience. }\end{array}$ \\
\hline 13 & MCC & Tiara & 19 & Female & $\begin{array}{l}\text { No ECCE training. She } \\
\text { used to work at an office } \\
\text { for a few months before } \\
\text { coming to work at MCC. } \\
\text { Her highest education is } \\
\text { secondary school. 7 } \\
\text { months of ECCE } \\
\text { working experience. }\end{array}$ \\
\hline
\end{tabular}

\section{Summary of the three childcare centres}

The following is a brief description of each of the three centres in the study:

a) Sunny Childcare Centre (SCC) is situated in a large residential house with four rooms. It is a one-storey building. The four rooms all have their own usage with one of the room allocated for the under threes with their two practitioners (Amy and Fifi). There were only five children under the age of three in this centre, providing a ratio of 2 adults to 5 children; all of the five children participated in the study. SCC's main business is for children aged 3 to 6 years and thus the other rooms were allocated for these older children. This centre has been operating since 2013. It uses English as the medium of instruction. 
b) Rainbow Childcare Centre (RCC) is a two-storey place where the ground floor is used for children under three years old and the upstairs area is used for kindergarten children from 3 to 5 years old. The centre has a licence to enrol children up to five year old only. RCC has been operating since 2011. There were 28 children under three registered in this centre and seven practitioners were there to care for them, a ratio of 1:4. This centre uses Bahasa Melayu as the medium of instruction.

c) Moonbeams Childcare Centre (MCC) is situated in a house in a residential area and comprised four rooms with a total of twenty-two children enrolled. It is a twostorey house dedicated to the care of under-three year olds. There are three rooms upstairs with one of them allocated for infants under one year old, and the other room for children from 1 to under 2 year old. There were five children in each room, looked after by one practitioner in each room: Tiara who looked after infants under one year old and Elina who looked after 1 to under 2 year olds. The ground floor is for children aged two to under three years old. At the time of the study, there were 12 children on the ground floor who were looked after by two practitioners (Husna and Rozita). MCC has been operating since 2009. This centre uses Bahasa Melayu as the medium of instruction. 


\subsection{Data collection}

Case study research accommodates various forms of data collection. The data for this study were collected by using semi-structured interviews with the practitioners, videorecorded observations of children's peer interactions followed by video-stimulated recall interviews with the practitioners, and a final focus group discussion with all the available participating practitioners. The diverse type of data collected enabled findings from each data set to be triangulated to check for accuracy of the findings. Triangulation is the process of corroborating evidence from different individuals, types of data, or method of data collection in descriptions and themes in qualitative research (Creswell, 2013). According to Creswell (2013), by triangulating information, a coherent justification for themes can be built to add to the validity of the study.

\section{Semi-structured interviews with practitioners}

A semi-structured interview with each of the practitioners before the start of the child observations provided the first data set for the study focused on the practitioners' views of children's peer interactions. A formal interview schedule was prepared and was used in a flexible and informal way during the interview sessions with open-ended questions and prompts used to open up answers for further elaboration. Wellington (2000, p. 71) pointed out that, "Interviews can reach the parts which other methods cannot reach." The interview was carried out in a room at the centre, away from the children and other adults to give freedom and privacy to the practitioners in answering the questions. All interviews were audio-taped with the permission of the practitioners. The interviews were held in Bahasa Melayu and I subsequently transcribed and translated them into English for analysis. The interview explored the practitioners' background, understanding of peer interactions and the practitioners' perceptions of how children interact with one another and my probing questions gave the participants freedom to talk about their opinions and beliefs about peer interactions among children under three years. 


\section{Video-recorded observations}

Video-recorded observations of each focal child's peer interactions were made at the childcare centres during two different sessions: one in the morning and one in the afternoon on two separate days. Most of the time, I recorded the sessions during the children's free play period and during mealtime. During free play there were times when the practitioners directed the children's play into doing activities like play dough and painting. On each day of video observation I recorded a total of 45 minutes, yielding 90 minutes of video recording per child (see Table 3.4). This decision was made based on the study of Deynoot-Schaub and Riksen-Walraven (2006), Licht et al. (2008) and Engdahl (2011). In their studies, they observed each child during free play periods for 45 minutes on separate mornings.

Table 3.4: Example of each child's observation sessions

\begin{tabular}{|l|l|l|}
\hline Participant & Sessions & Methods \\
\hline For each child & Morning & $\bullet 45$ minutes of video-recorded \\
& & observation \\
\cline { 2 - 3 } & Afternoon & $\bullet \begin{array}{l}\text { 45 minutes of video-recorded } \\
\text { observation }\end{array}$ \\
\hline
\end{tabular}

As this study looked at the kinds of peer interactions that occur among children under three years old in their childcare centres, video-recorded observations were necessary since such recordings provide researchers with immediate insights (Yin, 2014). I was a non-participant observer, one who observed without participating in the activities (Mutch, 2013). In each case study centre I followed 5 target children - which means that I had 15 target children overall across the three case studies. Thus in reporting this study, when I refer to "the children", I am referring to the 15 target children and not all the children in the study.

Using video observations was a huge benefit for my study as it enabled me to capture interactions as they happened. Moreover, I was able to get all my data in Malaysia within a short time period but video allowed me to re-view it in detail many times afterwards. 
Nonetheless, there were also some limitations to this approach: since I gathered video recordings of each child for no longer than 45 minutes each session, there was limited continuity of data per child. In other words, I could not tell what could have happened before and after the recording stops. So although 45 minutes per observation precluded extended continuity, having video data enabled me to review the video and this enabled me to look more closely at the embodied messages of the children that helped me interpret whatever may have been going on for them.

\section{Video-stimulated recall interviews}

Stimulated recall is an approach that was first developed by Benjamin Bloom to investigate students' thinking processes in lectures and discussion groups (Hodgson, 2008). Since then, the stimulated recall approach has become widely used by researchers in various disciplines such as music (Dempsey, 2010; Rowe, 2009) and nursing (Antonsson, Graneheim, Lundström \& Åström, 2008). Studies using stimulated recall techniques and also employing case study methodology have also been used very effectively within the teaching and learning area including in Wyatt and Arnold's (2012) investigation of mentoring in Omani schools, Hennessy and Deaney's (2009) study of teacher and researcher perspectives of pedagogic strategies, and Schepens, Aelterman, and Van Keer's (2007) investigation of student teachers' learning processes. This made the use of stimulated recall interviews in combination with case study methodology a likely fruitful approach in my study.

My use of the video-stimulated recall interview approach involved watching the video carefully at home or my office and keeping a note of episodes that I wanted to discuss with the practitioners. I selected the segments based on my notes and whenever I saw a child interacting with a peer in the video. The video-stimulated recall sessions with the practitioners were held at an agreed time, in the evenings and Saturdays, and involved replaying the video recordings of the children and asking them to recall their thoughts, be reflective, and give their comments on what they thought was happening at certain segments during the observation session (Rowe, 2009). In replaying the recordings to participants I gave them the authority to stop the video, fast forward or rewind it at any 
time and then give comments on the selected episodes. The video was stopped at points throughout the episode to let the practitioners comment on what they thought was happening with the children at that time. As the researcher, I also chose to play episodes where there were aspects that I was interested in discussing further. According to Gass and Mackey (2000), prompt questions are an effective tool for probing more deeply into the participants' thoughts during the stimulated recall interview.

According to Nunan and Bailey (2009) and Gass and Mackey (2000), stimulated recall is a procedure to stimulate the participants to review data from a certain event to access their thought processes when conducting an activity. The stimulated recall interviews were conducted as soon as possible after the observations, no later than one week, so that the practitioners could recall the event better. Two to three sessions of video-stimulated recall interviews were conducted at the three case study centres to complete the data collection process. I provided refreshments for the practitioners as each session of the videostimulated recall interviews took up around two hours of their time.

\section{Focus group discussion}

Focus group can be very engaging and can set up a situation where the interactions can lead to sharing and exchanging in-depth information (Wellington, 2000). According to Nunan and Bailey (2009), there are several strengths of focus groups. Firstly, it is less time consuming because it would take a lot longer to do individual interviews. Secondly, group discussions often promote thinking by participants based on the thoughts or comments of other members of the group. Thirdly, participants often feel more secure and comfortable when they are discussing their thoughts in the safety of a group than individually with an interviewer.

A focus group discussion was conducted with the practitioners after all the videostimulated recall interviews were completed to gather more information on the practitioners' views on the peer interactions in their childcare centres. At first, the practitioners were reluctant to do a focus group because of the time required and travel expenses to one venue. Thus, I had to arrange transport for the practitioners to come to 
one venue, which was at the RCC, to have a focus group discussion together. The focus group took about two hours and half on a Saturday morning because the practitioners were not working on that day. The practitioners were given information beforehand about the questions and topics that were to be discussed and then were given consent forms to sign (see appendix G-H). I started the focus group discussion with general questions about their daily work and on their experiences of working with children. This was to create a warm and relaxed atmosphere. When the practitioners looked settled and ready for the discussion, I started asking the interview questions related to children's peer interactions. The discussion was structured around broad themes identified in the individual interviews and during observations. According to Carey and Asbury (2012), focus groups are useful for exploring new topics as well as looking at behaviours and beliefs when little information is known. Since little is known about the peer interactions of children under three year olds in Malaysian childcare centres and how practitioners perceive them, focus group discussions with the practitioners were an essential component of this study.

\section{Summary of methods in collecting data}

The table below summarises the research questions and the methods that were used to gain the answers.

Table 3.5: Research questions and methods

\begin{tabular}{|l|l|}
\hline Research questions & Methods \& tools \\
\hline $\begin{array}{l}\text { 1. How do practitioners perceive peer } \\
\text { interactions among children under three }\end{array}$ & • Semi-structured interviews \\
years old in their childcare centres in & - Focus group discussion \\
Malaysia & \\
\hline $\begin{array}{l}\text { 2. What kinds of peer interactions occur } \\
\text { among children under three years old in } \\
\text { childcare centres in Malaysia? }\end{array}$ & $\begin{array}{l}\text { - Video-recorded observation of } \\
\text { children's peer interactions by }\end{array}$ \\
\end{tabular}


The figure below provides a visual representation of the methods that were used in collecting data for this research.

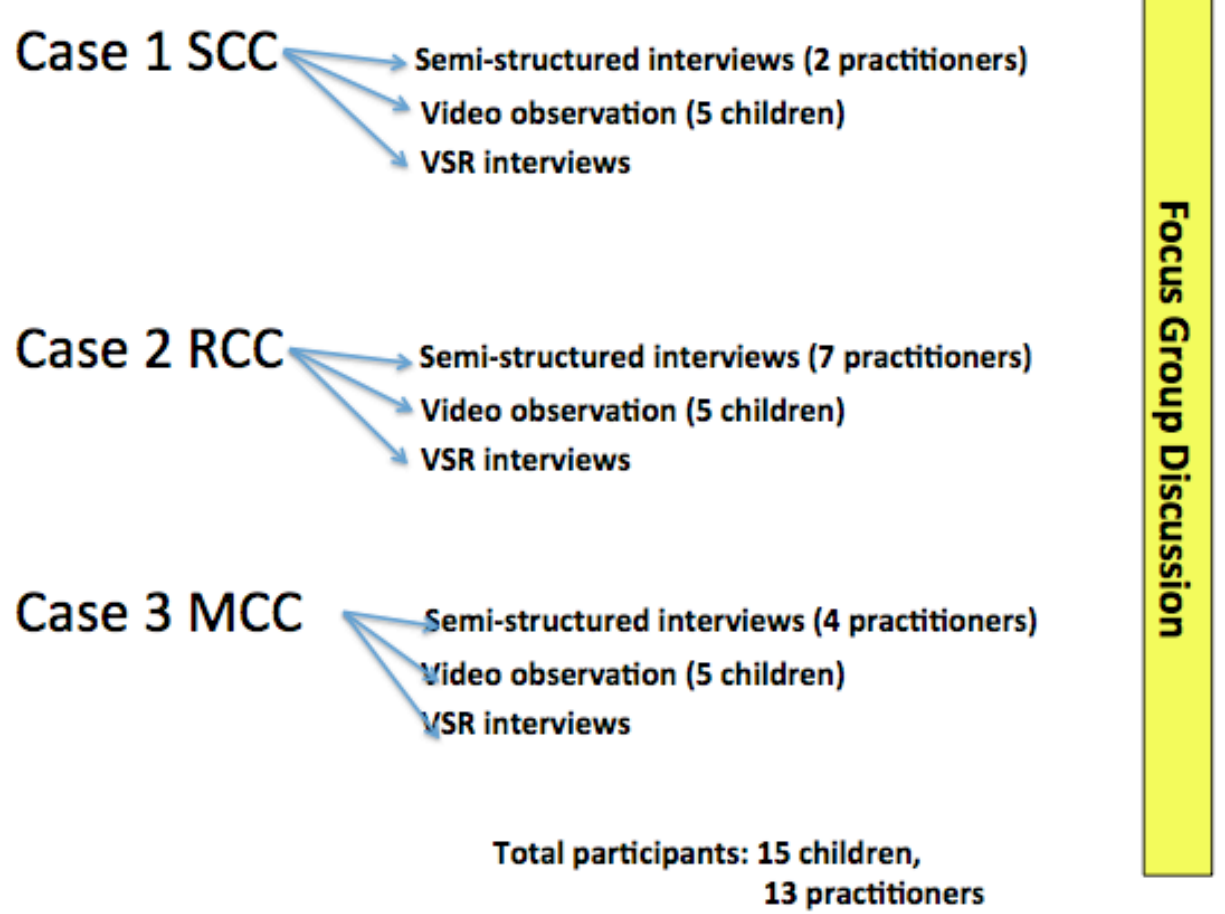

Figure 3.1 Data collection methods in each case study

The tables below summarise the methods, persons involved and the time taken during the data collection.

Table 3.6: Summary of data collected at Sunny Childcare Centre (SCC)

\begin{tabular}{|c|c|c|}
\hline Method & Persons involved & Time \\
\hline $\begin{array}{l}\text { Semi-structured } \\
\text { Interviews } \\
\text { (Practitioners) }\end{array}$ & $\begin{array}{l}\text { Amy } \\
\text { Fifi }\end{array}$ & $\begin{array}{l}60 \text { minutes } \\
90 \text { minutes }\end{array}$ \\
\hline $\begin{array}{l}\text { Video-recorded } \\
\text { observations } \\
\text { (Children) }\end{array}$ & $\begin{array}{l}\text { Willy } \\
\text { Anna } \\
\text { Ali } \\
\text { Ina } \\
\text { Roy }\end{array}$ & $\begin{array}{l}45 \text { minutes } \times 2=90 \text { minutes } \\
45 \text { minutes } \times 2=90 \text { minutes } \\
45 \text { minutes } \times 2=90 \text { minutes } \\
45 \text { minutes } \times 2=90 \text { minutes } \\
45 \text { minutes } \times 2=90 \text { minutes }\end{array}$ \\
\hline $\begin{array}{l}\text { Video-stimulated } \\
\text { recall interviews } \\
\text { (Practitioners) }\end{array}$ & $\begin{array}{l}\text { Amy } \\
\text { Fifi }\end{array}$ & 120 minutes $\times 2$ sessions \\
\hline
\end{tabular}


Table 3.7: Summary of data collected at Rainbow Childcare Centre (RCC)

\begin{tabular}{|l|l|l|}
\hline \multicolumn{1}{|c|}{ Method } & Persons involved & \multicolumn{1}{c|}{ Time } \\
\hline Semi-structured & Khalila & 120 minutes \\
Interviews & Sarah & 60 minutes \\
(Practitioners) & Fatimah & 60 minutes \\
& Maria & 45 minutes \\
& Jamilah & 50 minutes \\
& Baiti & 40 minutes \\
& Nadia & 90 minutes \\
\hline Video-recorded & Ibrahim & 45 minutes x 2=90 minutes \\
observations & Jasmin & 45 minutes x 2 =90 minutes \\
(Children) & Sulaiman & 45 minutes x 2 =90 minutes \\
& Omar & 45 minutes x 2 =90 minutes \\
& Rania & 45 minutes x 2 =90 minutes \\
\hline Video-stimulated & Khalila & 90 minutes x 3 sessions \\
recall interviews & Sarah & \\
(Practitioners) & Fatimah & \\
& Maria & \\
& Jamilah & \\
& Baiti & \\
& Nadia & \\
& & \\
\hline
\end{tabular}

Table 3.8: Summary of data collected at Moonbeams Childcare Centre (MCC)

\begin{tabular}{|c|c|c|}
\hline Method & Persons involved & Time \\
\hline $\begin{array}{l}\text { Semi-structured } \\
\text { Interviews } \\
\text { (Practitioners) }\end{array}$ & $\begin{array}{l}\text { Rozita } \\
\text { Husna } \\
\text { Elina } \\
\text { Tiara }\end{array}$ & $\begin{array}{l}100 \text { minutes } \\
55 \text { minutes } \\
100 \text { minutes } \\
60 \text { minutes }\end{array}$ \\
\hline $\begin{array}{l}\text { Video-recorded } \\
\text { observations } \\
\text { (Children) }\end{array}$ & $\begin{array}{l}\text { Nani } \\
\text { Ayu } \\
\text { Helmi } \\
\text { Rafiq } \\
\text { Zara }\end{array}$ & 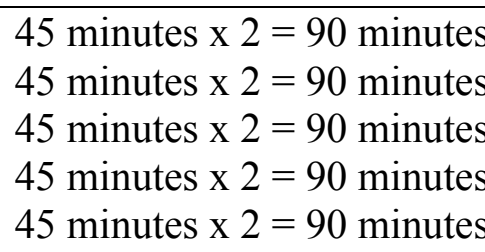 \\
\hline $\begin{array}{l}\text { Video-stimulated } \\
\text { recall interviews } \\
\text { (Practitioners) }\end{array}$ & $\begin{array}{l}\text { Rozita } \\
\text { Husna } \\
\text { Elina } \\
\text { Tiara }\end{array}$ & 90 minutes $\times 2$ sessions \\
\hline
\end{tabular}


Table 3.9: Summary of data collected during focus group discussion

\begin{tabular}{|l|l|l|}
\hline \multicolumn{1}{|c|}{ Method } & Persons involved & \multicolumn{1}{c|}{ Time } \\
\hline $\begin{array}{l}\text { Focus group discussion } \\
\text { (Practitioners) }\end{array}$ & Amy & 1 session of 150 minutes \\
& Fifi & \\
& Khalila & \\
& Sarah & \\
& Fatimah & \\
& Maria & \\
& Jamilah & \\
& Baiti & \\
& Nadia & \\
& Rozita & \\
& Husna & \\
& Elina & \\
& Tiara & \\
\hline Total & $\mathbf{1 3}$ practitioners & \\
& & \\
\hline
\end{tabular}

\subsection{Data analysis}

As discussed earlier the answers to my research questions were inductively derived from data gathered during semi-structured interviews, video-recorded observations, videostimulated recall interviews and focus group discussions. Data obtained were transcribed, translated, coded and analysed using a thematic analysis process across the data sources. Thematic analysis is a common way to analyse qualitative study, especially for case studies. Carey and Asbury (2012) stated that "thematic analysis is widely used to broadly identify, analyse and describe patterns or themes". The quality of the thematic approach must be weighed up against the researcher's analytical insights and critical analytical skills in interpreting the data (Braun \& Clarke, 2006). According to Braun and Clarke (2006), themes do not automatically appear. Rather, collecting, analysing and reporting on the findings could show systematic linkages between participants' experiences, attitudes or views regarding the interest of the study. Four steps were used to analyse the data thematically (Braun \& Clarke, 2012), namely: (1) familiarizing myself with the data; 
(2) generating initial codes; (3) searching and reviewing potential themes; and (4) connecting and presenting the themes while seeking their significance in relation to my research questions.

The answer to the first question, "How do practitioners perceive peer interactions among children under three years old in their childcare centres in Malaysia?" was answered by data gathered from semi-structured interviews, video-stimulated recall interviews and focus group discussion. The second question, "What kinds of peer interactions occur among children under three years old in childcare centres in Malaysia?" was informed by data gathered from video-recorded observations.

In familiarizing myself with the data, I first transcribed the video-recorded observations of the children and then transcribed all of the semi-structured interviews, videostimulated recall interviews and the focus group interviews of the practitioners. Interviews that were conducted in Bahasa Melayu were translated into English. Familiarising myself with the data also involved watching the videos and re-reading the transcripts (both in Bahasa Melayu and the translated English versions) over and over again. According to Dierckx de Casterlé, Gastmans, Bryon and Denier (2012), re-reading the verbatim transcripts triggers recall of the non-verbal signals associated with the data collection, and helps the researcher comprehend the insights of the data's stories.

Generating initial codes began during the process of data familiarisation. Codes are specific information considered to create themes. According to Clarke and Braun (2013), coding is a common step that needs to be done in a qualitative analysis. As I watched the videos of the children again and again, re-reading the practitioners' interviews, I began to identify codes for classifying the different types of actions within the children's peer interactions at their childcare centres, such as entry strategies; imitating peers; shared experiences; participation in routines; humourous exchanges; interrupted play; giving in and walking away, and so on. With more reading and re-reading of the transcripts, the codes were then sorted into categories. As these categories accreted examples and became further elaborated, or pruned back, I also sought to discover the main themes and 
links among them and to identify the patterns, which would explain the dynamics of peer interaction behind the data. This process resulted in bigger order themes being identified as the focus for much of the children's peer interactions including: creating a sense of belonging and togetherness; negotiating conflicts; exercising agency and social competence. These themes became the basis of the key findings in my study. The same was done with the practitioners' data in order to identify categories for practitioners' perceptions and their responses to the children's interactions.

Searching and reviewing potential themes was done as I scanned for patterns and grouped similar ideas or topics together in order to develop the themes. A theme was defined as an overreaching idea that covered several codes (Clarke \& Braun, 2013). I created mind maps for each research question. These mind-maps allowed me to capture the overreaching ideas, which then led me to relevant themes. The themes were then analyzed in order to grasp the overall story of my data. I also created sub-themes under the big themes in order to organize concepts that focused on specific elements. Over the data-gathering phase of the three case studies, a set of themes emerged that appeared to have validity across the cases.

Bringing all the findings together has resulted in four data chapters presented as chapters four to seven in this thesis. Chapter four answers the first research question of: "how do practitioners perceive peer interactions among children under three in childcare centres in Malaysia?" by using data gained from individual interviews with the practitioners at the start of data gathering while chapters five and six answer the second research question of "what kind of peer interactions occur among children under three years old in Malaysian childcare centres?" Chapter seven re-considers the first research question and presents an answer that this time is gained from data gathered from the video-stimulated recall interviews and focus group discussion. 


\subsubsection{Theoretical constructs}

Several theoretical constructs have been used to bring together the findings of this study. Firstly, Super and Harkness' (1986) concept of the developmental niche as incorporating the psychology of the caretakers was used to understand the practitioners' perceptions of the children's peer interactions. Lefebvre's (1987) concept of the everyday or everydayness, Rose-Krasnor's (1997) Social Competence Prism and the notion of agency were used to analyse the second research question. Additionally, Loizou's (2005) theory of the absurd, Licht's et al. (2008) work on conflicts between peers in infancy and toddler age, and de Waal's (2000) Relational Model were also used in analyzing children's peer interactions at their childcare centre. These theoretical constructs are discussed in more detail below.

\section{The Developmental Niche: Psychology of the Caretakers}

The 'Developmental Niche' by Super and Harkness (1986) is a theoretical framework that attempts to explain child development in terms of three sub-systems that work together with other features of a given culture to mediate the child's experience. The developmental niche has three components, which are: (1) the physical and social settings in which the child lives; (2) the customs of childcare and child rearing; and 3) the psychology of the caretakers. My study draws on the third component of the developmental niche: the psychology of the caretakers, and uses this as a way of explaining how the practitioners within the children's childcare setting mediated the children's experience. Super and Harkness (1986) argued that ECCE centres can be considered as a developmental niche because ECCE centres provide valuable opportunities for regular interactions as well as support and guidance for children's development (Davis \& Degotardi, 2015). According to Super and Harkness (1986), caregiving and childrearing are underpinned by the caregivers' psychology or the caregivers' understandings of their role, including their educational practices. This suggests that the practitioners' understandings impact the opportunities that they provide for children to interact with peers because practitioners use their schemata or understandings to guide children's' peer interactions. By considering the practitioners' perceptions and responses of children's peer interactions within their setting through the 
lens of Super and Harkness's concept of the developmental niche, it becomes possible to see that the practitioners' perceptions and responses can have an influence on children's peer interactions. Thus, in this study, I focus on the practitioners' psychology or their understandings of peer interactions towards children's learning and how this can influence the children's social competence.

\section{The concept of the everyday}

In analysing the children's peer interactions at their childcare centres, I found that the children became familiar with their peers and the routines of their childcare centres as a result of being there on a daily basis. By looking at the children's peer interactions within their childcare centres through the lens of Lefebvre's (1987) concept of the everyday, it became possible to see not just the similarity and repetitive nature of the children's interactions but also that their repetitive nature was inherently and simultaneously productively creative. In other words, while the children's interactions with each other showed repetitive patterns, their experiences with each other also produced change. This accords with Lefebvre's argument that the character of the everyday has always been repetitive and that the great contradiction of this repetition of the everydayness is that everything changes. In this study the children chose to undertake and repeat their interactions with others daily: I focussed on these rational repetitions of the everydayness of the children's lives in their childcare setting and looked at what these can reveal about children's learning to interact with peers, especially on the topic of belongingness, togetherness, agency and social competence.

\section{Social Competence Prism}

According to Campbell et al. (2016), social competence is especially important when young children transition into the early childhood years because their interactions with peers expand. Even though children interact with other children in informal ways prior to schools (such as at the playground and in the library), ECCE centres are commonplace in many western countries where children are exposed to peers at a young age. For children who attend ECCE centres, their centre itself can be a platform for children to learn to be socially competent with peers. 
In analyzing the children's peer interactions at their respective childcare centre, I have used Rose-Krasnor's (1997) three-level Social Competence Prism. Rose-Krasnor defined social competence as "effectiveness in interactions" and this is positioned at the topmost level of the prism, which indicates its importance. This is useful for my study because it shows how social competence is needed during children's interactions with peers. Additionally, the prism clearly shows that social competence is understood to incorporate a balance of a focus on the self and others. Being in an ECCE centre with peers requires children to have that balance between the self and others (Epstein, 2009; Fabes, Gaertner \& Popp, 2006). The skills-level at the bottom of the prism includes skills associated with social competence like cognitive, social and emotional abilities and motivations that reside within an individual. In other words, here the focus of the prism is on an individual's behaviours and motivations as the elements that combine together to create competence during interactions, relationships and in establishing group status. By incorporating this prism into my study I was able to look at how children use their social skills and how they create a balance between self and others when they are involved in peer interactions. Moreover, it is also useful in analyzing how the practitioners guided social competence in children and what these could mean to the children's learning.

\section{Agency}

For the purpose of this study, I have adopted Guo and Dalli's (2016) definition of agency, as: "a phenomenon of children's autonomy and capacity to learn" (p. 255). This is because I view the children in my study as active and capable of constructing their own interactions with minimal adult intervention. In other words, the children have the capacity to learn and take actions of their own volition. In this study, the notion of agency is used to refer to the choices the children make in everyday life as social beings and how these choices impact their peer interactions. 


\section{The theory of the absurd}

Loizou's (2005) theory of the absurd is incorporated into this study because it describes the children's production and appreciation of humour. Loizou found that children use humour in three ways: (1) funny gestures/ positions/ sounds/ words; (2) incongruous use of materials; and (3) incongruous actions. In analysing this study, I found that children in my study frequently used humour to interact with peers and looking at these interactions through the lens of Loizou's theory enabled me to understand the importance that humour plays in how children establish and maintain interactions with each other.

\section{Motivations underlying children's conflicts}

According to Singer et al. (2012) conflicts are inevitable when children get together. This is because group members have different interests which can be in opposition to others' making conflict a normal social phenomenon (Licht et al., 2008). In analysing the data, I discovered children get into conflicts with peers many times during their time at their childcare centres. In my effort to understand the children's conflicts, I considered the children's conflicts during peer interactions through the lens of Licht et al.'s notion that there are underlying motivations in children's conflicts. Licht et al. used the word 'motivation' in conflicts to refer to a child's specific goal during conflict episodes. By applying this analysis to my study, I focused on understanding why children have conflicts with their peers. Understanding what a child tries to achieve in a conflict can help with making sense of children's behaviour. Additionally, it can also help with pedagogical intervention (Licht et al.).

\section{The Relational Model}

While I used Licht's et al. (2008) notion of the motivations underlying conflicts to help me understand why children have conflicts, I complemented this approach through the use of use de Waal's (2000) Relational Model. de Waal's model focuses on the relational dynamics of conflicts and thus focuses on the relational interest during the conflict as in the conflict strategies that are used (de Waal, 2000; Killen \& de Waal, 2000; Singer et al., 2012). According to de Waal, conflicts of interest are settled in one of three ways: (i) tolerance with each other such as sharing and taking turns with an object; (ii) avoidance 
of confrontation; and (iii) aggression. In looking at the children's conflicts through the lens of de Waal's Relational Model, it became possible to consider not only why children had conflicts but also how they navigated their relationships to solve conflict. This analysis has implications for how children can be helped to improve their interactions with peers and their overall social competence.

\subsection{Ethical considerations}

Ethical approval for this study was gained from the Victoria University of Wellington of Education Ethics Committee (Reference number 21808 ) on the $25^{\text {th }}$ of June 2015 (see appendix I), before the study was conducted. Additionally, permission was gained from the Economic Planning Unit, a Malaysian government department, to conduct the study in Malaysia (see appendix J). Appropriate information was provided and a research pass was given prior to the study. These two processes were mutually reinforcing and supported the access and consent processes used in the study as outlined in sections 3.6. As noted already I did not encounter any refusals to participate and no participants withdrew from the study. Information sheets and consent forms used in this research can be found in the appendixes (A-H).

\section{Trustworthiness}

In order to ensure the trustworthiness of the study, four critical components for qualitative research were attended to: credibility, dependability, conformability and transferability (Merriam, 2009). First, credibility in my study is shown by my use of multiple sources of data (from semi-structured interviews, video-recorded observations, video-stimulated recall interviews and focus group discussion) about the same phenomenon from different perspectives. These multiple sources made data triangulation possible - one of several strategies identified by Cresswell (2014) to ensure credibility and to reduce personal bias in interpreting and analysing data. I also used two other strategies identified by Cresswell: (i) rich and thick descriptions, which in my study related to the detailed descriptive written records I developed of children's peer interactions in their naturalistic settings; and (ii) member checking of interview data. For 
the latter, I sent the interview transcripts (both individual semi-structured interviews, and focus group discussions) to the practitioners so that they could check their accuracy. I hand-delivered some of the transcripts by hand to the practitioners while I was still in Malaysia for the data gathering phase of my study, and I sent the others via email once I had returned to New Zealand. These two strategies mean that readers can be assured of the credibility and validity of my data and this enables readers to judge the quality of my interpretation of them.

Secondly and thirdly, dependability and confirmability are used as a check and balance mechanism on data consistency (Merriam, 2009). Dependability relates to the extent to which the data and interpretation are sound, reliable and consistent (Cohen, Manion, \& Morrison, 2000). Confirmability refers to the degree to which research results can be confirmed or verified by others who read and review the research results (Bradley, 1993; Cohen et al., 2000). Krefting (1991) suggested the strategy of coding the data repetitively because this can ensure a balance on data consistency. In my study this meant that I repetitively played back videos and interviews in order to check the consistency of my data coding: I coded the same data three times. All of the three results were compared in order to address the dependability and confirmability of the data. In addition to that, discussions and regular meetings with my supervisors contributed to the dependability and confirmability of my findings.

Lastly, according to Merriam (2009), transferability is defined as a way to apply what we have learned in a specific context to other similar contexts. My study is expected to provide enough information to guide ECCE practitioners in improving their teaching practices with children under three. It is also intended for the Ministry of Education in Malaysia to guide their decisions on improving ECCE quality and implement trainings to the ECCE practitioners to ensure better and quality ECCE in the nation. 


\subsection{Chapter Overview}

This chapter has outlined the research methodology for my study which is located within a social constructivist paradigm and uses a qualitative multiple-case study design involving semi-structured interviews, video-stimulated recall interviews and focus group discussions with 13 practitioners in three childcare centres in Selangor Malaysia, and video-recorded observation of 15 under three years old children across the three centres. It has outlined the procedures used in collecting the data and the theoretical constructs through which the data were analysed as well as ethical considerations involved in carrying out the study. The trustworthiness of this research was discussed and the measures taken to ensure it outlined. In the next chapter, I will present my analysis of the data on the practitioners' perceptions of children's peer interactions, starting with how practitioners perceived promoting children's peer interactions by facilitating group activities. 


\section{CHAPTER FOUR}

\section{PRACTITIONERS' PERCEPTIONS OF CHILDREN'S PEER INTERACTIONS}

\subsection{Introduction}

The first aim of this study was to find out how practitioners perceived peer interactions among under-three-year old children in childcare centres in Malaysia - a topic that is under-researched in this cultural context. According to Super and Harkness (1986), Shin (2010), and Davis and Degotardi (2015), how a practitioner understands children's peer interactions can impact the opportunities that they provide for children to interact with their peers. The practitioners in my study were asked about their perceptions of children's peer interactions three times during the study: firstly during the semi-structured individual interviews at the start of the project; secondly during the stimulated-recall interviews of selected video excerpts collected in Step 8 of the research procedure (see Table 3.1 in chapter 3), and thirdly during the final focus groups with practitioners. During both the stimulated recall interviews and the focus group, the practitioners were required to reflect on the children's behaviour, while in the initial individual interviews they were asked to express their existing views about peer interactions among the underthree year old children in their care.

In this chapter I discuss the practitioners' perceptions of young children's peer interactions in their respective centres and what they thought these interactions meant for the children's learning using the first data set from the teachers collected during the semistructured interviews with the individual practitioners before the start of the observations of the children's peer interactions. In this way, I was able to capture the practitioners' thinking before there was any chance that they might be influenced by any new knowledge gained during the course of the research project. I have analyzed the practitioners' perceptions by following the work of Davis and Degotardi (2015) on educators' understandings and beliefs about infant peer relationships in early childhood 
settings. Similarly to Davis and Degotardi's research, I used Super and Harkness' (1986) concept of the 'developmental niche' to frame this chapter, as well as chapter seven, which both focus on the views practitioners held about children's peer interactions.

As elaborated in more detail in chapter three, the 'developmental niche' by Super and Harkness (1986) is conceptualized as a system with three components: (1) the physical and social settings in which the child lives; (2) the customs of childcare and child rearing; and (3) the psychology of the caretakers. Super and Harkness argued that ECCE centres can be considered as a developmental niche because ECCE centres support and guide children's development (Davis \& Degotardi, 2015). While all of the three components are important for a child's development, this study only focused on the third component of the developmental niche: the psychology of the caretakers. According to Super and Harkness (1986), caregiving and childrearing are underpinned by the caregivers' psychology. This suggests that practitioners' perceptions can have an influence on children's peer interactions because what they perceive as important or unimportant can promote or constrain the children's interactions (Davis \& Degotardi, 2015). In addition, Rose-Krasnor's (1997) Social Competence Prism is used to frame the overall chapter on the contribution of peer interactions to the children's social competence.

In my study, two main themes were evident in how the practitioners spoke about their views of children's peer interactions, both of which are integrally bound to the way that the practitioners' saw their own role, specifically as: (1) promoting peer interactions by facilitating group activities; and (2) managing peer interactions by responding to children's conflicts. I elaborate on these two themes in the sub-sections below.

\subsection{Promoting peer interactions by facilitating group activities}

A key finding in this study is that most of the practitioners at the three case study childcare centres perceived their role in children's peer interaction as one of facilitating group activities for them to interact with their peers. Such a focus can be supported by findings such as those by Ishikawa and Hay (2006) who argued that it is important for 
humans to participate in social groups. Moreover, researchers have reported that peer group experience has important effects on the children's well-being and diminishes the risk of mental health problems (Hay, Payne \& Chadwick, 2004; Deater-Deckard, 2001). Adverse experiences increase that risk. Kemple and Hartle (1997) have pointed out that positive peer interactions and relationships between the children do not magically happen. It is up to the adults or practitioners to understand the social needs and capabilities of the children; they argued that the practitioners' role is to provide appropriate support to the children, for example by arranging that they sit together. In my study, organising group activities was a strategy most of the practitioners claimed to use as a way of supporting the development of children's peer interactions as can be seen in their conversations below:

Amy: Peer interaction to my understanding is when the children talk together. But it doesn't mean they need to talk verbally. It can be non-verbal like signaling their friends with body language. They use their hands and face to interact with friends... So if I want them to interact more with each other, I usually do group activities so that they sit together. They interact with each other then. I let them play with play dough too. They love play dough. They can play for hours with play dough if I let them. They sit and look at each other's creation and then they copy each other. They also show off their creation to their friends. Other activities that I do are drawing, colouring pictures and asking them to pick a book and sit together in a circle. Sometimes they share the book and then they talk about it. For example Anna pointed to a picture in Willy's book and then they all talked about the picture together. $\left(\mathrm{SCC}^{2}\right)$

The statement above indicates that Amy saw herself as promoting peer interactions by managing children's activities and bringing them together in groups. She recruited children into groups and gave instructions on what to do like picking a book and sitting in a circle. She described how the children interacted with each other during group activities

\footnotetext{
${ }^{2}$ Bracketed letters are an abbreviation of 'Sunny Childcare Centre' where Amy worked. This convention will be used after name of each practitioner referred to in each chapter.
} 
where non-verbal gestures were seen between them, including eye contact, looking at each others' work, imitating and showing objects to peers. Clearly, Amy was pleased to see the children interacting in this way. What is also clear is that Amy's strategy had the additional goal of managing children's activities so that they would sit down together. Looking at these data through the concept of the developmental niche, and its sub-system of the psychology of the caregivers (Super \& Harkness, 1986), it is clear that Amy's understanding and perceptions of peer interactions influenced how she promoted peer interactions at her childcare centre.

Amy was not the only one who mentioned setting up group activities as a way to make the children interact and sit together, as well as to manage them as a group. Nadia and Maria from Rainbow Childcare Centre also highlighted these matters:

Nadia: Peer interactions is when children mingle with each other... I think to increase interactions between the children, we have to do lots of activities: make them sit in groups and then do activities like colouring, painting, read flash cards or something like that. They'll be facing each other so they are bound to interact, like chatting in their own way. It's good to see them in groups. It's easier to control them too when they are together like that... less noisy. (RCC)

Maria: Sometimes when they play whatever they want in the room, it gets too noisy and out of control with running here and there. It's hard sometimes because the small babies are sleeping and the big kids make too much noise. So to reduce the noise I call them into a circle and let them do quiet activities like drawing or anything like that. I do see them interact when they are in a circle together like looking at each other, talking, smiling and laughing together... that is what peer interaction is all about to me. (RCC)

Like Amy, Nadia and Maria perceived children's peer interactions to be children mingling and doing things together. In creating opportunities for peer interactions among the children, Nadia and Maria reported how adult-led activities like paintings or drawing 
can increase interactions between the children. This was seen as a good way to promote children's peer interactions and their statements indicated that they valued group activities. What was also apparent was that the practitioners saw sitting together in a circle as an effective group management strategy and that this was an important goal for them. An additional goal for the practitioners was to reduce the noise level in the room. On another note, while Amy, Nadia and Maria did not mention the learning or the development of social competence that happened during these interactions, other practitioners like Jamilah and Sarah were more expressive about this aspect of peer interactions, and specifically focused on cooperation during children's group activities. For these practitioners (Jamilah and Sarah), peer interaction was about sharing resources and using them together as a group. This is evident in their comments below:

Jamilah: To me peer interaction is about sharing things... I think you have to do activities to support interactions like form groups and then let the children do things together. They learn how to cooperate with their friends when they are in a group. Like doing art by using watercolours, doing collages and sticking things on paper. The bigger kids are able to do things like that. Sometimes the little kids show interest in that too. They point at the colours and the bigger kids would smile and show the little kids the colours. The big kids help the little kids with the art. (RCC)

Sarah: Activities like arts and crafts or playing outdoors help them interact more with peers. We have to arrange those activities for them. Outdoor activities like swimming in the paddle pool are great too. Some days, we take the plastic pool out and put water in it. They love that. We can see that they interact a lot when we do those kinds of activities like sharing the toys or cooperating, laughing, smiling and chatting. (RCC)

It is clear in these statements that for Jamilah and Sarah, sharing resources is an important learning goal from peer interaction. Jamilah also pointed out the non-verbal gestures the children gave each other as they did arts and crafts, like smiling and pointing objects at 
peers, and children learning to help one another in making art pieces. Meanwhile Sarah commented on how the children interacted happily as they played and shared resources and that their interactions increased during these activities. Additionally, both Jamilah and Sarah (RCC)'s comments showed that they believed that they could support the children's learning about sharing and cooperation by arranging activities for the children, a view shared also by Elina (MCC) and Fifi (SCC). The latter believed that letting the children do one big task together could enhance peer interactions:

Elina: I think it is the teachers' role to make children interact more with each other by doing activities with the children or asking them to do a difficult task but one that they can work together on. For example yesterday, I asked Saleha to bring her bag to me. Her bag is big and heavy with lots of stuff in it, so she had to drag it to me. When I saw that, I asked Rafiq and Hakim to help Saleha. So the three of them dragged the bag together and brought it to me. They laughed together when they dragged the bag... asking the children to build a tall tower with blocks can also get children to do something together and yes they do interact when they do these kinds of activities together like talking, in their own ways. (MCC)

Elina's comments illustrate her beliefs about children's peer interactions as well as about the role of practitioners. Although Elina's words do not expressly mention the words "collaboration" and "cooperation", her statement: "...asking them to do a difficult task but one that they can work together on" shows that she values these qualities highly and suggests that her practice would seek to support children to acquire them.

Fifi from Sunny Childcare Centre elaborated more on the topic of how group activities can help children work together or cooperate to complete a task at the same time as enhancing their peer interactions:

Fifi: I think teachers have to do more fun activities for the children. When we do activities, the children sit together in a circle or sit together at the table. They face 
each other and that's when we see them interact a lot among themselves. For example, doing painting, play dough and playing with sand are all fun activities. So when they do things together, everyone has the same experience and can talk about it later. No child is left behind in the experience. When I first started to work here, I looked up in Google a lot on how to make rainbow rice, play dough and do arts and crafts. I made these with the children and I think these activities brought them closer. They have to work together to build something. Like baking one big cake. Everyone has to help towards that one cake and they have to cooperate to finish it. (SCC)

Fifi recognized that when children do the same thing together, they get to explore and experience their play together and that these activities can bring the children closer. This is an indication that she values togetherness in children's peer interactions (see also chapter 5). Fifi also saw group work as leading children to cooperate to get the task done. Moreover, Fifi's statement shows her awareness that, as Kemple and Hartle (1997) explained, materials and equipment can affect the social dimensions of children's play and that teachers can support children's peer interaction by changing the available materials. Clearly Fifi was very determined to learn how to support children in their peer interactions as was evident in her statement about looking up the internet for knowledge and information.

Taken together, these findings suggest that the practitioners at the three childcare centres perceived doing group activities at their childcare centres as one of the main strategies to enhance peer interactions among children under three years old. Using Super and Harkness' (1986) concept of the developmental niche, and the idea that the psychology of the caregivers (i.e., the third sub-system of the niche), is a good indicator of what they would promote for, or constrain, the children to learn, these data would suggest that the practitioners' practices would rely heavily on group activities to support learning of cooperation and collaboration during peer interactions (Davis \& Degotardi, 2015). Additionally, the practitioners perceived that group activities could reduce noise levels 
and that a result of adult-led group activities would be an increase in children's social competence.

These data show that the practitioners in my study had very strong views about the value of peer interactions, and expressed this value as emerging during group activities that they themselves set up. This suggests that in their psychology as practitioners, they saw themselves as responsible for setting up group activities as a way to facilitate peer interaction skills. One notable feature of their discussion was that the practitioners did not mention any learning outside of group such as learning in pairs but rather valued classroom harmony and group control. Yet researchers have shown that these strategies while valuable to establish group control and sustain classroom harmony - are limited in their ability to promote exploration and independence. According to Williams, Mastergeorge and Ontai (2010), recruiting children into groups may increase children's reliance on the practitioners to provide social opportunities for them rather than finding their own social experience with peers. Similarly, Legendre and Munchenbach (2011) and Rutanen (2007) stated that adults have to give space to children so that their interactions can be developed, otherwise the children might find the adults more attractive than their peers. Conversely, other researchers argue that practitioners have to help promote peer interactions among children under threes until they show independence because adults' presence and support are needed to teach young children more efficient ways to interact (Greve, 2005; Bae, 2012; Gjems, 2009; Hillesoy, 2016), Hillesoy additionally pointed out that practitioners might achieve this more easily if they were aware of how their actions may constrain rather than facilitate interactions. This differing views serve to highlight the importance of giving the right support to children's interactions with their peers and that the psychology of the practitioners is important in understanding what their actions could do to increase or decrease children's peer interactions (Hillesoy, 2016; Davis \& Degotardi, 2015). In the next section, I discuss how practitioners from my study perceived their role in children's conflicts and how this links to children's social competence. 


\subsection{Managing peer interactions by responding to children's conflicts}

The second big theme embedded in the way that the practitioners in this study spoke about under-three year olds' peer interactions was their perception of their role in responding to children's conflicts. Most of the practitioners perceived conflicts among the children as normal interactions that happen everyday and which needed them to step in quickly to end them. Most of the practitioners in this study made statements that suggested that they understood the conflicts between the children to be negative necessitating that they intervene in order to prevent harm among the children. This contrasts with some researchers' findings that adult intervention in children's conflicts can be negative because it does not give children the opportunity to practise social competences and problem solving skills (Clarke, McLaughlin \& Aspden, 2017; Majorano, Corsano \& Triffoni, 2015; Gloeckler, Cassell \& Malkus, 2014; Silver \& Harkins, 2007; Singer \& Hannikainen, 2002; Johnson \& Johnson, 1995). Some examples of the practitioners' views about conflict as a negative experience are below:

Maria: Sometimes their interaction is negative like fighting over toys. That happens everyday. (RCC)

Baiti: Snatching toys from friends, wanting the same toys and then screaming and crying about it. That's negative interactions to me. (RCC)

Fifi: Interactions between the children can be positive and negative. Positive is when they play nicely together but negative is when they scream, shout, cry. You know... fighting over something. Usually toys. (SCC)

Elina: Conflict among children is normal... but it is negative and we have to stop it because we don't want harm among them... everyday they are in conflict so many times. Sometimes repeating the same thing and fighting about the same toy over and over again. (MCC) 
Tiara: Conflict among the children is a negative thing and we as adults have to stop the conflicts from getting worst. (MCC)

According to Clarke, McLaughlin and Aspden (2017), when teachers view conflicts as negative, it may lead teachers to end conflicts prematurely in directive ways rather than taking opportunities during those teachable moments to teach children about social problem-solving skills, thus engaging in teaching social competence. Conversely, when conflicts are perceived to be learning moments, practitioners are better able to promote children's learning towards social competence and can empower children to learn about making choices (Gloeckler, Cassell \& Malkus, 2014; De Haan \& Singer, 2003). This complements Super and Harkness' (1986) idea of the developmental niche: and the idea that psychology of the caregivers can influence their strategies including how they tackle children's conflicts.

Past researchers have stated that practitioners usually use two major intervention strategies during children's conflicts: cessation and mediation (Chen, 2003). Examples of cessation strategies are directing children in what to do, separating the children, or generating their own solution to end the conflict. Mediation strategies on the other hand are when practitioners acknowledge the children's feelings, identifying the problem and offering follow-up support to the children. In their study, Williams, Mastergeorge and Ontai (2010), Silver and Harkins (2007) and Chen, Fein, Killen and Tam (2001) found that teachers used cessation strategies most of the time during children's conflicts despite knowing the benefits of mediation strategies. During the individual semi-structured interviews with the practitioners, I also found that the practitioners in my study used more cessation strategies than mediation strategies when responding to children's conflicts and that the strategies mainly sought to minimize conflicts between the children due to safety and classroom harmony. Separating the children, giving time out, and asking children to apologize were mentioned a few times by different practitioners at all three centres as can be seen below: 
Amy: When the children have conflicts, I usually tell them to stop. If the children still don't listen to me, then I go to them and separate them. After they have calmed down, I usually ask the children to say sorry and then hug each other and salam (shake hands). (SCC)

While Amy's strategies in stopping the conflict among the children were seen by her as necessary, they might arguably be seen as missed opportunities for learning because Amy did not further explain to the children why they should not fight or why they had to apologize.

Clearly, saying sorry, hugging and doing 'salam' are good habits that children should be taught as part of their repertoire of social skills because these actions have a good impact in the long run and restore damaged relationships and even strengthen relationships (Lazare, 2006); moreover, healthy relationships with peers are a building block of social competence (Rose-Krasnor, 1997). So, while forcing apologies, hugs and salam may be seen as primarily cessation strategies, these acts do have their own benefits. According to Lazare (2006), apologizing is good behaviour that can restore a damaged relationship and this is good for children's moral behaviour in the future. Similarly, the use of salam has a restorative effect on damaged relationships and is culturally common etiquette in Malaysia as well as some other Muslim countries around the world. Salam is an act of shaking hands by using both hands (clasping the right hand of another person using both hands) and is generally used in greetings and in some countries, also in reconciliations (Syakh Al-Munajjid, 2007). It is part of good morals, an expression of love between the two who shake hands and believed to dispel hatred and grudges among Muslims.

Fifi from the same centre as Amy, and Husna from Moonbeams Childcare Centre also used cessation strategies, however, as the excerpts below from their interviews shows, they seemed more aware of the need to use conflict situations as an opportunity for teaching children to be reflective about their behavior and about restoring peace: 
Fifi: If the fight is too disruptive, I usually separate them. Put one child on the thinking chair away from everyone and ask him or her to think about what they did... when a child is on the thinking chair, I sometimes ask him/her, "What did do?" "Why did you do it?" so that the child can think about his/her behaviour... If the child is ready to come down from the chair, I usually say, "Yes you can come but say sorry first and salam." After they say sorry to their friends, they are usually okay again. (SCC)

Husna: Usually when the children fight, I separate them. Fighting like hitting and kicking. I take one child and put her in the corner for 2-3 minutes to give her time out to think and ask her what happened between her friends. Afterwards, I let her continue playing with others. After a fight I always ask them to say sorry to their friends and salam. (MCC)

The three practitioners above clearly relied on cessation strategies in handling children's conflicts. The strategies of separating the children, giving time out, asking them to think about their behaviour and telling them what to do - such as say sorry and asking them to hug and salam (shake hands) with the peers - suggests that the practitioners were keen to end the conflict before it escalated rather than taking time to teach and encourage problem solving. However, the statements about asking the children what happened show that the practitioners acknowledged the children's feelings and that some mediation strategies like 'salam' were also being used. According to Shaykh Al-Munajjid (2007), it is believed that the Prophet once said, "There are no two Muslims who meet and shake hands with one another, but they will be forgiven before they part." For that reason, the practitioners used salam a lot in trying to reconcile the children's relationship after a conflict because they believe that salam can mend the negativity between the children. This view is stated in Fifi's comment below:

Fifi: I believe when they salam things will be okay again afterwards. You know, like how our mothers taught us when we were young. So now I teach the children the same thing. (SCC) 
Clearly, Fifi's thoughts and actions were very much influenced by her cultural heritage and the cultural etiquette of salam as a good act and a sign of forgiveness when repairing a conflict. This belief, handed down from generation to generation, clearly acted as part of Fifi's fund of knowledge (Moll, Amanti, Neff \& Gonzalez, 1992), or prior knowledge which Berthelsen and Brownlee (2007) have argued is very powerful in constructing ongoing beliefs about teaching. These ideas are also consistent with Super and Harkness' (1986) concept of the psychology of the caretakers acting as part of the developmental niche influencing children's development. This is an interesting finding when compared to reports by Clarke, McLaughlin and Aspden (2017) that early childhood teachers were not likely to encourage toddlers to say sorry because they believed that "sorry" is just a word that holds little meaning for toddlers and they might only say sorry to satisfy the adults without really understanding the purpose of doing it. Put alongside each other, these findings might suggest that redirecting children to apologize and to salam might be considered merely cessation strategies. However, this ignores the possibility that if the practitioners take time to explain the concept of saying sorry and salam and teach them about these actions, a good foundation could be laid for the future since the act of apologizing can restore and strengthen relationships (Lazare, 2006). Furthermore, it can also teach children about appropriate practices in the Malaysian culture where the act of salam between friends turns the cessation strategy into a mediation strategy by the practitioners.

Other practitioners in this study argued that they used cessation strategies in responding to children's conflicts like choosing solutions for toddlers because they feared for the children's safety (Gloeckler \& Cassell, 2012; Williams, Mastergeorge \& Ontai, 2010). The following are some examples from the practitioner interviews:

Tiara: For babies under one, when I see conflicts between them I will go near them right away and separate them so that the worst won't happen. Like the ones that have teeth, they might bite. They could poke their friends' eyes too with their fingers. (MCC) 
Sarah: If I see them having conflicts like hitting each other, I usually go to them quickly and then stop them from hitting each other to avoid injury. I do that by separating them. I lift one of the children up and take him/her away from the scene. (RCC)

The practitioners used these cessation strategies especially when the children got physical and became too disruptive with their peers: they feared for the children's safety and wanted to prevent potential injury. In addition, a practitioner (Nadia) commented that she would stop any conflicts quickly not only to avoid harm to the children but also because the thought of having to answer to the parents and to have parents feel worried was something she wanted to avoid:

Nadia: Yes I would stop conflicts that involve fighting over toys and hitting quickly because it's dangerous. I don't want to see blood on the children and then we have to tell the parents and explain what happened to their children. So I would rather keep them safe so that parents are not worried and angry. (RCC)

Thus for Tiara, Sarah and Nadia acting quickly to stop a conflict was a safety measure. At the same time, the practitioners did not explain to the children why certain actions were forbidden like biting peers, which indicated that they used cessation strategies rather than mediation ones. Overall, the practitioners seemed to want to maintain safety, as well as avoid worrying parents and answering to them. Moreover, they were keen to maintain peace and harmony in the environment so, as Fatimah (RCC) said, it was sometimes easier to "give a different toy or take away the toy so that they'll be quiet again".

Similarly, Fatimah's colleague, Maria, explained:

Maria: Usually they fight because they want the same toy. If I see them play together I just let them be without interrupting them. But if I see them want to begin a fight, I will intervene. When I see them snatching toys or pushing each 
other, I usually take away the toy and put it high on the shelf. So that no one can get it. If I let them be, it will get worse. They might push their friend until the friend falls down or pull the hair or something like that and then there'll be shouting and crying. (RCC)

Jamilah (RCC) and Elina (MCC) echoed these thoughts both explaining that when children fought over an object, they would take it away as otherwise there would be "fighting and crying about it".

This conflict cessation technique by the practitioners, used in the interest of avoiding harm and sustaining harmony is well documented by other researchers (e.g.,Williams, Mastergeorge \& Ontai, 2010), including in the recent study of young children's learning from conflict by Clarke, McLaughlin and Aspden (2017). These techniques that the teachers used, such as removing any toy from the children, indicated that the teachers' main intentions were to stop peer conflicts. But Roseth, Pellegrini, Dupuis, Bohn, Hickey, Hilk and Peshkam (2008) remind us that while taking the object away can ease conflicts between the children, it is also a short-term solution because the children will use the same behaviour repeatedly on other occasions.

Perhaps the practitioners' actions of using cessation strategies more than using mediation strategies could be attributed to their belief that conflicts among the children are negative behaviours (Clarke et al., 2017; Silver \& Harkins, 2007), thus leading the practitioners to miss the opportunities conflicts provide to teach the children about problem solving. Lack of training on how to enhance social competence among peers could be another reason for the way the practitioners in my study responded, given that most of them had no specific ECCE training at all. My analysis of the practitioners' interviews suggests that the practitioners in my study practice childrearing based on their background knowledge of how they were reared and how their mothers' generation reared little children in the past. Fifi's comment earlier in this chapter referring to "how our mothers taught us when we were young" suggests that she was much influenced by her mother's child rearing. 
Furthermore, other practitioners like Elina and Sarah commented that they learned childrearing from their mothers too:

Elina: I have no previous experience working in childcare centres but when I was younger, I took care of my little sisters and brother. Last year I babysat my little cousins too. (MCC).

Sarah: I never had training but in the past I helped my mum to look after my baby sister... I just learn from my mother. (RCC)

These statements suggest that limited training among the practitioners was potentially one of the reasons why the practitioners did not use conflicts as teachable moments to teach children about social problem solving. Knowing how to solve problems effectively is important because it is one of the skills approach to social competence (Rose-Krasnor, 1997). This finding has implications for the future of ECCE trainings in Malaysia.

In sum, most practitioners in this study reported using cessation strategies when children's conflicts were too disruptive and becoming too physical. In light of the argument put forward by Chen at al. (2001) and Peterson (2004) that when toddlers' conflicts become physical, the underlying reasons are more likely to be lack of socialemotional skills rather than aggressive intent, it would seem important that when responding to children's conflicts practitioners become more discerning in using strategies that help children to problem-solve these social situations. Peer conflict resolution - as an aspect of social-problem solving (Majorano, Corsano \& Triffoni, 2015) - is an important skill for social competence and learning (Rose-Krasnor, 1997; Denham \& Brown, 2010; Denham, 2006; Raver, 2002) so, by giving children the opportunity to solve their own problems, children would actually learn to develop social competence (Majorano, Corsano \& Triffoni, 2015). A clear implication of this argument is that practitioners should see conflicts as an advantage to the children's learning process and treat it as teachable moments (Gloeckler, Cassell \& Malkus, 2014; Bayer et al., 1995). 
The above sections show that the practitioners in my study mostly reported using cessation strategies in dealing with children's conflicts, with only three practitioners indicating that they sometimes also used some mediation strategies. In these mediation strategies the common element was that the practitioners would not only solve the conflict to preserve safety or diffuse the situation but they would also use the opportunity to explain to the children the consequences of their behaviours:

Amy: When the children fight about an object, like snatching and grabbing from their peers then I usually explain to them their mistake. Sometimes I would take the object away from them followed by explanations of their behaviour. Because they are children, if we take an object away, they don't know what the mistake is. They might repeat the same thing because they don't know what they did wrong. So I will tell them they are not supposed to throw toys at friends or they cannot snatch. Other times I would say, "That's not nice". I also explained what would happen to their friends if they do that, like they will get a bump in the head or fall down on the floor. (SCC)

Rozita: I don't usually intervene in the children's conflicts but when I do, that's probably because it was too much... it was getting dangerous. So I step in and ask them first what is the problem here? Then I usually explain that it's not good to fight like that and that they have to share the toys with each other or play with something else first and then come back when the toy is available again. (MCC)

Khalila reported a similar approach adding that to ensure children understood the consequences of their behaviours, and that one should not hit or kick:

You can try to show it on the child, for example tap the child on his/her hand or knee with your hand, the way they hit their friends but don't do it hard - just until the child can feel something so that he/she knows that it actually hurts when he/she does that to others and after that hopefully the child won't do it again. Of course you have to keep repeating that until they understand. (Khalila, RCC) 
This focus by the three practitioners on explaining and reasoning with children is interesting in light of the fact that they were the only three qualified ECCE teachers in the study; it suggests that their different approach to children's conflict, relative to the other ten practitioners, may have been a result of their specialist study of ECCE. Offering reasons and explanations to children are considered developmentally appropriate practices for ECCE teachers when responding to children's conflicts (Gloeckler, 2006). Goncu and Cannella (1996) report that asking questions of children is an effective tool for teachers to guide children towards an acceptable resolution. Similarly, Bayer et al. (1995) argued that teachers who take the child's perspective via questions, and engage in warm, comforting practices during conflicts, can help children manage their emotions and can facilitate toddlers' learning of simple social problem-solving strategies.

Amy, Khalila and Rozita's responses to the children's conflict showed sensitivity to the children's feelings and this too points to the importance of the practitioners' background knowledge and education - what Super and Harkness (1986) called the "psychology of the caregivers" - in shaping the way adults respond to children and their conflict. Practitioners' qualification level is frequently associated with the quality of childcare centres on the basis that formal education programmes prepare practitioners to implement good experiences for young children (Degotardi, 2010; Ireland, 2006; Lamb \& Ahnert, 2006). Howes (1997) found that teachers who have qualifications in ECCE were more sensitive, more responsive and less harsh with children when compared to teachers with less training, while Clarke-Stewart, Gruber and Fitzgerald (1994) showed that children's cognitive development was positively related to the practitioners' qualifications in childcare centres. Additionally, Kontos, Hsu and Dunn (1994) showed that teachers who are trained in ECCE were positively associated with children's development outcomes such as children's complex cognitive play. No wonder then that the trained teachers in my study and the untrained practitioners reported different perceptions and strategies for dealing with young children's conflicts. 
In sum, most of the practitioners in this study reported using cessation strategies in dealing with children's conflicts with the three trained practitioners additionally reporting using also some mediation strategies. These findings are consistent with earlier research which has reported that when practitioners perceive conflicts as negative behaviour, they tend to end the conflict quickly (e.g., Clarke, McLaughlin \& Aspden, 2017; Majorano, Corsano \& Triffoni, 2015; Johnson \& Johnson, 1995). In reference to Super and Harkness' (1986) concept of the developmental niche of which the psychology of the caregivers is a key component, the practitioners' background knowledge and perceptions emerged as important influencers of the practitioners' practice in the classroom. According to Singer and De Haan (2007), teachers' role is important in creating a context in which children learn positive social rules. Learning about positive social rules can help children become effective in interactions, otherwise defined as social competence (RoseKrasnor, 1997) leading to the conclusion that ECCE practitioners should view conflicts as opportunities for learning to become socially competent beings. Such a conclusion is also in line with Vygotsky's concept of scaffolding (1978) in which the role of an adult is seen to be that of someone who supports and guides the children rather than directing them on what to do (Russon, Waite \& Rochester, 1990; Arcaro-McPhee, Doppler \& Harkins, 2002). Vygotsky proposed that adults should guide and encourage children, leading them to do things on their own later without assistance. This involves offering suggestions, giving gentle feedback and altering the environment in order to facilitate learning opportunities (Williams, Mastergeorge \& Ontai, 2010). 


\subsection{Chapter Overview}

This chapter has presented the practitioners' perceptions of children's peer interactions at three case study childcare centres. In deciding on what to write, I was guided by the themes that were embedded in the practitioners' statements during the semi-structured interviews. In reference to Super and Harkness' (1986) concept of the developmental niche, my findings suggest that the practitioners' beliefs can indeed influence their actions and in this case, this was shown in the statements made by the practitioners about how they understood peer interactions among under-three year old children and how they reported supporting their learning during peer interactions.

The practitioners stated that organizing group activities for the children was one of the ways they could increase peer interactions among the children. This contrast with previous research that showed that children could lead their own interactions, explore and develop independence (Legendre \& Munchenbach, 2011; Williams et al., 2010; Rutanen, 2007) even without adult intervention. In focusing on conflict as a theme about which practitioners had much to say, it was clear that the practitioners responded to children's conflicts mostly by using cessation strategies with mediation strategies used only by the three practitioners who had ECCE training.

Looking closely at the interview data, the practitioners' statements showed that their responses to the children's peer interactions were mainly to maintain harmony at the centres and minimize conflicts among the children. Clarke, McLaughlin and Aspden (2017) found that the lack of teachers' in-depth knowledge about toddlerhood disabled effective teaching practices in ECCE settings. My study showed similar findings: there were missed opportunities for practitioners to support children's learning of the social skills needed towards becoming socially competent. In reference to the Social Competence Prism of Rose-Krasnor (1997), the bottom level of the prism (the Skills Level) includes specific abilities that have been identified in the skill approach to competence, such as social problem solving and affect regulation, perspective taking, to name a few. Children can learn and develop these skills through effective peer 
interactions with effective responses and guidance from the practitioners. According to Rose-Krasnor (1997), adults need to help children to achieve interpersonal goals, establish positive relationships and attain an appropriate place in relevant social groups where they can be considered socially competent. Thus, it is suggested that specialized training for childcare practitioners on how to respond appropriately to children's peer interactions may be an effective way to promote children's social competence.

In the next chapter, I present my analysis of the children's peer interactions based on my video-recorded observations of the children as they lived their daily lives at their respective childcare centre. The chapter answers the question of what kinds of peer interactions occur among under three year olds at childcare centres in Malaysia. 


\section{CHAPTER FIVE \\ CHILDREN'S INTERACTIONS IN ACTION: \\ CREATING A SENSE OF BELONGING AND \\ TOGETHERNESS}

\subsection{Introduction}

This chapter addresses the second research question of this study: "What kinds of peer interactions occur among children under three years old in childcare centres in Malaysia?" Thematic analysis of the observational data of children's experiences in the three case study centres (see section 3.8) resulted in the identification of two major themes in the children's experiences of peer interactions: creating belonging and togetherness; and managing conflicts. In this chapter I tell the story of how the children in this study interacted with each other to create a sense of belonging and togetherness; I focus on children's conflict interactions in chapter six.

As explained in the literature review, Koivula and Hannikainen (2017) defined belongingness as relationships among children and the feeling of belonging to a certain environment or community. Togetherness was defined as a feeling of emotional interconnectedness between children during a certain activity (Koivula \& Hannikainen).

Children's desire to be connected to one another, and the importance of emotional connectedness for children's development has been noted by numerous researchers (Brenner \& Mueller, 1982; Kernan, 2011; Kernan \& Singer, 2011; Singer \& De Haan, 2007; Mortlock, 2014) with Singer and De Haan and Mortlock further noting that children's actions can contribute to the maintenance of their sense of belonging and togetherness. Lin, Justice, Paul and Mashburn (2016) and Wittmer (2012) have additionally argued that the opportunities for children to learn to create a sense of belonging and togetherness, as well as to establish relationships, are greater in childcare centres where there are numerous opportunities for peer interactions. However, creating 
this sense of belonging and togetherness can also be challenging to young children as being part of the group is no easy task for children (Wilson, 1999).

My analysis of the children's actions in the everyday context of their childcare centre showed that the children interacted with each other in a way that showed they wanted to belong and be together in the group. My analysis followed the work of Guo and Dalli (2016) who studied the experiences of Chinese immigrants children as they started attending their first ECCE centres in New Zealand. Guo and Dalli argued that children were agentic in creating a sense of belongingness with peers. By focusing on the actions of two of the children in the study, the authors showed how the children used their agency to create a sense of belongingness, including by adapting to the centre and trying to fit in, seeking out English learning opportunities, and applying their home cultural practices in their new context.

While in Guo and Dalli's (2016) study children's belongingness is linked with the notion of everydayness and agency, in my study the children's sense of belonging and togetherness is additionally linked with the notion of social competence. Thus, in this chapter I elaborate on the children's experiences as they created a sense of belonging and togetherness in their everyday lives by using the Lefebvrian (2002) concept of the everydayness, the notion of agency, as well as Rose-Krasnor's (1997) social competence prism. I also draw on Loizou's (2005) theory of the absurd to analyse children's use of humour and laughter in the service of creating a sense of togetherness (see section 5.5). I argue that children's sense of belonging and togetherness grow alongside social competence, and through the children's exercise of their agency in making and taking opportunities to establish and maintain peer interactions. I present this chapter arranged around four dominant themes that I identified from the combined sources of data for the children: (1) belonging and togetherness as learning to be with peers; (2) belonging and togetherness as embracing the centre's routines; (3) Togetherness as responding to the needs of others and (4) Togetherness through humour and laughter. I begin by discussing the theme of belonging and togetherness as learning to be with peers and describe the different ways children use their agency and social competence in achieving this goal. 


\subsection{Belonging and togetherness as learning to be with peers}

According to Koivula and Hannikainen (2017) children try to find their own place and form relationships in social settings by approaching their peers and seeing where that would take them. Literature shows there are many ways children do this including by showing their interest in peers' play. In De Haan and Singer's (2001) study, verbal children showed their interest in others by applying their social skills of complimenting and questioning peers as well as expressing enthusiastic greetings. In my study where children were primarily pre-verbal, they showed their interest through embodied communication strategies like looking excitedly at peers, approaching and imitating them. I also observed many different ways in which children learned to be with their peers and in the process created a sense of belonging and togetherness. I discuss these firstly as a group of behaviours that I have categorized as entry strategies, and secondly, as behaviours that appeared to indicate the children's drive, and increasing competence, to be part of the group.

\subsubsection{Entry strategies}

Kim (2003) has argued that children who wish to join in their peers' play have to recognize the strategies that can lead up to their success. This can sometimes mean making multiple attempts before eventually gaining access to peers' play. Children who are able to modify their strategies after each failure are more likely to succeed in gaining access to their peer's play than those who keep repeating the same strategies (Corsaro, 1981). Understood through the theoretical lens of the Lefebvrian concept of everydayness (Lefebvre, 1987), which allows for the repetitive nature of the everyday to also create its own change dynamics, this idea opens the possibility that a child learns something from experiencing the same thing everyday including taking action to change a situation, for example through some degree of agency (Corsaro \& Molinari, 2008). For example, agency can work in the interest of a child's need to belong (Guo \& Dalli, 2016) and thus take action to enter a group. Successful entry strategies may lead up to a game with their peers that can be pleasurable to the children and being together in a group can promote social competence. 
My observations in the three case study childcare centres provided several examples of successful entry strategies; in the following sub-sections I discuss these examples under the headings: watching peers; using objects as tools; and imitating peers.

\section{Watching peers}

Watching peers is regarded as a necessary foundation for relationship formation (Davis \& Degotardi, 2015); it can develop understanding of others and of their relationships with others (Degotardi, 2011; Wang \& Baillargeon, 2006), which is one of the building blocks to social competence (Rose-Krasnor, 1997). I recognized that the children in my study used this strategy of watching peers in order to learn about their peers' activities and then used the information to successfully enter the other children's play as described in the following episode:

Ibrahim $(\mathrm{m}, 2 ; 5)^{3}$ from RCC was walking around the room looking here and there when Ahmad (m, 2;4) and Jasmin's (f, 2;1) movement caught his attention. Ibrahim stopped in his tracks and looked at Ahmad and Jasmin intently as they lay down on the floor side by side, kicking their legs in the air. As Ibrahim watched them, a fourth child called Najib $(\mathrm{m}, 1 ; 8)$ walked up to Ahmad and Jasmin and sat down next to Jasmin:

Najib looks at Jasmin and at the same time, Jasmin turns her head to Najib and looks at him. Their eyes meet. Looking slightly cross, Jasmin pushes Najib's body away from her. Najib grins and continues to look at Jasmin and then he touches Jasmin's left leg softly. Jasmin frowns at him before she pushes Najib's body again. Najib looks at Jasmin with wide eyes for a few seconds before he stands up and walks away from her and the activity. Ibrahim observes it all without making a sound. Slowly, Ibrahim walks to Ahmad and Jasmin and stops when he is standing next to Ahmad. Ibrahim then lies down next to Ahmad. Ahmad turns to look at Ibrahim and gives him a smile. Ibrahim smiles back at Ahmad and then

\footnotetext{
${ }^{3}$ ( $\left.\mathrm{m}, 2: 5\right)$ stands for the child's gender and age. (male, 2 years and 5 months)

${ }^{4}$ (f, 2:1) stands for the child's gender and age. (female, 2 years and 1 month)
} 
Ibrahim lifts his legs in the air and starts kicking like Ahmad and Jasmin. Ahmad and Jasmin look at Ibrahim and smile. Ibrahim continuously kicks his legs in the air while smiling at his peers. Then they all kick their legs in the air together while occasionally grinning at each other $\left(\mathrm{VORCC}^{5}\right)$.

As a researcher, I noticed how Ibrahim watched his peers prior to making a bid to enter their play; Ibrahim had also observed how Najib was denied access by Jasmin. Ibrahim probably learned something from watching the rejection of Najib's approach to Jasmin because instead of sitting next to Jasmin, as Najib had done, Ibrahim chose to stand next to Ahmad and then lay down next to him instead of Jasmin. Moreover, it was Ahmad who signalled that he welcomed Ibrahim by giving him a smile and Ibrahim's action of smiling back was likely a sign that he accepted the invitation. Only after confirming his acceptance did Ibrahim start kicking his legs in the air like his peers. The unspoken understandings between Ibrahim and Ahmad could be due to their everyday interactions at the centre. Ibrahim's behaviour in this episode showed a clear sense of agency: he chose to sit next to Ahmad and demonstrated the capacity to successfully enter peers' ongoing play. Moreover, Ibrahim's access to the play by Ahmad could also be due to Ibrahim and Ahmad's friendship. According to the practitioners and from my observations during the study, Ibrahim and Ahmad were very close friends and were involved in many joint interactions. While Najib probably did everything right in seeking access to the play, he did not have the friendship privilege like Ibrahim, and so was denied access to the play. His young age might also have been a disadvantage. According to the Social Competence Prism, socially competent behaviour varies by context. For example a child may be more successful with some peers than others (Rose-Krasnor, 1997) and Ibrahim and Najib's situations reflected this view. Another interpretation of the episode is that Jasmin was not being socially competent in the way she behaved to Najib and because Ibrahim understood that, he chose to avoid sitting next to Jasmin. From my observations, Ibrahim found a strategy to belong and be together with peers. His desire to join in his peers' play illustrated that it was within the situation of the children's daily lives at the centre that they learned how to meet their needs to belong and

\footnotetext{
${ }^{5}$ VORCC stands for Video Observation from Rainbow Childcare Centre.
} 
be together with peers. Clearly, Ibrahim demonstrated a sense of agency and socially competent behaviour when he made his own decision on how to enter his peers' play and be successful at it.

In SCC, Willy $(\mathrm{m}, 2 ; 9)$ was also observed on many occasions to use the strategy of visual attentiveness to get closer to his peers and eventually join in their play when given admission. In the episode below, Willy was looking at a book on his own while Anna (f, $2 ; 6$ ) and Ina (f, 2;8) were play-cooking not far beside him. Willy was flipping the pages of his book and seemed to be looking at the pictures on the pages when Anna's movement broke his concentration:

Willy looks up at Anna and Ina's direction. Anna is stirring a spoon in a bowl and then pretends to eat from it. Willy looks at Anna with interest. His eyes are wide open as he stares at Anna. Willy looks at how Anna smiles at Ina and brings the spoon to Ina's mouth. Ina smiles and pretends to eat the pretend food and exchanges smiles with Anna. Willy watches them. Then Anna and Ina walk to a whiteboard and seem to be talking to each other while Anna repeatedly stirs the pretend food in the bowl and then offers it to Ina. Eyes still on the girls, Willy stands up and walks towards them. He stands near the whiteboard as he watches the girls. Oblivious to Willy's stares, Anna and Ina keep on playing their game. After a few seconds of watching the girls, Willy begins to fumble with the whiteboard. Anna turns to look at Willy but Willy is looking at the whiteboard. Anna then continues to stir the spoon in her bowl, looks at it and brings the spoon to Ina's mouth while saying, "Panas" (hot). Ina opens her mouth and pretends to eat it. Willy turns to them again. Then Anna walks to a bookshelf with her bowl. She continues to stir the spoon at the bookshelf. Ina looks at Anna and then Ina picks up a book from a nearby table and lies down on the floor with the book. Anna walks back to the table and looks at Ina on the floor. Ina is now immersed in her book. Anna then pulls a chair and sits at the table. Willy watches the girls and then he walks to the table too and climbs on the table. Willy looks at Anna and smiles. Anna looks at Willy for a few seconds before she lifts her spoon and 
brings it to Willy's mouth. Willy smiles and pretends to eat it by munching the pretend food. Anna smiles at Willy while she continually stirs the spoon in the bowl. Then Anna says to Willy, "Duduk" (sit down). Willy looks at her and climbs down from the table and sits on a chair beside Anna. Anna smiles and lifts her spoon to Willy's mouth again. Again, Willy pretends to eat the food while smiling. They repeat this action a few times and look happy playing together. $(\mathrm{VOSCC})^{6}$.

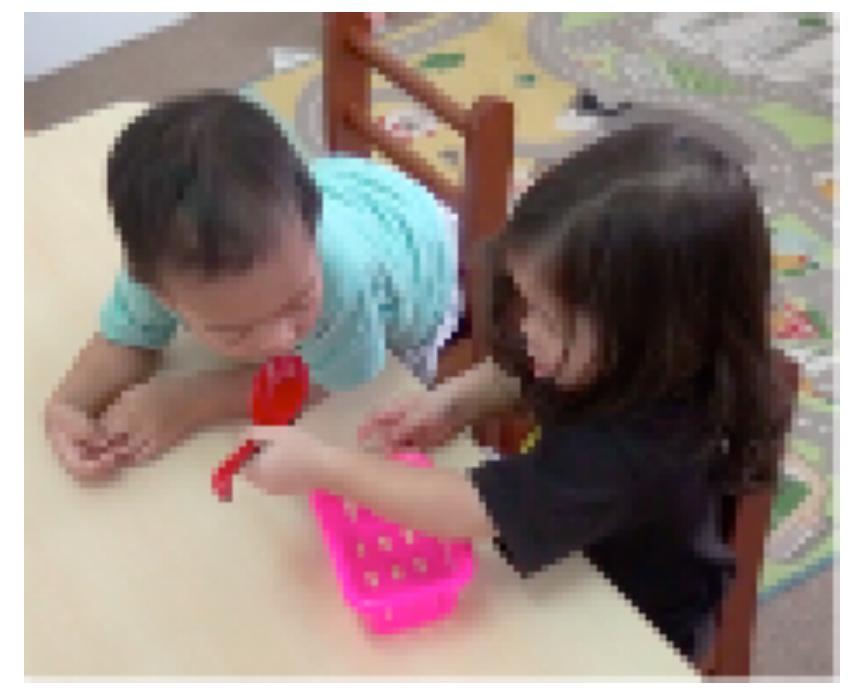

Figure 5.1 Anna lifts her spoon to Willy's mouth

In this example, Willy clearly was watching his peers in order to enter Anna's play. He looked at the girls playing first before he moved closer to them and only approached Anna after Ina appeared to be quitting the game. He smiled at Anna when Anna looked at him and these strategies of looking, waiting and smiling made Willy successful in gaining entry to Anna's game. Willy's behaviours in this example show a clear sense of agency and social competence: he demonstrated the capacity to successfully join in a game with peers. He seemed to know when to enter the play. Perhaps he predicted he would not be successful if he were to join Anna when she was playing with Ina and thus he only approached Anna when she was alone. After all, children do not like their play to be interrupted (Corsaro, 1981).

\footnotetext{
${ }^{6}$ VOSCC stands for Video Observation from Sunny Childcare Centre
} 
The two examples of Ibrahim and Willy show how they wanted to belong and be together by participating in their peers' play. It was clear that the children used the strategy of watching peers to learn about their peers and the activity before joining in the play. Wittmer (2008) said that children learn about their social world from direct observation of others. Living their daily lives in their respective centres gives children opportunities to watch and learn about others everyday. According to Lefebvre (1987), the everyday is repetitious. Due to the repetition of everydayness, children are able to learn some strategies to enter on-going play through exercising their agency and be successful in them. These experiences in turn can build up the children's social skills, which lie at the bottom of the Social Competence Prism.

\section{Objects as tools}

Another way in which the children could be seen to exercise their social competence and agency in gaining access to peers' play was in their use of objects. According to Eckerman, Davis and Didow (1989), some children are able to be involved in joint attention with their peers because they are interested in the same object. While the children in my study were at times interested in the same objects, their actions also showed they wanted to belong and be together in the group of peers and that objects were used as tools in order to be part of the group. The following is an example of this application of entry strategy:

Nani ( $f, 2 ; 3$ ) used the strategy of watching, smiling and then touching peers' object before proceeding to be successful in entering the group:

Nani is playing with a teddy bear alone at a shelf. She hugs and kisses the teddy bear while chatting to it. Nearby, Husna, a practitioner, puts down a big bead maze on the floor. Immediately, nine children walk to it and sit around the maze. Nani turns her head towards them. The children seem to be engrossed in their play, moving the beads along the maze. Nani looks at them intensely and then she suddenly lets go of the teddy bear and walks quickly towards the group. When she 
reaches them, she squeals, "Yeay!" in excitement and sits down in between Kira (f, 2;3) and Matt (m, 2;10). Kira looks at Nani and Nani smiles at her. They briefly exchange eye contact before both of them look at the bead maze again. Then Nani touches one of the beads and looks at Kira. However, Kira is not looking at Nani. Nani then moves a bead along the wires while looking up at her peers. The other children are all looking at their own beads while moving the beads along the wires. Kira turns her head to Nani and looks at her. Nani senses this and she turns to Kira too. Kira gives Nani a smile and Nani returns the smiles. Then they continue to look at their beads and moving them along the wires. All of the children are moving the beads along the wires with their hands intertwined with each other. Occasionally laughter and squeals are heard as they play like that together (VOMCC) ${ }^{7}$.

In this example, Nani seemed to want a sense of belonging and togetherness when she joined her peers in playing the bead maze. She seemed to be happily playing with the teddy bear alone but when she looked at a group of peers playing with the bead maze, she left the teddy and went to join her peers. Clearly, she wanted to be part of the group. As a strategy to enter the play, Nani touched the object and briefly glanced at her peers maybe looking for a reaction. She may have taken their silence as well as Kira's smile for her acceptance in the group. In this way, Nani demonstrated a skillful entrance in her peers' play, which has implications for competence at the Index Level of the Social Competence Prism, that is: maintaining the balance of self and the need of others. In successfully gaining this access to the group's play, Nani also showed agency in taking an opportunity to join in peers' interactions.

The following episode is another example of a younger child, Rania, who also demonstrated her interest in joining a group of peers. Similarly to Nani, Rania used an object as her tool to enter her peers' play, as illustrated in the following excerpt:

\footnotetext{
${ }^{7}$ VOMCC stands for Video Observation from Moonbeams Childcare Centre
} 
Rania (f, $0 ; 11$ ) was crawling around the room and pausing from time to time to look at her surroundings. As she crawled, she looked in the direction of Dani (m, 0;11) and Sam $(\mathrm{m}, 1 ; 4)$ and paused. The boys were playing with a bead maze that was hanging on the wall.

With her eyes wide, Rania looks at Dani and Sam who are moving the beads along the wires. The boys are oblivious to her stares. After a few seconds of watching her peers, Rania starts to crawl towards them. When Rania reaches them, she sits next to Sam and continues to look at them. The boys keep playing as if they are not bothered by her presence. They do not look at Rania. Rania then touches one of the beads. Immediately, Sam turns his head towards Rania. They exchange eye contact briefly before Sam looks at the bead maze again. Rania starts to move the beads around the wires. Then Dani looks at Rania and smiles. Rania just looks at him and then continues to move the beads. The three children sit side by side as they move the beads around the wires. Then Omar (m, 1;11) walks to the bead maze and sits down next to Rania. Rania turns to look at Omar before turning to the beads again. Omar watches the three children playing with the bead maze. Eventually, Omar also touches the beads and moves the beads along the wires. Rania turns to look at Omar again and Omar gives a slight grin at her. Rania grins back. They continue to look at the beads and move them along the wires. The four of them play like that together for a few minutes (VORCC). 


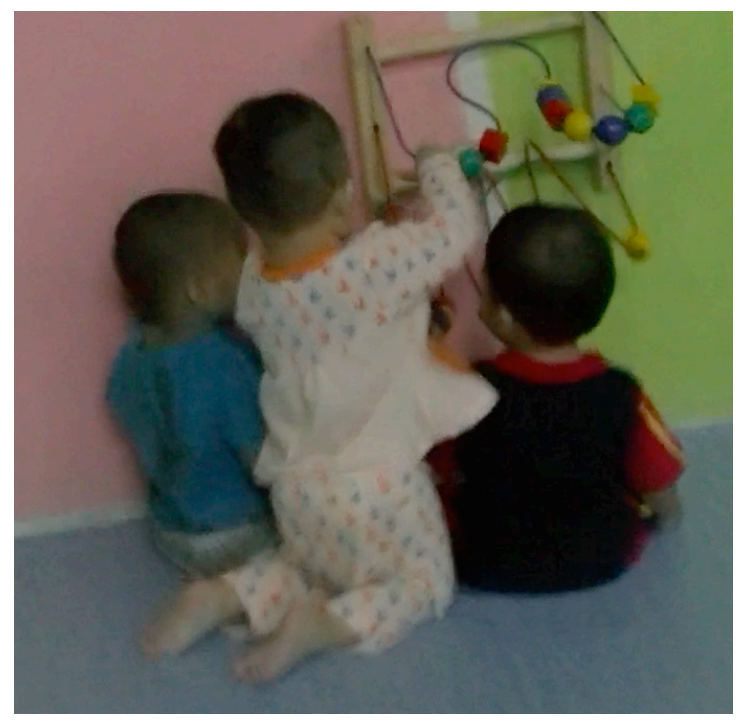

Figure 5.2 Dani, Rania and Sam playing with the bead maze together

Rania was showing her interest to join in the small group when she paused from crawling and watched the boys playing with the bead maze. It was clear that she wanted to play with the boys and the beads as she approached them. Rania also showed her capacity to use her agency and social skills in order to get herself in the small group. She sat next to Sam and watched him first before touching one of the beads. Only when she got a response from Sam did she continue to move the beads along the wires like the boys were doing. Sam did not reject Rania when she touched the bead and Dani smiled at her. These could be indications that they welcomed Rania into their play. Additionally, Omar also showed interest to play with the group by using the same strategy of sitting next to a group member, watching them and eventually touching the object of interest before pursuing playing together with the group. Such is an illustration of how children want to belong and be together in a group rather than playing alone. Like Corsaro (2003) said, children like doing things together and rarely do things on their own.

Taken together, Nani and Rania's behaviours highlight their competency in using social skills and exercising their agency to successfully join in their peers' play. According to the Social Competence Prism, the children's goals provide the direction for social behaviour. It can be seen that the children's goal of wanting to be together in a group drives the children to strive for what they want and reach their goals. 


\section{Imitating peers}

Imitating peers' actions was a further strategy the children used to gain access to peers' on-going play. According to Kim (2003) and Cromdal (2001), imitating peers' actions involves a low risk of rejection. Throughout my observations, imitation was one of the popular strategies used among the children in all three childcare centres. Children seemed to be successful in entering their peers' play when they imitated their peers, as in the following episode of Omar:

Omar $(\mathrm{m}, 1 ; 11)$ was playing running around the room with Sharifah $(\mathrm{f}, 1 ; 5)$. They looked to be having fun. After a while, Sharifah stopped running and sat down on the floor. She looked tired and Omar immediately followed suit. Omar then looked around him, as if searching for other opportunities to play. He turned to three peers who were sitting together in a straight line:

Omar looks at Liza (f, 2;3), Ahmad (m, 2;4) and Jasmin (f, 2;1) who are sitting on the floor. Ahmad is sitting between Liza and Jasmin. The three children are shouting, "Aaaaaaaaaaa" followed by laughter. Omar looks at them and grins to himself. He then walks towards them. Before sitting down with his peers, Omar looks at them and then squeezes between Liza and Ahmad who immediately turn their heads to Omar with little frowns. Omar looks at Ahmad, smiles and then shouts, "Aaaaaaaaaaa." Ahmad then smiles at Omar. As if on cue, Liza, Ahmad and Jasmin shout together again, "Aaaaaaaaaaa". They laugh at each other when they stop shouting. After a few seconds, Ahmad begins shouting again “Aaaaaaaaaaa." Omar, Jasmin and Liza grin at Ahmad and then they join in by shouting, "Aaaaaaaaaaa". They pause and laugh for a few seconds, after which Jasmin starts the shouting again, "Aaaaaaaaaa." The others look at her and follow: "Aaaaaaaaaaa." The children laugh and squeal before they shout again. They keep repeating this shouting game and then they laugh together while looking at each other (VORCC). 


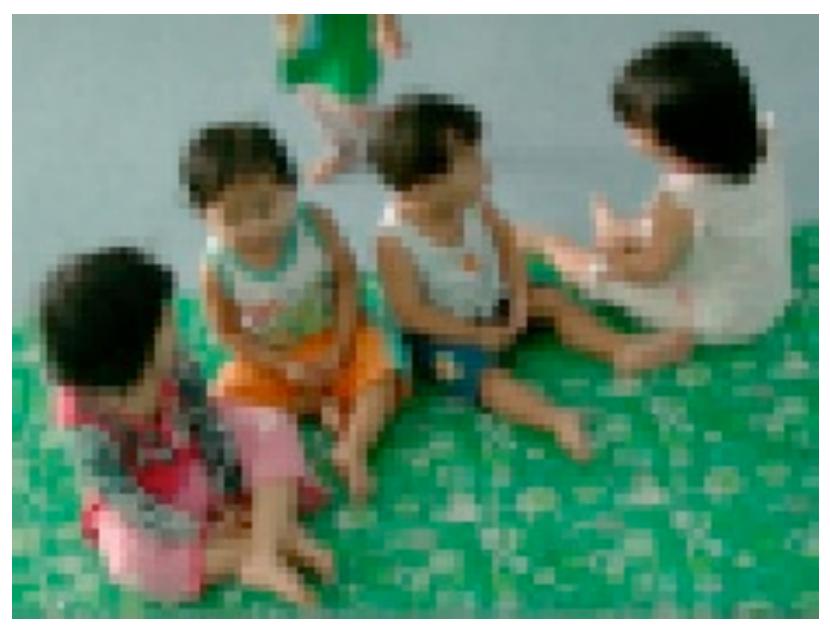

Figure 5.3 Liza, Omar, Ahmad and Jasmin shouting “Aaaaaaaaaaa.”

In the example above, when Omar squeezed in the space between Liza and Ahmad, the peers looked at him with a slightly annoyed face but Omar immediately imitated the way his peers shouted, "Aaaaaaaaaaa" in their game and that made Ahmad smile at him. That smile most probably signaled Omar's acceptance in the group. The fact that the rest of the peers continued shouting after that was another indication that the whole group accepted Omar into their play. Omar had demonstrated his understanding that peers did not like being disrupted in their play and when he quickly imitated their shouting, this got him access to the play. This also shows his capability in using his agency and how he was socially competent in gaining access to the group at that time. Omar also demonstrated his desire to belong in a group and play together with peers after his game with Sharifah ended. His actions revealed that he wanted to immediately be with other people and by joining Liza, Ahmad and Jasmin in their game he was able to create a sense of belonging and togetherness with them.

Another child, Ayu (f, 2;4), from MCC was also seen to demonstrate her eagerness to belong and be together in a group by using the strategy of imitating her peers to gain access to a group's play. In the following episode, a group of peers were jumping up and down. It started with Dayah (f, 2;11), who was jumping against the wall to touch a picture. While jumping, she accidentally fell down on the floor and was witnessed by Shafiq $(\mathrm{m}, 2 ; 11)$. Shafiq looked at Dayah and laughed. Dayah turned to look at Shafiq and laughed back. Then Dayah took Shafiq's hands and they both jumped up and down 
together. Dayah made herself fall down on purpose, pulling Shafiq with her. They both laughed hysterically. Dayah and Shafiq repeated their actions of jumping up and down and then letting themselves fall down on the floor and lying down. They laughed hard every time they fell down. Their laughter caught the attention of other children nearby. Ayu turned to look at them. Matt $(\mathrm{m}, 2 ; 10)$ and Helmi $(\mathrm{m}, 2 ; 7)$ ran to them and joined in the fun by jumping up and down too. Ayu smiled with interest and walked towards the group of jumping peers:

With a smile on her face, Ayu looks at Matt as she walks towards him. Then Ayu jumps up and down in front of Matt. Matt looks at her while squealing and jumping and then makes himself fall and lie down on the floor. As Matt rises up from the fall, Ayu takes hold of Matt's hands and Matt looks at her and smiles. They exchange smiles for a few seconds and then Matt continues to jump but this time he jumps with Ayu. Ayu laughs. Matt squeals and makes himself fall on the ground again, pulling Ayu along with him. They tumble on the floor, looking at each other and laughing loudly. More children have come to join the game now. They all jump up and down and then lie down on the floor. Occasionally, they all look at each other's actions and laugh. Ayu and Matt stand up again, hold hands and repeat their game of jumping up and down and falling onto the floor. Every time they fall down, they laugh and get back up again and repeat their actions of jumping and falling. Each time they do that, they laugh and squeal happily together (VOMCC).

In the above example, it can be seen that Ayu imitated her peers in their play of jumping up and down in order to have fun as a group. She jumped in front of Matt maybe because she saw him as her potential jumping partner. Matt did not show any sign of rejection and that may have prompted Ayu to step forward and hold Matt's hand. Matt's smile signalled acceptance into the play and shows that Ayu's imitation strategy was successful. This episode, like other episodes above, illustrates how Ayu was capable of using her agency and social skills to be accepted in the play. It also shows how Ayu learned about 
peer interactions through her participation in the everyday routines and activities at the centre.

In the same childcare centre, Shafiq $(\mathrm{m}, 2 ; 11)$ showed interest in Helmi's $(\mathrm{m}, 2 ; 7)$ play and this led him to getting an invitation to play with Helmi. In the episode below, Helmi had just walked into the main room from outside and was looking at a toy truck on a shelf:

Helmi walks to the truck, picks it up and tucks it into the waistband of his trousers. With a smirk on his face, he walks around the room. Shafiq, who is standing nearby, follows Helmi's movements with his eyes. Probably sensing he is being watched, Helmi turns to Shafiq and smiles. Shafiq smiles back in acknowledgement. Then Helmi picks up the truck from his waistband and points it at Shafiq while shouting, "Pong pong pong." Shafiq laughs and Helmi starts to run. Shafiq follows Helmi's footsteps and runs behind him. The boys run after each other in a circle. As they run, Shafiq shouts, "Pong pong pong" to Helmi and Helmi shouts back, "Pong pong pong" at the same time pointing the truck at Shafiq's body. Shafiq laughs and then runs to a shelf and picks up another toy truck. He points the truck to Helmi and keeps shouting, "Pong pong pong." Helmi squeals with laughter and keeps running (VOMCC).

The interactions between Helmi and Shafiq started when Shafiq showed his interest in Helmi. Shafiq eyed the way Helmi tucked the truck into the waistband of his trousers and Helmi, recognising Shafiq's interest, smiled an invitation for him to start a game. In this interaction, connection between the children was established when Shafiq responded positively to Helmi's playful pointing of the pretend pistol at him: he laughed, started running and exchanged shootings with Helmi. They seemed to know the rules of the game and to be having fun at it, which created a sense of belonging and togetherness between them. It was observed that Helmi was very skilled in sensing his peer's interest and he took that opportunity to invite his peer to play with him. Helmi's recognition of Shafiq's interest could not have been developed if it was not for his participation of the everyday routine and activities of his life experience. Helmi also showed capacity to use 
his agency in taking the opportunity to play with a peer. As such, this is an illustration of the children's abilities towards achieving social competence.

These data show that the children not only recognized the effective ways to successfully join in on-going play during peer interactions but were also successful in creating a sense of belonging and togetherness without the need of any interventions from adults. This indicates that despite their young age, these children were capable of using their agency in establishing and maintaining peer interactions. Furthermore, the children's eagerness to belong and be part of the group appeared to promote the children's agency and social competence as they learned about how to be successful in entering on-going play. In reference to the concept of everydayness by Lefebvre (1987), children in the three childcare centres appeared to learn about how to enter play and at the same time create that sense of belonging and togetherness by simply being at the centre everyday. This concept can also be seen not only during play entry but also during on-going play. I elaborate this idea in the next sub-section on 'becoming one of the group'.

\subsubsection{Becoming one of the group}

Throughout my observations made; the children appeared to be very active in making themselves fit in with the centre's life by participating in activities set out for them, pursuing opportunities to interact, and sharing experiences with peers. These findings are similar to those reported in Guo and Dalli's (2016) study which demonstrated that Chinese immigrant children in New Zealand early childhood settings actively adapted themselves to the everyday life of their EC centre through socializing and participating in activities with their peers, particularly those with whom they could communicate in their first language- Chinese. Their motivations to be with peers were driven by their need to belong into the group. Unlike the children in Guo and Dalli's study, the children in my study were not immigrants. However, they were also driven by the need to belong as well as establish togetherness in the group at their respective childcare centres. This leads me to believe that children anywhere have to work hard and use their agency and social skills in order to fit in into their community. 


\section{Participating in activities}

According to McMillan and Chavis (1986), when children belong to a group, they have this emotional connectedness among them, which is developed through participation in activities. And by doing activities together, they develop an emotional connectedness that is defined as togetherness (Koivula \& Hannikainen, 2017). This type of emotional connectedness could be seen in the children in this study while they were engaged in activities together in a group. Additionally, the children were also seen to practice their agency and social skills when they wanted to fit into these activities with their peers. The children's behaviours included showing their peers their objects, calling peers' names and supporting their peers. Some examples are illustrated in the episodes below:

One morning at SCC, Amy, a practitioner, called out to the children and put some playdough out on the table. Amy sat at the table and waited for the children to come. The children looked at the play-dough on the table excitedly. Willy (m, 2;9) squealed and said, "Play-dough!" and made his way to the table:

All of the five children in the room take their places at the table. They immediately take one piece of play-dough each and begin to punch and roll them. Willy is sitting next to Ali ( $\mathrm{m}, 2 ; 7)$. The children seem to be concentrating on their own play-dough. They roll, squash and punch the dough. From time to time, all of the children are seen to look at each other. They seem to be interested to see what their peers are making. Willy is squeezing his dough when Ali turns to him and calls his name. Willy turns to look at Ali who lifts his play-dough to show Willy what he has done. Willy smiles and lifts his play-dough too and then Willy brings his play-dough to touch Ali's play-dough. They exchange smiles before they play with their own play-dough again. After about two minutes, Willy sticks his play-dough on his chin. Ali turns to look at Willy and then Ali laughs while peeling off the play-dough from Willy's chin. Willy smiles and continues to play with his play-dough again. After a few minutes, Ali calls out Willy's name again, "Willy!" Willy looks at Ali and then Ali shows Willy some play-dough balls he has made. Willy smiles. At that moment, Roy $(\mathrm{m}, 2 ; 7)$ looks at Ali's play-dough 
too and laughs. Ali turns to Roy and laughs along with him. Willy looks at them and starts to laugh too. Ina (f, $2 ; 8$ ) and Anna (f, 2;6) look up from their playdough to see what is going on. Anna sees the boys laughing and she too grins and calls out Willy's name. Willy looks at her and smiles back. After a few moments of exchanging eye contact with everyone, the children look down at their playdough again and continue to play with them (VOSCC).

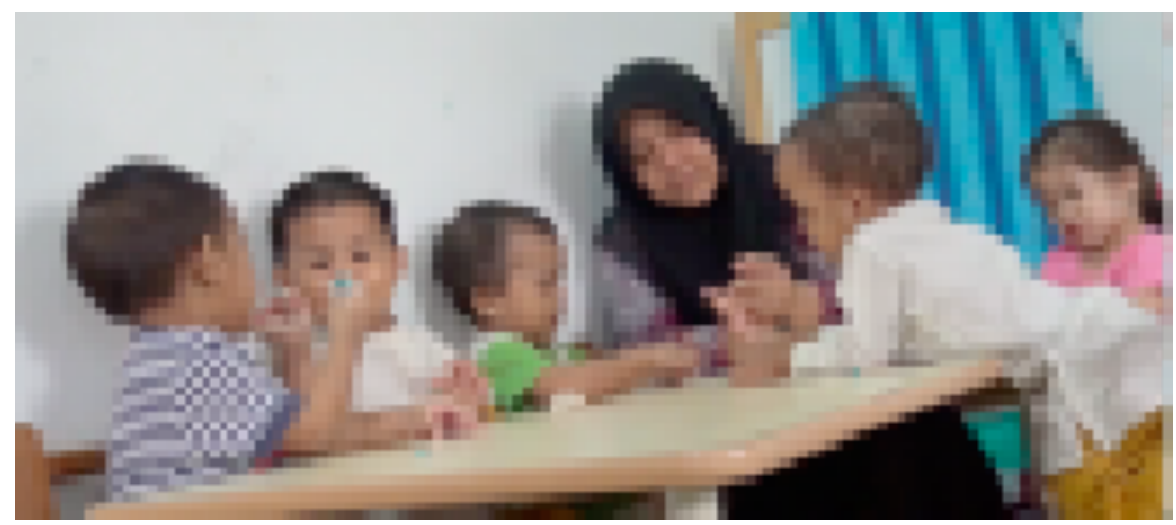

Figure 5.4 Willy and Ali showing their play-dough creation to each other

While this was an adult-led activity, the children found ways to get connected to each other as evident by the way they looked at each other and exchanged eye contact. By showing their interest in their peers through calling out each other's names and showing their creations to each other, the children showed signs of wanting to be part of the emotional connectedness (the belonging and togetherness), not just to physically be in the group together. The children were connected through laughter too. This was evident when Roy started to laugh and Ali laughed with him. Willy joined in the laughter when he saw the other two boys laughing. Anna was also seen to want to be part of the group because she grinned at the boys and called Willy's name to get his attention. The children's actions and behaviours were evidence that they are capable of using their agency and social skills in interacting with their peers even though an adult was with them at the table, thus illustrating the children's eagerness to be part of the group. 
Another example of children finding their own ways to belong and create togetherness in a group in the presence of an adult can be seen in the following example at MCC. On that day, Husna (a practitioner) was seen to lead an activity with the children:

Husna calls out, "Siapa nak main bola mari sini." (Those who wants to play ball: come here). Ayu (f, 2;4) turns to Husna and smiles. Dayah (f, 2;11), Helmi (m, $2 ; 7)$ and Safiah (f, 2;9) turn to Husna too and squeal, "Saya!" (Me). Then the three of them run to the practitioner and eventually all of the children end up next to Husna. Ayu looks at them, walks towards the group and stands behind Safiah. While holding a basket, Husna says, "Buat line. Sorang-sorang baling bola masukkan dalam bakul ni." (Make a line. One by one try to throw the ball into this basket). Husna stands back while holding the basket. Dayah throws the ball she is holding in Husna's direction but misses the basket. Dayah frowns but moves away from the line. Husna hands the ball to Safiah. Safiah smiles and throws the ball to the basket and it lands inside the basket. Safiah then jumps up and down while squealing, "Yeay!" The other children look at her and then they all jump up and down like Safiah and shout, "Yeay!" Ayu looks at her peers and then she too jumps and squeals, "Yeay!" Then Husna says, "Okay Ayu pula" (Okay Ayu's turn). Ayu steps forward and throws the ball in the basket's direction. The ball goes in and Ayu squeals, "Yeay!" while clapping her hands. Her peers look at Ayu and they all jump up and down too while squealing, "Yeay" for Ayu. Ayu grins and walks to the back of the line, giving Nani (f, 2;3) a turn to throw the ball into the basket. Nani misses the basket. Nani smiles and jumps up and down and then shouts, "Yeay!" happily. The others look at her and then imitate her by jumping up and down while squealing, "Yeay!" The children repeat this game a few times until everyone gets at least three turns at throwing the ball in the basket. Every time someone throws the ball, regardless of whether the ball goes in or misses the basket, the children jump up and down and squeal, "Yeay!" (VOMCC) 


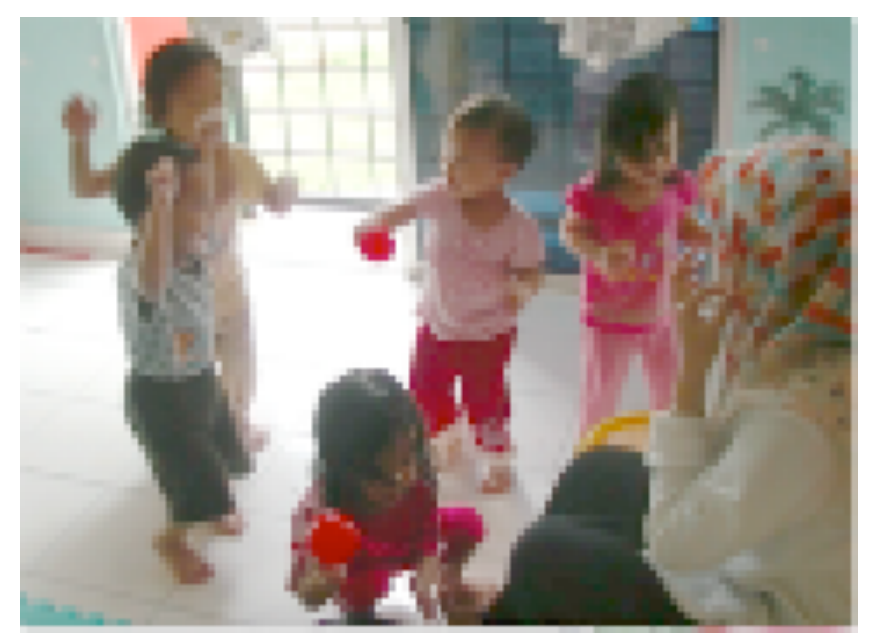

Figure 5.5 The children cheering and shouting "Yeay!"

The episode above shows how an activity brought the children together in a group. Even though an adult led the activity, the children were seen to create a sense of belonging and togetherness between them through the way the children squealed and cheered for their peers. Ayu imitated her peers by jumping and cheering for her peers. That activity of jumping and cheering made the children happy as could be seen by their glowing faces. They were not only happy, but they were also connected by this activity. When Nani missed the basket, she herself cheered, "Yeay!" Nani may not understand the whole concept of getting the ball into the basket, and this could be because she was the youngest among them, but her peers showed support by jumping and squealing with her. After that moment, the children cheered for their peers even though some of them missed the basket. Their actions showed they were supportive of each other and that they had an emotional connection with each other.

These data show that the children have a natural interest to belong and create togetherness with their peers. The two episodes above show how the children were skilled in making themselves included in the group, which means they have a degree of agency in establishing peer interactions. Looking at this through the lens of everydayness (Lefebvre, 1987), the children's agency can be seen as facilitated by the repetition of their everyday routines and by their need for a sense of belonging and togetherness. To accomplish that, they showed their interest in participating in activities that the 
practitioners have set out for them. In reference to the Social Competence Prism (RoseKrasnor, 1997), when one has goals and values in doing something, establishing togetherness can be seen to provide the direction and motivation for social behaviour.

\section{Pursuing opportunities to interact}

Apart from participating in activities that practitioners have set out for them, as already demonstrated the children were also seen to socialize on their own with peers as they created that sense of belonging and togetherness. My observations throughout this study showed that some of the children took every opportunity available to interact with their peers. In the following example, Rania (f, $0 ; 11$ ) was lying on the floor, playing with her soft toys by herself when a peer, Hamza (m, 1;9), walked towards her:

Rania is lying down on the floor while holding a soft toy in each hand. She jiggles and wiggles them and watches them move. She seems to be fascinated by them. Hamza, who has been eyeing Rania from afar, walks to her and sits next to her before reaching over to touch her face. Looking surprised, Rania looks at Hamza with wide eyes. Hamza smiles and touches her face again. Rania begins to smile and then laughs at him. Then Hamza pats Rania's tummy softly and she laughs again at him. Hamza laughs with her. Sulaiman (m, 1;1), who was playing nearby on his own, turns towards the laughter and watches them. He then walks towards Rania and Hamza and lies down next to Rania. Rania turns to Sulaiman and exchanges eye contact. Sulaiman lets out a laugh. Rania then squeals while Sulaiman continues to laugh at her. Hamza looks at them and he too joins in the laughter. They continue laughing and squealing at each other for some time (VORCC).

In the example above, the three children were seen to pursue opportunities to interact with each other. When Hamza showed interest in Rania, Rania carried on the interaction by smiling and laughing at Hamza even though she was surprised by the sudden interaction. It was unclear why Hamza was attracted to go over to Rania and what motivated him to touch her face and playfully pat her tummy but the contact between them led them into longer interactions with each other. Rania and Hamza smiled and 
laughed at each other and looked to be enjoying their interactions. When Sulaiman joined in their play soon afterwards, suddenly the three of them were playing and laughing together. This showed how responding to opportunities to interact with peers can lead the children into a broader sense of belonging to a group and creating togetherness with each other. The episode above also showed how Rania was socially competent at that time in responding to her peers' interactions. While Rania could have responded negatively by shoving Hamza away, she did not choose to do that and in doing so, Rania also illustrated her capacity to exercise her agency as well as social skills in establishing and maintaining peer interactions.

Similarly, in MCC, Nani (f, 2;3) was playing on her own when an opportunity to interact with her peers came by. Instead of rejecting her peers, Nani pursued the opportunity to interact, showing how well integrated and socially competent she was at the centre:

Nani is holding two balls in her hands and seems to be talking to herself. Suddenly, Asyraf (m, 2;9) and Helmi (m, 2;7) walk up to Nani holding a box between them. Asyraf calls out Nani's name and Nani turns to look at him. Asyraf and Helmi then lift the box and show Nani that the box had three small balls. Nani looks at them and smiles. Then she looks inside the box again and throws her two balls inside it. Asyraf smiles and he and Helmi walk away carrying the box with the additional two balls inside it. Nani looks around the room and spots two more balls on the floor; Nani runs to the balls, bends to pick them up and runs to Asyraf and Helmi offering to throw the additional two balls in the box too. Asyraf exchanges smiles with Nani and Nani reaches out to hold the edge of the box, walking around the room with the boys, looking for more balls to fill up the box. The boys and Nani happily play like that together for a few minutes while exchanging glances and smiles with each other (VOMCC).

In the episode above, Nani was playing alone when an opportunity to interact with her peers arose. Nani's contribution of balls to the boys' box appeared to gain her acceptance into Asyraf and Helmi's play; it was clear that Nani wanted to stay with the boys and took the initiative (which also showed her capacity in exercising her agency) to look for 
more balls to add to the box. Asyraf reacted positively towards Nani by smiling at her and that signal may have given Nani the courage to join in their walk, holding onto a part of their box. Clearly, Nani wanted to belong and have that togetherness with her peers.

In the following episode, Ayu (f, 2;4) was seen to socialize with her peers through playing with soft toys. Prior to the event, Ayu had just walked into the main room at the centre from the outdoor area where she had her morning tea. As she walked indoor, she looked at her peers, Dayah (f, $2 ; 11$ ) and Lily (f, 2;11) who were rolling on the floor and squealing at the same time:

Ayu looks at Dayah and Lily with interest. They are squealing as they roll on the floor. Ayu smiles as she watches them. Dayah and Lily take no notice of Ayu who smiles and watches them until Dayah stands up and walks to a shelf. Dayah picks a teddy bear up from the shelf and hugs it. Ayu looks at Dayah with wide eyes. Dayah turns to face Ayu. They exchange eye contact and then Dayah picks up a bunny soft toy from the shelf and hands it to Ayu while saying, "Ayu nah!" (Here Ayu!). Ayu looks at the bunny, smiles and takes it from Dayah. Ayu then hugs the bunny. Dayah looks at Ayu with a smile and says, "Jom main baby" (Let's play baby). Ayu smiles. Dayah then walks around the room and Ayu follows behind her. The girls walk about the room while carrying their 'baby'. After a while, Dayah runs to a corner and sits down. Ayu follows Dayah. Two more girls (Lily and Safiah) come with a doll each and join them playing in the corner. The girls smile at each other and continue to play with their 'babies' in the corner for a few more minutes (VOMCC).

Socializing with peers was seen as another way to fit in at the centre. According to the practitioners at MCC, Ayu is a shy girl and may need some help when interacting with her peers. So, while Ayu may be a shy girl, she was also willing to socialize with others as can be seen in the example above. In her efforts to do this, Ayu practiced her agency and social skills by using her non-verbal cues such as smiling and eye contact. Although her peers appeared at first to ignore Ayu's existence when she watched them, after a while Dayah invited Ayu to play with her by giving her a toy. Ayu pursued the 
opportunity to interact with Dayah as she accepted the toy bunny from Dayah. Ayu gained access to Dayah's play probably because she stayed on near Dayah even though she was ignored and when her eyes met Dayah's eyes, there may have been some unspoken understandings between them. When Dayah handed the bunny to Ayu, Ayu immediately gave the bunny a hug just like Dayah did, which indicated that Ayu was observant of Dayah's behaviours. Ayu's actions may have won Dayah's heart because Dayah smiled at Ayu and asked her to play 'baby' with her. Ayu's smile showed she was happy to play along with Dayah, which at the same time fulfilled her goal of playing with Dayah. It also marked Ayu's success in social competence with her peer.

Observing the children in socializing with their peers leads me to believe that the children are very capable of fitting in into their centres without constant help or intervention from the practitioners. The data show that even as the children participate in the everyday routines and happenings of the centre, and where Lefebvre's (1987) words: "days follow one after the other" (p. 10) implies the children learn something from this repetition of everydayness and eventually take actions and produce change towards their goals, exercising their agency to reach their goal, which is to establish and maintain peer interactions. The episodes above illustrated this where Rania was able to socialize and play a game with peers even though she was non-verbal; Nani was able to join in her older peers' game; and even the shyest child (Ayu) was able to interact with her peers by using non-verbal gestures and be understood.

\section{Shared experiences}

Another way children were able to fit in into their centres and be part of the group was by having shared experiences with their peers. According to Canella (1993), shared experience is the outcome of shared actions, which create a connection between interacting partners. Others have described shared experience as an interaction where children do something together and have a shared understanding of the underlying logic of that activity (Brenner \& Mueller, 1982). According to Trevarthen and Delafield-Butt (2017) and Musatti et al. (2017), children are born to be social, eager to have social contact and share their play experiences with peers. They are curious beings who want to do activities together as they go about their daily lives in the childcare centres. However, 
Koivula and Hannikainen (2017) argued, success in creating shared experiences also requires that children have the appropriate knowledge to do things together. This is illustrated in an episode at RCC where a group of children were seen to establish belonging and togetherness through their shared experiences of dancing to songs. The episode is shown below:

Nadia (a practitioner) put on a nursery rhyme DVD on the television. Having observed Nadia, Jasmin (f, 2;1) ran towards the television and stood in front of it. She had a big smile on her face:

Jasmin looks up at the television screen as a song entitled, "If you're happy and you know it clap your hands" comes on the screen. Jasmin smiles and seems to sing along to the song. When the song says, "Clap your hands," Jasmin jumps up and down while clapping her hands in glee. Idris (m, 2;8) and Sharifah (f, 1;5), who are looking at Jasmin from afar, smile and run to the television too. They stand behind Jasmin. Sensing their movement, Jasmin turns to them and briefly exchanges eye contact and smiles at Idris and Sharifah before she turns back to the television. Eyes on the screen, Jasmin swings her body from left to right with the rhythm of the song. When the song says, "Stomp your feet," the three children jump up and down at the same time. Jasmin laughs and turns around to face Sharifah. Jasmin grins at her and Sharifah returns her smile before Jasmin faces the screen again. Another boy, Ibrahim ( $\mathrm{m}, 2 ; 5)$, runs towards the television and joins the group too. Jasmin, Sharifah and Idris are now twirling around while jumping up and down. Ibrahim squeals and follows them by mimicking their actions. Then Ibrahim claps his hands while laughing. Jasmin turns and follows Ibrahim's lead to clap her hands. They look at each other and laugh. Idris observes Jasmin and Ibrahim and then he leaps towards Jasmin and claps his hands too. Jasmin smiles and twirls around again. She looks at her peers and jumps up and down while laughing. The others laugh with her and follow Jasmin as she jumps up and down. Then the song ends and the children stop jumping. Jasmin looks up at the screen and said, "Dah habis" (All done) and turns towards 
her peers. The children look at each other with a grin on their faces. Then another song, 'Bingo', comes on the screen. The children turn to the television again and start to jump up and down followed by squealing and laughing. They continue doing this for a few minutes until a practitioner calls them for snacks (VORCC).

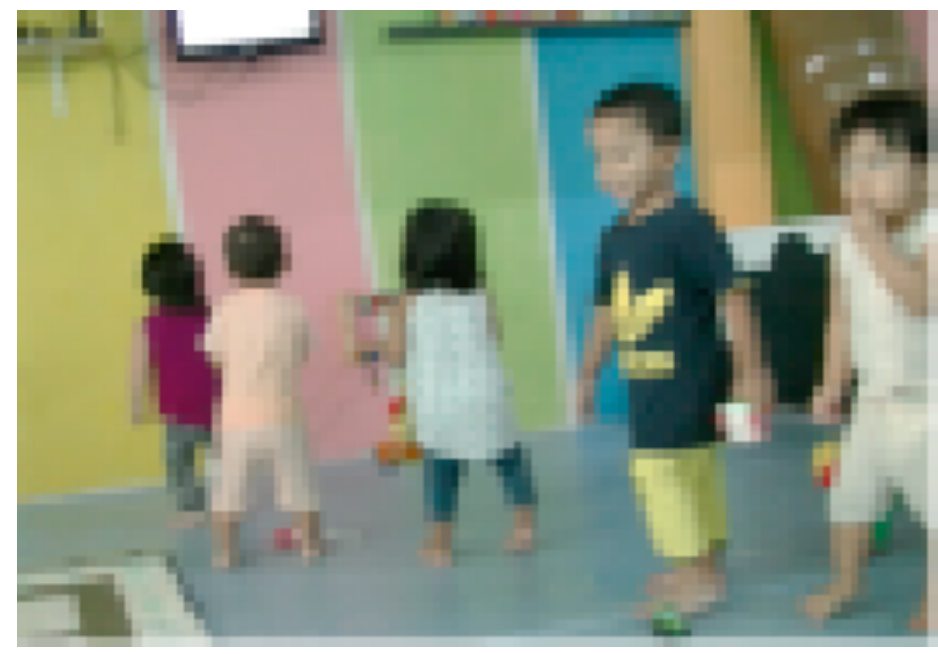

Figure 5.6 The children jumping and twirling around during the playing of a DVD with nursery rhymes

The children were clearly having fun singing and dancing to the song together. They showed the same understanding of what was going on and were able to enjoy the activity together. In an interview with Nadia, she indicated that the children were familiar with the songs and thus the children's interactions were based on a known routine. This statement is consistent with Lefebvre's (1987) concept of everydayness: the children learnt about the singing and dancing activity and created background knowledge about it that they then repeated and adapted. In relation to the Social Competence Prism, the children were seen to exercise their social skills and showed behaviours of wanting to do things together in a group. The children were observed to be reading each other and establishing what in developmental research is called "intersubjectivity" (Trevarthen \& Delafield-Butt, 2017). This was seen by their embodied communications such as exchanging eye contact and smiles as they made connections with each other. According to van Oers and Hannikainen (2001), humans react to an activity based on a pre-existing situation. The familiarity of the activity means the children had appropriate knowledge of 
what was happening. When shared experiences between the children are established, intimacy grows and they are able to do more activities together (Selman \& Schultz, 1990).

Another example of establishing shared experience was seen with Ibrahim (m, 2;5). In the episode that follows, Ibrahim was sitting alone in a corner when suddenly Omar (m, $1 ; 11)$ and Ahmad (m, 2;4) started a game of run-and-chase around the room. Ibrahim looked at them chasing each other with a smile on his face before he stood up and walked towards them:

Ibrahim laughs as he watches Ahmad and Omar running. Then Ahmad goes down on his knees and starts to crawl. Omar squeals and follows Ahmad by going down on his knees and crawling behind him. Ibrahim laughs as he looks at them in delight and then he too gets down on his knees and crawls behind Omar. The three boys crawl around the area, turning to face each other and laughing. Omar crawls faster and chases Ibrahim and Ahmad. Ibrahim and Ahmad squeal in delight and all three boys continue to crawl quickly, chasing and running away from each other while their laughter and squeals fill the room. As Ibrahim crawls, in his excitement to get away from Ahmad and Omar, he falls flat on the floor. Ibrahim looks surprised at first and then he laughs hard. Ahmad looks at Ibrahim and he quickly copies the way Ibrahim has fallen down. The boys laugh harder. Then Ahmad made a roaring sound, "Aauummm" as if he were a tiger and crawls quickly towards Ibrahim and Omar. Ibrahim laughs while Omar smiles and chases Ahmad. Ahmad squeals and crawls quickly away from Omar. The boys play like that together laughing and screaming as they go along with the game (VORCC). 


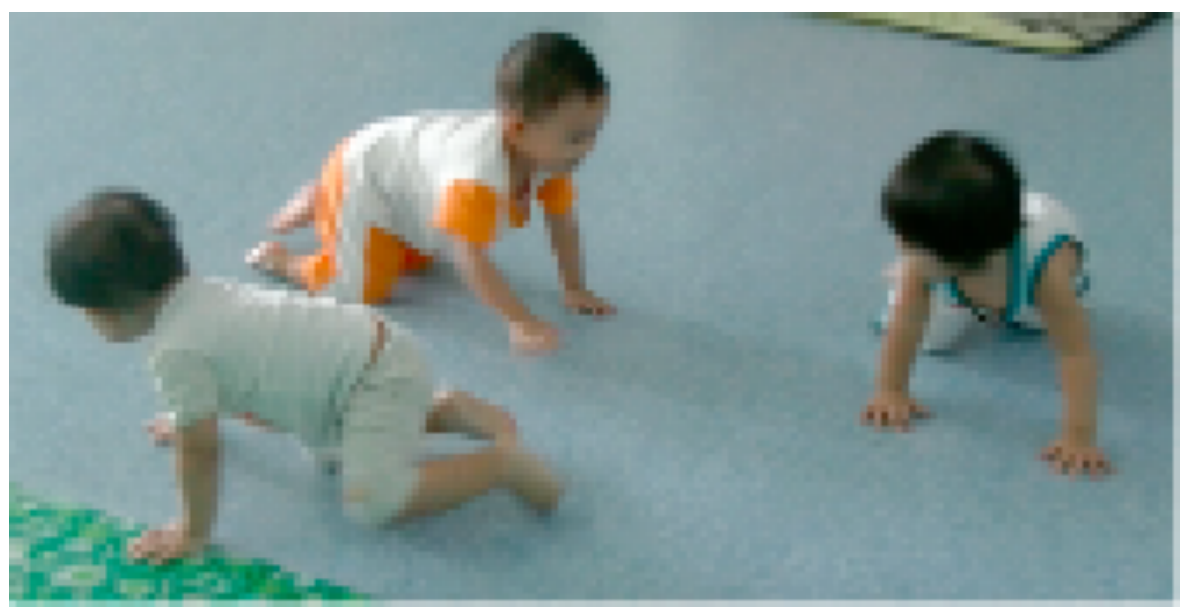

Figure 5.7 Ibrahim, Ahmad and Omar crawling and chasing each other

This excerpt vividly conveys the sense of delight the three boys shared in their run-andchase game that they soon modified into an animal chase, thus co-creating an imaginary world that they shared throughout the duration of this episode. The co-creation was enabled by their intent observation of each other and their imitation of each other's actions. One of the practitioners commented that the children played this game on many other occasions, which means they had previous knowledge of the game. Again, this shows how repetition of the everydayness gives children the opportunity to interact and learn something with peers as well as to creatively change an everyday action. Connection was established between the children which was seen by their non-verbal communication of looking at each other, having eye contact, smiling and using expressive laughter which all contribute towards creating a sense of belonging and togetherness.

Fitting in into a centre may not be easy for some children (Wilson, 1999) but taken together, the data in my study shows that the children were successful in achieving this when they had shared experiences, pursued opportunities to interact, and participated in activities with their peers in their respective childcare centres. The children's eagerness to be part of the group, to belong and construct togetherness with their peers seemed to supersede their shyness or worries of not being able to fit in. In relation to RoseKrasnor's (1997) Social Competence Prism, the children illustrated their capabilities at using their social skills in creating a sense of belonging and togetherness with their peers 
by smiling, mimicking each other, establishing eye contact and tolerance. These social skills lie at the bottom of the Social Competence Prism, identified in the skills approach to social competence (Rose-Krasnor, 1997). Furthermore, the children exercised their agency when they made a choice to interact with peers. All in all, children learn to be part of the group by exercising their agency and using social skills as well as learning from the repetitive nature of everydayness to create belonging and togetherness with peers. Next, I will discuss on how children create belonging and togetherness during the centre's routines.

\subsection{Belonging and togetherness as embracing the centre's routines}

Childcare centres have routines in their daily activities that contribute to children's peer group organization (Koivula \& Hannikainen, 2017; Corsaro \& Molinari, 2000). According to Singer (1998) and Corsaro (1988), routines are powerful tools that can help children in shaping a group. Routines are used by some teachers to foster positive values among children in group settings (Singer, 2002; Corsaro, 1997); they can create a sense of solidarity and commitment to a group (Singer, 2002), enhance bonding between the group members (Henry, 1992) as well as establish group membership (Corsaro, 1988) and a sense of belonging and togetherness (Maloney, 2000; Corsaro, 1997; Koivula \& Hannikainen, 2017; Van Oers \& Hännikäinen, 2001). Looked at through the conceptual lens of everydayness (Lefebvre, 1987), the recurring everyday activities at the three case study childcare centres such as lining up, mealtimes, and packing up, led me to conclude that the children's participation in routines at their childcare centres revealed a great deal about how they used their social skills and agency to create a sense of belonging and togetherness with peers.

\section{Lining up}

Lining up was a surprisingly enjoyable event for the children. They laughed, squealed and chatted excitedly as they participated in this activity. According to the practitioners, they taught the children how to make a line and told them whenever they were going out of their classroom that they first had to make a line. The everydayness of this activity led the children to get used to this routine as was evident by the quick way that they simply 
knew what to do when the practitioners gave the instruction to line up. The examples below show how such routines brought the children together and created a sense of belonging among them:

Anna (f, 2;6) was seen to be playing with a peg puzzle with Ali (m, 2;7) in their classroom when Amy, their practitioner, said that it was time to go outside. All of the children looked up at Amy with wide, bright eyes:

Willy ( $m, 2 ; 9)$ quickly walks to the door and stands in front of the door. Ina (f, 2;8) looks at Willy and quickly makes her way to the door too. Anna looks at Amy and smiles but returns to look at her puzzle again. Amy turns to Anna and Ali and repeats her instruction: "Time to go out. Line up everyone!" Ali stands up and runs to the line. Anna, who is still concentrating on her puzzle turns to look at Ali running. Then she looks at her peers lining up in front of the door. Slowly she smiles and shouts, "Yeay!" and quickly stands up. Roy (m, 2;7), who is standing at a bookshelf, looks at Anna and then he too shouts, "Yeay" while lifting both of his arms in the air. All of the children quickly run to the door. At the door, the children make a line. Anna walks to the line and stands behind Willy. She then puts her hands on Willy's shoulder. Willy smiles. The children seem to be chatting excitedly with each other. All of them place their hands on the shoulders of the peer in front of them, except for Willy because he is first in line. Anna smiles as she looks at her peers. Amy looks at them and says, "Straight line, please." The children quickly look in front and straighten their arms on their peers' shoulders. Amy then opens the door to the classroom and leads them outdoor. They walk outside with lots of smiles and laughter, making a linked-up chain that looks like a train (VOSCC).

According to Spagnola and Fiese (2007), Corsaro and Emiliani (1992) and Henry (1992) repeated routines offer the opportunity to create strong emotional bonds and are an investment to maintain connections between the participants. There were so many emotions expressed during the line-up: the children looked at their peers and smiled as 
well as squealed "Yeay" prior to lining up. The children clearly wanted to line up as a group: all of them lined up willingly and none of them wanted to be left behind as can be seen in the way that Anna and Roy quickly ran to join the group and in the way Anna wasn't initially willing to give up her play when Amy first gave instructions to line up but did so hurriedly when Ali deserted her to join the line. These behaviours also suggest that their social skills are internally driven in the accomplishment of a sense of belonging and togetherness. Their participation in this routine cemented a sense of belonging and togetherness, making lining up a pleasurable activity. Furthermore, the children were seen chatting to each other in an excited manner and when they placed their hands on each other's shoulders and walked like a train, their faces glowed with happiness.

In MCC, the children were also taught to line up when they needed to go somewhere. In the example below, the children were asked to line up for breakfast. The practitioners had prepared their meals at a table outdoors and thus the children needed to go outside to have their breakfast. Helmi $(\mathrm{m}, 2 ; 7)$ was playing with toy cars when Husna, the practitioner, asked the children to make a line at the door:

Husna looks at the children and says, "Okay line up please. Kita nak pergi makan" (We are going to eat). Dayah (f, 2;11), Matt (m, 2;10) and Lily (f, 2;11) quickly stand up and run to the door. They make two lines in front of the door: one line for the girls and the other line is for the boys. The other children look at the line and quickly put the toy they are holding on a shelf and run to the door too. Helmi is still playing with his cars on the floor but when Dayah and Matt start to sing the song "Line up, line up, everybody line up. We are going out, everybody line up please", Helmi turns his head towards his peers, smiles and then joins in the singing, "Line up please." He quickly places the cars on a nearby shelf and walks towards his peers. Helmi then gets into the boys' line and stands in front of Matt. Matt looks at Helmi and smiles. Helmi is looking at Nani (f, 2;3), who is lining up in the girls' line next to him. They exchange eye contact and smiles. The children repeat the song one more time while grinning at each other. Husna looks at them and asks, "Ready?" The children shout, "Yes!" and they immediately place their hands on their peers' shoulders. Husna smiles and opens the front door 
for them. "Okay jalan" (Okay walk). The children walk out towards the tables and chairs outside while making excited sounds and noises (VOMCC).

The example above shows how the children were brought together as they were making a line. Helmi was seen to want to be a part of the group when he started singing the line-up song and then ran quickly to the group to form a line. It was clear that he was happy to be in line with his peers. The other children seemed to be happy too when they had to line up and this was evident by their singing and happy expressions.

A routine activity like the two episodes above are great opportunities for the children to interact with their peers and at the same time exercise their agency and social skills. Anna and Helmi's behaviours showed a clear sense of agency when they initiated their involvement in being in the line with the others, which demonstrated their capacity to engage with peers. Not only did lining up create opportunities for learning, the children were also able to enjoy themselves by singing together and imagining they were in a train. Social skills such as cooperation and considering others' needs were exercised in this activity too because the children could not go outdoor if they did not form the lines. These social skills are important because they act as building blocks for the children's social competence development (Rose-Krasnor, 1997). Through the lens of everydayness (Lefebvre, 1987), routines that the children had to undergo each day at their childcare centre - like lining up - indeed opened up opportunities for them to be in a group.

\section{Mealtime}

Mealtime is another example where children come together in a joyful manner. As they eat about 2-3 times a day at their centres - breakfast, lunch and snacks - mealtime is considered an everyday centre routine. During mealtimes, the practitioners were seen to give instructions like "Recite your prayers before eating". The children's participation in this instruction during mealtime seemed to cement a sense of belonging and togetherness, making mealtimes more meaningful. Examples are shown in the episodes below. 
In SCC, it was customary for the children to recite prayers or blessings before they ate. They are taught to give thanks to God for providing the food and to do so they had to raise their palms up and cup them as they said thanks. In the episode that follows, Willy ( $\mathrm{m}, 2 ; 9)$ was sitting at the table with his peers during lunchtime. He looked around at his peers and waited for the cook to put food on his plate:

The cook goes around the table and puts food on each child's plate. As the cook puts food on Willy's plate, he looks at it and grins. Willy follows the cook's movement and watches her as she puts food on the other children's plate. When she is done, Zainab, a practitioner, says, "Okay time for doa (prayer)." Willy raises his hands and cups them while looking at Roy (m, 2;7) and Ali (m, 2;7). All of the children at the table cup their hands too. Zainab starts reciting the prayer in Arabic while all of the children recite with her. Then Zainab reads the translation of the prayer in English and the children recite along with her too. The children seem to have memorized the prayers already. Willy grins at Roy and Ali while reciting the prayers and the boys return Willy's grin. The other children are also looking at each other with a happy face while reciting their prayers together. After the prayer is done, Willy picks up his spoon and starts to eat his food. Anna (f, 2;6) and Roy who have their eyes on Willy also pick up their spoon and start to eat their food. Willy looks at Roy and raises his spoon to Roy. Roy grins and shows his spoon to Willy too while laughing before he puts the spoon in his mouth (VOSCC).

In the centre above, children were brought together during mealtime. As they sit at the table and face one another, they are bounded together as of by the invisible thread of the established routines they participate in, like saying prayers together before eating. These routines can make the children feel they belong and are a part of the group. This was evident in the way Willy was seen to grin at Roy and Ali when they were reciting the prayer. When Roy and Ali grinned back at Willy, they were likely giving him a sign of acknowledgement. Additionally, Anna and Roy's imitation of Willy's actions is also a sign of wanting to interact, and then Willy's action of raising his spoon to Roy, and Roy's 
response to it was a clear sign that they understood each other's gestures and they had established belonging and togetherness during mealtime.

Similarly in MCC, the children were seen to act as a group during mealtime. In this centre, the sense of belonging and togetherness was more evident through the mealtime conversations. In the episode below, the children were chatting to each other during their morning tea. They were seated outdoor at the dining table, munching their food while occasionally looking at each other. Nani (f, 2;3) was eating her banana when Dayah (f, $2 ; 11)$, who was sitting in front of her, asked a question:

Nani looks at her banana and takes small bites, one after the other. Dayah, who is munching a biscuit looks at how Nani eats the banana and asks her, "Sedap ke?" (Is it good?) Nani looks up at Dayah and nods her head. Dayah observes Nani for a few more seconds and then she turns to Husna, a practitioner, and asks for more biscuits. Husna puts three biscuits in Dayah's bowl. Dayah turns to her peers and says, "Saya punye lagi banyak" (I have more than you). Safiah (f, 2;9) and Shafiq $(\mathrm{m}, 2 ; 11)$ look at Dayah's bowl and reply, "Saya punya pun banyak" (Mine is a lot too). Nani looks at her peers and after a few seconds Nani says, "Saya punye banyakjuga" (I have a lot too) while showing five fingers to Dayah. Dayah looks at Nani and grins. Nani smiles back at her (VOMCC).

This example illustrates how Nani wanted to belong with her peers when she told Dayah that she had a lot of biscuits too. Her action showed how she did not want to miss out on the chance to speak when she heard everyone replying to Dayah's comment about how many biscuits she had. The children all grinned and smiled at each other as they gave their statements. Even though Nani was the youngest at the table, she showed a clear sense of agency: she put herself forward and makes herself belong in the group. 
In the same childcare centre, on another morning, the children were having their morning tea outdoor when an elderly man walked by the centre. Helmi (m, 2;7) was munching on his biscuits while looking around at his peers from time to time:

Matt (m, 2;10) looks up at the walk walking by through the fence and says, "Tu atuk" (There's grandpa). Husna, the practitioner replies, "Ye atuk" (Yes grandpa). All of the children turn to look through the fence at the 'grandpa.' Helmi looks at Matt and then turns to look at the man. Helmi smiles and then suddenly shouts, "Bye atuk! Bye atuk!" (Bye grandpa! Bye grandpa!) while waving his hands. The elderly man turns to look at the children and smiles. The other children look at the man and imitate Helmi by saying, "Bye atuk!" while waving their hands to him too. Then they look at each other and laugh and turn their head back to the 'grandpa'. The situation gets lively and exciting when the children laugh and scream together, "Bye atuk!" The elderly man looks at the children again and waves his hand back while smiling. The children keep waving their hands to him until he gets into his car and drives away. The children then resume eating their meals (VOMCC).

In the above episode, Helmi wanted to be part of the conversation. When Matt said, "There's grandpa", Helmi added to the statement by waving to the man and shouted, "Bye grandpa!" The children then got excited and imitated Helmi by waving their hands at the man and screamed, "Bye grandpa." Clearly, none of the children wanted to be left out of the action; they all wanted to do the same thing as their peers.

The three episodes above show how daily routines like mealtimes are a great opportunity for children to interact and learn more about each other. Children get to exercise their agency and social skills during this time. By applying Lefebvre's (1987) notion of everydayness, children's participation at mealtime can be seen as rational repetitions of experiences where children learn about others' behaviours and learn to fit in as well as to act to change the everyday activities, and upsetting the "monotony" (Lebfevre, 1987, p. 10) imposed by everydayness. The examples above are a clear indication that even 
children of the relatively young age as those in my study were capable of constructing their own sense of belonging and togetherness.

\section{Packing up}

Another daily routine in childcare centres is asking the children to pack up their toys after they have finished using them. Like lining up and mealtimes, the routine of packing up toys was seen on many occasions to create a sense of belonging and togetherness in the children. Some examples are shown below:

The practitioners at SCC regularly practised packing up toys and objects with the children after they have finished using them. In the following episode Anna (f, 2;6) was looking at books on her own when Amy, a practitioner, gave the instruction to the children to pack up their toys:

Anna is sitting in the corner of the room, looking at books while her peers, Willy $(\mathrm{m}, 2 ; 9)$ and Roy $(\mathrm{m}, 2 ; 7)$, are playing with rubber dinosaurs. They are throwing the dinosaurs in the air and laughing when the dinosaurs fall on the ground. Then the boys start to throw the dinosaurs in all directions in the room. Amy turns her head to look at them and when she sees how they are throwing the dinosaurs around, Amy says, "Okay no more. Pack up please." Willy frowns while Roy just grins at Amy. Amy picks up a box and hands it to Roy. "Put the dinosaurs inside. Pack up please." Willy looks at the carpet and picks two dinosaurs from the carpet and puts them in the box. Amy looks at him and starts to sing, "Pack up, pack up, everybody do your share." Breaking her concentration on the books, Anna looks up at Willy and Roy. Ali (m, 2;7) and Ina (f, 2;8) who are playing in another corner also look at Willy, Roy and Amy's direction. Anna looks at Willy and Roy who are putting the dinosaurs in the box. After a few seconds of watching her peers, Anna starts to sing the song, "Everybody do your share". She then stands up and picks a dinosaur from the carpet and puts it in the box too. Roy smiles at her. Ali starts to sing the song too, "Pack up, pack up, everybody do your share" and Anna joins him in singing. Now all of the children bend down and search for 
the dinosaurs on the carpet. When they find a dinosaur, they put it in the box grinning as they do it (VOSCC).

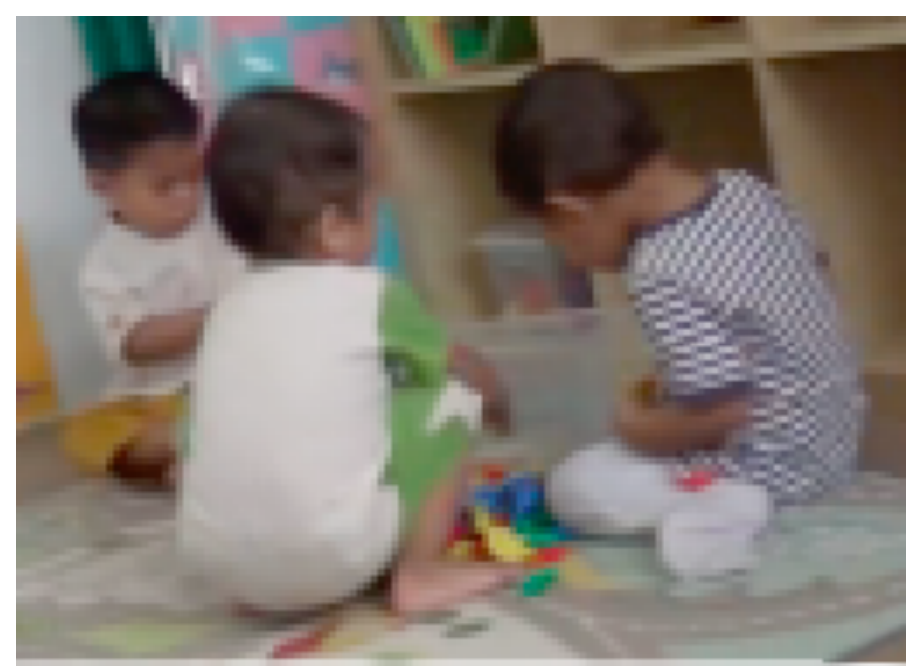

Figure 5.8 The children putting the dinosaurs into the box

Anna, who was not even playing with the dinosaurs, was seen to pack up Willy and Roy's toys. Anna was most probably attracted to the song because she turned to look at her peers when Amy sang the song. Maybe Anna wanted to help the boys pack the toys, however, Anna's behaviours show that she wanted to be part of the group and did not want to be left out. When she saw that the peers were tidying up the dinosaurs, she wanted to do it too, showing that she wanted to be part of the group. She seemed happy to be packing up with her peers and this was evident by her singing as she did the work. Likewise, Ali and Ina voluntarily put away the dinosaurs and seemed happy to be doing this as a group too. The children's choice to do things voluntarily in order to be part of the group shows a clear sense of agency. As Rose-Krasnor (1997) argued a healthy peer relationship is important in keeping a balance between self and others as it can lead to effectiveness in interactions. An example at another centre also shows how packing up toys does create a sense of belonging and togetherness among the children. 
In the episode that follows, Helmi ( $m, 2 ; 7)$ was playing with blocks when Husna, the practitioner, announced that they are going outdoor to play:

Helmi is building a tower with his blocks. He is playing with the blocks parallel to Shafiq $(\mathrm{m}, 2 ; 11)$ who is making a pistol. As they play, Husna says, "Okay kemas mainan semua. Kita nak main kat luar." (Okay tidy up the toys everyone. We are going out to play). Helmi looks at Husna and picks up an empty container beside him. He then stands up and begins to put blocks inside the container. Around him, all the other children at the centre are running around putting toys back where they belong. Helmi looks at the others and smiles. He then looks down at his container and puts another block inside it. Shafiq looks at Helmi and then he too put his blocks inside the box. Helmi and Shafiq briefly look at each other and then they continue to pick up blocks from the floor and put them in the same box. When they have picked up all the blocks around them, Helmi looks around the room. He spots some more blocks scattered around the room. Helmi lifts the container and begins to walk towards some blocks in the corner of the room. Shafiq looks at Helmi and immediately walks to him and holds the other end of the container. Helmi looks at Shafiq and smiles. With a mischievous grin, Helmi begins to make a siren sound, "Ne no ne no ne no" as he walks quickly towards some more blocks on the floor. Shafiq laughs and follows Helmi's pace. Lily (f, $2 ; 11)$, who is standing nearby, looks at them and smiles. She then quickly picks up some blocks from the floor and runs towards the boys to put the blocks in the container. Helmi looks at her and grins. Lily smiles and then puts her hand on the container and holds one side of it. The three of them are holding on to the container now while walking fast around the room looking for blocks. The children continuously make the siren sounds while stopping from time to time to pick up blocks and put them in the container. When the children finish tidying the room, Dayah (f, 2;11) says, "Dah siap teacher!" (It's done teacher!) and Husna smiles and gives instructions for the children to line up in front of the door (VOMCC). 
As packing up was a routine, the children right away knew what to do when they heard Husna's instruction. When Helmi looked at his peers tidying up, he smiled to himself and continued packing up. This may signal his acknowledgement of needing to do his part in the room even though he did not do it together with his peers. The fact that Shafiq joined Helmi in tidying up without being asked for his help shows that the children wanted to do things together. When Helmi made the siren noise, the packing up became lively and it attracted Lily's attention who joined in the group activity, exhibiting a sense of togetherness and wish to contribute in the group activity, as well as a sense of satisfaction at achieving the task. This satisfaction was evident when Dayah called out "It's done!" suggesting that she knew that packing up toys needed everyone's cooperation for the work to be accomplished and the reward of going outdoor to play was for everyone.

The examples above illustrate how the children were capable of taking their own actions, which also shows their sense of agency in creating a sense of belonging and togetherness with their peers through routines that were created for them at their respective childcare centres. In doing so, the children practiced their social skills with each other, including cooperation. Even though the nature of routines limited the choices available to children in order to meet the adults' goals (Brennan, 2005), the children's behaviour showed that they nonetheless found ways to meet their needs for belonging and togetherness (Guo \& Dalli, 2016). Looking through the lens of everydayness (Lefebvre, 1987), it can be inferred that daily routines taught children what was required of them in different situations and about the predictability of their peers and this encouraged agency and social competence (Brennan, 2005). 


\subsection{Togetherness as responding to the needs of others}

One way the children in this study created togetherness was by responding to the needs of others (Brown \& Levinson, 1987; De Haan \& Singer, 2001). Brown and Levinson's study with adults found that in constructing relationships and togetherness, adults give sympathy and satisfy another's desires by using language (Kousar, 2015). In their studies with verbal children (above the age of three), De Haan and Singer found that children satisfy the needs of others by offering help, expressing compassion, comforting other children and expressing social understanding, and Koivula and Hannikainen (2017) have argued that satisfying others' need is a behaviour that is linked to children's emotions and is important for a child's social development. For example, participating in meaningful play activities in childcare centres helps children to develop the sense of helping others (Hannikainen, 2007). In my study where children are younger and some are still preverbal, I found that most strategies identified by De Haan and Singer were also used by these younger children including: offering help to peers, and expressing empathy and giving comfort by using a few words and body language.

\section{Offering help}

In the episodes below, children were seen to offer help to their peers by using their agency and social skills, clearly resulting in a sense of togetherness.

Anna (f, 2;6) was sitting on the floor, reading a book when she heard Willy (m, 2;9) shouting angrily at Amy, a practitioner. Prior to the incident, Willy was kicking toys in the room. Amy told Willy that she would have to send him to the office if he kept on kicking the toys and Willy got upset and started kicking Amy's legs. To show her disagreement with Willy, the practitioner, Amy, stepped on Willy's socks:

Willy shouts at Amy. Startled by the noise, Anna turns to look at Willy and Amy's direction. With a frown in her face, Anna looks at Willy and seems to wonder what is going on. Willy shouts at Amy again while looking down at his feet. Anna looks at Willy's feet and notices that Amy has caught Willy's left sock, with his foot still in it, under her foot, effectively stopping him from moving 
anywhere. Willy is trying to pull his sock out from under Amy's foot but he is not successful. Willy shouts again at Amy and then he hits Amy's hands. Amy looks at Willy with a tight smile on her face. Anna watches them and then she stands up and walks to them. While still frowning, Anna looks up at Amy and hits Amy's hands. Amy ignores Anna and keeps her foot on Willy's socks. Willy shouts louder. Anna looks at Willy and then she looks up at Amy and shouts at her too. Willy turns to Anna and they briefly exchange eye contact. Willy then rolls his fist and punches Amy's hip. Anna watches them and then Anna rolls her right hand in a fist and hits Amy's hip too. Willy looks at Anna and Anna gives him a smile. Willy smiles back briefly before he turns towards Amy again. Amy frees the socks from under her foot and Willy quickly walks away from Amy. Anna watches Willy with a grin on her face before she walks back to her book (VOSCC).

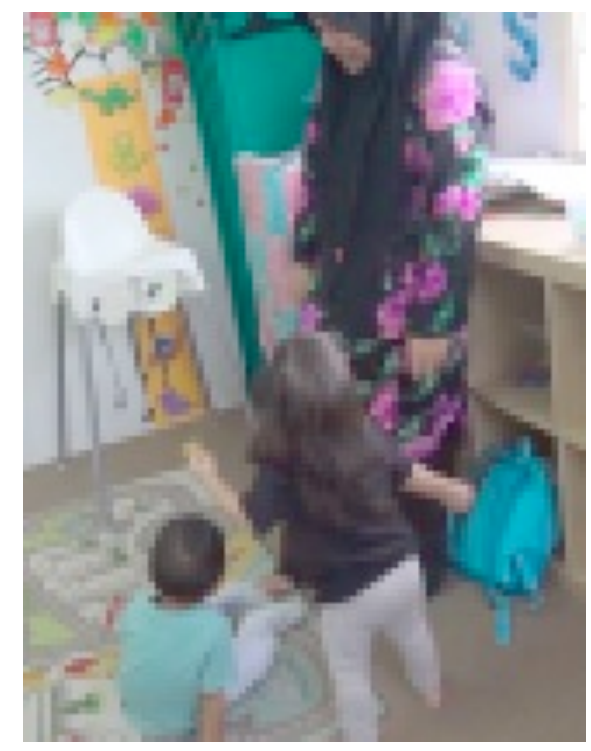

Figure 5.9 Anna helping Willy

In the above episode, Anna was seen to offer help to Willy when he was in distress. This shows Anna's sense of agency because she initiated her involvement in Willy's situation. It was clear that Anna understood what Willy wanted as she imitated his actions in order to free his sock from Amy. The children's solidarity and desire to help each other was apparent during this peer interaction. The children used a range of communicative tools 
in building a sense of connection and togetherness such as sharing eye contact (which was when the connection between them was established), smiling and cooperation. The children collaborated to overcome the use of adult power by Amy. The fact that Willy allowed Anna to help him indicated his willingness to collaborate with Anna and while doing so they constructed a sense of togetherness in freeing the socks from under Amy's foot. When they were successful in freeing the socks, a sense of triumph was shared between them, marking a success in social competence during that activity, and maybe also an act of subversion.

In another episode at MCC, Nani (f, 2;3) was also seen to offer help to her peer. Nani and Lily (f, $2 ; 11$ ) were sitting parallel to each other, playing with blocks. They each seemed to be building a tall tower. As they played, a movement by Lily caught Nani's eyes:

Nani looks on as Lily places a block on top of her tower but as she is placing the block, it falls on the floor. Nani looks at it and said, "Jatuh" (fall down). Nani immediately picks up the fallen block and puts it on top of Lily's tower. Lily smiles at Nani and Nani smiles back. Lily then continues to stack her tower while Nani keeps looking at Lily's tower. Suddenly Lily rummages in the pile of blocks in front of them as if looking for a certain block. Nani looks at Lily and then she looks at the pile. As she is looking, Nani picks up a yellow block and shows it to Lily. Lily, however, is concentrating on her tower and does not see Nani's action. So Nani says, "Leee nak?" (Leee want?) Lily turns to look at what Nani is showing her. Lily smiles at Nani as she looks at the yellow block and nods her head. Lily then takes the block from Nani's hand and stacks it on her tower. Nani looks at Lily's tower and smiles (VOMCC).

While playing parallel to Lily, Nani seemed to be interested in what Lily was doing. Nani offered help to Lily a few times during their play and showed her eagerness to construct a sense of togetherness with Lily through questioning, smiling and showing interest in Lily's play. Lily seemed happy at getting the help from Nani and this was evident in the way the children smiled at each other, which created a sense of connection between them. 
The two examples above illustrate how children form togetherness by satisfying others' needs through offering to help them. Anna was seen to help Willy in freeing his sock while Nani was seen to hand a block piece to Lily so that Lily could use it for her tower. The children's willingness to be involved with their peers indicated their capacity to use their agency to interact with peers. These examples further show how children made connections with their peers by applying social skills and how they constructed that sense of togetherness - an important task when joining a childcare centre (Koivula \& Hannikainen, 2017).

\section{Empathy and comfort}

The Social Competence Prism identifies empathy as one of the essential skills for social competence (Rose-Krasnor, 1997). Young, Fox and Zahn-Waxler (1999) defined empathy as an emotional response characterized by the feelings of concern for others and the need to ease their distress. According to De Haan and Singer (2001), expressions of empathy and compassion offered to peers, such as asking the peers what happened could bring people together. In my study, questioning peers about what happened was apparent among verbal children but also identifiable among non-verbal children who used other means to show their care for others.

Four children were involved in the next episode; they were all interested in one basket. Dayah (f, 2;11) was playing with the basket when Helmi (m, 2;7) came and interrupted her play. This resulted in Dayah getting angry and hitting Nani's hand. Ayu (f, 2;4) was seen to comfort Nani (f, $2 ; 3$ ) and in the process revealed a capacity for empathy:

Dayah is playing alone in a corner, throwing small balls one by one into a basket. By the smile on her face, she looks like she is enjoying her game. Ayu looks at Dayah with interest. Nani, who is standing nearby, is also looking at Dayah with interest. Suddenly, Dayah stands up and walks towards the front door, leaving the basket behind. Seeing an opportunity to play with the basket, Nani walks towards Dayah's basket and drops a ball in the basket while squealing, "Yeay!" Ayu looks at Nani and smiles and Nani returns Ayu's smile. Then Ayu steps forward to the 
basket and drops a ball in the basket too while squealing, "Yeay" like Nani. At that moment, Dayah comes back to the basket with several balls in her arms. Dayah puts the balls in the basket. Ayu and Nani look at Dayah but Dayah is not looking at them. Suddenly Helmi walks to the basket and turns the basket over making all the balls in the basket fall to the floor. Shocked, Dayah looks at Helmi angrily and screams. Helmi looks at Dayah and then runs off. Ayu just looks at them without intervening while Nani picks up a ball from the floor. Dayah turns to Nani angrily and hits Nani's hand. The ball in Nani's hand rolls on the floor. Nani screams and cries in shock. Ayu quickly walks to Nani and hugs her. Nani hugs Ayu back while pointing to Dayah with her right hand. Ayu looks at Dayah who is now carrying the basket of balls and running around the room with it. Ayu frowns and shouts, "Hey Dayah!” Nani looks at Ayu and imitated her, "Hey Dayah!" Dayah does not turn to look at them though. She keeps running in a circle with the basket. Nani looks at Ayu and laughs. Ayu looks at Nani and smiles back (VOMCC).

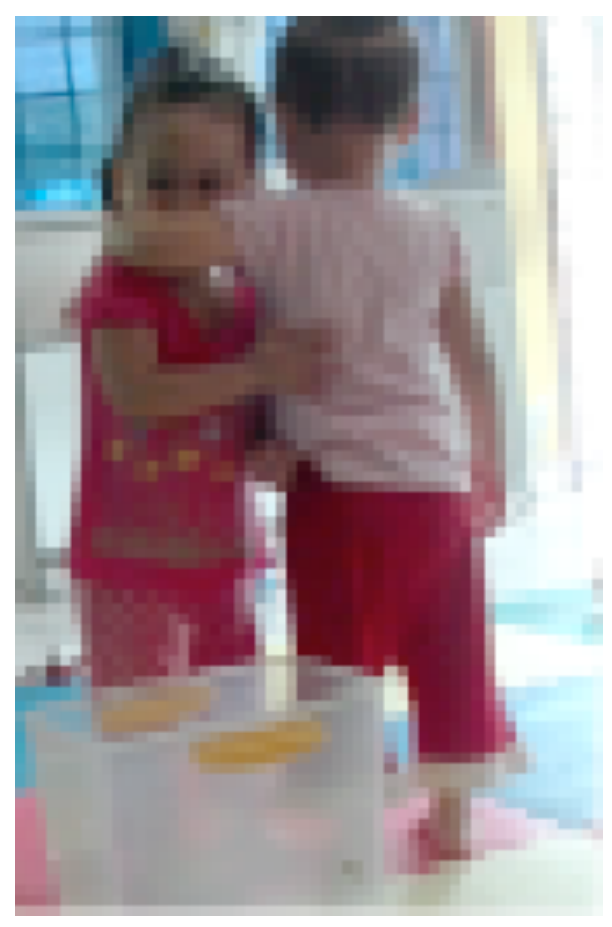

Figure 5.10 Ayu and Nani hugging 
It is clear that Dayah's basket was the centre of attraction to the children. However, Ayu and Nani only approached the basket when Dayah left it unattended. Ayu looked at Nani when she played with the basket and that was when the girls established a connection. After that, they played together and prolonged their connection while squealing, "Yeay". Their joy, however, didn't last long because Dayah came back to take ownership of her basket and hit Nani's hand. Nani cried and Ayu expressed her empathy towards Nani by comforting her and hugging her. This action by Ayu appeared to satisfy Nani's needs to be comforted and also showed an element of joint allegiance against Dayah. According to Rochat (2009), this act of caring and feeling for others is one of the ways to construct togetherness. Ayu showed her affection to Nani and Nani accepted the hug from Ayu, which also shows their desire to be together (Engdahl, 2012). Furthermore, Nani imitated Ayu when Ayu shouted Dayah's name and they exchanged eye contact, smiles and laughter when Dayah did not respond to them. All of these actions and behaviours demonstrated Ayu and Nani's capacity to use social skills in constructing togetherness.

Another example of empathy was evident in the same childcare centre when Helmi (m, $2 ; 7)$ was hurt one morning as he was playing on his own and ended up in a conflict with Ayu (f, 2;4) over some toy cars. The episode started with Ayu playing with the basket of balls which she left unattended while she went to look at others playing with blocks. Helmi, who had been playing with some toy cars, looked at the basket and left his toy cars to get the basket:

Helmi lifts a basket from the floor. He smiles and puts three small balls in the basket while shouting, "Makan makan" (eat eat) and walks around the room with the basket. He repeatedly walks around the room while shouting, "Makan makan." None of the children seem to take any notice of him except Ayu. Ayu looks at Helmi and gives him a slight frown. She then walks to him and hits the basket with her right hand. Helmi ignores her and continues to walk around the room with the basket. As he walks, he spots two more small balls on the floor and stops to pick them up before continuing to walk around the room with the basket and balls. Still looking at Helmi, Ayu once again walks closer to Helmi and hits 
the basket. This time, all of the balls from the basket fall on the floor. Helmi looks at Ayu with a shocked face. Then he sway the basket at Ayu which knocks Ayu's arm. Ayu reacts by pushing Helmi's chest and Helmi falls down and cries. Ayu sits down and looks at Helmi's face. Helmi's cries attracts Lily (f, 2;11) who walks quickly to Helmi and hugs him while asking, "Siapa buat?" (Who did it?). Helmi points to Ayu. Ayu frowns. Lily strokes Helmi's head and keeps hugging him. Ayu walks away from them and Helmi stops crying. Lily lets go of Helmi and takes a toy truck from a shelf behind her. She moves the toy truck to and fro and Helmi looks at Lily and laughs. Lily smiles back and pushes the truck forward to Helmi. They then play with the truck together (VOMCC).

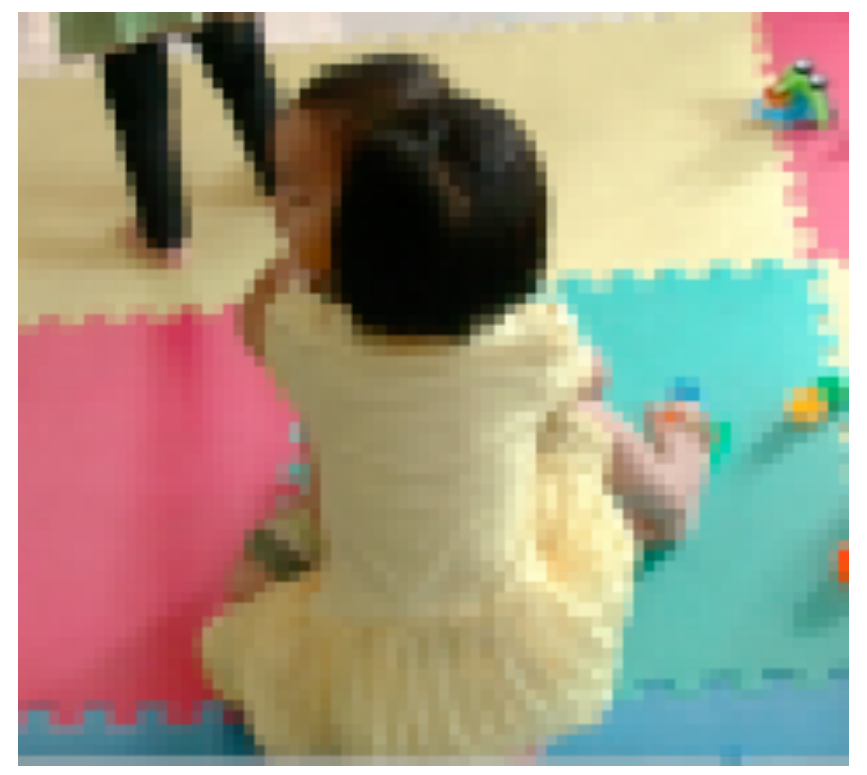

Figure 5.11 Lily hugging Helmi

In the episode above, Lily was seen to comfort Helmi by giving him a hug and stroking his head as well as asking him about who made him miserable, as Lily, who is slightly older than Helmi, is verbal. Lily's actions illustrated how she was satisfying Helmi's needs to be comforted and cared for when she showed her concern to him and also the fact of Helmi's willingness to be part of Lily's embrace shows mutual interest in being together. This incident was clearly one that gave them both a sense of togetherness and 
this was evident in how Helmi and Lily continued to play together with a toy truck long after Helmi was comforted and happy.

In the examples above it is clear that children were capable of feeling empathy with their peers and showed their concern to peers in distress by trying to comfort them. Non-verbal children showed their empathy by using their body language, such as hugging each other like Ayu and Nani, and like Nani pointing her finger at Dayah to show that Dayah was the one who hurt her. In her effort to ease Nani's sadness, Ayu shouted Dayah's name in anger showing her support for Nani's needs. Verbal children like Lily on the other hand asked the question, "Who did it?" and comforted Helmi by stroking his head gently and hugging him. Similar to De Haan and Singer's (2001) study, empathy and comfort were seen to bring the children together as they tried to satisfy the needs of others. Additionally, the children showed their capacity to use their social skills when they responded with empathy to their peers.

Taken together, responding to others' needs can be seen to be one of the ways to construct togetherness between the children in this study. There were numerous opportunities for the children to encourage a sense of collaboration, connection and community by being together which at the same time showed how they exercised their agency and their developing social competence. Not only did the children construct togetherness when they established connections, but they also learnt to use their social skills in achieving this goal. This shows that the children were able to find a balance between their own needs and the needs of others, which Rose-Krasnor (1997) argued is located in the index level of the Social Competence Prism. Additionally, the children used their understanding of peers' needs to satisfy those peers' desires, to show empathy and to give comfort to peers as well as to offer help to peers during interactions. Furthermore, it can be seen from their faces that the children were happy when they attended to their peers' needs and their peers were also happy to have their desires met. Looking through the lens of the concept of everydayness (Lefebvre, 1997), the children could be said to have learned to understand others' behaviours through familiarity with them, through their everyday encounters. In the next section I argue that apart from 
responding to others' needs the children in this study were also observed to create a sense of togetherness by using humour and laughter.

\subsection{Togetherness through humour and laughter}

According to Loizou (2005) and Degotardi and Pearson (2014), humour is one of the important tools through which infants and toddlers feel and construct togetherness, while Reddy (2008) notes that it takes at least two persons for humour and laughter to begin to exist. Children often laugh when they get together such as playing a game of run and chase or jumping on cushions. By contrast, children rarely laugh when they are playing alone, which indicates that they need to be together in order for humour and laughter to happen. There are a number of ways for humour and laughter to occur (Degotardi \& Pearson, 2014; Singer \& De Haan, 2007).

In seeking to understand the data from the perspective of children's social competence, in this study, I primarily used the Social Competence Prism by Rose-Krasnor (1997) to analyse the significance of my findings and when it came to understanding children's humour, I also drew on the theoretical framework used by Loizou (2005). Loizou (2005) studied infant humour to understand how infants produced and appreciated it, and proposed what she calls 'the theory of the absurd'. Loizou's work identified three themes around which she structured her analysis: incongruous use of materials; funny gestures; and incongruous actions. Considering my data from the perspective of Loizou's classification, I was able to classify instances of humour and laughter around two very similar themes - incongruous use of objects; and making funny sounds. The third theme identified by Loizou (2005) - incongruous actions - appeared embedded in both of the two themes I identified in my study and thus I have chosen to focus on these two themes in discussing how the children in my study used humour and laughter as part of their experience of togetherness with peers at their childcare centres. 


\section{Incongruous use of objects}

According to Singer and De Haan (2007), children laugh about incongruity or things that are out of their expectation. When a child uses an object incongruously, it means that the child turns the object into something different to what it is supposed to be. The episodes that follow illustrate how the children were involved in the incongruous use of objects and how their incongruous actions turned into humour and laughter, which at the same time brought them together.

Zara (f, $0 ; 10$ ) and Lea (f, $1 ; 0)$ were seen to be having fun playing with a cushion. Their play started after Zara had finished playing with a bag and turned to look around the room. Zara scanned the room with her eyes and stopped to look at Lea who was playing with a cushion in the middle of the room. Zara looked at Lea intensely for a few seconds before she crawled towards her:

Zara crawls towards Lea and looks at her. Lea is putting a cushion in between her legs and bounces up and down on it while squealing, "Aaaaaa." Zara looks at her with interest. Her eyes are wide and she has a slight smile on her face. Then she picks up a cushion from the floor and pats it a few times. Meanwhile, Lea continues bouncing up and down on her cushion while squealing, "Aaaaaa". Zara turns to look at Lea again. The girls look at each other. Lea grins at Zara while Zara looks at Lea's cushion, smiling all the while. Then Zara sits on her cushion like Lea and imitates Lea's bouncing, making a humming sound, "Hmmmmmm" and squealing. The girls face each other as they bounce up and down on their cushions and squeal. Occasionally, they smile at each other while continuing their bouncing and patting the cushions. Suddenly, Lea falls down flat on the floor. Zara immediately stops bouncing and looks at Lea. Still lying flat on her front, Lea looks up at Zara who smiles and pats Lea's shoulder once as if to ask her to continue, meanwhile continuing to bounce up and down on her cushion while laughing. Lea returns Zara's laugh and sits up straightaway and crawls to her cushion, and starts bouncing up and down again still laughing along with Zara. 
The girls continue to look at each other and laugh while they bounce up and down (VOMCC).

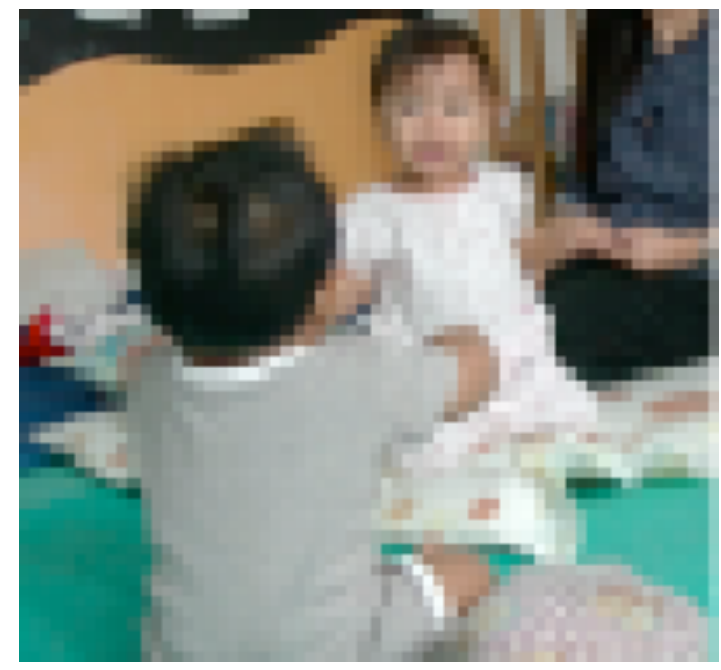

Figure 5.12 Zara and Lea looking at each other and laughing

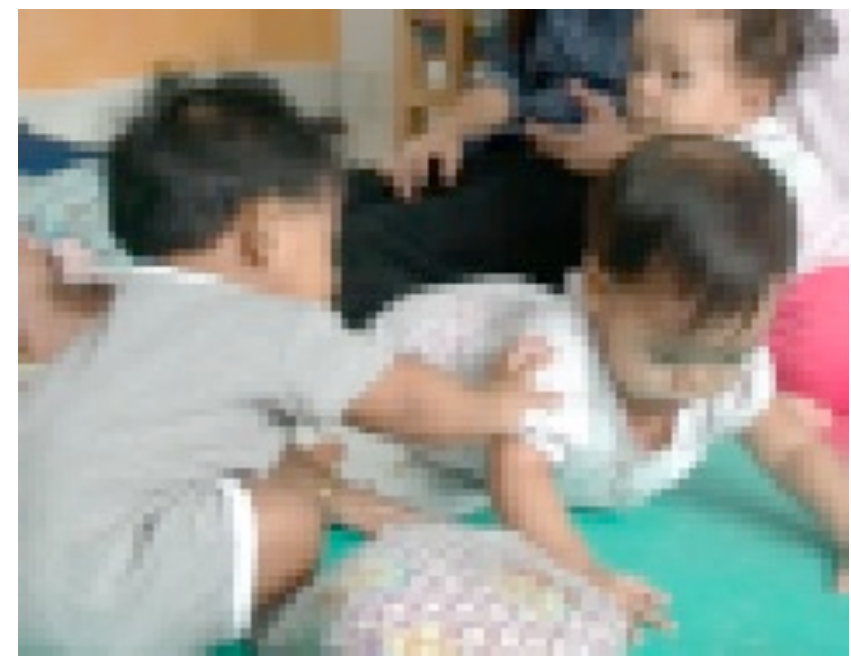

Figure 5.13 Zara patting Lea

Zara's interest in Lea's play led Zara to interact with Lea and at the same time practise her social skills in gaining access to the play. Lea's action of using the cushion to bounce up and down may have sparked Zara's interest in Lea's play. In the theory of absurd, Loizou (2005) describes how children would smile or laugh when they watch others use an object incongruously. This was seen when Zara smiled and looked at the way Lea used the cushion, which probably indicated Zara's awareness that Lea was using the cushion in an unusual way. The children seemed to establish connections when they looked at each 
other and smiled. It can be noted that these social acts of smiling and establishing eye contact made Zara successful in gaining a response from Lea. Zara may have taken Lea's smile as willingness to play together and used the opportunity to imitate Lea in bouncing up and down on the cushion and making funny noises. This got the girls laughing and squealing together. Furthermore, the episode shows how the children exercised their social competence in interacting with one another and at the same time constructed belonging and togetherness. When Lea stopped playing after she fell down, Zara patted Lea's back as if to reassure her and to ask her to continue. This indicated the game would not be the same without Lea, that they wanted to do things together and that this game of using an object incongruously does extend their interactions as well as establishes togetherness.

Another example of children being brought together when an object was used in an unexpected way occurred one morning at SCC. In the episode that follows, Anna (f, 2;6) and Ali (m, 2;7) were playing with puzzles individually but were sitting side by side. As Ali was putting a puzzle piece onto his puzzle board, the piece fell out of his hand onto the floor:

Anna looks at Ali's puzzle piece on the floor and as quick as lightning, she picks it up. Ali frowns at Anna and immediately tries to snatch the puzzle piece from Anna's hand but Anna puts her hand behind her back so that the puzzle piece is out of Ali's reach. Unexpectedly, Ali's frowning face turns into a laughing face as he laughs at Anna's behaviour. Anna looks at Ali laughing and she begins to laugh too. Then Anna raises her hand and shows the puzzle piece to Ali. Again, Ali tries to reach for the puzzle piece but Anna immediately puts her hand behind her back again. Once again they laugh at this together. They repeat doing this a few times until Anna hands the puzzle piece to Ali. Ali looks at it and unexpectedly, puts the puzzle piece in his mouth and pretends to eat it. He makes the sounds, "Ummmm" as he pretends to chew the puzzle piece. Anna looks at Ali and laughs hard. Ali laughs along with her. Then Anna picks another puzzle piece from the floor and puts it in Ali's mouth. Ali makes the sound again, 
"Ummmm" while pretending to chew the puzzle piece. They laugh again at this and continue to do the action several times, laughing hard each time Ali pretends to eat the puzzle (VOSCC).

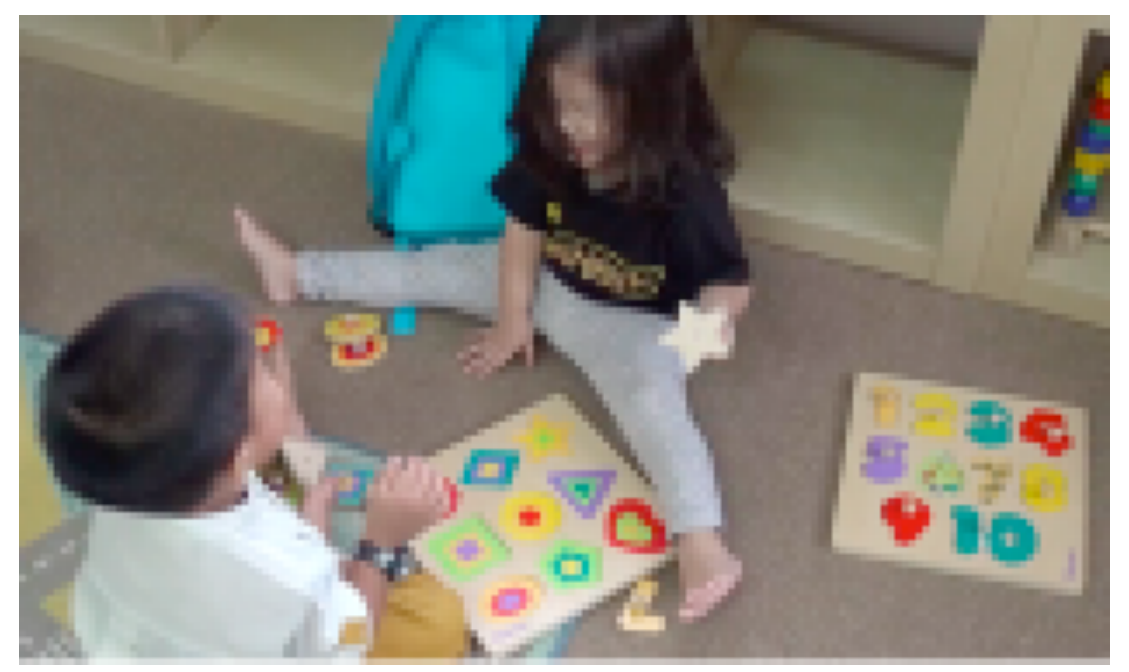

Figure 5.14 Ali and Anna laughing together after using the puzzle incongruously

In this episode, Anna and Ali were playing alone at first before the incongruity of events brought them together. It can be seen how togetherness was constructed when the unexpected happened (when Anna hid her hand behind her back) and Ali laughed at her instead of being angry. The incongruous use of objects made their interactions last longer as they kept repeating their actions over and over again, pretending to eat the puzzle. Due to the joy in their interaction, the children continued to use the object in an unexpected way (putting in the mouth) and had fun together throughout their play. In reference to the Social Competence Prism (Rose-Krasnor, 1997), the children's goal and values can provide the direction and motivation for social behaviours. What could have easily become a conflict between Anna and Ali turned out to be a social interaction between peers. Anna seemed to love seeing Ali laughing at her and thus she directed her behaviour into a game instead of refusing Ali to have the puzzle. Ali's positive reaction to her behaviour motivated Anna to continue the game and this interaction has implications for competence in the index level of the Social Competence Prism, which is the balance between self and others. 
The theory of the absurd explains how some events are thought to be humorous to children because the events are a mismatch with the children's knowledge and do not fit their existing knowledge about the world (Loizou, 2005). As in the example above, the children laughed about the incongruous use of objects. This indicated that young children may be aware of how objects should be used and when used differently it can spark amusement, which may lead to humour, laughter as well as much enjoyment, including when the children made themselves funny. The children's joy during these humorous events was also clearly a way of creating togetherness by exercising their social skills in achieving their goals. Like Reddy (2008) said, humour exists only in relation. She argued that young children would not carry on with their humorous acts if others did not find it funny. This was true in my data because when Zara smiled at Lea, it reinforced Lea to carry on with her actions and the same was seen when Ali laughed at Anna and Anna subsequently repeated her actions a few times more.

\section{Making funny sounds}

Making funny sounds likewise created much humour and laughter. According to Singer and De Haan (2007), children laugh when they hear funny sounds because it is a mismatch with what they are used to. This kind of laughter can be described as an amused kind of laugh when they find things that are odd or humorous (Reddy, 2008) as can be seen in the examples below.

Omar (m, 1;11) from RCC was observed on many occasions to use humour and laughter while playing with his peers. Among the games that he enjoyed were run-and-chase games as well as jumping. In the episode below, Omar was playing on his own before Sharifah (f, 1;5) came over and joined him:

Omar is looking around the room when he suddenly stops to look at some cushions stacked in the corner; he grins and runs towards the stack of cushions. Omar's movement seems to attract Sharifah who looks in Omar's direction, squeals and starts to run behind Omar. As Omar reaches the cushions, he sits down on one of them and looks at Sharifah. Omar gives Sharifah a smile and Sharifah grins back at him. But instead of sitting down like Omar, Sharifah steps 
on the cushions and starts to jump up and down. Omar looks at Sharifah with interest and then he stands up quickly and jumps up and down on the cushions too. The children look at each other and laugh while jumping up and down on the cushions. After a few seconds, Omar stops jumping, followed by Sharifah who looks at Omar and with a mischievous grin, lifts her left hand and touches Omar's back as if to encourage him to continue jumping up and down. Omar looks at her and shouts, "Aluuuuu" while laughing. Sharifah looks at him with wide eyes and squeals. Omar repeats his shout:"Aluuuuu” and then he looks directly at Sharifah and laughs. Sharifah laughs harder and their laughter fills the room as they continue to make funny sounds like that for a few minutes (VORCC).

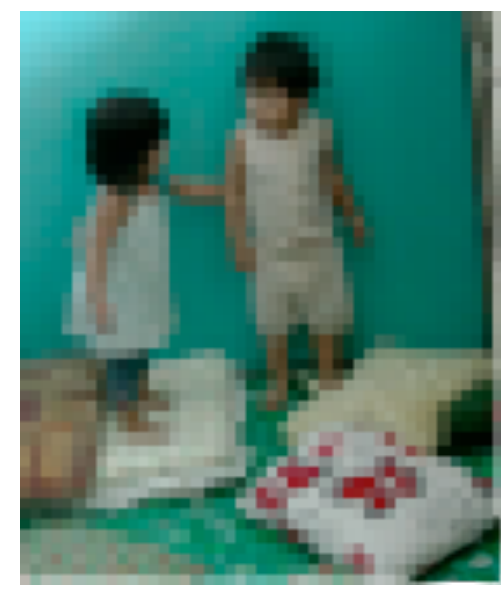

Figure 5.15 Sharifah touches Omar's back

It was clear that the children were establishing connections through exchanging eye contact and smiles. When Sharifah started to jump on the cushions with her eyes on Omar, it was as if she was inviting Omar to join her. Understanding her intentions, Omar joined Sharifah in jumping on the cushions. When Omar stopped jumping, Sharifah touched Omar, as if to nudge him to continue jumping, but instead of continuing to jump, Omar made a funny sound, "Aluuuuu" which brought so much delight to Sharifah. Omar's understanding of Sharifah's intention could be attributed to their everyday familiarity with each other at the centre and their routine activities, which - as noted before - can also produce change (Lefebvre's, 1987). From the perspective of Loizou's (2005) theory of the absurd, as children play and explore, they may produce unexpected sounds and 
watch how their peers respond to their actions. This was seen when Omar suddenly shouted, "Aluuuuu" after Sharifah touched his back. The amused look on Sharifah's face seemed to encourage Omar to repeat the funny sound he had made and their game was extended with more laughter. The children's interaction can be considered as effective because it complements the purpose of their interactions, which appeared to be having fun with peers. According to Rose-Krasnor's (1997) Social Competence Prism, one of the challenges in social interaction is finding a balance between the need of the individual and the needs of others. While we cannot be hundred percent sure of Omar's intentions and needs when he made the funny sounds, we can gain an insight into his intentions by watching his actions closely - a micro-analytic practice that goes back to Daniel Stern's early work on infant-mother communication (Beebe, 2017). Omar's behaviours led me to believe that he was merely having fun and entertaining Sharifah because he was laughing when he made the funny sound, to which Sharifah responded with laughter. Sharifah on the other hand wanted to continue their game of jumping up and down. Even though Omar did not oblige, he offered an alternative fun action to Sharifah by which Sharifah was seen to be delighted. This shows how Omar was skilled at finding the balance between his needs and Sharifah's needs, and at the same time continued their experience of togetherness.

Another example of a child entertaining a peer by making funny sounds was Liza (f, 2;3) who, like Omar, probably wanted to entertain her peer for the sake of having fun. In the example below Liza played a game with Rania (f, 0;11 months) which made both of them laugh. Just before the excerpt starts, Rania had been looking at some posters on the wall on her own when she turned around and, seeing a group of peers watching cartoons on television with Jamilah, one of the practitioners, she started to crawl towards Jamilah:

Rania smiles at Jamilah as she crawls towards her. When she reaches Jamilah, Jamilah smiles at her, lifts her up and puts Rania on her lap. Rania looks happy on Jamilah's lap who holds both of Rania's hands and claps them. Rania laughs. Her laughter attracts Liza, who is sitting in front of Jamilah. Liza turns around and looks at Rania. Then Liza smiles at Rania and leans forward towards her saying, 
"Woof woof!" Rania's eyes open wide in surprise followed by a loud laugh. Liza smiles. Then Liza repeats her actions and shouts, 'Woof woof!". Rania laughs harder and this time Liza laughs with her. Liza repeats herself a few more times before she turns back to the television and Rania plays with Jamilah again (VORCC).

By looking at other children sitting in a group with Jamilah in front of the television and crawling over to them, Rania expressed her desire to be with them. Rania's laughter attracted an older peer, Liza, to play with her. When Liza made a dog's sound, "Woof woof," Rania looked surprised and delighted. Rania's laughter at Liza's humorous act reinforced Liza to repeat making the sound and at the same time prolonged their interactions. As discussed by Loizou (2005), children make funny gestures and watch the consequences of their actions. When they receive a positive response, they tend to repeat their actions because of the joy it brings. The positive relationship the children maintained during those events furthermore illustrates that these two very young children were also exhibiting their emerging capacity to balance their own needs as well as those of others (Rose-Krasnor, 1997).

These illustrative examples are certainly consistent with Loizou's 'theory of the absurd' with my data matching closely two of the three themes identified by Loizou, namely: the incongruous use of objects; and making funny sounds. The third theme mentioned in the theory of the absurd (incongruous actions) can be seen to be intertwined in both of the themes in my study. These humorous acts or acts of funniness as termed by Reddy (2008), not only created amusement and joy in children but also constructed a sense of togetherness. From the lens of the everydayness (Lefebvre, 1987), children's everyday interactions with their peers gave the children opportunities to get to know their peers and then create change and in this case, they created togetherness by being humorous. This was seen when the funny events attracted peers' attention and brought the children into interaction. Once the peers showed signs of interest like smiling, eyes open wide or laughing, the children tended to repeat their humorous actions many times and laughed together while playing with each other. Additionally, the children were able to exercise 
their agency and social skills through these humorous events such as responding to the peers' jokes. McGhee (1989) agreed that humour in social interactions is positively related to one's social competence. Furthermore, humour and laughter in the children's play seemed to prolong the children's interactions. This is evident in the way they kept repeating their actions and continued to laugh about the humour together.

\subsection{Chapter Overview}

This chapter unfolds the story of how the children in my study achieved a sense of belonging and togetherness by living their everyday lives in their respective childcare centres. Observations of the children's behaviour led me to conclude that having a sense of belonging and togetherness is not something that happens by itself. The children had to find their own strategies in order for it to happen. The children in this study were seen to learn to be with peers, embrace the routines of their childcare centres, respond positively to their peers' needs and apply humour and laughter thus enabling each other to feel connected and to create that sense of belonging and togetherness with their peers. For most of the time that the children in the study were observed they were seen to comply with the adult's instructions when it came to doing something in a group, such as routine activities like lining up to go outside the classroom, praying during mealtime, and packing up toys in the room. While familiarity with the rules might be the reason for the children's compliance with these rules, such compliance could also be an indication of the collectivist rather than individualistic nature of Malaysian culture (Hofstede, Hofstede \& Minkov, 2010). A few common traits of collectivistic cultures include working as a group and supporting others, doing what is best for society, and the central role of families and communities in a person's lives (Cherry, 2018). This means that maintaining harmony within the group is an important aspect of collectivistic culture. In addition, according to Balakrishnan (2009), in the Malaysian culture, children are taught to respect elders, to speak politely to them, and to be caring towards them. They are also taught to acknowledge the elders with great respect, which also means children are not allowed to talk back to their elders. Thus, the children's compliance to the teacher's expectations 
and having good relationship with peers could be a reflection of the Malaysian collectivistic culture as well as their inherited culture of respecting elders.

I have also described and discussed the ways children under three years old in this study used their agency and social skills in constructing a sense of belonging and togetherness. The episodes presented clearly show how the children wanted to connect with their peers and be part of relationships. In relation to the bottom level of the Social Competence Prism (Rose-Krasnor, 1997), the children were seen to be capable of using their social skills when interacting with peers, which then led the children to have that sense of togetherness. The children were clearly motivated by the goal of connecting with peers and directed their behaviours, such as mimicking peers or offering objects to peers, to achieve this goal. In so doing, there is evidence that the children were competent at the index level of the social competence prism (Rose-Krasnor) where their individual and peers' needs have to be held in balance. The children were seen to be quite skilled at balancing these needs when they responded to their peers' needs by offering help, showing empathy and showing understanding to peers in their situations and at the same time looking after their own needs.

Bringing together insights from Guo and Dalli's (2016) and De Haan and Singer's (2001) study of children's belonging and togetherness, with Lefebvre's (1987) concept of the everydayness, Rose-Krasnor's (1997) Social Competence Prism, and Loizou's (2005) Theory of Absurd as analytic tools with which to interpret my data, I conclude that children under three years old have their own ways of constructing togetherness with their peers by exercising their agency, and their non-verbal communicative and social skills. The children both had and created a lot of opportunities to collaborate and communicate with their peers. In the next chapter, I look at how interactions between peers can break down when they are involved in conflicts. 


\section{CHAPTER SIX WHEN CHILDREN HAVE CONFLICTS}

\subsection{Introduction}

This chapter discusses the second key theme identified from coding the observational data: that is, the conflicts that occurred during the children's peer interactions, firstly by focusing on the "motivations" (Licht, Simoni \& Perrig-Chiello, 2008) that gave rise to the children's conflicts; and secondly by analysing the strategies the children used to resolve their conflicts.

As I have noted already, the development of positive peer interactions can be challenging at times for children and conflicts can be part of the challenge. Epstein (2009) argued that children often get into conflicts with others because children are egocentric and focus on their own needs. They do not mean to be selfish or intend any harm to their peers but because they can only focus on their own goals, they get frustrated when things do not go their way. I have also noted Rose-Krasnor (1997)'s argument that children's goals and values provide the direction and motivation for their behaviours and this has implications for social competence.

In my study, I use the term "motivations" in the manner of Licht, Simoni and PerrigChiello (2008) who studied conflicts between peers in infancy and toddler age through an observational study of 28 children under 2 years old in a Swiss childcare centre. Licht et al. identified seven motivations behind the children's conflicts and argued that possession of objects was not the main reason children get into conflict, as previously believed (Hay, 1985; O'Brien, Roy, Jacobs, Macaluso \& Peyton, 1999). Instead, the dominant reason children found themselves in conflict was because the children wanted to retain their play (Licht et al.). While my analysis also found that possession of an object was not the main reason for children's conflicts, this was still one of the top reasons for the occurrence of conflicts along with interrupted activity, and exploration and curiosity. 
In the second part of the chapter, I present my analysis of the strategies children used in resolving conflicts by drawing on the Relational Model proposed by of de Waal (2000) which focuses on the relational dynamics of conflicts. My analysis found that during conflicts children: seek adults' interventions; give in and walk away; and give an alternative object to peers. These findings suggest that young children are capable of solving their own conflicts even without adults' interventions. However, the children's conflict resolution strategies may not be the most effective and this can negatively affect the development of their social competence (Rose-Krasnor, 1997). I argue that even though children have their own reasons and motivations for engaging in conflicts, and practiced their social competence in resolving conflicts at their childcare centre, they still would have benefitted from guidance from the practitioners to help them develop the most effective conflict resolution strategies.

\subsection{How conflicts arise}

In this first part of the chapter, I focus on understanding why children have conflicts. Understanding what a child tries to achieve in a conflict can help with pedagogical intervention (Licht, Simoni \& Perrig-Chiello, 2008). As explained in the literature review, Licht et al. (2008) used the word 'motivation' in conflicts to refer to a child's specific goal during a conflict. Following Licht et al.'s (2008) approach I identified three main motivations that gave rise to conflicts for the children in my study: (1) the desire to possess objects; (2) interrupted activities; and (3) exploration and curiosity. These motivations are elaborated in the sub-sections below.

\subsubsection{Possession of objects}

Struggles over objects were commonly observed between the children in this study during which the children either showed a need to control an object or defend it from being taken by another child. Licht et al. (2008) mentioned that during these conflicts, four characteristics of possession conflicts were evident: the child's verbal and nonverbal expressions referred to the child's own self like "mine!" or hugging the object to themselves; gestures indicating a bond between the child and the object; the expression of 
intense emotional involvement; and satisfaction from holding the object. In the resultant conflicts, the need to acquire, or hold on to an object was clearly evident whether the child wanted to take an object from another child, or was protecting the object from another child. According to Licht et al. (2008), conflicts involving possession of objects were seen in their study when children were 22 months and older because of the selfawareness element that the children showed. The characteristics of possession conflicts as mentioned by Licht et al. were found in my study too as illustrated in the following events:

One morning in Sunny Childcare Centre, Willy ( $\mathrm{m}, 2 ; 9)$ was playing with some animal figures on his own when Roy's laughter caught his attention. Willy looked in Roy's direction where Roy was happily sitting on a plastic transparent box:

Willy grins as he eyes Roy (m, 2;7 years old) before walking quickly towards him. Willy then squats down in front of Roy and seems to be asking Roy for the box by extending his right hand and saying some (inaudible) words to Roy. Roy ignores Willy by frowning at him and continues to sit on the box while tapping his feet lightly on the ground. Willy frowns in anger and suddenly pulls the box out from under Roy and holds onto it. Roy cries in shock and Willy shouts angry words at Roy while holding on to the box. Roy continues to cry while both of his hands hold on to the box. The boys are now pulling the box towards each other while crying and shouting. Amy, a practitioner who is nearby, looks at them. She then quickly walks towards the screaming boys and takes the box from them. Willy stands against the wall while Roy continues to cry while pointing to the box in Amy's hand. (VOSCC) 


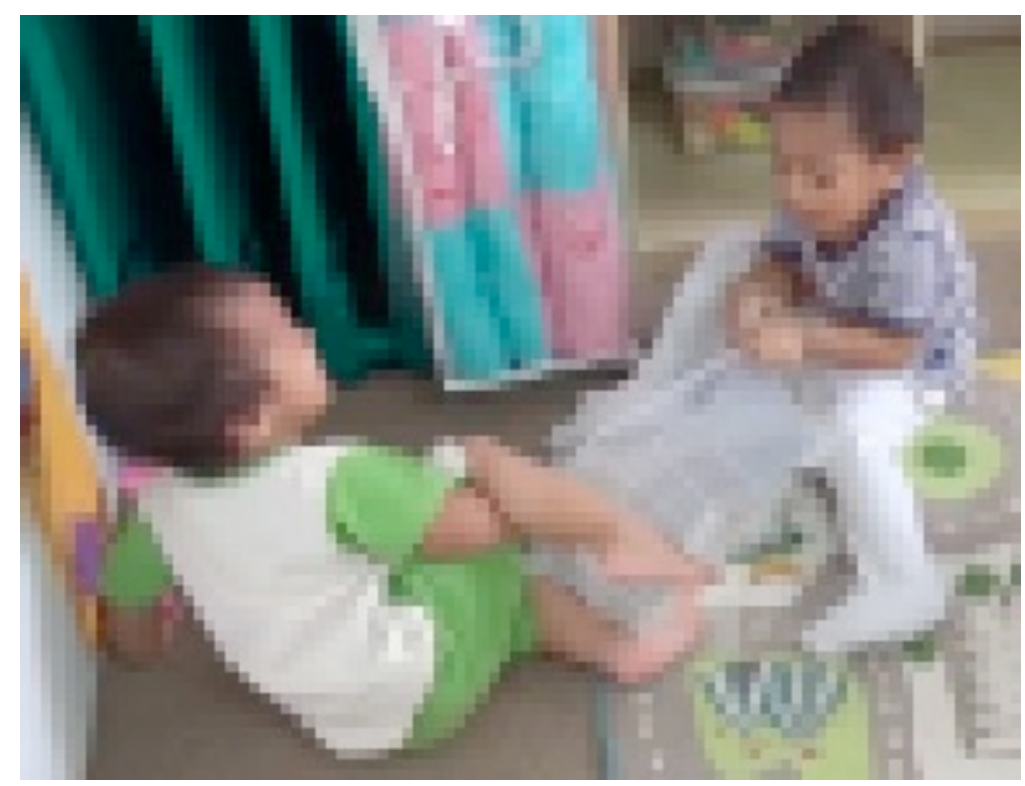

Figure 6.1 Roy and Willy pulling the box

The episode above shows how Willy wanted to play with the transparent box that Roy was playing with after seeing Roy having a good time with it. Willy showed characteristics of wanting to possess the objects (see Licht's et al. 2008) by hugging the object towards himself and expressing intense emotions such as anger, screaming and crying in trying to acquire the object. Even though both of the children did not use verbal language much in communictaion, Willy's gestures and body language clearly showed that he wanted to have the box and when his request was turned down, he became rough to reach his goal: he pushed Roy off the box. Willy's unsuccessful action when Roy did not give up his box, further suggests that Roy was determined to defend his object from being taken. Likewise, Willy also showed determination in achieving what he wanted by defending the box once he got hold of it. Both Willy and Roy also expressed strong emotions such as anger and frustration in gaining the object. It can further be interpreted that Roy was trying to retain his play by protecting his object from being taken from Willy. An adult then intervened in the conflict and the struggle between Willy and Roy stopped there with both the children appearing to be unsatisfied. While Amy's reason in removing the box might be well-intentioned, it could be argued that her action left the children with no room to learn how to solve the conflict either by themselves or with guidance. 
Another example of possession conflict is evident in the episode below. Ibrahim $(\mathrm{m}, 2 ; 5)$ showed characteristics of wanting to possess Ahmad's (m, 2;4) toy with the result that the children got in a struggle over the toy:

Ibrahim looks at Ahmad who is holding a stuffed toy snake. Ibrahim smiles as he looks at Ahmad and walks to him. When he reaches Ahmad, Ibrahim takes hold of the middle part of the snake and starts to pull it towards him. Ahmad looks at Ibrahim's hand on the snake and frowns. Ibrahim pulls the snake harder but Ahmad holds it tightly, protecting it from being snatched. Ibrahim pulls even harder. Ahmad begins to scream while shouting, "Nak!" (I want). Ibrahim starts to scream too while pulling the snake. Their screaming catches the attention of Maria, a practitioner. Maria looks at them and calls out their names, "Ibrahim, Ahmad!" Both of the children ignore Maria. Ibrahim keeps pulling the snake towards him and finally, Ahmad lets go of the snake. As soon as he loses the snake, Ahmad puts his left hand in his mouth, sucking on his fingers. Ibrahim looks at Ahmad for a while before he walks away from Ahmad while hugging the snake. (VORCC)

Clearly, the above episode shows how the desire to possess an object gave rise to a conflict. Ibrahim showed his desire to possess the toy snake after looking at Ahmad playing with it. Like Licht et al. (2008) and Eckerman, Whatley and McGhee (1979) explained, children's desire for an object is often awakened after seeing a peer using the object. Ibrahim's action of taking the snake from Ahmad showed he wanted to take possession of the toy and his satisfaction when he finally got hold of it was clearly evident on his face: he hugged the snake and walked away with it, even though he didn't go on to play with it. He just held on to it while walking around the room. This behaviour is in line with Licht's et al. (2008) explanation of possession conflict where a child demonstrates a need to control the object and feels satisfied just by holding the object. Furthermore, both of the children clearly showed a strong desire to keep the snake and this was seen through their struggle in pulling the snake towards themselves, shouting 
and screaming as well as their deliberate ignoring of the adult's intervention; the latter are also characteristics of possession conflict described by Licht et al. (2008). A practitioner was aware of the conflict but, as in the previous episode, there was a missed learning opportunity to solve the conflict between the children.

These two espisodes are indicative of other instances in my data where the desire to possess an object gave rise to conflicts for the children in this study, as in Licht et al.'s (2008) study. The children did not use many words in communicating what was in their minds but their body language easily showed their desires and goals. Each child was seen to struggle hard to win the conflict, which indicated self-awareness as suggested by Licht et al. (2008) but in the end, not all children were left satisfied after the conflict. Where there were interventions by adults, the children involved in the conflicts lost the object and did not have the satisfaction of possessing it. While the practitioners' goal was probably to end the conflict quickly, in some cases there were missed opportunities for the children to learn about sharing resources and taking turns and to learn how to solve problems. Instead of encouraging problem solving, the practitioners removed the object from the children or called their names without doing anything when one child snatched the object from a peer. This may teach the children that fighting over objects is not an action condoned by adults and, yet also that sometimes they could get away with snatching an object off a person to win a conflict.

\subsubsection{Interrupted activity}

Another impetus for conflict, as observed in this study was when a child's activity was interrupted by his or her peer. As Licht et al. (2008) previously documented, a conflict could arise when a child was occupied with an object and then a peer comes and interrupts the child by taking the object, preventing him or her from concluding the activity. The child then offers resistance that is focused on maintaining or finishing the interrupted activity. Licht et al. argued that this conflict situation is different from conflict about possession of objects because the children involved in this interrupted-activityconflict showed no anger towards their conflict partners but showed a strong desire to have the object back in order to continue with their activity; once the children have the 
object again, they continue with their play. Through their study, Licht et al. found that interrupted activity is a motivation for conflict at all ages of toddlerhood although it decreases with age and suggested that interrupted activity conflicts are common among young children. The following excerpts illustrate Licht's et al. description of motivations for resistance during interrupted activity.

In the episode below, Nani (f, 2;3) was playing on her own when Matt (m, 2;10) came over and interrupted her play. Matt's actions got him into a conflict with Nani:

Nani is picking up small balls around the room and putting them in a transparent plastic box. She places her box near a bookshelf while she runs around the room looking for more balls. Matt looks at Nani from across the room and walks towards her box to get a closer look. Matt looks at the balls in Nani's box with interest. He then sits down and lifts the box and turns it upside down. All of the balls in Nani's box spill out. Nani turns her head at the sound of balls falling and looks at the balls rolling on the floor. When she realizes what Matt has done, Nani screams and cries while flapping her arms. Nani's cries get louder, showing her unhappiness. Matt looks at Nani and then Matt quickly picks up a ball and put it in the box again. Nani stops screaming and crying and then runs to her box. She begins to pick up the balls from the floor and put them in the box again. Matt looks at her for a few second before he walks away from Nani. (VOMCC)

In the episode above, it is clear that conflict between Nani and Matt started because Nani was upset with Matt for interrupting her play and emptying the box of balls on the floor, preventing her from continuing with her play. As described by Licht et al. (2008), this type of conflict showed neither anger nor expression of insult towards the peer but explicitly the desire to have the object back. Nani's behaviour corresponds with this statement because she did not show any sign of anger at Matt even though Matt emptied her box. She was upset with her activity being disturbed and her crying showed this unhappiness. It is evident that Nani wanted to regain her play because she ran to her box 
after Matt put a ball in it and continued with her play. This clearly shows the motivation for Nani's conflict was her interrupted activity.

Another example of interrupted activity that sparked conflict among children can be seen in the episode below in which Ibrahim (m, 2;5) was playing with Ahmad (m, 2;4) when Suzy (f, 2;6) came and disturbed their play, preventing the boys from continuing with their play:

Ibrahim and Ahmad are jumping from one cushion to another in a corner of the room, laughing and squealing as they jump. The noise they make attracts other children in the room. The children turn towards them and watch them jump. Suzy looks at the boys with interest. She has a smile on her face as she watches them. Suddenly, Suzy runs towards Ibrahim and Ahmad and, reaching the cushion area, she quickly lies down on the biggest cushion there with a grin on her face. Ibrahim and Ahmad jump from a small cushion to a big cushion with Ibrahim taking the lead. Ibrahim is about to jump on the biggest cushion when he sees Suzy on it. Ibrahim stops jumping and looks down at Suzy with a frown on his face. He sits down and then hits Suzy's head repeatedly while making a sound, "Hap hap hap." Suzy quickly rolls over and sits up. She frowns at Ibrahim and in an angry voice she shouted some words (inaudible) to Ibrahim. Ibrahim then tries to push Suzy off the cushion but Suzy is not budging from her place. Ibrahim looks at her with a sad face and then he lies down on another cushion, not saying anything. Ahmad looks at Ibrahim and then he too lies down on the cushion next to Ibrahim. The boys lie like that for a few seconds, looking at each other before Ahmad bursts out laughing. Ibrahim laughs too and suddenly a new game has started between the boys. (VORCC) 


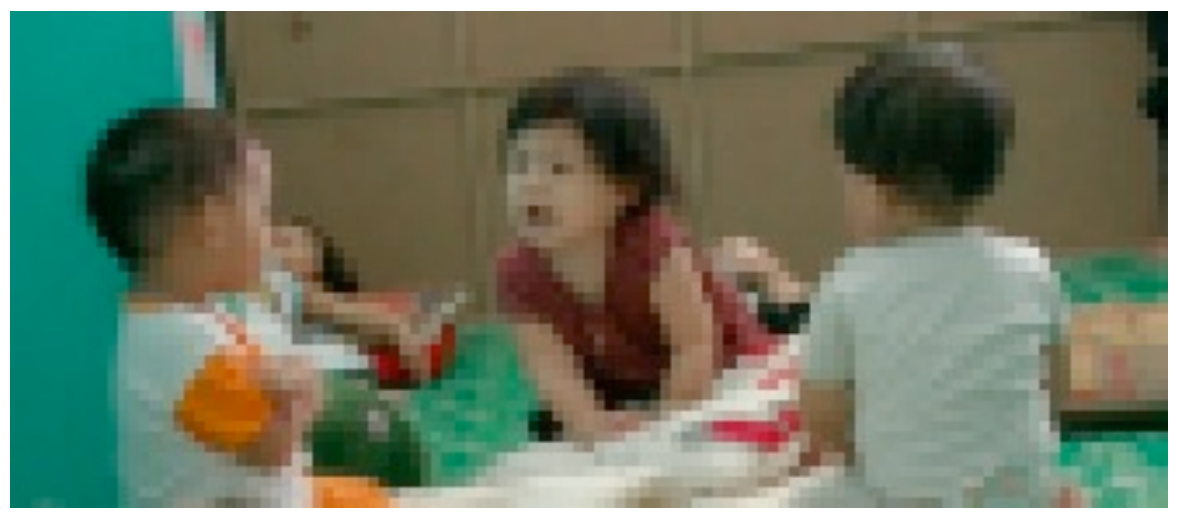

Figure 6.2 Suzy shouted at Ibrahim

At first glance, the children's conflict in this excerpt might look like the boys were upset with Suzy for entering their play area but on closer analysis it was clear that Ibrahim was upset because Suzy was sitting on the cushion which he and Ahmad were playing with. The boys' play was interrupted because Suzy was blocking their jumping activity. In trying to gain back the cushion, Ibrahim hit Suzy's head and also tried to push Suzy off the cushion, which made Suzy angry. Ibrahim's intention did not look like a desire to hurt Suzy; rather he was trying to get the cushion off Suzy. Ibrahim did not seem angry at Suzy, but rather he looked sad when he saw Suzy sitting on the cushion. Ibrahim's behaviour is consistent with Licht's et al. (2008) explanation about interrupted activity as the motivation for this conflict because the child did not show anger or insult towards the peer but only showed his desire to gain back his object. When Ibrahim could not gain the cushion back, he seemed to lose interest in the play and he showed this by lying down on another pillow. In this way, the conflict between Ibrahim and Suzy also ended. This is additional evidence that he was only interested in continuing his play and when his needs were not met, he lost interest in the object. This episode is a clear example of how continuous play was the goal in this conflict.

The two episodes above provide clear examples to how children's activities can break down when other children come and interrupt them. While the children who interrupted the activities showed interest in entering their peers' play, their behaviours did not gain their peers' acceptance, which indicated that the children may need scaffolding in becoming more socially competent. This issue of conflict during interrupted activity can 
be linked to the children's peer culture. According to Corsaro (1981), children constructed their own peer culture when they interacted with peers. Children do not like disruptions during their on-going play and they tend to protect their play space from intruders. Corsaro (1985) stated that interaction among young children is fragile, and peer activities can break down with even minimal disruption; furthermore the need to protect interactive space is a concern shared by all children. This was seen when Suzy was attempting play entry but Ibrahim denied access; and at the same time Suzy's actions caused Ibrahim and Ahmad's play to break down. Corsaro (2003) argued that children are not being selfish by keeping others out, but rather they wanted to protect their play from breaking down and that adults who are not aware of the dynamics of children's culture and the effect of interrupted activities may misunderstand the children's behaviour.

\subsubsection{Exploration and curiosity}

Licht et al. (2008) explained that in exploration conflict, a child first looked at another child manipulating an object and then the child focused on taking the object from the peer with conflicts resulting over the object. As in Licht's et al. study, conflicts often occurred when the children in my study saw an attractive object in their peers' hands and felt the need to explore it, but the peers who had the object were protective of it as illustrated in the episodes below:

One morning in Sunny Childcare Centre, the under-threes were seen to be sitting near a bookcase in their classroom. They were holding a book each. Anna (f, 2;6) was looking down at a book in her lap when she lifted her gaze to look at the others:

Anna looks at her peers who are all looking down at their books. Anna then turns to Willy $(\mathrm{m}, 2 ; 9)$ who is concentrating on his book. She gazes at Willy for a few seconds before she crawls to him and looks over his shoulder at his book. Anna has a slight frown on her face as she is looking at the book. Suddenly Anna snatches the book from Willy. Shocked, Willy looks at Anna with furious eyes and screams at her while trying to pull the book back from her. For a few seconds, 
both of them are holding the book tight, each pulling the book towards them while screaming. Hearing the commotion, Amy (a practitioner) turns to them and says, "Share Anna, Willy. Share!" Anna looks at Amy and lets go of the book. Willy quickly hugs the book to his chest. Anna looks at Willy briefly before she walks to Amy and sits next to her. (VOSCC)

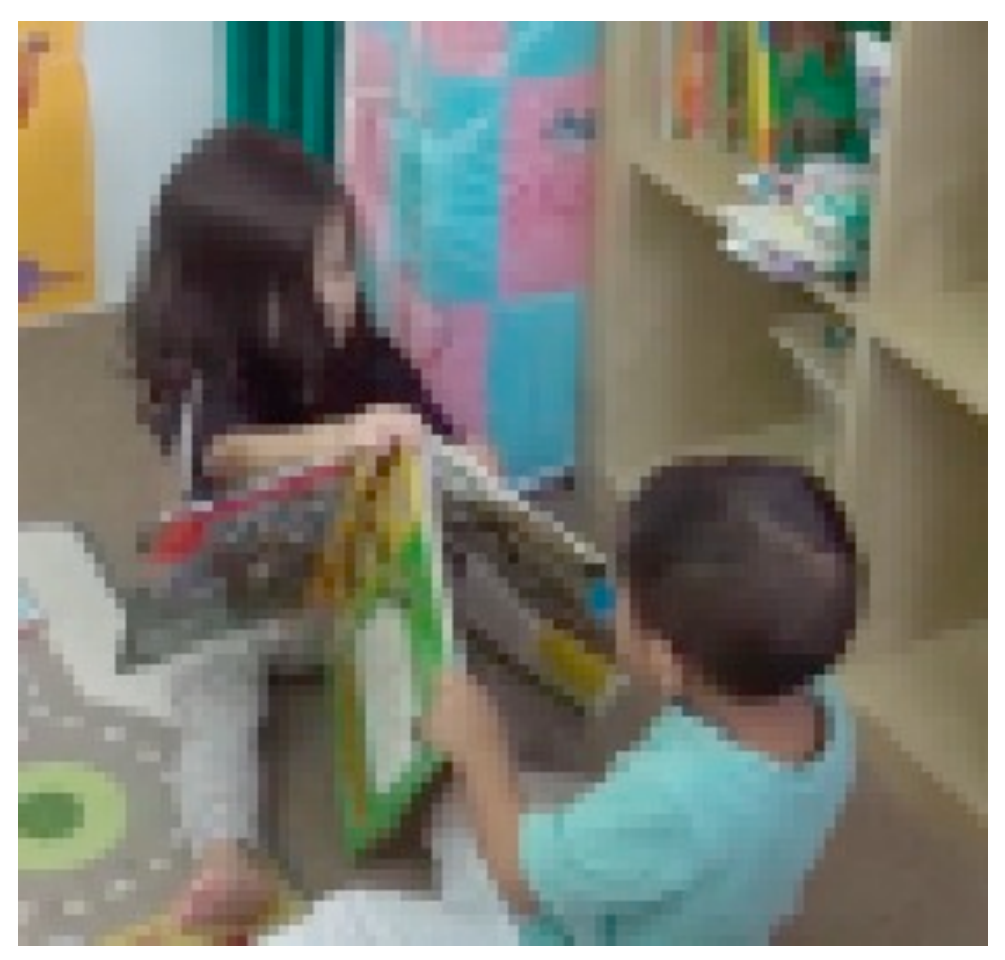

Figure 6.3 Anna and Willy pulling a book

Clearly, Anna was curious to look at Willy's book and explore it as was evident when she crawled to Willy to have a better look. The frown on her face as she looked at the book seemed to show her curiosity towards the book. Anna tried to obtain the book from Willy but her behaviour led her into a conflict with Willy. Anna's behaviour of snatching the book suggests a need to become more socially competent in negotiating with her peers. The practitioner's intervention in the ensuing conflict succeeded in ending the conflict between the children but not in getting them to share the book as she had suggested, in order that Anna's needs be met. This suggests that another strategy is needed in the conflict intervention, not just to end the conflict between the children but to have their 
underlying needs satisfied too. Clearly, the motivation for this conflict was Anna's curiosity and her urge to explore the book.

The following episode from Rainbow Childcare Centre likewise illustrates exploration conflict:

Ibrahim $(\mathrm{m}, 2 ; 5)$ is sitting on the floor and looking around the room. He has just finished playing with a toy and looks like he is looking for something else to do. He spots Fina (f, $0 ; 10$ months) holding a red pouch and observes how Fina is fidgeting with the pouch, turning it over and over. He slowly makes his way towards her and squats down in front of her and pulls the red pouch from her hand. Fina immediately screams. Ibrahim ignores the scream and opens the pouch to look inside. Fina pulls the pouch towards her but Ibrahim holds the pouch tightly to him and continues to look inside the pouch. Fina keeps on screaming. Ibrahim smiles as he peeks inside the pouch. Pouting, Fina grabs the pouch again and this time she is successful. Ibrahim lets go of the pouch and smiles at Fina. Fina returns the smile while patting the pouch. Ibrahim watches her for a few seconds before he stands up and walks away. (VORCC)

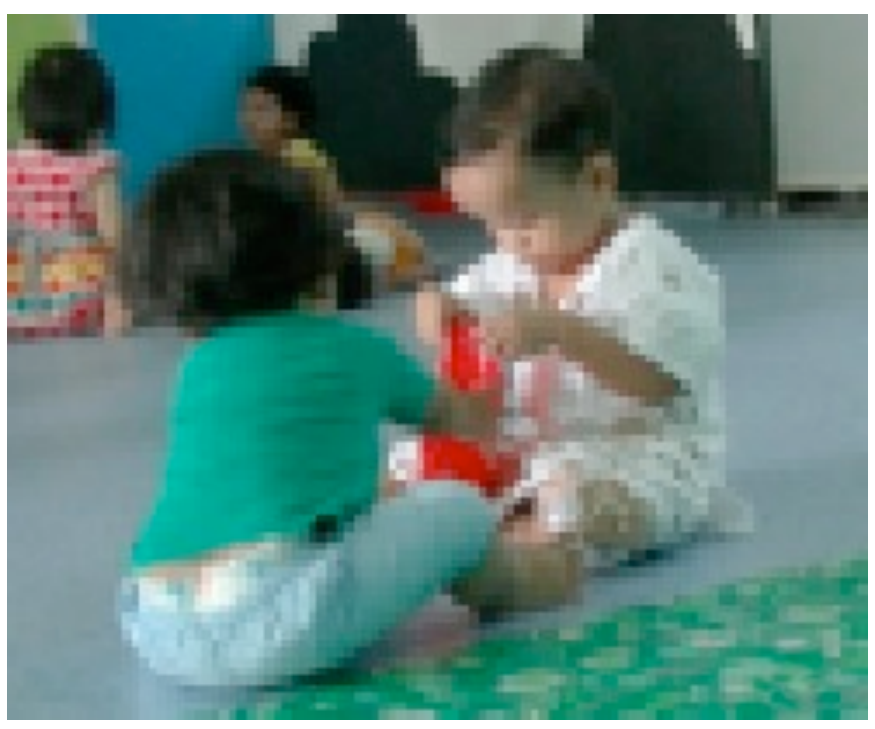

Figure 6.4 Ibrahim was curious about the contents of the red pouch 
As in the previous example, the incident above suggests that the motivation for the illustrated conflict was pure curiosity. Ibrahim looked curious to see what was inside Fina's red pouch and he fulfilled his curiosity by exploring the pouch. Ibrahim snatched the pouch from Fina, which caused Fina to scream but in striving to reach his goal, Ibrahim ignored Fina and strove hard to look inside the pouch. Once he succeeded, he smiled at Fina, signaling that his goal had now been achieved: he had satisfied his curiosity. Interestingly, Fina smiled back at Ibrahim maybe to show her happiness in gaining back the pouch or perhaps as an initiative at reconciling their conflict. According to Singer and De Haan (2007), ignoring peers and smiling at them are common strategies used by children to prevent escalation of a conflict. As can be seen in the episode above, Ibrahim used both strategies during the conflict and Fina chose to return Ibrahim's smile which may indicate that both of the children were not interested in prolonging the conflict.

The two episodes above show how the children were curious about their peers' objects and how their curiosity and exploration gave rise to conflict because their peers did not want to be disturbed. In fulfilling their goals, the children showed determination in exploring the objects and used strategies such as getting close to a peer, looking and then grabbing the object to have a closer look. According to Licht et al. (2008), children have a natural urge to explore their surrounding and this type of conflict arises out of their pure curiosity and exploration needs. It is natural for the children to see an object in another child's possession to be attractive and thus they want to have a closer look at it (Eckerman et al., 1979). Both of the episodes neither showed jealousy of peers' object nor drive for possession of the object; they simply wanted to have a look. So, this suggests that the children's motivation for the conflicts above were due to exploration as termed by Licht et al. (2008).

To recap this first section of the chapter, there were three dominant motives that gave rise to conflicts for children under threes in the three Malaysian childcare centres in my study: possessions of objects, interrupted activities, and exploration. This concurs with Licht's et al. (2008) study where he also found the three motivations to be the main reasons for children's conflicts. Understanding the underlying reasons behind the children's conflicts 
can help practitioners at the childcare centres with pedagogical interventions, not just an intervention to end the conflict but interventions that can help the children with problem solving. This in turn can help children to become effective in peer interactions, which can help them succeed in social competence (Rose-Krasnor, 1997). In the next section of this chapter, I will present how children in this study resolved peer conflicts.

\subsection{Resolving conflicts}

In this second part of the chapter, I focus on how children resolved their conflicts with their peers. According to Majorano et al. (2015), conflicts are common in children and they are actually natural elements of peer interactions and exploration of the environment. Many researchers claim that peer conflicts have significant value in the children's social development (Chen et al., 2001; Doppler et al., 2002; Singer et al., 2012) not the least being that they learn to deal with them. This idea is not new as Piaget's work (1932) suggested that children would become more mature in their social skills when they have the opportunities to participate in resolving their own problems. When adults are not present during the children's conflicts, the children have to rely on their own strategies to end the conflict: while Chen et al. and Doppler et al. argued that children are capable of resolving peer conflicts without any adult intervention, Arcaro-McPhee, Doppler and Harkins (2002) found that young children would engage in conflict resolution strategies when provided with opportunities to practise these skills. Throughout this study, I observed three major conflict resolution strategies by the children, which are: seeking adult's intervention; giving in and walking away; and giving their peer an alternative object. de Waal's (2000) Relational Model was used to analyze the findings of the children's conflict resolution strategies. As discussed in chapter two, The Relational Model focuses on the relational dynamics of conflicts which suggest that a conflict may help to define the relationship between opponents, resulting in a more intimate and productive relationship. I begin by describing the first conflict resolution strategy used by the children during their conflicts and discuss what it means for their learning. 


\subsubsection{Seeking adult's interventions}

Van Hoogdalem et al. (2008) argued that young children rely on the adults around them when they are in emotionally uncertain situations, such as conflicts. Through my observations, I saw many instances that supported Van Hoogdalem et al.'s argument as in the examples below:

Willy ( $\mathrm{m}, 2 ; 9)$ was playing with a bead maze on his own near some bookshelves when he looked at Roy (m, 2;7). Roy was sitting inside a transparent plastic box and seemed to be content playing by himself:

Willy watches with interest as Roy squeals happily inside his box. He then runs quickly towards another identical box nearby, on the way picking up a toy sword from the floor and then climbing inside the box like Roy. Willy sits in his box squealing and screaming with glee. Roy turns to look at Willy and smiles. Willy returns the smile and then Willy hits the side of his box with his toy sword. Bang! Bang! Bang! Willy keeps hitting his box with his sword. Roy eyes Willy's sword eagerly. Willy hits his box again: Bang! Bang! Bang. Grinning, Roy climbs out of his box and runs to Willy. He touches Willy's sword and then tries to snatch the sword from Willy. Frowning, Willy holds on tight to his sword. They both fight over the sword for a while, screaming while pulling at each end of the sword. Then Roy lets go of the sword and Willy now has it back. Just then, Amy (a practitioner) walks in the room and Roy quickly looks at her and says, "Share share!" while pointing to Willy's sword. Willy frowns at Roy and shouts angry expressions to Roy who runs to Willy and tries to grab the sword again. Amy looks at them. Willy holds the sword tightly and starts to run too. Not giving up, Roy chases Willy. They run around in circles while shouting and screaming. Amy raises her voice and says, "Give it to me, Willy" and she walks to Willy and takes the sword from his hand. She then says, "Thank you". Willy just looks at her and stands still against a wall. Roy walks to Amy and tries to take the sword from Amy's hand while saying, "Share share!" to which Amy replies, "No, this is mine." Roy starts to cry while Willy looks at them briefly before he walks away. 
Interestingly, the children were seen to be playing another game together a few minutes after this conflict. (VOSCC)

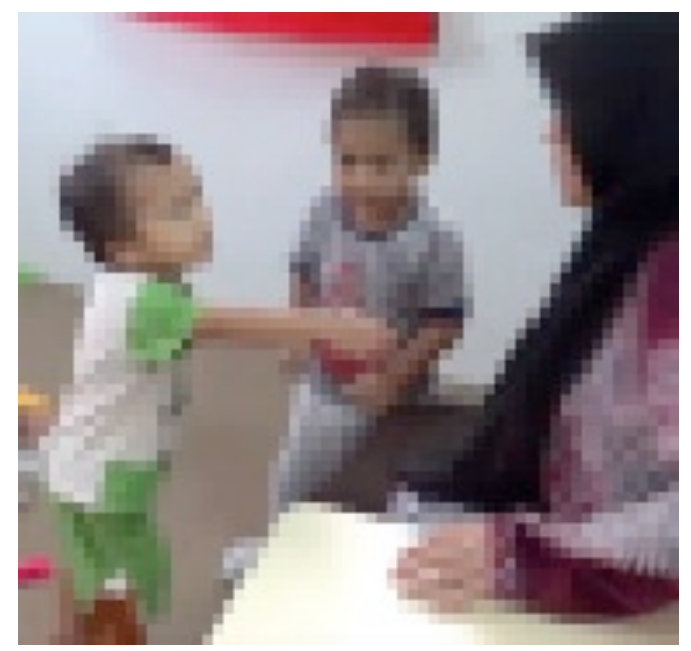

Figure 6.5 Roy asking for an adult's intervention

In the episode above, Roy wanted what Willy had and tried to snatch the sword from Willy who wouldn't let go of it. As soon as Roy spotted an adult, he looked at the adult and said, "Share Share!" while pointing to the sword. However, Amy did not immediately intervene in their conflict, but watched them for a while before she intervened. When the boys kept on fighting over the sword, Amy intervened by taking away the sword from Willy. Willy accepted that the sword was lost and walked away but Roy insisted on having it by saying, "Share share!" to Amy. This indicated that Roy was asking for the adult's help in acquiring the sword while Willy yielded. Using the perspective of the Relational Model (de Waal, 2000), the children were competing over an object. They used both verbal and non-verbal gestures to express themselves but they did not show any aggression towards each other. de Waal's Relational Model predicts that the tendency to initiate aggression increases with the number of opportunities for competition, the resource value, and the reparability of the relationship, while it decreases with the risk of injury and the value of the relationship. It is possible that Willy valued his relationship with Roy, because the practitioners did mention that they were good friends, and thus he may not have wanted to risk the relationship by being too aggressive. de Waal (2000) further explained that aggressive behaviour, tolerance and avoidance of 
confrontation are three possible ways in which conflicts of interest are settled. While aggression and tolerance were not visible during this conflict, the act of avoidance was seen in Willy when he made the decision to walk away without defending his object from Amy or Roy. After a while, the children were seen to be playing together happily, which indicated that even though they were in a conflict not long before, they were able to play together again. This is what de Waal (2000) labelled as the reparability of the relationship, meaning that despite the conflict, young children are capable of undoing the damage to the relationship and reconciling without any adult's intervention.

Another example of a child seeking an adult's intervention is presented below. In this episode, Sulaiman $(\mathrm{m}, 1 ; 1)$ was involved with Omar $(\mathrm{m}, 1 ; 11)$ in a conflict over a card that Sulaiman was holding:

Sulaiman is walking about the room with a card in his hand. As he walks, he looks at Omar who is standing against a wall and looking about the room. Probably sensing he is being watched, Omar turns and looks at Sulaiman. $\mathrm{He}$ notices the card in Sulaiman's hand and walks quickly to Sulaiman and reaches for the card in his hand. But Sulaiman sways his hand out of Omar's reach while making a distressed sound: "Arghhh". Omar frowns at Sulaiman and tries to take the card again but he accidentally pushes Sulaiman who falls and lands on his bottom crying. Sulaiman quickly looks at Khalila, a practitioner who is nearby, and points his finger at Omar. Khalila has witnessed everything and she calls out Omar's name. Omar looks at Khalila with wide eyes and walks away from Sulaiman. Sulaiman stops crying and looks at the card in his hand. He continues to sit there for a while, tossing and turning the card while babbling on his own. (VORCC)

Omar seemed to be curious about what Sulaiman was holding and wanted to have a closer look. However, his motivation to explore the card resulted in a struggle with Sulaiman who did not want to let go of the card. Omar ended up in an open conflict with Sulaiman but was not successful in reaching his goal. According to de Waal (2000), when 
damage to a relationship is repairable, open conflict becomes more likely. Omar may have predicted that his relationship with Sulaiman was repairable because on later occasions they were seen to play together, laughing and smiling. This also indicates that young children are able to reconcile successfully after a conflict. However, during this conflict, Sulaiman was clearly upset with Omar's behaviour and as a strategy to resolve the conflict, Sulaiman sought an adult's intervention. While Sulaiman could not use words to tell what happened, he pointed his finger at Omar as if to tell Khalila that Omar bothered him, thus successfully using his non-verbal cues to communicate. Sulaiman's success was evident when Omar walked away from him immediately after the adult intervened and thus ended the conflict. However, from the perspective of practices that enhance social competence, one can also see this interaction as a missed opportunity for learning about respecting others' space and about taking turns. As it was, the practitioner did not comment on anything beyond calling Omar's name and when Omar walked off, the practitioner left it at that.

The two episodes above show one of the dominant strategies children used in attempting to solve their conflict with their peers: seeking an adult's intervention. As also illustrated in the examples above, children used other strategies prior to looking for an adult. They tried to protect their objects from being snatched by holding on to them, they screamed, shouted and made some disapproval noises at their opponents. When all these efforts were not successful, then the children looked for an adult's intervention. This is natural because often children rely on adults for protection (Chen et al., 2001; Gloeckler et al., 2014). However, researchers disagree about, and often question, the efficacy of adult intervention in children's conflict because adults appear to end children conflicts quickly rather than taking advantage of them as teachable moments (Bayer et al., 1995; Gloeckler et al., 2014), as was the case in both the two episodes above. When adults intervene, the conflict usually ends with children walking away from the scene, leaving no opportunities for the children to solve the conflicts themselves or be guided by the adults on solving the conflicts (Gloeckler et al., 2014). In the rest of this chapter, I present how children resolved their conflicts without any adult intervention. However, I argue that 
interventions from adults could get the children to learn the best problem solving for their situations, resulting in a balance of self and others' need in order to be socially competent.

\subsubsection{Giving in and walking away}

According to Gloeckler et al. (2014), young children may engage in object conflict even though plenty of other materials are present or when duplicate objects are available (Caplan et al., 1991). In their study of conflict and its resolution in small groups of oneand two-year-olds, Caplan et al. (1991) found that when adults did not intervene in children's conflicts, $89 \%$ of the conflicts were resolved with the children yielding to their peers' desires. Similarly, in my study I have observed that another major conflict resolution strategy the children used was giving in to a peer's desires and walking away from the peer. The examples are illustrated in the episodes below.

Anna (f, 2;6) and Ina (f, 2;8) from Sunny Childcare Centre got into a conflict when both of them wanted the same book. Ina tried to prevent the book from being snatched away from her but Anna was determined to have it:

Anna is sitting near a bookshelf and seems to be looking at pictures in a book. After a few seconds, Anna puts her book down on the carpet and looks at Willy who is also looking at a book. At that moment, without Anna realizing it, Ina walks to Anna's book on the carpet and picks it up. Anna meanwhile is still looking at Willy and seems interested in what he is reading. Anna walks to Willy and touches his book. Willy looks up at Anna and screams. A practitioner, Amy, looks at them and asks Anna, "Where is your book, Anna?" Anna looks at the carpet where she has left the book and frowns. Continuing to look around for her book, she spots it in Ina's hand. Anna looks at Amy and points her finger at Ina. But Amy is not looking at Anna anymore and does not see her pointed hand. Anna keeps looking at Ina with a disapproving look and then screams and runs towards her. Seeing Anna coming towards her, Ina immediately lifts the book up over her head and out of Anna's reach. Anna tries to grab it by stretching her hands upwards and jumping to reach the book but to no avail. Anna keeps 
screaming while trying to get the book. After a while, Ina brings the book down and hands the book to Anna. Anna quickly takes the book from Ina's hands and runs to a corner with the book. Then Anna flips open the book and looks at the pages while Ina sits down on a chair and plays with some dolls. (VOSCC)

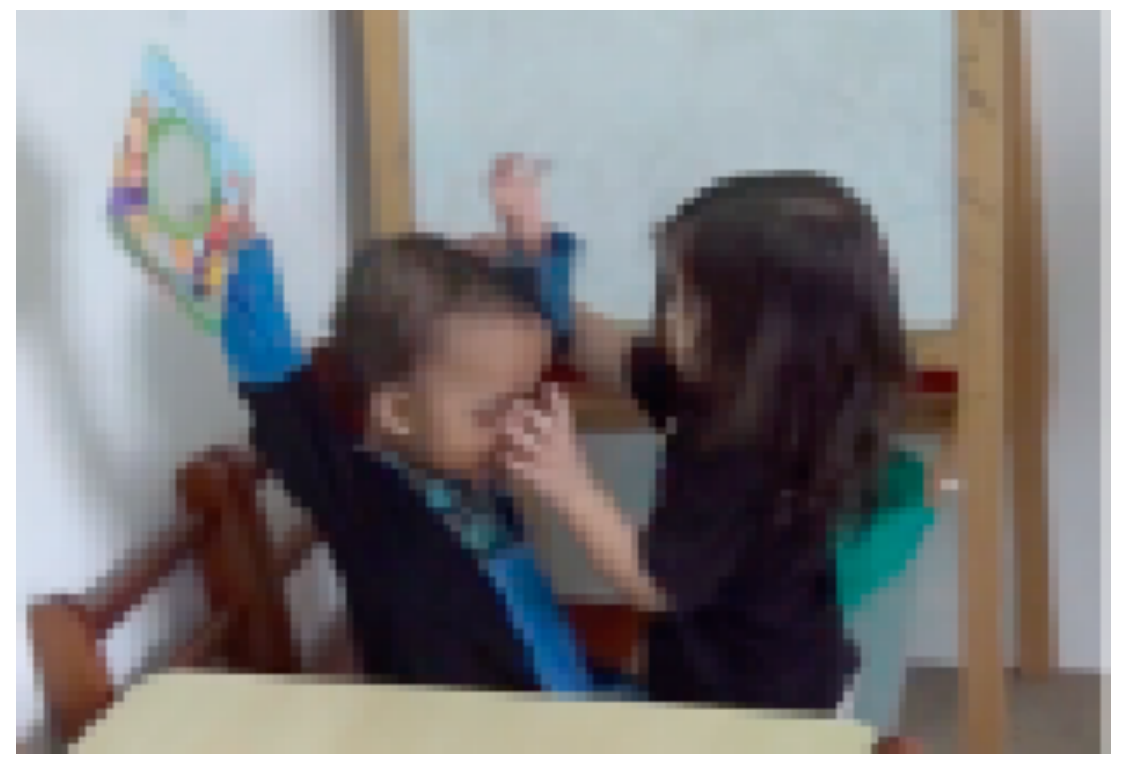

Figure 6.6 Ina and Anna having a conflict about a book

The episode above is an example of how two children got into a conflict over a book. No adult intervened in this conflict and after a number of unsuccessful attempts by Anna to retrieve the book by screaming, Ina gave in and let Anna have the book back. The conflict ended there and the children were seen to do their own thing after that. This is evidence of how young children below the age of three are capable of solving their own conflicts. de Waal (2000) noted that three of the several ways to resolve a conflict are: aggression, tolerance and avoidance. In this episode, Ina was seen to yield to Anna's wishes and I interpreted her behaviour as using the avoidance strategies in settling the conflict. Ina gave the book back to Anna, which suggested she avoided a prolonged conflict with Anna. In line with Singer and De Haan (2007), giving in is a common strategy used by children to prevent the escalation of a conflict and this was seen in Ina's behaviour in the episode above. 
In other situations, I have observed how children also gave in to their peers involuntarily, that is because they had no other option in those situations. Such a situation was not described in de Waal's (2000) Relational Model but I encountered a number of examples of it in my data. I present one example below in which Sulaiman $(\mathrm{m}, 1 ; 1)$ gave in to an older peer, Dahlia (f, 2;0) and thus ended the conflict between them:

Sulaiman is playing with a rubber dinosaur and a toy car alone on the floor. He seems to be making noises with his mouth as he plays. Dahlia, who is sitting across the room, seems attracted by Sulaiman's noises and observes him. After some time, Dahlia walks quickly towards Sulaiman and snatches the dinosaur from his hand. Sulaiman looks up at her in shock and quickly moves to pull tightly on one of the dinosaur's legs while screaming. Dahlia tries to pull the dinosaur away from Sulaiman but Sulaiman won't let it go. Dahlia screams. Both of them are holding one end of the dinosaur while screaming at each other. After a few more seconds of pulling, Sulaiman gives in by letting go of the dinosaur. Dahlia hugs the dinosaur to her chest while smiling. Sulaiman looks at Dahlia for a little while and then he stands up and walks away from her. (VORCC)

It is clear that Dahlia wanted Sulaiman's toy and her behaviour of snatching it from Sulaiman put the children into a conflict. Dahlia's motivation for this conflict was possession of the dinosaur because she was seen to hug the object to her chest and did not show any sign of giving the object back to Sulaiman. Dahlia used physical force to get what she wanted. Sulaiman probably had no intention to get into a conflict with Dahlia. He was only trying to protect his object from being taken. Initially both children would not let go of the toy and they screamed to show their anger and frustration. The conflict between them ended without any adult intervention when Sulaiman gave in to Dahlia by letting go of the toy and walked away from the scene. In line with The Relational Theory (de Waal, 2000), Sulaiman's behaviour showed tolerance and avoidance. Instead of letting the conflict escalate, Sulaiman ended the conflict by using the strategy of giving in and walking away from Dahlia. My analysis suggests that apart from what de Waal (2000) described as tolerance and avoidance, Sulaiman had to involuntarily let go of his toy 
because Dahlia was older and had the advantage of being stronger than Sulaiman. Thus Sulaiman may have predicted he could not win the conflict and decided to give in to Dahlia's desires. Another way of looking at it is that Sulaiman might not find the object worthy of his struggle and that he chose to let it go as suggested by de Waal (2000) who argued that the resource's value does have an impact of a person's decision whether to carry on fighting for the object or not.

Age and strength could be factors to yielding and walking away from conflicts but in the episode below, I present an example of two similar age infants having a conflict over a ball and Zara (f, $0 ; 10$ ) giving in due to getting into a conflict involuntarily too. The example below also shows how an infant is capable of resolving a conflict without any intervention of an adult.

Zara is exploring a ball that she has found under the cot. Zara looks at it with interest, turning it around and looking at it from every possible angle. As Zara is preoccupied with the ball, Mimi (f, 0;11) watches her in silence with her mouth hanging open. After a few seconds, Mimi crawls towards Zara and touches the ball. Zara looks at Mimi and frowns. Oblivious to Zara's frown, Mimi squeals and laughs as she continues to touch the ball. Zara keeps on frowning and then pulls the ball towards her. Mimi gives another squeal and pulls the ball towards her too. They are both pulling the ball towards them now and as they are pulling, the ball rolls on the floor. Mimi quickly crawls to the ball and picks it up. Zara looks at Mimi and the ball for a few second with a disapproving look before she crawls away to another toy. (VOMCC)

Clearly, the example above shows how an object in a child's hands attracts the attention of another child. Conflict between Zara and Mimi occurred when both of them wanted the same ball. While probably feeling angry with Mimi for taking her ball and disturbing her play, Zara chose to give in to Mimi and crawled away, which ended their conflict without any intervention from an adult. Interpreted from the perspective of the Relational Model of conflict (de Waal, 2000), Zara showed avoidance and tolerance in ending her 
conflict. She avoided being in a more complex conflict by not going after the ball when Mimi took it, and tolerated Mimi's behaviour. From my analysis, Zara might have given up the ball involuntarily because the ball was already in Mimi's hands but she also could have done so to avoid further conflict, which indeed ended the conflict.

All of the episodes above illustrate how children below the age of three are capable of resolving or ending their own conflicts without any intervention from adults. It was notable that when adults were not within their proximity, the children did not search out an adult to intervene in their conflicts. Instead, they took the initiative to solve the conflicts themselves. The episodes above showed how the children gave in to their peers and walked or crawled away from the areas. According to Singer and De Haan (2007), giving in to their peers is a common strategy in resolving conflict because it prevents the conflict from becoming worse. In reference to the Relational Theory by de Waal (2000), children who gave in to their peers during conflict displayed tolerance and avoidance in settling the conflict which may suggest that the children valued their peer relationship, or did not want to take the risk of getting injured, or both. My analysis recognized that the children might also give in to conflicts and walk away because of situations over which they had no control, such as the age gap, their relative physical strengths, and proximity of object. At the same time, while the children showed themselves capable of ending their conflicts without the adults' help, the episodes above clearly showed a number of missed opportunities for learning to take turns and sharing their resources. An inescapable implication from these findings is that it would be beneficial for the children to have adults' interventions from time to time especially in guiding them into effective problem solving where both parties are satisfied with the outcome. 


\subsubsection{Giving an alternative object}

The final conflict resolution strategy I observed in my study involved the children giving an alternative object to their peers. Children have been observed to offer objects to their peers to enhance tolerance (Verbeek, Hartuo \& Collins, 2000) and to restore interactions with their peers (Singer \& De Haan, 2007). The examples below illustrated this strategy:

Willy $(\mathrm{m}, 2 ; 9)$ was playing alone with some toy eggs on the floor when Ina (f, 2;8) came and sat in front of him to watch him play. After watching him for a while, Ina wanted to take one of the eggs but Willy would not allow it:

Willy hits the eggshells with a toy hammer to crack the eggs open and smiles when he is successful. Ina seems curious and walks slowly to Willy to have a closer look. She sits in front of Willy and watches him play. Willy does not seem to be bothered by Ina's presence and keeps repeating his actions, hitting the eggshells one by one. After some time, Ina takes one of the eggs from Willy's pile and looks at it. Willy immediately shouts at her while frowning. Ina looks up at Willy and frowns too. Then she puts the egg behind her back. Willy screams and tries to snatch the egg from Ina's hands but Ina holds the egg tightly. Willy casts his eyes at a shelf nearby, runs to it and takes some dinosaur figurines from there. He then hands the dinosaurs to Ina. Ina looks at the dinosaurs in Willy's hand for a few seconds before she takes them. She then hands the egg back to Willy. Willy takes it quickly and continues his activity while Ina walks away with the dinosaurs. (VOSCC)

Willy's offer to Ina of an alternative object to play with ended his conflict with her. No adult intervened in this conflict. In retrieving the egg from Ina, Willy at first used physical force by trying to snatch the object to achieve his goal but was not successful. Willy then gave Ina an alternative object, which was successful. Ina showed what de Waal (2000) termed as tolerance in her behaviour when she accepted the object and gave the egg back to Willy. The tolerance in Ina's behaviour showed how she understood 
Willy's intention and thus ended the conflict between them enabling Willy to continue with his play.

The peer conflict that Kira (f, 2;3 years old) was involved in below is another example of the strategy of giving an alternative object to end a conflict over objects. However, Kira was not as lucky as Willy because her peer did not accept her alternative object. In the following episode, Rafiq (m, 1;4) was interested to play with Kira's box:

Rafiq is sitting on the floor, looking at everyone in the room. His eyes look from left to right as if scanning the room stopping on Kira who is holding a box and is putting small balls into it. One by one, she picks up balls from the floor and puts them into her box. Rafiq squeals as he looks at her and crawls towards her. When he reaches Kira, he sits in front of her box and grabs hold of the box. Kira looks at Rafiq and scowls, then lifts her hand and hits Rafiq's face. Rafiq cries, putting his hand to his face. Kira watches as Rafiq cries. Then Kira grabs a ball from the box and drops it on Rafiq's lap. Rafiq stops crying and looks at it. He smiles at the ball before he grabs hold of the box again. Rafiq looks inside the box and seems to be delighted to see the balls in the box. Again, Kira scowls at him. Then Kira takes another ball from the box and drops it on Rafiq's lap again (repeating the action she had successfully tried earlier). But this time, Rafiq does not look at the ball on his lap and instead keeps on looking at the balls in the box tilting it towards his side. Kira lets go of the box and just looks at Rafiq. After a few seconds, Kira takes two balls from the box and hits them together. She smiles at her balls and goes on playing with them while Rafiq plays with balls on his own. (VOMCC)

Clearly, it can be seen that Rafiq was interested in Kira's box. Kira tried to protect her box from being taken by acting aggressively. According to de Waal (2000), aggression is one way to end a conflict but in Kira's case, her aggressive behaviour was not successful because Rafiq did not go away. Instead, he stayed where he was, crying. Kira then used a second strategy, which was giving an alternative object to Rafiq. Rafiq seemed delighted 
by the ball at first but his interest did not last long because he turned his attention to Kira's box again. Kira's scowl showed that she was bothered by Rafiq's presence. Kira's second attempt to lure Rafiq away from the box by giving him two balls did not work and it can be seen from her facial expression that she was disappointed. The conflict ended when Kira showed tolerance, which the Relational Model described as another strategy used in settling a conflict. Kira yielded to Rafiq's desire and let him share the box with her, possibly to avoid a more intense conflict ahead. Kira must have weighed her options and decided not to go ahead with the conflict and shared her resources instead.

Again, the two episodes above showed how the children in my study were capable of ending their own conflicts without any intervention from the practitioners. Giving an alternative object to a peer was the third dominant strategy used by the children in this study in settling their conflicts. The strategy can be successful as well as non-successful like in the example of Kira but the children were resourceful in finding other alternatives to solve the conflict such as yielding and giving in to a peer's desire. When one strategy did not work, they tended to find another strategy to end the conflict. However, a lot of missed opportunities for learning occurred when no practitioners intervened in the conflict. For instance, the children could have learned about turn taking, sharing, give and take and respecting personal space instead of always yielding and giving in to a dominant peer's desires. Thus, the need for practitioners to intervene in children's learning is highlighted.

\subsection{Chapter Overview}

Taken together, in this chapter I have described and discussed how conflicts were observed to arise between children under three years old as well as the strategies they used in order to resolve or end their conflicts. Guided by Licht's et al. (2008) study on children's conflicts, three dominant themes capture the issues around which conflict arose: Possessions of objects, interrupted activity, and exploration and curiosity. During these conflicts, the children showed willpower to win their conflicts and used many strategies in reaching their goals even if some of them were not the most peaceful strategies to use with others, such as hitting and snatching objects. The rationale for investigating the 
motivation for the children's conflicts is that it can help practitioners with pedagogical interventions that could help the children with problem solving more effectively.

As I have discussed, when the practitioners' interventions were few and limited, the children were seen to solve their conflicts by themselves. My analysis of children's behaviour in resolving peer conflicts utilized de Waal's (2000) Relational Model, which explains the relational dynamics of conflicts. Three themes emerged from this analysis showing that children attempted to resolve their conflict by: seeking an adult's intervention; giving in and walking away; and giving an alternative object to peers. In regards to the Relational Model of de Waal (2000), the children were seen to use all three suggested ways in settling a conflict, which are aggression, tolerance and avoidance. Most of the time throughout my observations, the children opted for tolerance and avoidance rather than aggression and this can be seen in their behaviours through their non-verbal cues and body language. My analysis also recognized an additional way that children resolved their conflicts with peers, which was to involuntarily back off in situations they could not control or in which they could not exert power. In other words, some children involuntarily had to give up the fight due to stronger or older opponents.

This issue of children involuntarily giving up a fight due to inequality of power raises questions on missed learning opportunities about equality and the sharing of power. In the examples discussed in this chapter, practitioners were seen to be absent during the children's conflict. Even though it is important to give space to children to interact with their peers, it is also important to know when to step in (Gloeckler, Cassell \& Malkus, 2014), for example, stepping in when more powerful children are taking advantage of the less powerful children. Thus, practitioners have to be alert and keep a look-out when children are in conflict. Again, this might require training or learning about children's conflicts and about strategies of how to intervene in their conflicts. One suggestion is to use mediation strategies (which were lacking among the practitioners in my study. See chapter 4) when practitioners see such inequality (Kreidler, Whittall \& Tsubokawa, 1999). A practitioner can immediately go to the children who are in conflict and sit with them to help them work to out their conflicts by creating an environment where problem 
solving can take place. The practitioner can acknowledge the children's feelings of hurt and frustrations as well explain about ground rules of no snatching or taking turns with the objects. With young children, things may take time but the learning that comes from it will be worth it (Kreidler, Whittall \& Tsubokawa, 1999). This also hints at the importance of the hidden curriculum which practitoners must not lose sight of (Lee \& Recchia, 2008). Teachers will need to make a conscious effort to demonstrate how power can be shared by being role model themselves or talking about it with the children, showing the consequences for others and the impact of their choices on others (Lee \&Recchia, 2008; Goodman, 2000). According to Lee and Recchia (2008), teachers often ignore the power dynamics between children and this leads to missed opportunities to raise questions about children's behaviours. Feelings of discomfort experienced by children must be recognized and validated so that children can reflect on it and learn how to share their power with others thorugh the guidance of the practitioners (Lee \& Recchia, 2008).

All in all, conflicts can give opportunities for children to learn and practise their social competence because through conflicts children can learn about sharing, turn taking, being a responsible friend, to name a few. This can benefit the children in terms of increasing their social and problem solving skills (Piaget, 1932; Arcaro-McPhee, Doppler \& Harkins; 2002). In regards to the Social Competence Prism of Rose-Krasnor (1997), children have to learn social skills including social problem solving skills to become socially competent. For children under three, they may need scaffolding in learning about these social skills. However, the practitioners in this study appeared to be generally absent during the children's conflicts, which made for missed opportunities for learning for the children. In the next chapter, I put my focus on the practitioners' reflections on the children's peer interactions as these became evident during video-stimulated recall discussions and in focus groups. I focus also on their thinking about what children's peer interactions means for children's learning. 


\section{CHAPTER SEVEN \\ REFLECTING ON PEER INTERACTIONS: \\ PRACTITIONERS' VIEWS USING VIDEO-STIMULATED \\ RECALL AND FOCUS GROUP DISCUSSIONS}

\subsection{Introduction}

In this chapter, I once again return to the first research question of this study, which was to find out how practitioners perceived peer interactions among children under three years old in childcare centres in Malaysia. As in chapter 4, where I first addressed this question, I use Super and Harkness' (1986) concept of the psychology of the caregiver to frame my discussion, but whereas in chapter four I presented an answer to this question based on data collected through the semi-structured interviews with practitioners at the start of the project, in this chapter I turn my attention to the data collected after I had conducted case study observations of the children's peer interactions in the project.

During this latter phase of the study I showed the practitioners video excerpts from the children's interactions I had observed among peers and asked them to reflect on what they thought was going on for the children; I subsequently also held focus group discussions with the ECCE practitioners using probing questions to engage them in deeper discussion on the topic. As elaborated in more detail in the literature review and chapter three, Super and Harkness's (1986) concept of the 'developmental niche' proposes that caregiving and childrearing are underpinned by the caregivers' psychology. In chapter four, I argued that in the early interviews the practitioners' discussions revealed that their psychological orientation to peer interactions appeared organized around two key themes: their role as facilitators of group activities for the children; and their role as managers of children's conflicts. In this chapter, I present data from the latter part of my study, which suggests that the process of being involved in the study, and the opportunity to discuss peer interactions among under-three year olds during videostimulated recall interviews, had opened the practitioners' eyes to the many learning that 
were happening for the children during peer interactions. I discuss these learnings under three key themes: (1) learning outcomes of play; (2) learning outcomes of familiarity; and (3) learning outcome of having friends, drawing also on Rose-Krasnor's (1997) Social Competence Prism to frame up the overall chapter on how the practitioners understood the contribution of peer interactions to the children's social competence.

\subsection{Learning outcomes of play}

The idea that play is an important part of childhood and contributes to learning in a myriad of ways was a dominant theme in how the practitioners perceived peer interactions among the children. As numerous theorists and researchers have said, play enables children to learn about and explore the world around them (Aureli \& Colecchia, 1996; Elkind, 2007). Mayall (2002) views children's engagement in play as leading to the construction of knowledge, ideas and meanings. Tahmores (2011) said that play is important for the children's mental development because when children play they learn to communicate, solve problems as well as have a chance to develop their creativity. Educational theorists such as Jean Piaget and Lev Vygotsky both emphasized the importance of play in promoting children's cognitive development. Piaget argued that children actively acquire knowledge through playing in the environment while Vygotsky stated that play is the source of learning and provides opportunities for interactions between the children (Zigler \& Bishop-Josef, 2006). In a study conducted by Aureli and Colecchia (1996), preschool children who attended childcare centres were found to play and interact more with peers when compared to the children who did not attend any childcare centres. The sections below describe and discuss what the practitioners in this study perceived as important learning for children during playtime with their peers in their childcare centres. 


\subsubsection{Sharing resources}

According to Blandon and Scrimgeour (2015) and Williamson, Donohue and Tully (2013), the infant and toddler years are crucial for the development of prosocial behavior such as sharing, helping, comforting and cooperation. Wu, Hursh, Walls, Stack and Lin (2012), Hay (1994) and Hogan, Scott and Bauer (1992) similarly stated that prosocial behaviour for toddlers includes: joining other children for play; following rules; helpfulness; empathy; turn-taking and sharing toys, which can all contribute to the development of social competence (Rose-Krasnor, 1997). In other words, when children have opportunities to interact with peers, they learn social skills, which are crucial for their social development (Blandon \& Scrimgeour, 2015).

The practitioners in this study recognised that when children play together, they develop a number of social skills, including sharing their toys with peers. They believed that sharing is a learning task that children achieve as a result of being at the centre for a period of time:

Amy: The positive outcome of playing together is that they can share their things with others. When Anna was a new child at the centre, she didn't know how to share. She likes pink you see. So when there were pink things around she said they were hers and she would not let anyone touch the things. I keep telling her that we have to share things here. After a while of being here, I can see that she can share, even pink things. She knows they are not hers but they are for everyone to use... Two days ago, Anna shared a toy with Willy without fighting. They shared a pink teapot. $\left(\mathrm{FG}^{8}\right)$.

Amy reported having seen some changes in the children's behaviour as they spent more time at the centre. She gave an example of Anna who did not like the idea of sharing when she first arrived at the centre, but, over time, Anna learned about sharing as a result of peer interactions and Amy's verbal reprimand. Amy's statement of "I keep telling her that we have to share things here" indicated that Amy gets herself involved in the

\footnotetext{
${ }^{8}$ FG: Focus Group
} 
children's learning by repeatedly reminding the children about social rules. Amy saw playing with peers and reminding them about social rules as ways for children to become prosocial and she was obviously happy with the change in Anna's behaviour. Amy's behaviour is consistent with the idea promoted by Super and Harkness's (1986) concept of the developmental niche in which it is argued that the psychology of the caregivers, including their beliefs, influence the way children develop. This idea can be seen in the way Amy's belief about sharing being part of prosocial behaviour led her to constantly remind the children about sharing.

Similarly, Amy's colleague, Fifi, reported that children learn to share resources as they play with peers:

Fifi: The children learn to share when they play together. Like books over there (pointing to a bookshelf). They have a few favourite ones that they like to read over and over again. Before this, when one was reading, another came and snatched the book. But after several times of telling them to share, they don't snatch as often anymore. They learn to look at the book together instead. (FG).

Like Amy, Fifi saw telling children about social rules as a way for the children to learn about sharing. Here, it is evident that Fifi's belief about social rules was reflected in her approach to the children. Fifi also pointed out that the children did not snatch as often anymore, thus indicating that snatching or conflicts were behaviours that the practitioners sought to eradicate among the children through constant reminders.

Practitioners from the other two centres reported a similar approach: they taught children how to share objects by telling and giving instructions about sharing:

Elina: The children learn to share and give toys to their friends when their friends want to play with them. Sometimes they fight over a toy and when I see that I usually ask them to stop fighting and share the toy instead. From there I can see that they learn about sharing as they interact and play together. They share more 
than they fight now. Sometimes they fight over me too because they are jealous for my attention. Like last week Saleha sat on my lap. Then Rafiq came and frowned at us. So I said to Rafiq you have to share me and then he smiled. One child sat on my left leg and the other sat on my right leg. They were both happy then. (FG).

Like the other practitioners above, Elina perceived that when children played together, it could help them learn to share their toys. Elina's comment also suggested that she saw it as her duty as a practitioner to tell the children to share rather than fight over objects. She clearly perceived that telling children what to do teaches them to do it and she seemed happy to see the children doing what they are told. Again, this shows how a practitioner's belief leads her to espouse particular actions.

Another practitioner from Rainbow Childcare Centre highlighted that taking turns with the toys was important because there were not enough resources for everyone to use at the same time:

Nadia: During outdoor play, one child plays with a tricycle and then others want it too. They'll be snatching and screaming. So we have to teach them to share by telling them there's only one and you have to wait for your turn. So they wait and share the tricycle after their friends are done with it. (FG).

Nadia's comment on teaching the children to share shows how she perceived it as the role of the practitioners to teach the children to be socially competent and take turns when they were playing together especially when there was only one object of interest at that time. Nadia's comment suggested that she too saw telling or giving instructions as a way to teach the children about sharing.

These comments by the practitioners illustrated their views that peer interaction is more than just playing together. The practitioners saw learning to share as deriving from playing together under the social guidance of the centre's adults. This is in line with what 
Hurwitz (2003) and Pellegrini and Smith (1998) said, that play allows children to learn how to share and work in groups. In regards to Super and Harkness' (1986) notion of the practitioners' psychology being part of the children's developmental niche, the practitioners' statement showed that their perceptions of peer interactions were seen by them to guide their actions, which was telling the children to share their resources when playing together. The practitioners' comments above also indicated that children may come to the centre without the will or ability to share - as in Anna's case - but as they live their daily lives at the centre, they were expected to learn to share their toys with others. The practitioners perceived that repeated reinforcement, such as telling the children to share, could change the children's behaviour from snatching to sharing.

\subsubsection{Communicating with peers}

Apart from learning to share toys as an outcome of play, the practitioners valued play as a way for children to communicate with each other. During a video-stimulated recall interview with the practitioners at Moonbeams Childcare Centre, they discussed how children listened to each other and imitated their peers' words as they communicated. For example, Rozita explained that:

It's very normal for the children to imitate each other. Like in this video of the children here, they are imitating each other. I think imitating one another is how they interact too, a kind of communication. They imitate their friends' words. I think it's because they have limited vocabulary, so they imitate what others say. It's their way of learning the language too. When they are together, they have a chance to learn and practise language. (MCC, VSR ${ }^{9}$ ).

Elina nodded in agreement with Rozita's statement, adding:

Yes you can see in this video that the children talk among themselves when they play together. Adults don't understand what they are saying but they seem to

\footnotetext{
${ }^{9}$ VSR: Video-Stimulated Recall
} 
understand the message their friends are giving. They listen to their friends' language and they repeat it and laugh together. (MCC, VSR).

Clearly, both Rozita and Elina recognised that children used imitation to communicate with each other. This recognition was awakened as they watched the children's videos and discussed the videos among them, which shows how videos and discussions can deepen one's thinking. The practitioners perceived that imitating others' speech is a way for the children to learn the language. Rozita used the word 'learning', which indicated that she acknowledged what communication could bring to the children's cognitive development. This is in line with what Catron and Allen (2008) said, in other words that play is a powerful tool for language learning because in play children expand their vocabulary and improve their receptive and language skills as they are forced to communicate with their peers. While Elina did not provide more details on what it could mean for the children's development, her description implied that children enhance their language through communication with peers. In Davis and Degotardi's (2015) study, the educators also recognized imitation as a way for the children to communicate with each other. They perceived imitation as attempts to seek peer attention, play entry and share social connection in order to build relationships with peers.

The practitioners in my study did not mention imitation as an initiation to play entry, however they did mention that imitation between peers could initiate a game or conversation between the children:

Amy: Playing together is good for their communication skills. They get to communicate when they play and start a game. Like Willy the other day, he kept saying 'Apa khabar?' (how are you?) to his friends. Then Ali and Roy copied him and kept repeating 'apa khabar?' to everyone they passed by in the centre, both to children and adults. The three of them greeted people that morning and everyone replied by saying something to them and then the boys laughed about it together. (FG). 
Amy's comment about the significance of play for the development of children's communication skills was illustrated with the example of how Willy used the phrase, 'apa khabar?' to his friends and opened up a game to the children: he started a trend of greeting everyone who passed by, as well as provided a chance to communicate with other people. This is in tune with Kyratzis' (2004) statement that games are major speech events for forming alliances with peers. When the children played the game together, they had fun and at the same time learned something about communicating with others such as receiving responses. Similarly, another practitioner, suggested that a game can start a conversation:

Husna: The children copied each other when they played together like copying body movements... like dancing and they also copied each other's words. Like when one child listened to her friend's word and then she copied the words. The others soon followed her and from there sometimes they laughed and they started talking to each other. (FG).

Husna's observation that children's imitation of each other's words led them into starting a conversation with each other echoes Eckerman and Didow's (1988) insight that in friendship that imitation plays an important role in achieving social coordination. Husna's comment clearly shows that the children achieved social coordination when they successfully communicated with each other even though she herself did not explicitly state this.

Beyond imitations and using words to communicate, some practitioners recognized that children used body language when they wanted to communicate. They said that the children became aware of their peers' emotions as a result of playing with peers every day at the childcare centres as is evident in the comments below:

Khalila: Not all under three year olds know how to talk. It's more about babbling or single words right? So when they are playing together and interacting, there are also a lot of gestures, sounds and movement. That's how I see peer interactions at 
this age. So when they don't use words, they use objects or body movements but they are able to understand each other. (RCC, VSR).

Maria: The children who don't know how to talk yet use different ways to communicate. Like Omar, if he wants his friend to play with him, he usually goes to the friend and pulls the friend's hands. Like in this video, you see him pulling his friend's hand. Sometimes pulling the clothes too... That's his way of saying I want to invite you to play with me... usually his friends understand him. (RCC, VSR).

Fifi: Sometimes the children don't talk when they play together but they interact by looking at each other... I can see in this video, just by eye contact, Anna, Wily and Roy could understand what their friends want (SCC, VSR).

Husna: Everyday they come and play with each other. Sometimes they just use signals when talking to each other. Not words, just hand movements but they understand each other and can play together. When friends are sad or angry, they understand that too and give comfort to them. (FG).

Amy: The children do understand each other. For example last week Anna hit me. She wanted a toy but I said no. So Anna was angry and hit me. I pretended to cry and called Willy's name. Willy looked at me and came near and then he started to say things to Anna. I didn't understand what he said but Anna looked like she understood him. I think Willy understood Anna's anger at me and he was trying to calm me down or something. After that both of them walked away from me and played with some other toys on their own. (SCC, VSR).

These statements by Khalila, Maria, Fifi, Husna and Amy show that they recognized that communication among peers is multimodal and that there are other ways to communicate with each other when language is limited; in other words, they recognized that the children expressed their needs by using body language and their peers seemed to 
understand them. According to Eckerman, Davis and Didow (1989), toddlers used nonverbal gestures in relating their actions to their peers like how Maria described Omar pulling his peer's hand as a way of inviting the peer to play with him. The practitioners further emphasized that the children understood the emotions of their peers and that the children were capable of giving comfort to their peers when needed. The practitioners' comments reflected how they saw play as bringing the children together and gave opportunities for them to communicate and understand their peers. According to Canning (2011), children not only explore their sense of self but their understanding of others also grows when they play together. Khalila, Maria, Fifi, Husna and Amy were aware of the non-verbal communication the children displayed with their peers and this indicated that the practitioners were quite observant of the children's interactions with each other.

All of the practitioners above highlighted how peer interaction through playing together can lead children to communicate with each other, thus making play a medium of communication. Communication is not just talking by using language but also non-verbal means such as eye contact and body language. In a study by Vickerius and Sandberg (2006) on parents' perspectives on children's play, they found that parents too viewed the benefits of play as increasing children's language learning. In the parents' view, children develop the language faster when they have peers to communicate with. Vickerius and Sandberg (2006) further explained that when children play together, they learn about expressing their needs, compromising, negotiating, listening to other children, solving problems and making decisions which were all aspects of communication that the practitioners in this study also commented on. 


\subsubsection{Understanding peers' intentions, needs and emotions}

As I have demonstrated in the previous section, the practitioners in my study perceived that when children play together, they can understand each other's intentions, needs and emotions and that this would not happen if they did not play and interact with peers on a daily basis. In this view it is necessary for children to interact regularly to develop an understanding of relationships with others, an argument made also by Davis and Degotardi (2015). According to Svetlova, Nichols and Brownell (2010), children's ability to understand the goals, desires and emotions of their peers increases during the second year of life because in the first year of life, infants are beginning to understand positive and negative emotions expressed by others (Phillips, Wellman \& Spelke, 2002). Similarly, Vickerius and Sandberg (2006) argued that children learn about others' feelings when they play, and develop empathy and understanding about others' needs. The videostimulated recall discussions of the practitioners in my study indicated an awareness of this dynamic:

Elina: When playing together, the children also understand what each other wants. Maybe they are used to their friends because they meet everyday. Like when they play with something, for example just now Rafiq threw his teddy bear in the air to Saleha and Saleha laughed. If Saleha didn't understand, she might think Rafiq wanted to hurt her but actually they were playing in the same way that they might throw confetti in the air. They play like that regularly. (MCC, VSR).

Jamilah: I can see that the children who cannot talk yet sometimes scream at their friends. But not all screams are negative. It depends on the situation. Like Omar in this video, he likes screaming. Screaming is fun for him. Sometimes the scream attracts others' attention and suddenly other children come and play with him. So I think that means his friends know what he wants and that his screaming might mean I'm inviting you to play. (RCC, VSR). 
Both Elina and Jamilah commented that they saw understanding peers' needs as an outcome of play. They perceived that because the children were used to one another as a result of coming to the centre everyday, the children were able to know and understand what was going on with their peers. In Davis and Degotardi's (2015) study, they found that interactions with peers regularly help children to develop an understanding of others. Clearly, both Elina and Jamilah acknowledged this. Jamilah also recognized that communication relies on more than words noting that Omar's screaming was an invitation to play rather than making chaos. Due to this recognition, the practitioners let the children carry on with their play without any intervention. This is an example of how a practitioner's belief can affect his or her teaching approach in an ECCE centre which is consistent with Super and Harkness' (1986) notion of the psychology of the caregivers.

Other practitioners also highlighted how the children can understand each other when they play together and that the practitioners were happy to see children cooperating in their games. The following comments during video-stimulated recall interviews illustrated this:

Fifi: As Anna is playing with Willy and Ina, surely they understand each other. They are playing cooking and they must understand what is going on because they are playing together, looking happy and cooperating in the game. Adults can watch and make guesses on what they are playing but only they know the truth to their game. Playing together makes them understand what each other wants in a game I think. (SCC, VSR).

Khalila: These children play together all the time. Sometimes we don't even know what they are playing but they look very involved with each other, that means they understand each other as they play their games, laughing, screaming and running around. They look happy so that means everything is well. Even though we don't understand what they are doing or playing, as long as they understand each other, that is fine. They are happy, adults are happy too. (RCC, VSR). 
Nadia: In this video, I think they are playing chasing. A tiger is chasing the others. That's why they are running away from Ahmad. Ahmad is the tiger and the others are getting away from the tiger. But who knows? Only they know what's happening in their game. When they are having fun and happy, we can relax a bit. (RCC, VSR).

Fifi, Khalila and Nadia recognized that even though adults may not understand what was going on between the children as they played together, the children themselves were able to understand their games and this is evident through their laughter, squealing and how they respond to each other. Fifi's comment that the children must know what was going on in their play since they played together, Khalila's comment that the children looked very involved and Nadia's comment that only the children knew what was happening in their game indicated that they understood the children's ability to create their own play themes and that children do understand each other as they play. The practitioners' comments reflected an understanding that children create their own peer culture even though the practitioners may not recognize this term. Other researchers have documented this understanding also; for example Corsaro (1985) argued that children are always constructing their own peer culture when playing with peers. They have their own rules, values and understandings that are unique to them as a group.

In addition, the practitioners also highlighted that as long as the children were happy, the adults were happy too which indicates that they valued children's happiness as they played together. Children's happiness is important as it is linked to their well-being (Moore \& Lynch, 2017; Langton \& Berger, 2011; Jutras \& Lepage, 2006) and understandably this was of concern to the practitioners. However, their statement could also mean that the adults were happy because they did not have to deal with conflicts and Nadia's statement of 'we can relax a bit' gave that clue. Clearly, the adults were happy to see the children cooperating in their game and they found things less stressful when things were going well between the children. 
Taken together, the comments from the practitioners above indicated that when stimulated by the video excerpts of peer interactions, the practitioners' discussions showed that they were in fact quite observant of the children's understanding of peers' intentions, needs and emotions as they played together. Their comments showed that they recognized that children who attend childcare centres have the benefits of developing understanding of others, and that they not only can learn to read others' cues but they can also cooperate when playing games, which gave delight to the practitioners as the environment became happy. Furthermore, the practitioners focused on how children understood messages and cues that their peers were sending or showing. The excerpts of children's behaviour presented in this section illustrate how children formed relationships, created peer culture, and learned about the social world as they played together while the practitioners' statements reflected their understanding that children have their own 'peer culture' even though they did not use this term.

All things considered, in reference to Super and Harkness' (1986) notion of the psychology of the caregiver as a key influencer of a child's developmental niche, it would seem that the perception that play is beneficial for children was an important component of the practitioners' psychology and this was evident in the way the practitioners focused on the benefits of play and discussed how play can lead children to learn about sharing, and about communicating and understanding each other. Furthermore, the fact that the practitioners were able to think deeply and discuss this subject while they watched the children's recorded videos during the video-stimulated recall interviews, and the focus group discussions with other practitioners, but not during the initial interview, suggests that the video-stimulated recall interviews and focus group discussions opened up their thinking about the children's peer interactions under their care. Not all children under three years old could talk but the practitioners commented that this did not hinder them from playing together as they used non-verbal communicative tools to interact. These are important skills in developing the children's social competence as mentioned in the Social Competence Prism by Rose-Krasnor (1997). The children need to interact with peers so that they can learn to be effective during 
interactions. So play isn't just play. It is an interaction between children that leads them to understand others (Davis \& Degotardi, 2015).

\subsection{Learning outcomes of familiarity}

In addition to play, the practitioners also perceived familiarity to be an important part of peer interactions. Aureli and Colecchia (1996) similarly noted that children who go to childcare centres regularly have the opportunity to become familiar with their peers as they interact with the same people. This can therefore have a positive effect on the children's development particularly in making connections, gaining confidence, and friendships - an insight that the practitioners in my study commented on at various times in video-stimulated recall interviews and focus group discussions.

Davis and Degotardi (2015) also reported that one of the benefits of attending childcare centres is that children have the opportunities to interact with the same peers on a regular basis. Howes and Philipsen (1992) noted the benefits of regular attendance and reported that toddlers interact differently with familiar and non-familiar peers. With familiar peers, children were more cooperative, engaged in more positive social interaction, and showed more concern about them as opposed to non-familiar peers (Blandon \& Scrimgeour, 2015). Past researchers said children might be less able to engage successfully in specific play rituals with non-familiar peers because they have developed a play pattern with familiar peers (Eckerman, Davis \& Didow, 1989). This means that the non-familiar peers might take a while to understand games that the children play with familiar peers on a regular basis. Playing with non-familiar peers may mean starting things from the beginning again and it may take a while to move forward. With familiar peers, children are able to move forward together and start where they have left off at their last meeting because they have developed rapport before this. In this section of the chapter, I discuss the practitioners' perceptions of how familiarity with peers develops children's learning in childcare centres, and why it is beneficial for children to interact with the same peers for a period of time. 


\subsubsection{Making connections}

Making connections with peers was perceived to develop due to familiarity with peers. During a video-stimulated recall interview that was focused on Willy and Roy at Sunny Childcare Centre, the practitioners reflected at length on the video excerpts and commented on how familiarity makes the children happier as they were able to connect to each other's experience:

Fifi: That's another one of their favourite game (referring to the video). They like to put that box on their head because it's like putting on a helmet. Roy and Willy ride motorbikes to come here. Their fathers ride motorbikes to bring and fetch the children. So when they play with the box over their heads, it's like wearing helmets and riding a motorbike. (SCC, VSR).

Amy agreed with Fifi's comment and added:

Yes, the children were pretending to play motorbikes. That's probably because they are used to riding motorbikes. If it were another child, maybe that other child would make the container as a hat and not a helmet. (SCC, VSR).

Fifi futher added:

When Willy put the transparent box over Roy's head, Roy stood up and immediately played with Willy. Willy didn't say anything but Roy understood. No need for instruction from Willy. Roy knew what to do already. (SCC, VSR).

The practitioners recognized that Roy understood what Willy was doing when he put the box on Roy's head even though there was no verbal exchange between the children. The practitioners expressed how Willy and Roy were familiar with the context of their play. The practitioners attributed the children's common experience of riding motorbikes with their dad as the basis of joint play. This is in line with what Canella (1993) said, in other words that shared experience leads to a connection between interacting partners and 
through familiarity of experience, children are able to have a sense of connections when interacting with each other. Broadhead (2009) found in her study that children often look for the same playmates in certain games especially when they get older and more familiar with other children in the centre. This explains Willy's actions as he chose Roy to play the 'helmet' game as a result of their motorbike experience and familiarity with the situation. The practitioners were able to recognise this when they watched the video, something that they would not have thought of if they did not watch the video and this is evident in Fifi's comment below:

This is fun. It opens my mind about the children's everyday interactions. Can we watch more videos? (SCC, VSR)

Other practitioners also recognized that familiarity is linked with making connections between peers. Differently from Fifi and Amy above, who mentioned children making connections through their experiences, the practitioners below highlighted connections being made between peers as the children grew more familiar with each other:

Khalila: Children under three have limited vocabulary but you don't need words to make other kids understand you. Like a child can move a toy in front of his peer and suddenly the peer understands the gesture. Maybe if you know that person for a long time, you can understand his personality more and you have a better relationship with that person. Like Omar playing with Sharifah: they don't talk but they understand each other. They can connect because they know each other already. (RCC, VSR).

Khalila's comments about the importance of familiarity draw strongly on her observations of how a child's relationship to his/her peer can blossom as they grow to know more about each other, and understand them more as well as discover who they themselves are (Zero to three, 2010). Likewise, Rozita also recognized how a relationship with someone can make people feel connected: 
Rozita: The longer children know each other the better they understand each other and the better their relationship too, I think, because they can connect with each other when they play... A new child at the centre will take some time to familiarize herself / himself to the new surroundings and new friends. (FG).

Clearly, both Khalila and Rozita further recognized that connections between the children did not have to rely on them being verbal since familiarity with each other led them to understand what another child wanted through their gestures and other non-verbal communicative behavior.

In sum, the practitioners at the three case study centres showed a clear appreciation of the importance of familiarity for children to making connections with others. In other words, familiarity with peers was understood as allowing infants to draw on their experiences together and to build relationships with peers. This was evident during the videosimulated recall interviews and focus group discussions during which the practitioners showed their intuitive sense of what children were getting out of familiarity. Moreover, the practitioners made some quite specific statements about the value of observing children closely; they found it "fun" as well as instructive.

\subsubsection{Gaining confidence}

Gaining confidence was also mentioned as a learning outcome of familiarity with peers. According to Kochanska and Radke-Yarrow (1992), children who regularly socialize in playgroups and explore new environments grow to be more confident of themselves when they are toddlers, making those actions among infants an important developmental task. During the focus group discussion, some practitioners expressed a similar view and emphasized that children who attended childcare centres become more confident in themselves when they are familiar with the people around them and with the setting:

Rozita: This is like their second home, because they come here every day and spend a lot of time here. They meet the same friends. So they grow confident of themselves and are not shy with their friends anymore. When they first came here, 
some of them were very shy, scared and didn't mingle with others. Now they are better. (FG).

Husna agreed with Rozita's statement:

"Yes. Like Ayu, she was a very shy girl. She didn't join in activities like singing and dancing. When Tiara (a practitioner) asked the children to follow her dance movements, Ayu just looked at her. She was shy and didn't want people to look at her dance. She just stood there and watched others do the singing and dancing. But now she is becoming more confident of herself and joined in the activities with her friends more." (FG).

Tiara added to Husna's comments:

"I think Ayu is used to me now. I always do dancing with the children so I think Ayu is used to that now and maybe she thinks there's nothing to be shy about and she is used to all her friends here. She is a confident girl now, not like before." (FG).

The above discussions show that the practitioners recognised familiarity as an important contributor to children's sense of self-confidence and comfort. They saw shyness as a behaviour that could hinder peer interactions. This is in line with Fox, Henderson, Marshall, Nichols and Ghera (2005) statement that children who are shy, wary and reserved in front of unfamiliar people could become stressed and anxious during social encounters. The practitioners claimed that with time, children at the centres become more confident of themselves as they become familiar with the environment, practitioners and peers. This is good for the children's social competence development because it can lead to effectiveness in interactions as mentioned by Rose-Krasnor (1997). The children see each other at the centre on a daily basis and have interactions with each other. The children know what is expected to happen as in the case of Ayu above. Laursen, Furman and Mooney (2006) emphasized that children enjoy the companionship of peers, and that 
good relationships with peers may lead the children to feeling self-worthy and socially competent. As Rose-Krasnor mentioned, when children have the balance of an individual's goals and maintaining positive relationship with others, they are more likely to be successful in the social competence measure represented at the index level. The example of Ayu, shared by Husna and Tiara above, shows how friendship and familiarity can make a child become more competent and confident in their actions such as becoming more social and joining in activities with peers, which represented the balance between fulfilling self goals and positive interactions with others.

Other practitioners highlighted how the children became familiar with the activities at the centres and how the familiarity made the children confident of themselves too:

Nadia: When the children hear a song on the radio or TV, they automatically will start to dance. They dance together with peers, keeping up with the song. They know these nursery rhyme songs already because we put it on from time to time so they know the actions for the song like clapping and jumping. They are not shy and very confident. When they get some steps wrong, they just laugh together with their friends and do it again. (RCC, VSR).

Maria: They are familiar with the songs so they know when to clap and when to stomp their feet, and because they are with their friends that they know for sometime. They dance together with their friends without any adults instructing them to do it. They are confident now because they know the songs and they have fun with their friends. (RCC, VSR).

Both Nadia and Maria saw familiar activities as boosting the children's confidence because the children knew what was coming such as clapping to the right tune. My analysis of the children's behaviour suggested that familiar activities brought the children together which can be referred back to the children's eagerness to create that sense of belonging and togetherness in the group. The children seemed to be having fun doing familiar activities together and Maria's line of, "They dance together with their friends 
without any adults instructing them to do it" indicated that the practitioners recognized the powerful effect of group activities with children in creating togetherness even though they did not mention this explicitly.

Taken together, when the practitioners in this study were given opportunities to be reflective of the children's peer interactions with the help of video-stimulated recall interviews and focus group discussions, the practitioners recognised that familiarity with peers had an important impact in building children's self-confidence around peers and in the activities at the centres. Past research found that 1-year-olds showed more positive interactions with familiar than unfamiliar peers (Lewis, Young, Brooks \& Michalson, 1975). Likewise, other researchers found children were more socially active, had more frequent social play, more verbalization, more complex interactions with familiar peers (Doyle, Connoly \& Rivest, 1980). According to Doyle et al., a familiar peer increases the frequency of social interaction and the complexity of toy play in which they are more constructive, more creative and more dramatic when compared to playing with an unfamiliar peer, inferring that children become more confident when they are more comfortable with peers, possibly elicited by previous learning of positive and successful social behaviours with them (Doyle et al.).

\subsubsection{Developing friendships}

During the video-stimulated recall interviews as well as the focus group discussions, the practitioners further perceived familiarity to be connected to developing friendship among the children. According to Howes and Philipsen (1992) and Hay, Payne and Chadwick (2004), during the second year of life, children start to have a particular preference for a peer and this could develop and blossom into a friendship throughout the preschool years.

This was evident when Khalila commented during a video-stimulated recall interview:

Some of the children have been here for more than a year. They came when they were babies and they have grown up together with their friends. So they know 
each other. They even have best friends. Like Jasmin's best friend is Suzy. When Jasmin comes in the morning she will look for Suzy and when she sees Suzy, she goes to her and gives Suzy a hug. (RCC, VSR).

Khalila used the term 'best friends' to describe Jasmin's friendship with Suzy and although Corsaro (1985) suggested that young children may not perceive frequent play mates as 'best friends' because they don't have the understanding of the concept yet (Damon, 1977), it was clear in my study that the children did view familiar and frequent playmates as their preferred friends. Thus while some might argue that the term "best friends" has a deeper meaning that includes recognition of personal qualities upon which the concept is based, Khalila's example of the children's friendship is significant in linking it to familiarity and their developing friendship towards each other.

Other practitioners used the word 'favourite', 'good' and 'close' to describe the children's developing friendships:

Nadia: The children interact more with their favourite friends. Like Ibrahim is close to Ahmad. They enrolled in this centre about the same time and they are about the same age. So they play with each other a lot and have become good friends. It's cute to see them hugging and holding hands together. (FG).

Referring to practitioners' comments above, both Khalila and Nadia recognised that when the children are familiar with each other as a result of being together in the centre for some amount of time, their relationship develops into friendship, as in the case of Jasmin and Suzy and Ibrahim and Ahmad. The shift from a peer relationship to a relationship of friendship was marked by the fact that the children liked holding hands and hugging each other when they met and played together. 
Husna from Moonbeams Childcare Centre shared a similar view. In a video-stimulated recall interview where Ayu is seen to hug Nani, Husna commented:

Ayu is very affectionate. She is very concerned when someone is crying. So she gave Nani a hug because Nani was crying and Nani did not seem to mind it. Nani hugged Ayu back so you can see that they like each other. Besides, Ayu and Nani are close. They've known each other from the baby room upstairs and then they came down here together when they turned two. So they've been friends for a long time. (MCC, VSR).

Here Husna recognises that Ayu's affection towards Nani was more than just giving Nani comfort but rather the result of their familiarity with each other, which bought them 'close' as Husna puts it. Ayu and Nani have known each other since infants when they were cared for in the 'baby room' and then transferred to their current room at two years of age, which means that they had known each other longer than they had known the other children. According to Laursen, Furman and Mooney (2006), children enjoy the social support that peers provide as they get older, a view echoed by Husna's comment that Nani enjoyed the comfort Ayu gave her.

On another occasion, Husna again used the word 'close' to describe other children's relationship:

Helmi and Safiah are very close to each other. They are best friends. Safiah doesn't mind if Helmi wants to play with her or if Helmi takes her toys but Safiah usually cries when others do it. Helmi is an exception. They play together, hold hands together and then at home, their mothers say they always talk about each other. (MCC, VSR).

Husna described the children's closeness as illustrated through sharing toys, holding hands and talking about each other at home. Husna agreed that the children had a special friendship at the centre. 
The practitioners in Sunny Childcare Centre also gave similar comments about children's familiarity and the developing friendship among them:

Fifi: Willy and Roy are close. They knew each other even before they came to this centre. Before this, they were at another centre and then their mothers brought both of them to this centre together. So that's why we always see them together. They are good friends and they always prefer to play with each other. (SCC, VSR).

Amy: Willy always looks for Roy and Roy always looks for Willy when they want to do something that requires another friend. To Willy, Roy is his first choice when finding a play partner and to Roy, Willy is his first choice too. Knowing each other for a long time helps their friendship and I think maybe they have more interactions together than with other children. (SCC, VSR).

Both Fifi and Amy commented that Willy and Roy's preference for one another developed due to their familiarity. The children's time together attending a different centre meant that they had known each other far longer than they had known the other children in the centre. Apart from that, the practitioners recognized familiarity to be associated with more interactions between the children. This is in line with Aureli and Colecchia's (1996) study, which claimed that familiarity with peers helps improve the children's social competence. In a study by Parry (2014), on his observation of two children, Ray and Isaac, it appeared that the children played with the same peers frequently. It was also noticeable that when they were in a group of peers, the observed children kept their focus on interacting with their preferred peers. The practitioners in Parry's study suggested that the children had known each other longer because they had been in the same story group for some time prior to the study leading Parry to speculate that it is possible for the children to choose playing with their preferred peers because they were more confident in exercising their social competence with them than unfamiliar peers (Parry, 2014; Konstantoni, 2012). The same could be speculated with the children 
in my study where they may have chosen their preferred play partners because they were used to them.

The comments by the practitioners in this section summed up how they perceived children's interactions with familiar peers as strengthening connections between them, building their confidence and developing friendships with one another, which all have a connection to building up the children's social competence (Rose-Krasnor, 1997). In this study, it was clear that the practitioners recognized the social competence benefits that accrued to very young children from interactions with familiar peers. Looked at through the construct of Super and Harkness' (1986) developmental niche, and the idea that the psychology of the caregiver influences child outcomes, these findings suggest that practitioners are likely to further enhance their sensitivity to the complex interactions that under-three year olds engage in, if they had the opportunity to observe and reflect in depth on children's peer interactions on a more regular basis.

\subsection{Learning outcomes of having friends}

In addition to commenting on the learning outcomes of familiarity, during the videostimulated recall interviews and focus group discussions the practitioners contributed a number of statements that showed the significance they put on having friends at an early age and the importance they attached to young children attending childcare centres. Particular benefits from having friends emphasized by the practitioners were: (i) the development of empathy: and (ii) preparation for school.

\subsubsection{Developing empathy}

According to Rose-Krasnor (1997), empathy is one of the specific abilities that have been identified in the skills approach to social competence and Canning (2011) has argued that even as young as two years, children can show signs of empathy with peers who demonstrate that they are hurt (see also Svetlova, Nichols \& Brownell, 2010). In my study, most of the practitioners offered examples of children in their centres giving comfort to their peers. Some examples are shown below: 
Rozita: The children are concerned about each other. There are times when their friend is sick, they will give more attention to that friend like stroking the friend and when a friend is absent, they will ask where is he/she and why is he/she is not here. Then when I say he/she is sick, they say things like, 'Kesian dia' (poor him/her). So we can see that they have empathy towards their friends... I think they learn from us adults because we show empathy towards the children. So the children imitate us. (FG).

In this excerpt Rozita recognized that children develop care and empathy towards their friends as a result of being around them as well as because the adults modelled such behaviour, which Pech (2013) would describe as part of the teacher's role in building a positive and caring classroom environment (see also Miller \& Pedro, 2006; Watson, 2003). As Rozita mentioned, one of the things that the practitioners did at the centre was modeling empathy. Rozita used the word 'learning' in her comment showing her broad understanding of learning, as well as that she valued learning in children's everyday interaction with peers.

Husna from the same centre also spoke about children developing empathy at the centre, as did Amy and Fifi from Sunny Childcare Centre, each noting that empathy was an important learning outcome:

Husna: Lily was trying to comfort Helmi when he cried (referring to video). They comfort each other all the time because they are friends. When one cries, a peer will come and ask what happened and then they will hug and stroke the peer's head or back. In this video, Lily is seen to hug Helmi when he is crying. Maybe Lily wanted to make Helmi happy again. (MCC, VSR).

Amy: Roy was upset because his toy got stuck on a desk. Anna turned to see who was crying and then she helped him retrieve the toy. I think Anna sympathized with Roy and that's why she tried to help him. The children learn about their 
friends' emotions when they are together. The child's emotion and their friends' emotions might be different. So having friends make them learn about each other's differences. (SCC, VSR).

To this, Fifi added:

Fifi: Anna saw what happened and tried to help Roy. Roy didn't ask for help but maybe Anna felt sorry for him. The children have empathy towards each other and they do help each other sometimes. (SCC, VSR).

Clearly these practitioners were very aware of how children showed empathy to any unhappy peer (by stroking, helping and hugging the peer in their effort to comfort the peer) and how young children are capable of feeling sad for their peers and want to make them happy again by comforting them. It can also be inferred from each of their comments that they valued the learning about human emotions that happened at these times. The excerpts also show that the practitioners recognised that having friends is more than about just being together. Having friends helps children to learn about others' feelings and that the children can express empathy when they see their peers in distress. Overall, the above excerpts show that the practitioners were aware that attending childcare centres is beneficial for young children because it gave them opportunities to learn about peers' feelings and this develops empathy in them, one of the important social skills needed to be a socially competent person (Rose-Krasnor, 1997). Some of the practitioners were able to connect friendship and empathy to the children's learning and this is evident by the way they mentioned the word 'learning' during the interviews, which indicated that they recognized what having friends can do to the children's development. 


\subsubsection{Preparation for school}

While developing empathy among peers is seen as beneficial to children's friendship development, the practitioners in this study also believed that when children make friends at childcare centres, they develop social competence which can help them be ready for school later on in their lives. According to Wu et al. (2012), social competence is connected with school readiness and academic success. Children who are socially competent are in good position to develop positive attitudes, adjust to school, get better grades, and achieve more in school in the future. Other researchers also believe that children's early relationships with their peers are a significant predictor of later social and emotional competence and academic success in school (Rosenthal \& Gatt, 2010; Hamre \& Pianta, 2005).

Most of the practitioners in this study linked attending childcare centres and having friends at an early age to social competence later on in school. Some examples of their comments on the subject are below:

Jamilah: In my opinion, exposing children to socializing with friends at an early age is actually good. Because when they have to go to school later, they will be prepared. If they are not prepared, they might be scared and even cry when they go to school because they are scared of the strangers. And they would have problem socializing and adapting to school. (FG).

Jamilah predicted that if children did not have the social experience they get in childcare centres, they would have some difficulties in socializing with peers at school. This is in line with what Lally (2010) said which is that school readiness interventions should start as early as infancy because children need social and other skills (emotional, intellectual and language) to be successful in school. 
Likewise, Rozita commented:

When they are mixed together in a childcare centre, it's just like school. They learn how to communicate with their friends and adults. And strangers too, like their friends' parents. It's important that they socialize with other people from a young age. They are now turning three years old. Later when they are seven years old, when they have to go to school, it's easier for them to adapt to the school environment because they have this experience here at childcare. Hopefully they won't be scared or awkward. (FG).

Rozita recognized that socializing with peers and having friends at the childcare centre was beneficial for the children's social competence and could prepare the children for school later on in their lives. According to Denham, Wyatt, Bassett, Echeverria and Knox (2009), Spence (2003) and Galejs and Stockdale (1982), children who are socially competent demonstrate more positive school behaviours than children who lack social competence. Moreover, socially competent children are believed to be in a good position to adjust well to school and be academically successful (Ladd, Birch \& Buhs, 1999; Wu et al., 2012; Blair, 2002; Van Hecke et al., 2007).

The perception that childcare experience was linked to preparation for school was also discussed by Khalila and Nadia from Rainbow Childcare Centre:

Khalila: I think exposure to peers is important. Because at home, let's say there's no one at home, they only have their parents, then they won't be exposed to other children. They need people their own age to interact. They need friends. If they have early exposure, I think it's easier for them to socialize with others at school later. (FG).

Nadia: I think children who come to childcare centres can learn to make friends; I think it's good this way. So when they go to school later, we don't want them to 
not know how to interact or make friends. At least here they get to practise that and when they go to school later, it's easier for them. (FG)

Clearly Khalila and Nadia saw attendance at the childcare centre as a stepping-stone for school, arguing that early exposure to friends means that the children can practise their interaction skills and be prepared for school. When children attend ECCE centres, they develop social competence, including social problem solving, which is known to predict school readiness and later mental health and well-being (Blair, 2002; Denham, Blair, DeMulder, Levitas, Sawyer, Auerbach-Major \& Queenan, 2003; Denham, 2006; Gloeckler, Cassell \& Malkus, 2014). As mentioned earlier, social competence has also been linked with academic skills and school adjustment too (Rosenthal \& Gatt, 2010; Raver \& Zigler, 1997); but the practitioners in my study did not mention these benefits.

The practitioners' comments above show that they perceived children's friendship to be beneficial in developing empathy towards peers and to prepare the children for school when the time came. The practitioners also linked having empathy and preparation for school with social competence. Being good at social competence does not happen by itself but it needs guidance and interactions with other people (Rose-Krasnor, 1997). Thus, how practitioners perceived peer interactions is important as it can effect the way they support children's peer interactions at their respective childcare centres (Davis \& Degotardi, 2015; Super \& Harkness, 1986). According to Denham (2006), one goal of high quality practitioners is to guide children to increase their social competence. Children who acquire social competence are known to do better in school, develop friendship easier and more confident in themselves than their peers who lack these skills (Denham et al., 2003; Bowman, Donovan \& Burns, 2001; Raver, 2002). Thus, having peers at an early age should be beneficial for children as they get to exercise social competence with their peers. 


\subsection{Chapter Overview}

This chapter is about the practitioners' perceptions of children's peer interactions at their respective childcare centres as they were revealed during video-stimulated recall interviews and focus group discussions. By framing this chapter with Super and Harkness's (1986) concept of developmental niche, and specifically the notion of the psychology of the caretakers, the practitioners' perceptions and understanding of children's peer interactions were explored. This notion assumes that the way practitioners perceive and understand children's peer interactions can impact the opportunities they provide for the children. Three themes were identified in the data collected through video-stimulated recall interviews and focus group discussions. The practitioners saw the learning outcomes of play, of familiarity, and of having friends as important for children's peer interactions. They further elaborated that as the children interacted daily with peers at the childcare centres, they were able to share resources, communicate with peers, understand others' intentions, needs and emotions, make connections, gain confidence, develop friendship, develop empathy and be ready for school. Rose-Krasnor (1997) suggested that the children's developing cognitive, emotional, motor and communication skills facilitate the growth of the social abilities displayed by the under three years old children in my study and are important for children's learning because they can help children's drive to competence. It takes careful observation and thoughtful reflection on the practitioners' part to identify these abilities in children.

Some of the practitioners mentioned that this study opened up their eyes and thoughts to different ways of looking at the children's peer interactions. Elina said in the focus group interview:

When you asked me to think about the children's peer interactions, it made me see things that I never saw before. Like I never thought these children are capable of doing this and that but when I see their videos and thought deeper, I can see that there is so much potential in them. (FG) 
Elina's comment suggested that she recognized that being reflective of her own thinking could open up perspectives that she had never thought of before. According to Jenkinsm and Hewitt (2010), a teacher's job is not just planning the daily curriculum but also to be reflective. Thus, one clear implication from my study is that practitioners should be given opportunities to reflect on their practices as this can expand their thinking about teaching and about how to support children's learning and development (Hill, Stremmel \& Fu, 2005). According to Kane (2008), it is necessary for researchers to continue collecting practitioners' perceptions on the matter of teaching so that the practitioners can remain motivated in their profession.

This current study collected practitioners' perceptions on children's peer interactions and shows the value for practitioners to be reflective about their practices. In the next chapter, I will conclude this thesis by summarizing the findings from this study and discussing its implications. 


\section{CHAPTER EIGHT DISCUSSION}

\subsection{Overview of the research}

My study set out to explore the kinds of peer interactions that occur among children under three years old in childcare centres in Malaysia and how they are perceived by the practitioners at their childcare centres. My interest in this topic arose from the growing participation rates of under-three year olds in childcare centres in Malaysia and the dearth of research on how these interactions might be nurtured to enhance the children's social competence. Within contemporary Malaysian society there is strong interest in enhancing early childhood education provision. This is because there is a connection between education and economic growth (Ozturk, 2001) and early childhood education is perceived as the first step in the educative process.

My study is situated within a social constructivist worldview that recognises the importance of peer interactions and of the practitioners' influence upon children's learning. It was guided by two research questions: (i) "How do practitioners perceive peer interactions among children under three years old in their childcare centres in Malaysia?" and (ii) "What kinds of peer interactions occur among children under three years old in childcare centres in Malaysia?" I investigated these questions through the use of qualitative multiple-case study methodology. I used four key methods of data collection: semi-structured interviews with childcare practitioners, video-recorded observations of children in their childcare centre, video-stimulated recall interviews with practitioners, and focus group discussions. Three childcare centres were involved in the study and within each centre five children were selected to be observed; all of the practitioners took part in interviews and were invited to participate in video-stimulated recall interviews and focus group discussions. 
Theoretically, my study utilised a number of constructs to analyse and interpret the data. Super and Harkness' (1986) concept of the developmental niche with its notion of the psychology of the caregiver was used to frame and analyse the practitioners' perceptions of, and responses to, the children's peer interactions at the three case study childcare centre. Furthermore, I used the Lefebvrian (2002) concept of the everydayness, RoseKrasnor's (1997) social competence prism, the notion of agency (Guo \& Dali, 2016), Loizou's (2005) theory of the absurd, Licht's et al. (2008) work on conflicts between peers, and De Waal's (2000) relational model in analysing the research question about the kinds of peer interactions that occur in childcare centre in Malaysia. In analysing the data from my interviews with the practitioners at the start of the study, I identified two main themes related to the first research question of the practitioners' perceptions of children's peer interactions. After the interviews, the study continued with recorded observations of the children's everyday lives at their childcare centres. Analysing these data led me to identify two main themes as characterising the children's peer interactions. Once the observations of the children were completed, the practitioners were invited to take part in video-stimulated recall interviews in each centre during which they were asked to discuss what they saw happening when the children were involved in peer interactions. Focus groups with the practitioners from all three centres were then held to further explore the practitioners' thinking about peer interactions in an environment where they could be more reflective about this topic as a group and with the benefit of the video-stimulated recall interviews.

\subsection{Summary of research findings}

The findings of my research are summarized in several sub-sections below starting with the insights I gained into my first research question: "How do practitioners' perceive peer interactions among children under three years old in their childcare centres in Malaysia". I then discuss the findings related to my second question "What kinds of peer interactions occur among children under three years old in childcare centres in Malaysia" and the significance of these findings for children's development of social competence and agency. I also discuss the implications of these findings for the practitioners' practices. 


\subsubsection{How do practitioners perceive peer interactions among children under three years old in their childcare centres in Malaysia?}

The practitioners in my study were asked about their perceptions of children's peer interactions three times during the study: firstly, during the semi-structured individual interviews at the start of data gathering; secondly during the stimulated-recall interviews focused on selected video excerpts, and thirdly during the final focus group discussions with all the practitioners from the three centres who were able to attend the session. In the initial individual interviews, the practitioners were asked to express their existing views about children peer interactions among the under-three-year old children in their childcare centres. The individual interviews provided a picture of how the children's peer interactions were understood by these largely untrained practitioners. Two main themes were evident in how the practitioners spoke about their views of children's peer interactions and how they saw their own role during this interactions: (1) promoting peer interactions by facilitating group activities; and (2) managing peer interactions by responding to children's conflicts.

The practitioners believed that group activities at the childcare centres enhance the children's peer interactions because they have a chance to communicate as they sit together in a group. This view, expressed during the individual interviews, was corroborated by the video data, which showed that the practitioners' practices relied heavily on group activities, justified during the interviews as supporting the learning of cooperation and collaboration. Additionally, the practitioners perceived that group activities could reduce noise levels. Looking at these data from the perspective of Super and Harkness' (1986) notion of the developmental niche, which proposes that the psychology of the caregiver can have an influence in their childrearing practice, one can conclude that the psychology of the practitioners in my study included the idea that they saw themselves as responsible for setting up group activities as a way to facilitate peer interaction skills and that they valued classroom harmony and group control. Their actions, captured in the video observations, were consistent with their actions and this validates the idea that understanding the psychology of the practitioners is important for understanding the effect of their actions on children's peer interactions. 
Another important thing that the practitioners highlighted during the interview was that the practitioners saw conflicts during the children's interactions as something negative because conflict can break down the interactions. Most of the time, the practitioners saw conflicts as dangerous and harmful. Thus in their effort to end the conflicts, most of the practitioners intervened in order to prevent harm among the children by using cessation strategies, with some also appearing to sometimes use mediation strategies. Of note was the fact that those practitioners who used mediation strategies were those who had a background of training; by contrast the untrained practitioners relied on cessation strategies most of the times. Examples of cessation strategies include taking the object away from the children, separating the children, asking the children to apologise, salam, and giving time out. Examples of mediation strategies on the other hand were: acknowledging the children's feelings and explaining to the children about their behaviours. The practitioners believed that these cessation and mediation strategies were the best strategies for them to use in times of conflict so that they can prevent harm and injury among the children. The perception that adults need to intervene in children's conflicts contrasts with some researchers' findings that adult intervention in children's conflicts can be destructive because it does not give children the opportunity to practise problem solving skills and social competence.

Also noteworthy in my study were the differences in the ways the practitioners discussed peer interactions during the individual semi-structured interviews before the observational data gathering started and how the practitioners saw children's peer interactions after looking at video footage of children's peer interactions during videostimulated recall interviews. What the practitioners did not mention during the individual semi-structured interviews was that the children are very capable of establishing interactions on their own without being asked to sit together in groups. They also did not mention that while conflicts can be negative, they can also provide learning opportunities for practitioners to teach children about positive social rules (Singer \& De Haan, 2007). Furthermore, not many of the practitioners connected peer interactions to the development of children's social competence and agency. Some practitioners mentioned teaching children about sharing resources, taking turns, and to cooperate during activities 
but they did not explicitly discuss the role of peer interactions in helping children boost their social competence and giving them a chance to practise their agency.

By contrast, when the practitioners were interviewed again after the observations of the children's peer interactions were completed, the practitioners seemed to have a deeper understanding of the children's peer interactions. On this occasion, the practitioners' perceptions of very young children's peer interactions were collected during videostimulated recall interviews and a focus group discussion. These methods appeared "to open their eyes" and broaden their thinking as they discussed this topic together with other practitioners. During the video-stimulated recall interviews and focus group interviews, the practitioners were now able to see how children's peer interactions gave opportunities for learning to happen with their discussion focusing on three main themes: (1) learning outcomes of play, (2) learning outcomes of familiarity, and (3) learning outcomes of having friends. Additionally, the practitioners' perceptions were more attuned to the children's social competence development and showed a deeper understanding of what was really going on during the children's peer interactions at their respective childcare centres. Notably, however, the practitioners still did not give the children credit for using their agency, perhaps indicating that they were not familiar with the term, thus also suggesting the importance of training. Among the valued outcomes of peer interactions that the practitioners did discuss were: sharing; understanding peers' intentions, needs and emotions; developing empathy; and gaining confidence. This study shows how it is very beneficial for practitioners to reflect on their practices. In this study it can be seen that the reflections had the effect of deepening the practitioners' thinking about the influence of their behaviour and practices on the very young children's learning. 


\subsubsection{What kinds of peer interactions occur among children under three years old in childcare centres in Malaysia?}

After the first individual semi-structured interviews with the practitioners, I conducted observations of the children's everyday lives at their childcare centres. As reported in chapters five and six, a key finding from these observations was that there was a lot more that happened at the childcare centres during the children's peer interactions than what the practitioners reported during the initial individual interviews. While the practitioners gave importance to getting the children to sit together in groups so that interactions could occur, the children were seen to be actively interacting on their own even when they were not sitting in groups. By looking through the lens of Lefebvre's concept of everydayness (2002), I found that the children's interactions within their childcare centres created learning opportunities for children to create a sense of belonging and togetherness and deal with conflicts among peers. My analysis followed the work of Guo and Dalli (2016) who studied the experiences of Chinese immigrant children as they started attending their first ECCE centres in New Zealand. While in Guo and Dalli's (2016) study children's belongingness is linked with the notion of everydayness and agency, in my study the children's sense of belonging and togetherness is additionally linked with the notion of social competence. I argue that children's sense of belonging and togetherness grow alongside social competence, and through the children's exercise of their agency in making and taking opportunities to establish and maintain peer interactions.

In finding their way at their childcare centre, the children were seen to actively create that sense of belonging and togetherness by negotiating entry and becoming one of the group and thus also exercising their social competence and agency. The children were observed to want to enter their peers' ongoing play. They did this by watching others; using objects as their tools in entering the play, and imitating peers. When the children watched others prior to making their entry bid into ongoing play, they learned about others' activities as well as learned about others' behaviours. They used their knowledge from observing others to successfully enter their peers' ongoing play. The children showed interest in others' play and successfully entered the play by using objects too. They touched the objects of interest and waited for a reaction from their peers such as a smile, or even a lack of reaction, as a sign of acceptance before they continued playing with the objects 
together. Imitating peers was another popular strategy in gaining access to peers' play. They imitated their peers' shouting, laughing, squealing and jumping and these actions eventually led to successful play entries. In addition, the children were actively trying to become one of the group by participating in activities, pursuing opportunities to interact whenever a chance came by, and having shared experiences between them. Even though adults led some activities at the centres, children were seen to be skilled in creating that sense of belongingness and togetherness with peers like calling each other's names, laughing and cheering for their peers. The children wanted to be together and to do things together because when they had a chance to just be alone, they looked for a peer/peers and socialized with them. The children pursued interaction when they had opportunities instead of turning away from the opportunities, which showed their eagerness in being a part of the group.

It was also observed that the children learned how to create belonging and togetherness at the same time as exercising their social competence and agency by embracing the centre's routines such as lining up whenever they wanted to go somewhere, sitting together at the dining table during mealtime, and packing up their toys after playtime. Children were seen to laugh, squeal and chat excitedly during lining up. Belongingness and togetherness were seen when they placed their hands on each other's shoulders and walked in a train-like manner. They were also seen to sing during lining up and their faces showed that they were enjoying themselves. At mealtime, the children read prayers together prior to eating and joined in conversations in creating that sense of togetherness. Packing up toys together with peers was also seen as a cooperative activity because they helped each other to put things away. Some children sang together while packing up and some turned it into a game like making a wailing siren noise as they picked up toys from the floor.

The children were also seen to create togetherness as they learn to respond to the needs of others by offering help and by showing empathy and comfort to peers in need. By interacting with familiar peers on a daily basis at their childcare centres, the children developed a sense of how to help others and when to show empathy and comfort when 
peers needed them. Examples of children helping one another are when two children collaborated to overcome the use of adult power (see chapter 5) and a child handed out toys to a peer. Whenever peers were in distress, some children were seen to give out a hug or comforting words to soothe their peers. The children showed they had learned from the numerous opportunities for them to encourage a sense of collaboration, connection and community by being together. Additionally, through drawing on Loizou's (2005) theory of the absurd, I have argued that children used humour and laughter in the service of creating a sense of togetherness. They did this when they used objects incongruously and made funny sounds, which not only sparked fun in their interactions but at the same time created togetherness.

Just like any other relationships, the children's relationships can also break down due to conflicts. The practitioners talked about how they reacted to children's conflicts and the strategies they used to ease these situations. Most of the times, the practitioners commented that the children were involved in conflicts because of an object. By observing the children's conflicts, I found that conflicts were more than just about an object. In my study, I use the term "motivations" in the manner of Licht et al. (2008) who studied conflicts between peers in infancy and toddler age through an observational study in a Swiss childcare centre. Licht et al. identified seven motivations behind the children's conflicts and argued that possession of objects was not the main reason children get into conflict, as previously believed. My analysis is consistent with that of Licht et al.'s on this point, nonetheless possession of an object was still one of the top reasons for the occurrence of conflicts with very young children. In my observations, conflicts arose at the three case study centres because of: (1) possession of objects; (2) interrupted activity; and (3) exploration and curiosity. This suggests that there were deeper reasons why children got into conflicts with the obvious implication being that unless the practitioners observe conflicts unfolding, or are able to ask the children about the conflicts, they will not get a clear picture behind every conflict. 
The practitioners also spoke about how they used cessation strategies and some mediation strategies in resolving the children's conflicts. What the practitioners did not discuss, and perhaps did not even realise, was that during the times adults were not around to witness the children's conflict situations, these very young children were capable of resolving their own conflicts. In this study I observed three major conflict resolution strategies by the children: (1) seeking an adult's intervention; (2) giving in and walking away; and (3) giving their peer an alternative object. Using De Waal's (2000) Relational Model as an analytical lens, I have argued that some of the children tried to resolve the conflict by first seeking an adult's intervention, but found their own ways to solve the conflicts when adults did not give a helping hand. Other than that, the children learned to give in and walk away, and give an alternative object to their peers when they were in a conflict that involved possession of objects. In regards to the Relational Model of De Waal (2000), the children were seen to use all three suggested ways in settling a conflict, which are aggression, tolerance and avoidance. Most of the time throughout my observations, the children opted for tolerance and avoidance rather than aggression and this could be seen in their non-verbal cues and body language. My analysis also recognized an additional way that children resolved their conflicts with peers, which was to back off in situations they could not control, or in which they could not exert power. In other words, some children involuntarily had to give up the fight due to stronger or older opponents.

Overall, the conflicts I observed can be said to have given opportunities to the children to learn and practise their social competence. While these are rich learning experiences for the children, as discussed in chapter six, the practitioners do need to be present from time to time to mediate during these conflicts because practitioners need to guide the children to learn about taking turns, sharing, give and take, respecting other people's personal space and other social competence skills. The practitioners in this study appeared to be generally absent during the children's conflicts, or intervened too quickly, and applied more cessation than mediation strategies when intervening in the children's conflicts, which made for missed opportunities for children's learning. 


\subsubsection{Implications for social competence development and agency}

This study has highlighted the importance that those who work with young children understand the significance of peer interactions for the development of children's social competence and agency skills. The practitioners mentioned children's social competence development from time to time during the semi-structured interviews, video-stimulated recalls and focus group discussions but they did not mention children's agency. I argue that children's peer interactions grow alongside social competence, and through the children's exercise of their agency in making and taking opportunities to establish and maintain that peer interactions.

As mentioned before, whenever the children had the chance to interact with their peers at their respective childcare centres, they were seen to be actively seeking to create a sense of belonging and togetherness with their peers. In creating this belonging and togetherness, the children were actually learning to be socially competent and how to use their agency in getting what they wanted or reaching their goals. By using RoseKrasnor's (1997) Social Competence Prism in explaining the social competence of the children in this study and by adopting Guo and Dalli's (2016) definition of agency, I was able to discuss how peer interactions are related to social competence development and agency. For example, as the children interacted with their peers, they learned how to negotiate entry strategies, show empathy, be part of the group, imitate peers and how to deal with peers when there was a conflict, which are all part of learning to become socially competent. According to Rose-Krasnor (1997), the skills level at the bottom of the social competence prism "represents the behavioural and motivational base upon which the higher levels are built" (p. 123). This means that children need to learn a lot of skills such as empathy, communication, social problem solving and taking turns in order to be effective in interaction. Through daily interactions with peers at their childcare centres, the children learn how to socialize with peers and develop these social competence skills and hopefully become effective in their interactions with others beyond their childcare centres. Agency is shown when the children use their autonomy, have the capacity to learn and take actions of their own accord. These qualities were evident when the children pursued opportunities to interact, in the decisions they made in creating that 
sense of belonging and togetherness, and what they did and did not do during conflict moments.

This study is important because of its potential to heighten the awareness of practitioners working with children under the age of three years about what is really going on during the children's peer interactions at their childcare centres. It is also important for practitioners to realise that even very young children, such as infants, engage in peer interactions even if these are non-verbal ones, such as through eye contacts, body language and facial expressions. In addition, it is important for practitioners to be mindful that children's peer interactions lead to a richness of learning and development in the areas of social competence and agency. Peer interactions are not just about being able to communicate with each other but also about creating a sense of belonging and togetherness as well as resolving conflicts positively among peers.

\subsubsection{Implication for practitioner training and practices}

This study brings into focus that training in early childhood education is important for those people who want to work with children, be it centre preschool, a childcare centre, or a nursery. Throughout the study, it was clear that while the practitioners showed some understanding of children's peer interactions, their initial views about peer interactions were quite limited and did not show a full awareness of what was going on in the children's peer interactions. The practitioners suggested that putting children into groups was a way to encourage interactions and to manage conflicts among the children, which they saw as negative behaviours that needed to be ended. However, sometimes they ended the conflicts prematurely without any lessons being learned by the children. Additionally, the practitioners were not familiar with some terms or jargons used in ECCE such as 'peer culture'. Nevertheless, the practitioners' understandings broadened considerably when they were given a chance to comment on the videos of the children's peer interactions during the video-stimulated recall interviews. Moreover, the focus group discussions with the other practitioners deepened the practitioners' thoughts on children's peer interactions at their respective childcare centres. This shows that the practitioners benefitted from the opportunity to stop and reflect with colleagues on the children's 
interactions during the video-stimulated recall discussions and this helped them realize what truly goes on during children's peer interactions at a childcare centre. The way that VSR supported practitioners' learning implies that video can be a potentially powerful tool in professional development for teachers.

One suggestion that I could make for practices in ECCE is that centre managers or head teachers in ECCE centres in Malaysia could consider doing video-stimulated recall and focus group discussions with their practitioners at their respective centres during their regular meetings. The centre managers or head teachers could place a GoPro in the room, maybe on a shelf where it is not easily accessible and noticeable by the children. This method was also used in Shoecraft and Flückiger's (2018) study with young children around video cameras. The researchers saw benefits of using a GoPro such as having a wide-angle lens and therefore can capture almost the entirety of the classroom. So, by using a GoPro to capture the children's and their practitioners' lived experiences at an ECCE centre, the centre managers or head teachers can select footage for discussion about the potential learning that the children gained from interacting with peers. This can deepen the practitioners' thinking about children's learning when they discuss the video footage with their colleagues about what is going on for the children.

Therefore, a key implication from this study is that it is important that practitioners are knowledgeable about children's peer interactions and about the impact they have on the children's learning, leading to the conclusion that training in ECCE prior to, or while working in a childcare centre, is needed. While the children gained a lot of knowledge by interacting with their peers daily at their childcare centres, it was clear that the practitioners were in a potentially very powerful position to support the children's interactions. My study shows that practitioners are more likely to do so if they understand what is going on for the children. In turn this means that the practitioners need to be alert to what is going on for the children, to have the time to devote to observing children in a meaningful way, and also have the knowledge to interpret what is going on in the observed interactions. Sometimes the children need advice or explanations from the practitioners and if the practitioners are not trained to understand the children's cues, they 
are not able to give the right response to the children. The practitioners have the opportunity to give encouragement to the children in a way that supports their social competence development and the use of agency in their everyday life so that they can be effective in their interactions with others. This knowledge of how to give support, encouragement and responding positively to children's conflicts, cannot be left to chance but requires specialised trainings particularly for those working with very young children under the age of three.

\subsection{Research contributions}

This research provides three main contributions relating to young children's peer interactions: (1) it contributes to international research in the field of children's peer interactions especially for under threes; (2) it contributes to knowledge about how to support children's peer interactions; and (3) it contributes to knowledge about good classroom practices. These are explained in more details below.

\subsubsection{Contribution to the field of children's peer interactions especially under three year olds in Malaysian early childhood education centres}

Many studies (both quantitative and qualitative studies) have been conducted on children's peer interactions with some studies having also focused on children who are under three years old at their childcare centres. My study differs from earlier studies in that it is based in Malaysia where ECCE is still a relatively new social and educational endeavour staffed by largely unqualified practitioners. This study thus breaks new ground in providing an initial investigation that can serve to open this area for further study. The data provided insights into the interactions that occurred at three Malaysian childcare centres and showed how practitioners' understandings of what is really going on when children get together, or interact with each other, can be broadened through focused analysis and discussion.

The findings further suggest that children are active beings who use their agency during peer interactions. The children were seldom seen to be alone. Rather, most of the time, 
the children wanted to be with their peers or wanted to interact with their peers and thus they were seen to actively seek opportunities to create a sense of belonging and togetherness at their childcare centres. In addition to using their agency, children were developing their social competence as they interacted with their peers with my data showing a richness of learning that grew as they learned how to use their social competence in reaching their peer interaction goals. For example, the children embraced the routines of their childcare centres, responded positively to their peers' needs and applied humour and laughter thus enabling each other to feel connected and to create that sense of belonging and togetherness with their peers.

The present study also contributes to the literature by drawing on constructs from a range of social constructivist theoretical perspectives: (1) Lefebvre's concept of the everydayness; (2) Social Competence Prism; (3) The notion of agency; (4) The theory of the Absurd; (5) Motivations underlying children's conflicts and (6) The Relational Model to explain the dynamics involved in children's peer interactions at the three case study childcare centres. The findings of this study indicate that children's peer interactions are complex and that is much going on in their interactions, which practitioners have to understand and acknowledge.

In summary, the analysis of data in my research shows that children under three year olds are competent at interacting with their peers and in the process are able to create a sense of belonging and togetherness with the others at their childcare centres. But having a sense of belonging and togetherness is not something that happens by itself for these children. They have to find their own strategies in order to reach their goals. Alongside reaching their goals (creating a sense of belonging and togetherness), the children use their agency and learn some skills towards social competence. Hence, the findings of this study should be useful to the literature on children under three years old and their peer interactions, to childcare practitioners and other researchers in this field. 


\subsubsection{Contribution to knowledge about supporting children's peer interactions}

The findings of this study offer an understanding of how the Malaysian practitioners in my study viewed very young children's peer interactions. In this study, most of the practitioners were young, untrained in ECCE, and had limited experiences in child rearing. Given that Malaysia is working towards providing high quality education services (Malaysia Education Blueprint 2013-2025) as the first step within the educational system, it is important to understand how current early childhood education practitioners perceive children's peer interactions to provide a base-line understanding that can inform future training for the childcare workforce. In semi-structured interviews with practitioners it was clear that they had some understanding of what peer interactions were all about. However, when the practitioners were given a chance to view the children's peer interactions on video, and talked about the topic during the videostimulated recall interviews and focus group discussions, they were able to see a great deal more of what went on during children's peer interactions. Additionally, the practitioners' views were broadened and their thinking on the topic of under-three year old children's peer interactions was deepened.

Thus, the present study contributes to the literature by displaying that the use of videostimulated recall interviews and focus group discussions with the practitioners are useful techniques for getting practitioners to broaden their thinking on certain topics. These methods may be applied in other research projects aimed at gathering perceptions from a group of people. In this study, video-stimulated recall interviews were useful in helping the practitioners see what goes on during children's peer interactions as well as enabled them to think deeper about the topic. It shows that the practitioners not only understood more of what went on during children's peer interactions, but also they were able to reflect on their practices and understand what their practices can contribute towards the children's learning.

The findings of this study also offer understandings on how to support very young children's peer interactions. The children in this study showed their eagerness to create a sense of belonging and togetherness through entry strategies, becoming one of the group, 
embracing the centre's routines, responding to the need of others and having humour and laughter. Such findings can be used to alert practitioners to keep an eye out for these behaviours and be supportive of the children's learning. Practitioners can support the children by teaching them turn-taking, and to encourage sharing and cooperation to name a few. In addition, practitioners have to be aware that there are many reasons why conflicts arise so that they can give the right support to the children and take the opportunities that arise for teaching the children problem solving.

Thus, this study can help practitioners become mindful and observant of the children's behaviour. Peer interactions can be a learning platform for the children in using their agency and develop their social competence. Therefore, understanding the children's behaviours, and knowing what to do to be supportive of children's peer interactions may help children become effective in interactions not just in their childcare centres but also throughout life.

\subsubsection{Contribution to good classroom practices}

This study provides insights into children's peer interactions in three childcare centres in Selangor, Malaysia. The insights may contribute to understanding how young and untrained childcare centre practitioners might perceive other very young children's peer interactions. The next sub-sections outline some important contributions these findings could make to classroom practices, which other practitioners in Malaysia and beyond can use to support very young children's peer interactions.

\section{Enhancing children's peer interactions}

In this study, the practitioners believed that arranging group activities for the children could promote the children's sociability with their peers (see section 4.2) and my data showed that organising group activities was a strategy most of the practitioners claimed to use as a way of supporting the development of children's peer interactions. The practitioners did this by bringing the children together in groups and arranging that they sit together. Activities like games, play-dough, blocks and baking a cake were some 
examples of the activities that were conducted during this group setting. According to the practitioners, interactions could be seen during these group activities as the children used their non-verbal gestures such as eye contact, facial expressions and body language to communicate with peers. Additionally, the children were also seen to learn some social competence skills as they learned to share and cooperate when they used resources together in a group. While these strategies are valuable to establish group control and sustain classroom harmony, researchers (eg: Davis \& Degotardi, 2015; Williams et al., 2010) argue that these strategies are limited in their ability to promote exploration and independence. Practitioners have to understand that peer interactions can also happen outside group activities, such as in pairs.

\section{Conflicts as learning moments for the children}

According to Gloeckler, Cassell and Malkus (2014) and De Haan and Singer (2003), when conflicts are perceived to be learning moments, practitioners learn how to empower children through making choices and are better able to promote children's learning to be socially competent (see section 4.3). In this study, most of the practitioners used cessation strategies in dealing with children's conflicts with some practitioners appearing to use mediation strategies too. Past researchers suggested that using mediation strategies in dealing with children's conflicts - such as acknowledging the children's feelings, identifying the problem, and offering follow-up support to the children (Chen et al., 2001). Additionally, practitioners have to keep in mind that conflicts are learning moments for the children and that they should use mediation strategies more in dealing with conflicting situations. According to Chen (2003), practitioners who use mediating intervention strategies to facilitate children's conflicts can help them learn to understand peers' intentions and manage their own needs and intentions as well. For example, asking children to apologize and salam may be good for them to learn about forgiveness if the practitioners take time to explain these actions instead of just asking them to do the acts and not explain about them. 


\section{Let them play}

When the children play together, they find ways to communicate even though some children do not talk yet. Pre-verbal children learn to use their non-verbal communicative tools to interact. Thus, play isn't just play. It is an interaction between children to understand others (Davis \& Degotardi, 2015). These are important skills in developing the children's social competence as mentioned in the Social Competence Prism by RoseKrasnor (1997). The children need to interact with peers so that they can learn to be effective during interactions. It is through play that children engage and interact in the world around them. During reflections through video-stimulated recall interviews and focus group discussion, the practitioners in this study commented that through play, children learn how to share resources, communicate with peers both through verbal and non-verbal means and the children learn to understand the peer's intentions, needs as well as peers' emotions (see section 7.2). Hence, practitioners should give a lot of opportunities for the children to do free play at their childcare centres so that the children can benefit from the richness of learning that happens when they play together with peers.

\section{Ensure the children become familiar with each other}

Children who go to childcare centres have the opportunities to become familiar with their peers as they attend the centre regularly and interact with the same people (Aureli \& Colecchia, 1996). The practitioners in this study mentioned how they observed familiarity with peers to have a lot of benefits in children's peer interactions (see section 7.3). The children were seen to have more connections with familiar peers than the less familiar ones. Apart from that, the children were believed to have more confidence when interacting with the familiar peer and their relationship with each other may develop into friendship. Furthermore, this relationship can develop empathy in children as they learn to be together with peers and these peer interactions in turn can get the children ready for school (see section 7.4). This suggests that it is helpful for practitioners to support children's growing peer interactions so that they can get familiar with each other because there are so many benefits of familiarity. 


\section{Improving practice}

Practitioners often find managing a childcare setting difficult, especially managing or caring for very young children under the age of three years. The findings from this study indicate that children's peer interactions are so much more complex than what the practitioners perceived them to be. The children were seen to be active in creating a sense of belonging and togetherness with their peers at their childcare centres through a lot of ways such as negotiation of play entries and putting humour and laughter in their interactions. Thus, this finding can help practitioners see what is important to the children and at the same time help the practitioners improve on their classroom practices. Classroom practices like supporting and scaffolding the children's peer interactions may help the children in their everyday interactions with peer not only to be effective in interacting with peers at the childcare centre but also to develop their agency and social competence which are useful throughout life.

\subsection{Limitations of the study}

One of the limitations of the study was that the use of a case study framework, while useful for opening up this area of study in Malaysia, nonetheless provides only a limited picture of the kinds of peer interactions among children under three years old in childcare centres across Malaysia. Moreover, the time constraints of a doctoral research project mean that the study was able to capture only a small sample of the children's peer interactions. The findings of this research of the children's peer interaction may or may not be what the children experienced throughout the whole year. Secondly, the practitioners' answers to the interview questions about how they perceived children's peer interactions may not have captured a complete picture of their thinking. By contrast, the video-stimulated recall interviews and the focus group discussions with the practitioners provided more elaborated perspectives suggesting that the framework of the VSR and focus group may have enabled them to talk more deeply than the individual interview format. Thirdly, only three childcare centres were studied in this research. This number of centres cannot be representative of all of the childcare centres in Malaysia or even all of the childcare centres in Selangor. However, other practitioners of childcare centres who read this research should be able to judge for themselves whether the 
findings transfer to their own context. Last but not least, a further limitation was that most children in this study could not talk yet and could not express themselves in words making them unable to clearly confirm that what I have written is a correct statement or interpretation of their experience or of what I saw on the video. My interpretation therefore had to rely mainly on the children's body language and gestures as well as what I could confirm from the video-stimulated recall interviews with the practitioners which helped me greatly in interpreting what was happening with the children.

\subsection{Areas for future research}

Much research has been conducted on children's peer interactions but not many peer interaction studies have focused on children who are under three years old. Of all the researchers conducted in this area, many were from the western world while research in Asian childcare centres is still limited. In Malaysia, the number of research projects on young children at their childcare centres is growing but again, not many have focused on children under three years old and no research focused on children's peer interactions by using the methods I have used in this study: semi-structured interviews with the practitioners, direct observations of the children's peer interactions, video-stimulated recall interviews and focus groups discussions with the practitioners after collecting the children's data. The need for further research in this area is therefore still strong.

Future research is needed to look at the children's peer interactions across a greater number of childcare centres in Malaysia, not just in Selangor. It is important to understand what goes on during the children's peer interactions in other parts in Malaysia too because once we understand what children do during peer interactions, then practitioners are better equipped to give children the support they need to build children's social competence as well as their agency.

A study could also be undertaken to investigate qualified (as opposed to untrained) practitioners' perceptions of children's peer interactions and find out how they support or encourage children's peer interactions at their childcare centres in Malaysia. The practitioners in my study were mainly practitioners who had no ECCE qualifications or 
trainings and thus their perceptions may differ from those of practitioners who are qualified in ECCE. The findings can give insights on the type of training needed for childcare centres' practitioners prior to their career.

In addition to this, this study looked at children's peer interactions and linked them to social competence development and agency. Future research can look at other areas of children's development such as cognitive development or moral development and link it to children's peer interactions. This may allow the impact of children's peer interactions in Malaysia to be captured and linked with children's development in the Malaysian ECCE context.

\subsection{Concluding thoughts}

All of the three childcare centres in my study had practitioners who were enthusiastic and willing to learn something new. In each childcare centre, I witnessed many wonderful peer interactions among the under three years old children. The children were happily interacting with their peers and at the same time a richness of learning occurred as they discovered more about themselves by exercising their agency and developed their social competence. The practitioners were highly supportive of the study by participating and by being willing to share their views on children's peer interactions; they were also willing to be reflective about their practices by discussing them during video-stimulated recall and focus groups. Nevertheless, there was still room for improvement. As already mentioned, the practitioners in this study were not ECCE trained and thus their views on children's peer interactions may have been limited to their intuitive senses and not informed by theoretically-based arguments. This issue can constrain the practitioners' understanding of children's peer interactions and thus might also limit the support they are able to give to the children in building their social competence development and agency. Additionally, having unqualified and untrained practitioners at childcare centres can raise serious questions about the quality of the education system as well as the quality of the very young children's lives. Children go to these centres everyday with some children spending their time at these childcare centres for more than 40 hours a week. I believe that children deserve to live in an environment that is very rich in learning as well 
as getting support and encouragement from knowledgeable practitioners who know what they are doing in developing the children as a person as well as the next generation of the nation. We have to take steps, even though small, to work towards a better education for these very young children. The Lorax reminds us, "unless someone like you care a whole awful lot, nothing is going to get better. It's not" (Dr. Seuss, 1971). 


\section{REFERENCES}

Angeleri, R. \& Airenti, G. (2014). The Development of Joke and Irony Understanding: A Study With 3- to 6-Year-Old Children. Canadian Journal of Experimental Psychology/Revue canadienne de psychologie expérimentale, 68(2), 133-146. doi:10.1037/cep0000011

Antonsson, H., Graneheim, U. H., Lundström, M., \& Åström, S. (2008). Caregivers' reflections on their interactions with adult people with learning disabilities. Journal of psychiatric and mental health nursing, 15(6), 484-491. doi: 10.1111/j.1365-2850.2008.01259.x

Arcaro-Mcphee, R., Doppler, E. E., \& Harkins, D. A. (2002). Conflict Resolution in a Preschool Constructivist Classroom: A Case Study in Negotiation. Journal of Research in Childhood Education, 17(1), 19-25.

Arthur, M., Bochner, S., \& Butterfield, N. (1999). Enhancing peer interactions within the context of play. International journal of disability, development and education, 3 , 367-381.

Aureli, T., \& Colecchia, N. (1996). Day care experience and free play behavior in preschool children. Journal of Applied Developmental Psychology, 17(1), 1-17. doi:10.1016/S0193-3973(96)90002-7

Bae, B. (2012). Children and teachers as partners in communication: Focus on spacious and narrow interactional patterns. International Journal of Early Childhood, 44 (1), 53-69.

Bagwell, C. L., \& Schmidt, M. E. (2011). Friendships in Childhood and Adolescence. New York: The Guilford Press.

Bandura, A. (1986). Social foundations of thought and action: a social cognitive theory. Englewood Cliffs, N.J: Prentice-Hall

Balakrishnan, V. (2009). Teaching moral education in secondary schools using real-life dilemmas. Unpublished $\mathrm{PhD}$ thesis. Victoria University of Wellington, New Zealand.

Barnett, W. S. (2011). Effectiveness of early educational intervention. Science, 333(6045), 975-978. doi: 10.1126/science. 1204534

Baumeister, R., \& Leary, M. (1995). The need to belong: Desire for interpersonal attachments as a fundamental human motivation. Psychological Bulletin, 117(3), 497.

Bayer, C. L., Whaley, K., \& May, S. (1995). Strategic Assistance in Toddler Disputes: II. Sequences and Patterns of Teachers' Message Strategies. Early Education and Development, 6(4), 405-432. doi:10.1207/s15566935eed0604_7

Beebe. B. (2017). Daniel Stern: Microanalysis and the empirical infant research foundations. Psychoanalytic Inquiry, 37(4), 228-241.

Belsky, J. (2006). Effects of child care on child development in the USA. In J. J. v. Kuyk (Ed.), The quality of early childhood education (pp. 23-32). Arnhem, The Netherlands: Cito.

Bergen, D. (2001). Finding the humor in children's play. In J. L. Roopnarine (Ed.), Conceptual, social cognitive, and contextual issues in the fields of play (pp. 209222). Westport, CT: Ablex Publishing. 
Berk, L. (1985). Relationship of caregiver education to child-oriented attitudes, job satisfaction, and behaviors toward children. Child care quarterly, 14(2), 103-129. doi:10.1007/BF01113405

Berthelsen, D., \& Brownlee, J. (2007). Working with Toddlers in Child Care: Practitioners' Beliefs about Their Role. Early Childhood Research Quarterly, 22(3), 347-362.

Blair, C. (2002). School readiness: integrating cognition and emotion in a neurobiological conceptualization of children's functioning at school entry. American Psychologist, 57(2), 111-27.

Blandon, A. Y., \& Scrimgeour, M. B. (2015). Child, Parenting, and Situational Characteristics Associated with Toddlers' Prosocial Behaviour. Infant and Child Development, 24(6), 643-660.

Booren, L. M., Downer, J. T., \& Vitiello, V. E. (2012). Observations of Children's Interactions with Teachers, Peers, and Tasks across Preschool Classroom Activity Settings. Early Education and Development, 23(4), 517-538.

Bowman, B., Donovan, M. S., \& Burns, M. S. (2001). Eager to learn: Educating our preschoolers. Washington, DC: national Academy Press.

Bradley, J. (1993). Methodological issues and practices in qualitative research. Library Quarterly, 63(4), 431-449.

Braun, V., \& Clarke, V. (2006). Using thematic analysis in psychology. Qualitative Research in Psychology, 3(2), 77-101.

Braun, V., \& Clarke, V. (2012). Thematic analysis. In H. Cooper (Ed.), APA Handbook of Research Methods in Psychology: Vol. 2. Research designs (pp. 57-91) Washington, DC: American Psychological Association.

Brennan, M. A. (2005). "They just want to live with us." Young children: Learning to live the culture. Unpublished PhD thesis. Victoria University of Wellington, New Zealand.

Brenner, J., \& Mueller, E. (1982). Shared Meaning in Boy Toddlers' Peer Relations. Child Development, 53(2), 380-391.

Broadhead, P. (2009). Conflict resolution and children's behaviour: Observing and understanding social and cooperative play in early years educational settings. Early Years: An International Journal of Research and Development, 29(2), 105118.

Bronfenbrenner, U. (1979). The ecology of human development. Cambridge, MA: Harvard University Press.

Brown, P. \& Levinson, S. C. (1987). Politeness : some universals in language usage. Cambridge: Cambridge University Press.

Brownell, C. A. (1990). Peer Social Skills in Toddlers: Competencies and Constraints Illustrated by Same-Age and Mixed-Age Interaction. Child Development, 61(3), 838-848.

Bryman, A. (2008). Social research methods. Oxford: Oxford University Press.

Bukowski, W. M., Buhrmester, D., \& Underwood, M. (2011). Peer relations as a context for development. In M. Underwood \& L. Rosen (Eds.), Social Development (pp. 153-179). New York: Guilford.

Bukowski, W. M., Newcomb, A. F., \& Hartup, W. W. (1996). The Company They Keep: Friendships in Childhood and Adolescence: Cambridge University Press. 
Burger, K. (2010). How does early childhood care and education affect cognitive development? An international review of the effects of early interventions for children from different social backgrounds. Early Childhood Research Quarterly, 25(2), 140-165. doi:10.1016/j.ecresq.2009.11.001

Butovskaya, M., Verbeek, P., Ljungberg, T. \& Lunardini, A. (2000). A multicultural view of peacemaking among young children. In F. d. W. Aureli, F. B. M. (Ed.), Natural conflict resolution (pp. 243-262). Berkeley, CA: University of California Press.

Buysse, V., Goldman, B. D., \& Skinner, M. L. (2003). Friendship Formation in Inclusive Early Childhood Classrooms: What Is the Teacher's Role? Early Childhood Research Quarterly, 18(4), 485-501. doi:10.1016/j.ecresq.2003.09.007

Cameron, E. L., Kennedy, K. M., \& Cameron, C. A. (2008). "Let me show you a trick!": a toddler's use of humor to explore, interpret, and negotiate her familial environment during a day in the life.(Report). Journal of Research in Childhood Education, 23(1), 5.

Campbell, F. A., \& Ramey, C. T. (1995). Cognitive and School Outcomes for High-Risk African-American Students at Middle Adolescence: Positive Effects of Early Intervention. American Educational Research Journal, 32(4), 743-772. doi: $10.2307 / 1163334$

Campbell, J. J., Lamb, M. E., \& Hwang, C. P. (2000). Early Child Care Experiences and Children's Social Competence between 1.5 and 15 Years of Age. Applied Developmental Science, 4(3), 166-175.

Campbell, S. B., Denham, S. A., Howarth, G. Z., Jones, S. M., Whittaker, J. V., Williford, A. P., \& Darling-Churchill, K. (2016). Commentary on the review of measures of early childhood social and emotional development: Conceptualization, critique, and recommendations. Journal of Applied Developmental Psychology, 45, 19-41. doi:10.1016/j.appdev.2016.01.008

Canella, G. S. (1993) Learning through social interaction: shared cognitive experience, negotiation strategies, and joint concept construction for young children. Early childhood research quarterly, 8, 427-444.

Canning, N. (2011). Play and practice in the early years foundation stage. London: Sage Publication Ltd.

Caplan, M., Vespo, J., Pedersen, J., \& Hay, D. F. (1991). Conflict and Its Resolution in Small Groups of One- and Two-Year-Olds. Child Development, 62(6), 15131524.

Carey, M. A., \& Asbury, J.-E. (2012). Focus group research. Walnut Creek, CA: Left Coast Press.

Carta, J. J., Greenwood, C. R., Luze, G. J., Cline, G., \& Kuntz, S. (2004). Developing a general outcome measure of growth in social skills for infants and toddlers. Journal of early intervention, 26(2), 91-114.

Carter, C., \& Nutbrown, C. (2016). A Pedagogy of Friendship: young children's friendships and how schools can support them. International Journal of Early Years Education, 24(4), 395-413.

Caruso, D. A., Dunn, L., \& File, N. (1992). Cognitive Curriculum Practices in Preschool Programs: Implications for Teacher Preparation. Journal of Research in Childhood Education, 7(1), 27-36. 
Catron, C. E. \& Allen, J. (2008). Early childhood curriculum: a creative play model. Upper Saddle River, New Jersey: Pearson/Merrill Prentice Hall

Chaney, C. (1993). Young children's jokes: a cognitive developmental perspective. Paper presented at the Annual Meeting of the Western States Communication Association, Albuquerque.

Chen, D. W., Fein, G. G., Killen, M. \& Tam, H. (2001). Peer conflicts of preschool children: issues. Resolution, incidence, and age-related patterns. Early Education and Development, 12(4). 523-544.

Chen, D. W. (2003). Preventing Violence by Promoting the Development of Competent Conflict Resolution Skills: Exploring Roles and Responsibilities. Early Childhood Education Journal, 30(4), 203-208.

Chen, D. W., Fein, G. G., \& Tam, H. P. (1998). Teacher interventions in the conflicts of preschool children: Effects of children's age and conflict behavior. Paper presented at the Annual Meeting of the American Educational Research Association, San Diego, CA.

Cherry, K. (2018). Understanding Collectivist Cultures. How culture can influence behavior. Retrieved on 20 July 2019 from https://www.verywellmind.com/whatare-collectivistic-cultures-2794962

Chiam, H. K. (1999). Excellence in Early Childhood Education Selangor Pelanduk Publications (M) Sdn Bhd.

Child Care Centre Act 1984. Child Care Centre Regulations 2012. (2012) Arrangement of Regulations Malaysia: Attorney General Chambers of Malaysia.

Chmiliar, L. (2010). Multiple-case designs. In A. Mills, G. Durepos, \& E. Wiebe (Eds.), Encyclopedia of case study research (pp. 583-585).

Clarke, L., McLaughlin, T. W., \& Aspden, K. (2017). Promoting learning during toddlers' peer conflicts: teachers' perspectives. Early Years, 1-15.

Clarke, V., \& Braun, V. (2013). Teaching Thematic Analysis: Overcoming challenges and developing strategies for effective learning. The Psychologist, 26(2), 120-123.

Clarke-Stewart, A., Gruber, C. P., \& Fitzgerald, L. M. (1994). Children at home and in day care. Hillsdale, NJ: Lawrence Erlbaum Associates.

Corsaro, W. (1981). Friendship in the nursery school: Social organization in a peer environment in Asher, S. R. and Gottoman, J. (Eds.), The development of children's friendships, (207-241). New York: Cambridge University Press.

Corsaro, W. A. (1985). Friendship and peer culture in the early years / William A. Corsaro. Norwood, N.J.: Norwood, N.J. : Ablex Pub. Corp.

Corsaro, W. (1997). The Sociology of Childhood. Thousand Oaks, CA: Pine Forge Press.

Corsaro, W. (1988). Routines in the peer culture of the American and Italian nursery school children. Sociology of Education, 67. 1-26.

Corsaro, W. A. (2003). "We're friends, right?" : inside kids' cultures / William A. Corsaro. Washington, D.C.: Washington, D.C. : Joseph Henry Press.

Corsaro, W. A. (2012). Interpretive Reproduction in Children's Play. American Journal of Play, 4(4), 488-504.

Corsaro, W. A. \& Molinari, L. (2008). Entering and observing in children's worlds. In P. Monrad Christensen \& A. James. (eds.) Research with Children: Perspectives and Practices. ( $2^{\text {nd }}$ ed). NY: Routledge. 239-290. 
Corsaro, W. \& Emiliani, S. (1992). Child care, early childhood education, and children's peer culture in Italy. In M. E. Lamb, K.J. Sternberg, C. P. Hwang \& A. G. Broberg (Eds.), Child care in context: Cross-cultural perspectives (pp.81-115). Hillside, NJ: Erlbaum.

Corsaro, W. A. \& Molinari, L. (2000). Entering and observing in children's worlds: A reflection on a longitudinal ethnography of early education in Italy. In $\mathrm{P}$. Christensen \& A. James (Eds.), Research with children. Perspectives and practices (pp. 179-200). New York: Falmer Press.

Creswell, J. W. (2009). Research design: qualitative, quantitative, and mixed methods approaches. Los Angeles: Sage.

Creswell, J. W. (2013). Research design: qualitative, quantitative, and mixed method approaches. Los Angeles, Calif: SAGE.

Creswell, J. W. (2014). Research design: qualitative, quantitative, and mixed methods approaches. Thousand Oaks: SAGE Publications.

Cohen, L., Manion, L., \& Morrison, K. (2000). Research methods in education (5 ed.). New York: RoutledgeFalmer.

Cromdal, J. (2001). Can I be with? Negotiating play entry in bilingual school. Journal of pragmatics, 33, 515-543.

Damon, W. (1977). The Social World of the Child. San Francisco: Jossey-Bass.

Davis, B., \& Degotardi, S. (2015). Educators' understandings of, and support for, infant peer relationships in early childhood settings. Journal of Early Childhood Research, 13(1), 64-78. doi:10.1177/1476718X14538600

Dawe, H. C. (1934). An Analysis of Two Hundred Quarrels of Preschool Children. Child Development, 5(2), 139-157.

Deater-Deckard, K. (2001). Annotation: Recent research examining the role of peer relationships in the development of psychopathology. Journal of Child Psychology and Psychiatry, 42(5), 565-579.

Dempsey, N. P. (2010). Stimulated Recall Interviews in Ethnography. Qualitative Sociology, 33(3), 349-367.

Department of Social Welfare Malaysia. (2013). Portal Rasmi Jabatan Kebajikan Masyarakat. Retrieved 05 June 2015 from http://www.jkm.gov.my

Department of Statistics, M. (2010). Population distribution and basic demographic characteristics Population and housing census of Malaysia. Putrajaya:

Department of Statistics, Malaysia.

Deegan, J. G. (1991). An ethnography of children's friendships in a fifth-Grade culturally diverse class. Paper presented at the annual meeting of the American Educational Research Association, Chicago.

Degotardi, S. (2010). High-quality interactions with infants: relationships with early-childhood practitioners' interpretations and qualification levels in play and routine contexts. International Journal of Early Years Education, 18(1), 27-41. doi:10.1080/09669761003661253

Degotardi, S. (2011). From greetings to meetings: How infant peers welcome and accommodate a newcomer into their classroom. The first years Tga Tua Tuatahi: New Zealand of Infant and Toddler Education. 13(2), 29-33. 
Degotardi, S., \& Davis, B. (2008). Understanding Infants: Characteristics of Early Childhood Practitioners' Interpretations of Infants and Their Behaviours. Early Years: An International Journal of Research and Development, 28(3), 221-234. doi:10.1080/09575140802393686

Degotardi, S. \& Pearson, E. (2009). Relationship Theory in the Nursery: Attachment and beyond. Contemporary Issues in Early Childhood, 10(2), 144-155.

doi:10.2304/ciec.2009.10.2.144

Degotardi, S. \& Pearson, E. (2014). The relationship worlds of infants and toddlers: multiple perspectives from early years theory and practice. Open university press. Berkshire.

Denham, S. A., Blair, K. A., DeMulder, E., Levitas, J., Sawyer, K., Auerbach-Major, S. \& Queenan, P. (2003). Preschool emotional competence: Pathway to social competence? Child Development, 74(1), 238-256.

Denham, S. A. (2006). Social-Emotional Competence as Support for School Readiness: What Is It and How Do We Assess It? Early Education \& Development, 17(1), 57-89. doi:10.1207/s15566935eed1701_4

Denham, S. A., Wyatt, T. M., Bassett, H. H., Echeverria, D., \& Knox, S. S. (2009). Assessing social emotional development in children from a longitudinal perspective. Journal of Epidemiology and Community Health, 63(1), 37.

Denham, S. A., \& Brown, C. (2010). "Plays Nice with Others": Social-Emotional Learning and Academic Success. Early Education and Development, 21(5), 652.

De Haan, D., \& Singer, E. (2001). Young Children's Language of Togetherness Le Langage de e Togetherness f des Jeunes Enfants El Idioma del Sentimiento de Unio'n de Los Menores. International Journal of Early Years Education, 9(2), 117-124.

De Haan, D., \& Singer, E. (2003). Use your words: A sociocultural approach to the teacher's role in the trasition from physical to verbal strategies of resolving peer conflicts among toddlers. Journal of Early Childhood Research, 1(1), 95-109.

de Waal, F. B. M. (2000). The first kiss. In F. Aureli \& F. B. M. de Waal (Eds.), Natural conflict resolution. Berkeley, NJ: University of California Press.

de Waal, F. B. M. (2000). Primates: A Natural Heritage of Conflict Resolution. Science, 289(5479), 586-590.

DeVries, R., \& Zan, B. (1994). Moral classrooms, moral children: creating a constructivist atmosphere in early education. New York: Teachers College Press.

Deynoot-Schaub, M. G., \& Riksen-Walraven, J. M. (2006). Peer interaction in child care centres at 15 and 23 months: Stability and links with children's socio-emotional adjustment. Infant Behaviour \& Develeopment, 29, 276-288.

Dierckx de Casterlé, B., Gastmans, C., Bryon, E., \& Denier, Y. (2012). QUAGOL: A guide for qualitative data analysis. International Journal of Nursing Studies, 49(3), 360-371. doi:http://dx.doi.org/10.1016/j.ijnurstu.2011.09.012

Dinehart, L. H., Katz, L. F., Manfra, L., \& Ullery, M. A. (2013). Providing Quality Early Care and Education to Young Children Who Experience Maltreatment: A Review of the Literature. Early Childhood Education Journal, 41(4), 283-290. doi: http://dx.doi.org/10.1007/s10643-012-0553-6 
Dockett, S., Kearney, E., \& Perry, B. (2012). Recognising Young Children's Understandings and Experiences of Community. International Journal of Early Childhood, 44(3), 287-305. doi:10.1007/s13158-012-0073-y

Doppler, E., Harkins, D. \& Arcaro-McPhee, R. (2002). Empathy and conflict in a constructivist preschool classroom. Journal of Research in Childhood Education, 17(1), 19-25.

Doyle, A., Connoly, J. \& Rivest, L. (1980) the effect of playmate familiarity on the social interaction between infant peers. Child development, 51, 217-223.

Dunn, J. (2004). Children's Friendships: The Beginnings of Intimacy. Oxford: Blackwell Publishing.

Early Childhood Care and Education Policy. Implementation Review 2007. (2008) (Vol. 2014, pp. 1-145). Malaysia: Curriculum Development Centre. Ministry of Education Malaysia.

Eckerman, C. O. \& Didow, S. M. (1988). Lessons drawn from observing young peers together. Acta Paediatrica Scandinavica, 77, 55-70.

Eckerman, C. O., Davis, C. C. \& Didow, S. M. (1989). Toddlers' emerging ways of achieving social coordination with a peer. Child Development. 60, 440-453.

Eckerman, C. O., Whatley, J. \& McGhee, L. J. (1979). Approaching and contacting the object another manipulates: A social skill of the one-year-old. Developmental Psychology, 15, 585-593.

Education for All 2015 National Review: Malaysia. (2014): World Education Forum \& UNESCO.

Elicker, J., Ruprecht, K. M., \& Anderson, T. (2014). Observing infants' and toddlers' relationships and interactions in group care. In J. H. Linda \& S. Jennifer (Eds.), Lived spaces of infant-toddler education and care: explorng diverse perspectives on theory, research and practice. Dordrecht: Springer Netherlands.

Elkind, David. (2007) The power of play: learning what comes naturally. London: Cambridge Press.

Engdahl, I. (2011). Toddler Interaction during Play in the Swedish Preschool. Early Child Development and Care, 181(10), 1421-1439.

Engdahl, I. (2012). Doing friendship during the second year of life in a Swedish preschool. European Early Childhood Education Research Journal, 20(1), 83-98.

Epstein, A. S. (2009). Me, you, us : social-emotional learning in preschool / Ann S. Epstein. foreword by Lilian G. Katz. Ypsilanti, Mich. : Washington, DC: Ypsilanti, Mich. : HighScope Press.

Fabes, R. A., Gaertner, B. M., \& Popp, T. K. (2006). Getting along with Others: Social Competence in Early Childhood. In K. McCartney \& D. Phillips (Eds.), Blackwell Handbook of Early Childhood Development (pp. 297-316). Malden, MA: Blackwell Publishing.

Fox, N., Henderson, H., Marshall, P., Nichols, K., \& Ghera, M. (2005). Behavioral inhibition: linking biology and behavior within a developmental framework. Annual Review of Psychology, 56, 235-262

Galejs, I., \& Stockdale, D.F. (1982). Social competence, school behaviors, and cooperative- competitive preferences: assessments by parents, teachers and school-age children. Journal of Gen Psychology, 141, 243-52. 
Gallacher, L. (2016). Theorizing young children's spaces. In A. Farrell, S. L. Kagan, \& E. K. M. Tisdall (Eds.), The SAGE handbook of early childhood research (pp. 118132). London SAGE.

Gass, S. M., \& Mackey, A. (2000). Stimulated recall in second language research. Mahwah, NJ: Lawrence Erlbaum Associates, Publishers.

Gjems, L. (2009). Adults as context for social learning in kindergarten. European Early Childhood Educational Research Journal, 17(3), 297-307.

Gloeckler, L. R. \& Cassel, J. M. (2012). Teacher practices with toddlers during social problem solving opportunities. Early childhood education Journal, 40(4), 251-257.

Gloeckler, L. R., Cassell, J. M., \& Malkus, A. J. (2014). An Analysis of Teacher Practices with Toddlers during Social Conflicts. Early Child Development and Care, 184(5), 749-765.

Gloeckler, L. R. (2006). Teacher/caregiver practices influencing the early development of emotion regulation in toddlers. Unpublished $\mathrm{PhD}$ thesis. University of North Carolina at Greebsboro, USA.

Goin, R. P. (2006). A review of peer social development in early childhood. Early Child Development and Care, 142(1), 1-8.

Goldstein, L. S. (1999). The Relational Zone: The Role of Caring Relationships in the Co-Construction of Mind. American Educational Research Journal, 36(3), 647673. doi:10.3102/00028312036003647

Goncu, A. \& Cannella, V. (1996). The role of teacher assistance in children's construction of intersubjectivity during conflict resolution. New Directions for Child Development, 73, 57-69.

Gonzalez-Mena, J., \& Eyer, D. W. (2012). Infants, toddlers, and caregivers: a curriculum of respectful, responsive, relationship-based, care and education. New York: McGraw-Hill.

Goodfellow, J. (2014). Infants initiating encounters with peers in group care environments. In L. J. Harrison \& J. Sumsion (Eds.), Lived spaces of infanttoddler education and care: Exploring diverse perspectives on theory, reserach and practice. Dordrecht: Springer Netherlands.

Goodman, J. F. (2000). When being nice isn't good. Education Week, 20(3), 30-34.

Granger, K. (2017). Promoting High Quality Teacher-Child Interactions: Examining the Role of Teachers' Depression, Perceptions of Children's Peer Relationships, and Contextual Factors. In L. Hanish, T. Abry, R. Bradley, \& D. DeLay (Eds.): ProQuest Dissertations Publishing.

Gray, D. E. (2009). Doing research in the real world. Los Angeles: SAGE.

Green, B., Malsch, A., Kothari, B., Busse, J., \& Brennan, E. (2012). An Intervention to Increase Early Childhood Staff Capacity for Promoting Children's SocialEmotional Development in Preschool Settings. Early Childhood Education Journal, 40(2), 123-132. doi:10.1007/s10643-011-0497-2

Greve, A. (2005). Friendship relations among toddlers. Journal of Australian Research in Early Childhood Education, 12(1), 81-91.

Guba, E. G., \& Lincoln, Y. S. (1994). Competing paradigms in qualitative research. In N. K. Denzim \& Y. S. Lincoln (Eds.), Handbook of qualitative research (pp. 105117). Thousand Oaks: SAGE Publications. 
Guo, K., \& Dalli, C. (2016). Belonging as a force of agency: An exploration of immigrant children's everyday life in early childhood settings. Global Studies of Childhood, 6(3), 254-267.

Guo, K. L. (2010). Chinese immigrant children in New Zealand early childhood centres : a thesis submitted to the Victoria University of Wellington in fulfilment of the requirements for the degree of Doctor of Philosophy in Education / by Karen Liang Guo. Thesis (Ph.D.)--Victoria University of Wellington, 2010.

Hamre, B. K., \& Pianta, R. C. (2005). Can Instructional and Emotional Support in the First-Grade Classroom Make a Difference for Children at Risk of School Failure? Child Development. 76(5), 949-967.

Han, H. S. (2009). Sociocultural Influence on Children's Social Competence: A Close Look at Kindergarten Teachers' Beliefs. Journal of Research in Childhood Education, 24(1), 80-96. doi:10.1080/02568540903439425

Hannikainen, M. (2007). Creating togetherness and building a preschool community of learners: The role of play and games. In T. Jamboor and J. V. Gil (Eds). Several perspectives on children's play (147-160). Antwerpen: Garant.

Hännikäinen, M. (2005). Rules and agreements - And becoming a preschool community of learners. European Early Childhood Education Research Journal, 13(1), 97110. doi:10.1080/13502930585209581

Hännikäinen, M., \& Van Oers, B. (1999). Signs and Problems of Togetherness in a Community of Learners. ERIC, 42.

Harkness, S., \& Super, C. (1997). An infant's three Rs. Natural history. New York NY, 106(9), 45-45.

Hartup, W. W. (1986). On relationships and development. In W. W. Hartup \& Z. Rubin (Eds.), Relationships and development (pp. 1-26). Hillsdale, NJ: Erlbaum.

Hartup, W. W. (1996). The Company They Keep: Friendships and Their Developmental Significance. Child Development, 67(1), 1-13. doi:10.2307/1131681

Hartup, W. W. (2005). Peer Interaction: What Causes What? Journal of Abnormal Child Psychology, 33(3), 387. doi:10.1007/s10802-005-3578-0

Hartup, W. W. (2008). Critical Issues and Theoretical Viewpoints. In K. H. Rubin, W. M. Bukowski, \& B. Laursen (Eds.), Handbook of Peer Interactions, Relationships, and Groups. United States of America: Guilford Publications.

Hartup, W. W., French, D. C., Laursen, B., Johnston, M. K., \& Ogawa, J. R. (1993). Conflict and Friendship Relations in Middle Childhood: Behavior in a Closed-Field Situation. Child Development, 64(2), 445-454. doi:10.1111/j.14678624.1993.tb02920.x

Hartz, K., Williford, A. P., \& Koomen, H. M. Y. (2017). Teachers' Perceptions of Teacher-Child Relationships: Links With Children's Observed Interactions. Early Education and Development, 28(4), 441-456. doi:10.1080/10409289.2016.1246288

Hay, D., Nash, A., \& Pedersen, J. (1983). Interaction between Six-Month-Old Peers. Child Development, 54(3), 557.

Hay, D. F. (1985). Learning to form relationships in infancy: Parallel attainments with parents and peers. Developmental Review, 5(2), 122-161. doi:10.1016/02732297(85)90007-3 
Hay, D. F. (1994). Prosocial development. Journal of Child Psychology and Psychiatry, $35,29-71$.

Hay, D. F., Payne, A., \& Chadwick, A. (2004). Peer relations in childhood. Journal of Child Psychology and Psychiatry, 45(1), 84-108. doi:doi:10.1046/j.00219630.2003.00308.x

Heckman, J. J. (2011). The Economics of Inequality. The Education Digest, 77(4), 4.

Henry, M. (1992). School rituals as educational contexts: Symbolizing the world, others, and self in Waldorf and college prep schools. Qualitative Studies in Education, 5(4), 295-309.

Hennessy, S., \& Deaney, R. (2009). "Intermediate Theory" building: Integrating multiple teacher and researcher perspectives through in-depth video analysis of pedagogic strategies. Teachers College Record, 111(7), 1753-1795.

Hicks, D. (1996). Contextual inquiries: a discourse-oriented study of classroom learning. In D. Hicks (Ed.), Discourse, Learning, and Schooling (pp. 104-145 ). Cambridge: Cambridge University Press.

Hill, L., Stremmel, A., \& Fu, V. (2005). Teaching as inquiry: Rethinking curriculum in early childhood education. Boston: Allyn \& Bacon, Pearson Education.

Hillesoy, S. (2016). The contribution of support teachers in facilitating children's peer interactions. International journal of early childhood. 48(10). 95-109.

Hinde, R. A. (1979). Towards understanding relationships. London: Academic Press.

Hodgson, V. (2008). Stimulated Recall. The SAGE Dictionary of Qualitative Management Research. London, United Kingdom: SAGE Publications Ltd.

Hofstede, G., Hofsteded, G. J. \& Minkov, M. (2010). Cultures and Organizations: Software of the mind. New York, USA: McGraw Hill Press.

Hogan, A. E., Scott, K. G. \& Bauer, C. R. (1992). The adaptive social behavior inventory (Asbi): A new assessment of social competence in high-risk three-yearolds. Journal of Psychoeducational Assessment, 10(3), 230-239.

Honig, A. S. (1982). Prosocial Development in Children. Young Children, 37(5), 51-62.

House, J. S., Landis, K. R., \& Umberson, D. (1988). Social Relationships and Health. Science, 241(4865), 540-545. doi:10.1126/science.3399889

Howes, C. (1981). Danny and Robyn, Becca and Amy: Making friends at childcare. (unpublished manuscript). Boston: Harvard University Press.

Howes, C. (1987a). Social compentency with peers: Contributions from child care. Early Childhood Research Quarterly, 2(2), 155-167. doi:http://dx.doi.org/10.1016/0885-2006(87)90041-X

Howes, C. (1987b). Social competence with peers in young children: Developmental sequences. Developmental Review, 7(3), 252-272. doi:http://dx.doi.org/10.1016/0273-2297(87)90014-1

Howes, C. (1988). Peer Interaction of Young Children. Monographs of the Society for Research in Child Development, 53(1), 1-77.

Howes, C., Droege, K. \& Philipsen, L. (1992). Contribution of peers to socialization in Early Childhood. In M. Gettinger, S. N. Elliot, \& T. R. Kratochwill (Eds.), Preschool and early Childhood Treatment Directions (pp.113-143). New York: Routledge. 
Howes, C. (1996). The earliest friendships. In W. M. Bukowski, A. F. Newcomb, \& W. W. Hartup (Eds.), The Company They Keep: Friendship in Childhood and Adolescenc (pp. 66-86). Cambridge: Cambridge University Press.

Howes, C., Hamilton, C. E., \& Philipsen., L. C. (1998). Stability and Continuity of Childcaregiver and Child-peer Relationships. Child Development, 69(2), 418-426.

Howes, C., \& Lee, L. (2006). Peer relations in young children. In L. Balter \& C. S. Tamis-LeMonda. (Eds.), Child Psychology. A handbook of contemporary issues. (Second Edition ed.). New York: Taylor \& Francis Group.

Howes, C., \& Matheson, C. C. (1992). Sequences in the development of competent play with peers: social and social pretend play. Journal of Developmental Psychology, 28(5), 961-974.

Howes, C., \& Philipsen., L. C. (1992). Gender and friendship: Relationships within peer groups of young children. Social Development, 1, 230-242.

Howes, C. (1997). Children's experiences in center-based child care as a function of teacher background and adult:child ratio. Merrill-Palmer Quarterly, 43, 405-425

Hurd, H. D., \& Gettinger, M. (2011). Mothers' and teachers' perceptions of relational and physical aggression in pre-school children. Early Child Development and Care, 181(10), 1343-1359.

Hurwitz, S. C. (2003). To be successful, let them play! For parents particularly. Childhood Education, 79(2), 101-102.

Innocenti, M. S., Stowitschek, J. J., Rule, S., Killoran, J., Striefel, S., \& Boswell, C. (1986). A naturalistic study of the relation between preschool setting events and peer interaction in four activity contexts. Early Childhood Research Quarterly, 1(2), 141-153.

Ireland, L. (2006). When babies have teachers: A study of how three community-based children's services employ teachers in infant-toddlers program. Paper presented at the Asutralian Association for Research in Education Conference, Adelaide, SA.

Ishikawa, F., \& Hay, D. F. (2006). Triadic interaction among newly acquainted 2-yearolds. Social Development, 15(1), 145-168.

James, A. (2000). Embodied being(s): Understanding the self and the body in childhood. In A. Prout (Ed.), The Body, Childhood and Society (pp. 19-37). Great Britain: Macmillan Press.

Jenkinsm, K., \& Hewitt, A. (2010). A teacher's vision: A friendly teaching environment that supports growth and learning. Childhood Education, 86(5), 316-320.

JKM. (2013). Portal Rasmi Jabatan Kebajikan Masyarakat. Retrieved 23 December 2014 from

http://www.jkm.gov.my/content.php?pagename=kursus_asuhan_permata\&lang=b $\underline{\mathrm{m}}$

Johnson, K. E., \& Mervis, C. B. (1997). First steps in the emergence of verbal humor: A case study. Infant Behavior and Development, 20(2), 187-196.

Johnson, D. W. \& Johnson, R. T. (1995). Teaching students to be peacemakers. Edina, $\mathrm{MN}$. Interaction book.

Jung, E. (2014). Cultivating social competence in young children: Teachers' beliefs about and practices involving the development of children's social competence. In D. J. Walsh, K. Bost, M. Ostrosky, \& P. Rodkin (Eds.): ProQuest Dissertations Publishing. 
Jutras, S., \& Lepage, G. (2006). Parental perceptions of contributions of school and neighbourhood to children's psychological wellness. Journal of Community Psychology, 34(3), 305-325.

Kane, R. (2008). Perceptions of teachers and teaching: A focus on early childhood education. Report to the Ministry of Education. New Zealand.

Katz, J. R. (2004). Building Peer Relationships in Talk: Toddlers' Peer Conversations in Childcare. Discourse Studies, 6(3), 329-346.

Katz, L. G., \& McClellan, D. E. (1997). Fostering children's social competence : the teacher's role. Washington, D.C.: Washington, D.C. : National Association for the Education of Young Children.

Kemple, K., \& Hartle, L. (1997). Getting along: How teachers can support children's peer relationships. Early Childhood Education Journal, 24(3), 139-146.

Kemple, K. M. (1991). Preschool children's peer acceptance and social interaction. Young Children, 47-54.

Kemple, K. M., David, G. M., \& Hysmith, C. (1997). Teachers' Interventions in Preschool and Kindergarten Children's Peer Interaction. Journal of Reserach in Childhood Education, 12(1), 34-47.

Kemple, K. M., Hysmith, C., \& David, G. M. (1996). Early Childhood Teachers' Beliefs About Promoting Peer Competence. Early Child Development and Care, 120(1), 145-163.

Kernan, M., \& Singer, E. (2011). Peer relationships in early childhood education and care. Abingdon: Routledge.

Kernan, M. (2011) Children's and parents' perspectives on play and friendships. In M. Kernan \& E. Singer (Eds.), Peer relationships in early childhood education and care. New York: Routledge.

Kim, Y. (2003). Necessary social skills related to peer acceptance. Childhood Education, 79, 234-238.

Killen, M., \& de Waal, F. B. M. (2000). The evolution and development of morality. In F. d. W. Aureli, F. B. M. (Ed.), Natural conflict resolution (pp. 352-372). Berkeley, CA.: University of California Press.

Kochanska, G., \& Radke-Yarrow, M. (1992). Inhibition in toddlerhood and the dynamics of the child's interaction with an unfamiliar peer at age five. Child Development, 63(2), 325-335.

Koivula, M., \& Hännikäinen, M. (2017). Building Children's Sense of Community in a Day Care Centre through Small Groups in Play. Early Years: An International Journal of Research and Development, 37(2), 126-142. doi:10.1080/09575146.2016.1180590

Konstantoni, K. (2012). Children's Peer Relationships and Social Identities: Exploring Cases of Young Children's Agency and Complex Interdependencies from the Minority World. Children's Geographies, 10(3), 337-346.

Kontos, S., Hsu, H. -C., \& Dunn, L. (1994). Children's cognitive and social competence in child-care centers and family day care homes. Journal of Applied Developmental Psychology, 15, 387-411.

Kousar, S. (2015). Politeness Orientation in Social Hierarchies in Urdu. International Journal of Society, Culture \& Language, 3(2), 85-96. 
Kreidler, W. J. \& Whittall, S. T. (1999). Early childhood adventures in peacemaking 2nd ed., MN: Redleaf Press

Krefting, L. (1991). Rigor in qualitative research: The assessment of trustworthiness The American Journal of Occupational Therapy, 45(3), 214-222.

Kyratzis, A. (2004). Talk and interaction among children and the co-constructions of peer groups and peer culture. Annual review of anthropology, 33, 625.

Ladd, G. W., Birch, S. H., \& Buhs, E. S. (1999). Children's Social and Scholastic Lives in Kindergarten: Related Spheres of Influence? Child Development, 70(6), 13731400.

Lally, J. Ronald (2010). School readiness begins in infancy. Phi Delta Kappan Magazine, 92(3), 17-21.

Lamb, M. E., \& Ahnert, L. (2006). Nonparental child care: Context, concepts, correlates and consequences. In W. Damon, R. M. Lerner, K. A. Renninger, \& I. E. Sigel (Eds.), Handbook of child psychology: Volume 4: Child psychology in practice $\left(5^{\text {th }}\right.$ ed.). Hoboken, NJ: Wiley.

Langton, C. E., \& Berger, L. M. (2011). Family structure and adolescent physical health, behavior, and emotional well-being. Social Service Review, 85(3), 323357.

Laursen, B. P., Furman, W., \& Mooney, K. S. (2006). Predicting interpersonal competence and self-worth from adolescent relationships and relationship networks: variable-centered and person-centered perspectives. Merrill-Palmer Quarterly, 52(3), 572-600.

Lazare, A. (2006). Apology in medical practice: an emerging clinical skill. JAMA, 296(11), 1401-1404.

Lee, Y. \& Recchia, S. L. (2008). Who's the boss? Young children's power and influence in an early childhood classroom. Early Childhood Research and Practice. 10(1).

Lefebvre, H. (2002). Critique of everyday life: Foundations for a sociology of the everyday. (J. Moore, Trans. Vol. Verso). London.

Lefebvre, H., \& Levich, C. (1987). The everyday and everydayness: Yale French Studies, 73, 7-11.

Legendre, A. \& Munchenbach, D. (2011). Two-to-three-year-old children's interactions with peers in child-care centres: Effects of spatial distance to caregivers. Infant Behavior and Development, 34(1), 111-125.

Lewis, M., Young, G., Brooks, J., \& Michalson, L. (1975) The beginning of friendship. In M. Lewis and L. Rosenblum (Eds.), Friendship and peer relations. New York: Wiley, 1975.

Licht, B., Simoni, H., \& Perrig-Chiello, P. (2008). Conflict between Peers in Infancy and Toddler Age: What Do They Fight about? Early Years: An International Journal of Research and Development, 28(3), 235-249. doi:10.1080/09575140802065458

Lin, T.-J., Justice, L. M., Paul, N., \& Mashburn, A. J. (2016). Peer interaction in rural preschool classrooms: Contributions of children's learning-related behaviors, language and literacy skills, and problem behaviors. Early Childhood Research Quarterly, 37, 106-117. 
Lincoln, Y. S., Lynham, S. A., \& Guba, E. G. (2011). Paradigmatic controversies, contraditions, and emerging confluences, revisited. In N. K. Denzim \& Y. S. Lincoln (Eds.), The SAGE Handbook of Qualitative Research. Los Angeles: SAGE.

Loizou, E. (2005). Infant humor: the theory of the absurd and the empowerment theory, International Journal of Early Years Education, 13(1), 43-53.

Loizou, E. (2007). Humor as a means of regulating one's social self: two infants with unique humorous personas. Early Child Development and Care, 177(2), 195-205.

Loizou, E. (2005). Humour: A Different Kind of Play. European Early Childhood Education Research Journal, 13(2), 97-109.

Løkken, G. (2000). Tracing the social style of toddler peers. Scandinavian Journal of Educational Research, 44(2), 163.

Lombrozo, T. (2006). The structure and function of explanations. Trends in Cognitive Sciences, 10, 464-470.

Majorano, M., Corsano, P., \& Triffoni, G. (2015). Educators' Intervention, Communication and Peers' Conflict in Nurseries. Child Care in Practice, 21(2), $1-16$.

Maloney, C. (2000). The role of ritual in pre-primary classroom settings. Paper presented at the Australian Association for Research in Education. Sydney, Australia.

Manaster, H., \& Jobe, M. (2012). Bringing Boys and Girls Together: Supporting Preschoolers' Positive Peer Relationships. Young Children, 67(5), 12-17.

Mashburn, A. J., Hamre, B. K., Downer, J. T., \& Pianta, R. C. (2006). Teacher and Classroom Characteristics Associated With Teachers' Ratings of Prekindergartners' Relationships and Behaviors. Journal of Psychoeducational Assessment, 24(4), 367-380.

Mathers, S., Eisenstadt, N., Sylva, K., Soukakou, E., \& Ereky-Stevens, K. (2014). Sound Foudations: A review of the reserach evidence on quality of early childhood (pp. 68): University of Oxford.

Malaysia Economic Monitor December 2013: High Performing Education. (2013) The World Bank. Bangkok, Thailand.

Malaysia Education Blueprint (2013-2025). Malaysian Education Blueprint. Retrieved 21 July 2014 from https:/www.moe.gov.my/images/dasar$\mathrm{kpm} /$ articlefile_file_003108.pdf

Malaysia Education Blueprint (2013-2025): Prelimanary Report. (2012). Malaysia.

Malaysia Education Blueprint (2013-2025): Annual Report. (2017). Malaysia.

Mayall. B. (2002). Towards a sociology for childhood : thinking from children's lives. Buckingham; Philadelphia : Open University Press.

Merriam, S. B. (1998). Qualitative research and case study applications in education. San Francisco, Calif: Jossey-Bass.

Merriam, S. B. (2009). Qualitative research: A guide to design and implementation. San Fransisco, CA: Jossey-Bass.

McGhee, P. E. (1979). Humor: its origin and development. San Francisco: Freeman.

McGhee, P. E. (1989). The contribution of humour to children's social development. In P. E. McGhee (Ed.), Humor and children's development. A guide to practical applications (pp. 119-134.). New York: Haworth Press. 
McMillan, D. W., \& Chavis, D. M. (1986). Sense of community: A definition and theory. Journal of Community Psychology, 14(1), 6-23.

Mercer, N. (2000). Words and minds : how we use language to think together / Neil Mercer. New York: Routledge.

Mill, D., \& Romano-White, D. (1999). Correlates of Affectionate and Angry Behavior in Child Care Educators of Preschool-Aged Children. Early Childhood Research Quarterly, 14(2), 155-178. doi:10.1016/S0885-2006(99)00007-1

Miller, R., \& Pedro, J. (2006). Creating respectful classroom environments. Early Childhood Education Journal, 33(5), 293-299.

Mireault, G. C., Crockenberg, S. C., Sparrow, J. E., Cousineau, K., Pettinato, C., \& Woodard, K. (2015). Laughing matters: Infant humor in the context of parental affect. Journal of Experimental Child Psychology, 136, 30-41. doi:10.1016/j.jecp.2015.03.012

Mireault, G. C., \& Reddy, V. (2016). Humor in Infants: Developmental and Psychological Perspectives. Cham: Cham: Springer International Publishing.

Mueller, E., \& Brenner, J. (1977). The Origins of Social Skills and Interaction among Playgroup Toddlers. Child Development, 48(3), 854-861.

Moll, L. C., Amanti, C., Neff, D. \& Gonzalez, N. (1992). Funds of knowledge for teaching: Using a qualitative approach to connect homes and classrooms. Theory in Practice, 31(2), p. 132-141.

Moore, A., \& Lynch, H. (2017): Understanding a child's conceptualisation of well-being through an exploration of happiness: The centrality of play, people and place, Journal of Occupational Science, 1-18.

Mortlock.A. (2014). Belonging and togetherness: Toddlers' use of playful rituals. First Years: Nga Tau Tuatahi, 16(1), 21-25

Musatti, T., Mayer, S., Pettenati, P., \& Picchio, M. (2017). Toddlers' participation in joint activities with peers in nido. In E. White \& C. Dalli (Eds.), Under-three year olds in policy and practice. policy and pedagogy with under-three year olds: cross-disciplinary insights and innovations. Singapore: Springer.

Mutch, C. (2013). Doing educational research: a practitioner's guide to getting started. Wellington: NZCER Press.

Nsamenang A.B. (2008) Constructing cultural identity in families. In: Brooker L and Woodhead M (eds) Developing Positive Identities: Diversity and Young Children. Maidenhead: Open University Press, pp. 17-32.

Nunan, D., \& Bailey, K. M. (2009). Exploring second language classroom research: a comprehensive guide. Boston, MA: Heinle, Cengage Learning.

O'Brien, M., Roy, C., Jacobs, A., Macaluso, M., \& Peyton, V. (1999). Conflict in the Dyadic Play of 3-Year-Old Children. Early Education \& Development, 10(3), 289-313.

O'Connor, E., \& McCartney, K. (2007). Examining teacher-child relationships and achievement as part of an ecological model of development. American Educational Research Journal 44(2), 340-369.

Oppenheimer, L. (1989). The nature of social action: Social competence versus social conformism. In B. H. Schneider, G. Attili, J. Nadel, \& R. P. Weissberg (Eds.), Social competence in developmental perspectives (pp. 41-69). New York: Kluwer Academic/Plenum. 
Over, H. (2016). The origins of belonging: social motivation in infants and young children Philosophical Transactions of the Royal Society of London. B-Biol. Sci. 371(1686).

Ozturk, Ilhan. (2001). The Role of Education in Economic Development: A Theoretical Perspective. SSRN Electronic Journal. 10.2139/ssrn.1137541.

Paley, V. G. (1993). You can't say you can't play / Vivian Gussin Paley. Cambridge, Mass.: Cambridge, Mass. : Harvard University Press.

Parry, J. (2014). Making connections and making friends: social interactions between two children labelled with special educational needs and their peers in a nursery setting. Early Years, 34(3), 301-314.

Parten, M. (1932). Social Participation Among Pre-School Children. Journal of Abnormal and Social Psychology, 27, 243.

Patton, M. Q. (2002). Qualitative research and evaluation methods (3rd edition ed.). Thousand Oaks, California: Sage Publications.

Pech, S. (2013). Peer pals: supporting positive social-emotional behaviors in a kindergarten classroom. Childhood Education, 89(4), 217-223.

Pellegrini, A. D. and Smith, P. K. (1998). The development of play during childhood: forms and possible functions. Child Psychology and Psychiatry Review, 3(2), 5157.

Peterson, C. (2004). Looking forward through childhood and adolescence: developmental psychology. Sydney: Pearson Education.

Phillips, A. T., Wellman, H. M., \& Spelke, E. S. (2002). Infants' ability to connect gaze and emotional expression to intentional action. Cognition, 85(1), 53-78.

Piaget, J. (1926). The language and thought of the child. Oxford, England: Harcourt, Brace.

Piaget, J. (1932). The moral judgment of the child. New York: Hartcourt.

Prout, A. (2011). Taking a step away from modernity: reconsidering the new sociology of childhood. Global Studies of Childhood, 1(1).

Punch, K. E. (2005). Introduction to social research quantitative and qualitative approaches (2nd ed.). London: SAGE Publications

Raver, C. (2002). Emotions matter: Making the case for the role of young children's emotional development for early school readiness. Social Policy Report/ Society for Research in Child Development, 16(3), 10-26.

Raver, C. C., \& Zigler, E. F. (1997). Social competence: An untapped dimension in evaluating head start's success. Early Childhood Research Quarterly, 12(4), 363385.

Reddy, V. (1991). Playing with others' expectations: Teasing and mucking about in the first year: . In A. Whiten (Ed.), Natural theories of mind. Cambridge, MA: Basil Blackwell.

Reddy, V. (2008). How infants know minds / Vasudevi Reddy. Cambridge, Mass.: Cambridge, Mass. : Harvard University Press.

Rizzo, T. A. (1988). Friendship Development Among Children in School Praeger.

Rochat, P. (2009). Others in mind: Social origins of self-consciousness. Cambridge, UK: Cambridge University Press.

Rockel, J., \& Craw, J. (2011). Discourse of happiness in infant-toddler pedagogy. NZ Research in ECE Journal, 14, 121-131. 
Rogoff, B. (1998). “Cognition as Collaborative Process.” In Handbook of Child Psychology, vol. 2, edited by W. Damon, D. Kuhn, and R. S. Siegler, 5th edition, 679-744. New York: Wiley.

Rogoff, B. (2003). The cultural nature of human development / Barbara Rogoff. Oxford [England] Oxford [UK] a New York: Oxford England : Oxford University Press.

Rogoff, B., Mistry, J., Goncu, A., \& Mosier, C. (1993). Guided Participation in Cultural Activity by Toddlers and Caregivers. Monographs of the Society for Research in Child Development, 58(8), 1-174. doi:10.2307/1166109

Rose-Krasnor, L. (1997). The Nature of Social Competence: A Theoretical Review (Vol. 6, pp. 111-135). Oxford, UK.

Rosenthal, M. K., \& Gatt, L. (2010). "Learning to Live Together": Training Early Childhood Educators to Promote Socio-Emotional Competence of Toddlers and Pre-School Children. European Early Childhood Education Research Journal 18(3), 223-240.

Roseth, C. J., Pellegrini, A.D., Dupuis, D. N., Bohn, C. M., Hickey, M. C., Hilk, C. L., \& Peshkam, A. (2008). Teacher intervention and U. S. preschoolers' natural conflict resolution after aggressive competition. Behavior, 145, 1601-1626.

Ross, H. S., \& Lollis, S. P. (1989). A social relations analysis of toddler peer relationships. Child Development, 60(5), 1082-1091.

Rossetti-Ferreira, M. C., de Moraes, Z., de Oliveira, R., Campos-de-Carvalho, M. I., \& Amorim, K. S. (2011). Peer relations in Brazilian daycare centres. In M. Kernan \& E. Singer (Eds.), Peer relationships in early childhood education and care. New York: Routledge.

Rourou, A., Singer, E., Bekkema, N., \& De Haan, D. (2006). Cultural perspectives on peer conflicts in multicultural Dutch child care centres. European Early Childhood Education Research Journal, 14(2), 35-53.

Rowe, V. (2009). Using video-stimulated recall as a basis for interviews: some experiences from the field. Music Education Research, 11(4), 425-437.

Rubin, K. H., \& Rose-Krasnor, L. (1992). Interpersonal problem solving. In V. B. V. Hassett \& M. Hersen (Eds.), Handbook of social development. New York: Plenum.

Russon, A., Waite, B., \& Rochester, M (1990). Direct Caregiver Intervention in Infant Peer Social Encounters. The American Journal of Orthopsychiatry, 60, 428.

Rutanen, N. (2007). Two-year-old children as co-constructors of culture. European Early Childhood Education Research Journal, 15(1). 59-69.

Salamon, A., \& Harrison, L. (2015). Early Childhood Educators' Conceptions of Infants' Capabilities: The Nexus between Beliefs and Practice. Early Years: An International Journal of Research and Development, 35(3), 273-288.

Salamon, A., Sumsion, J., Press, F., \& Harrison, L. (2016). Implicit theories and naïve beliefs: Using the theory of practice architectures to deconstruct the practices of early childhood educators. Journal of Early Childhood Research, 14(4), 431-443.

Sarafino, E. P. (1985). Peer-peer interaction among infants and toddlers with extensive daycare experience. Journal of Applied Developmental Psychology, 6(1), 17-29.

Schepens, A., Aelterman, A., \& Van Keer, H. (2007). Studying learning processes of student teachers with stimulated recall interviews through changes in interactive cognitions. Teaching and Teacher Education, 23(4), 457-472. 
Selman, R.L., \& Schultz, L.H. (1990). Making a friend in youth. Chicago: University of Chicago Press.

Seuss. (1971). The Lorax. United States: Random House.

Sham'ah, M.-Y. (2013). [Malaysia] Early Education and Development in Malaysia: Issues and Challenges in Providing a Framework for a Multiethnic Society. ECEC around the World (Child Research Net). Retrieved 20 December 2014 from http://works.bepress.com/shamah md-yunus/6

Shantz, C. (1987). Conflicts between Children (Book Review) (Vol. 58, pp. 283). Chicago, etc.: University of Chicago Press for the Society for Research in Child Development, etc.

Shaykh Muhammad Saalih Al-Munajjid (2007). Islam question and answer. Retrieved on $3^{\text {rd }}$ January 2018 from https://islamqa.info/en/92806.

Shin, M. (2010). Peeking at the relationship world of infant friends and caregivers (Vol. $8)$.

Shin, M., \& Partyka, T. (2017). Empowering Infants through Responsive and Intentional Play Activities. International Journal of Early Years Education, 25(2), 127-142.

Shoecraft, K., \& Flückiger, B. (2018). Conducting qualitative video research with young children. Qualitative Research Journal, 18 (3), 238-247.

Silver, C., \& Harkins, D. (2007). Labeling, affect and teachers' hypothetical approaches to conflict resolution: an exploratory study. Early Education and Development, 18(4), 625-645.

Singer, E. \& De Haan, D. (2007). Social life of young children: Coconstruction of shared meanings and togetherness, humor, and conflicts in child care centres. In O. N. Saracho \& B. Spodek. (Eds.), Contemporary perspectives on social learning in early childhood education. Charlotte: Information Age Publishing.

Singer, E., van Hoogdalem, A.-G., De Haan, D., \& Bekkema, N. (2012). Day care experiences and the development of conflict strategies in young children. Early Child Development and Care, 182(12), 1-12.

Singer, E. (1998). Shared care for children. In M. Woodhead, D. Faulkner \& K. Littleton, (Eds.), Cultural worlds of early childhood, (pp.101-116). London \& New York: Routledge \& Open University.

Singer, E. (2002). The logic of young children's (nonverbal) behaviour. European Early Childhood Education Research Journal, 10(1), 55-64.

Singer, E., \& De Haan, D. (2007). The social lives of young children. Amsterdam: SWP.

Singer, E., \& Hännikäinen, M. (2002). The teacher's role in territorial conflicts of 2-to 3-year-old children. Journal of Research in Childhood Education 17(1), 5-18.

Southam, M. (2003). Therapeutic Humor: Attitudes and Actions by Occupational Therapists in Adult Physical Disabilities Settings. Occupational Therapy In Health Care, 17(1), 23-41.

Spagnola, M., \& Fiese, B. H. (2007). Family routines and rituals: a context for development in the lives of young children. Infants and Young children, 20(4), 284-300.

Spegman, A. M. \& Houck, G. M. (2005). Assessing the Feeding/ Eating Interaction as a Context for the Development of Social Competence in Toddlers. Issues in Comprehensive Pediatric Nursing, 28(4), 213-236.

Spence S. H. (2003). Social skills training with children and young people: theory, 
evidence and practice. Child Adolescent Mental Health, 8, 84-96.

SSM \& Unicef. (2010). Establishment of a child care centre at the work place by by corporate and business employers (pp. 1-9). Kuala Lumpur: Companies commission of Malaysia and United Nations Children's Fund.

Strain, P. S., Shores, R. E., \& Kerr, M. M. (1976). An experimental analysis of "spillover" effects on the social interaction of behaviorally handicapped preschool children. Journal of applied behavior analysis, 9(1), 31-40.

Super, C. M. \& Harkness, S. (1986). The developmental niche: a conceptualization at the interface of child and nature. International joural of bahavioral development, 9. 545-569.

Svetlova, M., \& Nichols, S. R. and Brownell, C. A. (2010). Toddlers' prosocial behavior: from instrumental to empathic to altruistic helping. Child Development, 81(6), 1814-1827.

Tahmores, A. H. (2011). Role of play in social skills and intelligence of children. Procedia - Social and Behavioral Sciences, 30, 2272-2279.

Trevarthen, C. \& Delafield-Butt, J. (2017). Intersubjectivity in the imagination and feelings of the infant: implications for education in the early years. In E. Jayne White \& C. Dalli (Eds.), Under-three year olds in policy ad practice. Singapore: Springer.

Turunen,T. \& Perry, B. (2013) Immigrant-background Australians' recollections of justice, injustice and agency in stories about starting school. Contemporary Issues in Early Childhood 14(4): 335-344.

Van Hoogdalem, A.-G., Singer, E., Bekkema, N., \& Sterck, E. (2008). Young children who intervene in peer conflicts in multicultural child care centers. Behaviour, 145(11), 1653-1670.

Van Nijnatten, K. (2010) Children's Agency, Children's Welfare: A Dialogical Approach to Child Development, Policy and Practice. Bristol: The Policy Press, University of Bristol.

Van Oers, B., \& Hännikäinen, M. (2001). Some Thoughts About Togetherness: An introduction Re'flexions sur e Togetherness f Algunos Pensamientos Sobre el "Sentimiento de Unio'n". International Journal of Early Years Education, 9(2), 101-108.

Van Hecke, V. A., Mundy, P. C., Acra, C. F., Block, J. J., Delgado, C. E., Parlade, M.V., Meyer, J. A., Neal, A. R. and Pomares, Y. B. (2007). Infant joint attention, temperament, and social competence in preschool children. Child Development, $78,53-69$.

Verma, S., \& Peters, D. L. (1975). Day care teachers' practices and beliefs. The Alberta Journal of Educational Research, 21, 46-54.

Verbeek, P., Hartup, W.W. \& Collins, W. A. (2000). Conflict management in children and adolescents.In Aureli, F. \& De Waal, F.B.M. (Eds.) Natural conflict resolution. Berkley: University of California Press.

Vickerius, M. \& Sandberg, A. (2006) The significance of play and the environment around play. Early Child Development and Care, 176 (2), 207-217.

Vygotsky, L. S. (1981). The genesis of higher mental functions. In J. V. Wertsch (Ed.), The concept of activity in soviet psychology (pp. 144-188). New York: Sharpe.

Vygotsky, L. S. (1978). Mind in society. Cambridge: Havard University Press. 
Walker, D., Small, C., Bigelow, K., Kirk, S., Harjusola-Webb, S., \& Mark, N. (2004). Strategies for promoting communication and language of infants and toddlers. Juniper Gardens Children's Project. United States of America.

Wang, S., \& Baillargeon, R. (2006). Infants' physical knowledge affects their change detection. Developmental Science, 9. 173-181.

Wellington, J. J. (2000). Educational research: contemporary issues and practical approaches. New York; London: Continuum.

Whaley, K. L., \& Rubenstein, T. S. (1994). How toddlers 'do' friendship: a descriptive analysis of naturally occuring friendship in a group child care setting Journal of Social and Personal Relationship, 11, 383-400.

Wheeler, E. J. (1994). Peer Conflicts in the Classroom: Drawing Implications from Research. Childhood Education, 70(5), 296-299.

White, R. W. (1959). Motivation reconsidered: the concept of competence. Psychological review, 66, 297.

White, E. J. (2014). A dialogic space in early childhood education: Chronotopic encounters with people, places and things. In J. H. Linda \& S. Jennifer (Eds.), Lived spaces of infant-toddler education and care: explorng diverse perspectives on theory, research and practice. Dordrecht: Soringer Netherlands.

Williams, S. T., Mastergeorge, A. M., \& Ontai, L. L. (2010). Caregiver Involvement in Infant Peer Interactions: Scaffolding in a Social Context. Early Childhood Research Quarterly, 25(2), 251-266. doi:10.1016/j.ecresq.2009.11.004

Williams, S. T., Ontai, L. L., \& Mastergeorge, A. M. (2010). The development of peer interaction in infancy: Exploring the dyadic processes. Social Development, 19(2), 348-368. doi:10.1111/j.1467-9507.2009.00542.x

Williamson, R. A., Donohue, M. R., \& Tully, E. C. (2013), Learning how to help others: two-year-olds' social learning of a prosocial act. Journal of Experimental Child Psychology, 114(4), 543-550.

Williford, A., Whittaker, J. E., Vitiello, V., \& Downer, J. (2013). Children's Engagement Within the Preschool Classroom and Their Development of Self-Regulation.

Early Education \& Development, 24(2), 162-187. doi:10.1080/10409289.2011.628270

Wilson, B. J. (1999). Entry behavior and emotion regulation abilities of developmentally delayed boys. Developmental Psychology, 35, 214-222.

Wittmer, D. (2012). The Wonder and Complexity of Infant and Toddler Peer Relationships. Young Children, 67(4), 16.

Wittmer, D. (2008). Focussing on peers: The importance of relationships in the early years. Washington, DC: Zero to Three.

Woolfolk, A. (2004). Educational Psychology (9th Edition ed.). Boston, MA: Allyn \& Bacon.

Wu, C., Hursh, D. E., Walls, R. T., Stack, S. F., \& Lin, I. (2012). The Effects of Social Skills Training on the Peer Interactions of a Nonnative Toddler. An Education and Treatment of Children 35(3), 371-388.

Watson, M. (2003). Learning to trust. San Francisco, CA: Jossey-Bass.

Wyatt, M., \& Arnold, E. (2012). Video-stimulated recall for mentoring in Omani schools. International Journal of Mentoring and Coaching in Education, 1(3), 218. 
Yin, R. K. (2003). Case study research design and methods (Vol. 5). California: SAGE Publications.

Yin, R. K. (2009). Case study research design and method. Los Angeles: SAGE Publications.

Yin, R. K. (2014). Case study research: design and methods. Los Angeles: SAGE.

Young, S. K., Fox, N. A. \& Zahn-Waxler, C. (1999). The relations between temperament and empathy in 2-year-olds. Developmental Psychology, 35(5), 1189-1197.

Zero to three (2010). Zero to three. Retrieved on $5^{\text {th }}$ January 2018 from https://www.zerotothree.org/resources/227-tips-on-helping-your-child-buildrelationships

Zigler, E. F., \& Bishop-Josef, S. J. (2006). The cognitive child versus the whole child: lessons from 40 years of head start. Play = Learning: How Play Motivates and Enhances Children's Cognitive and Social-Emotional Growth in D. G. Singer, R. M. Golinkoff and K. Hirsh-Pasek (Eds.) Oxford University press. 


\section{APPENDICES}




\section{Appendix A: Manager's information letter and consent form}

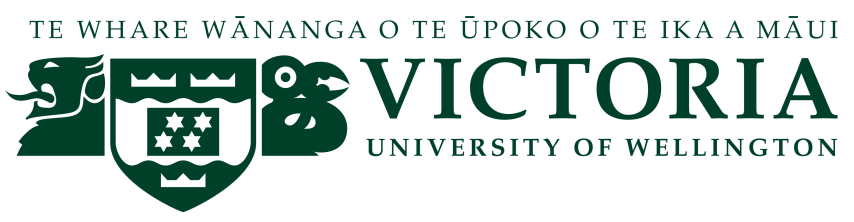

Dear

\section{INFORMATION SHEET \\ PhD project: Peer interactions among under three year olds in Malaysian childcare centres: A case study approach.}

I am currently enrolled as a PhD student at Victoria University of Wellington in New Zealand. My research project is an investigation on peer interactions among children aged under three years. Research on children's peer interactions shows that there are many benefits children can gain when they interact with other children in childcare centres. I am undertaking three case studies in three Early Childhood Care and Education settings in Selangor.

I write to ask if you would be happy for me to conduct the case study at your centre and to approach practitioner and parents about this. The project would involve me coming into your centre over the period of about 6 weeks in order to interview all of the practitioners, video-tape children's interactions with their peers and conduct group videostimulated recall interviews with the practitioners. The practitioners would also be invited to attend a focus group discussion with a group of practitioners from another childcare centre. The practitioners will be individually invited. There is no obligation for an individual practitioner to be involved in the study.

My project has two specific questions.

3. How do practitioners perceive peer interactions among children under three year olds in their childcare centres in Malaysia?

4. What kinds of peer interactions occur among children under three year olds in childcare centres in Malaysia? 
The data gathering would involve:

- An initial visit to your centre in order to provide further detail about the research processes, answer any questions that you and/or the management may have about the research, and to familiarise myself with your centre;

- Three to four visits to orient myself to your centre, and enabling both you and the children to become more familiar with me and with the video camera. During these visits, I would also collect contextual data e.g., physical layout and daily organisation of the programme and information about your centre/staff philosophy and your daily activity planning.

- Each of the practitioners at the centre will be asked for a one-on-one semistructured interview with me to get their perception of peer interactions among children under three year olds in their childcare centre. This interview will be audio-taped to assist with the transcription of the data.

- Then, data will be gathered for a maximum of 2 hours a day for 2 days per week in the centre via video recordings of five children interacting with their peers. The video observations will involve two 45 minute observations per child on 2 different days.

- Within a week of the videotaping, I would return to the centre to share excerpts from the videos and discuss these with the practitioners in order to gather their thoughts about children's peer interactions. The discussion will be audio-taped to assist with the transcription of the data. The discussion would probably take 2 hours and would be scheduled for a time that was suitable for the practitioners (either during the day or in the evening). Repeat viewings and prompt questions may be used in order to probe more deeply into the practitioners' thinking and practices during the recorded interactions.

- After all the data from semi-structured interviews, observation visits and videostimulated recall interviews are obtained from all of childcare centres, the participating practitioners from the three centres are asked to come together for a focus group discussion to further discuss their perception and responses to peer interactions among children under 3 year olds in their childcare centre. This discussion will be audio-taped to assist with the transcription of the data.

For the purpose of this study, I am seeking centres who meet the following criteria:

- Centres that have children under 3 year olds

- All practitioners are above 18 year olds.

- The centre is not currently engaged in a research project (nor has been in the previous three years)

- Staff are employed predominantly fulltime, rather than part-time.

- The case study centres are located in Selangor. 
The centre has the right to withdraw from the project up until the data gathering phase has been done. An individual practitioner or child (via the child's parents) also has the right to withdraw from the project up until the data gathering phase has been done.

My supervisors, Professor Carmen Dalli and Professor Vanessa Green, are also available to discuss any questions you may have about the research project. Their contact details are:

Professor Carmen Dalli

Email: Carmen.Dalli@vuw.ac.nz
Professor Vanessa Green

Email: Vanessa.Green@vuw.ac.nz

This research has been approved by Victoria University of Wellington Human Ethics Committee. Video recording of children's peer interactions and audio recordings of interviews and focus group discussion will be electronically wiped within five years of the conclusion of the project.

If you are interested in being considered for selection as a case study centre for this research project, please complete the attached informed consent form and return to me. If you require further information, please feel free to contact me, as follows:

Farhana Wan Yunus

Phone: +603-33935712

Email:Farhana.WanYunus@vuw.ac.nz

Yours sincerely,

Farhana Wan Yunus 
PhD project: Peer interactions among under three year olds in Malaysian childcare centres: A case study approach.

\section{Informed Consent Form - Manager}

I have been given and have understood an explanation of this research project. I have had an opportunity to ask questions and have them answered to my satisfaction.

I give Farhana Wan Yunus permission to undertake a case study as part of her $\mathrm{PhD}$ research in centre.

I would like a summary of the finding sent to centre.

Signed:

Name:

Date: 


\section{Appendix B: Practitioners' information letter and consent form}

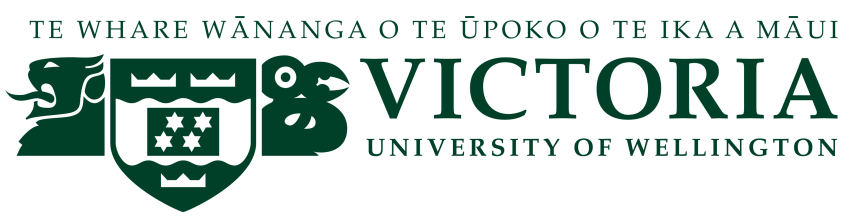

Dear

\section{INFORMATION SHEET \\ PhD project: Peer interactions among under three year olds in Malaysian childcare centres: A case study approach.}

My name is Farhana Wan Yunus. I am currently enrolled as a PhD student at Victoria University of Wellington in New Zealand. My research project is an investigation on peer interactions among children under three year olds in three childcare centres in Selangor. This sheet provides you with information about the project and includes an informed consent form for you to sign if you are willing to be a participant in the project.

\section{Research design}

My project has two specific questions.

1. How do practitioners perceive peer interactions among children under three year olds in their centres in Malaysia?

2. What kinds of peer interactions occur among children under three year olds in childcare centres in Malaysia?

\section{Data gathering processes}

The project would involve me coming into your centre over the period of about 6 weeks in order to interview all of the practitioners, video-tape children's interactions with their peers and conduct group video-stimulated recall interviews with the practitioners. The practitioners would also be invited to attend a focus group discussion with a group of practitioners from another childcare centre.

The data gathering would involve:

- An initial visit to your centre in order to provide further detail about the research processes, answer any questions that you may have about the research, and to familiarise myself with your centre;

- Three to four visits to orient myself to your centre, and enabling both you and the children to become more familiar with me and with the video camera. During these visits, I would also collect contextual data e.g., physical layout and daily 
organisation of the programme and information about your centre/staff philosophy and your daily activity planning.

- You will be asked for a one-on-one semi-structured interview with me to get your perception of peer interactions among children under three year olds in your childcare centre. This interview will be audio-taped to assist with the transcription of the data.

- Then, data will be gathered for a maximum of 2 hours a day for 2 days per week in the centre via video recordings of five children interacting with their peers. The video observations will involve two 45 minute observations per child on 2 different days.

- Within a week of the videotaping, I would return to the centre to share excerpts from the videos and discuss these with you in a group in order to gather your thoughts about children's peer interactions. The discussions will be audio-taped to assist with the transcription of the data. Each discussion would probably take 2 hours and would be scheduled for a time that was suitable for you (either during the day or in the evening. Repeat viewings and prompt questions may be used in order to probe more deeply into your thinking and your practices during the recorded interactions.

- After all the data from semi-structured interviews, observation visits and videostimulated recall interviews are obtained from three childcare centres, the participating practitioners from three centres are asked to come together for a focus group discussion to further discuss their perception and responses to peer interactions among children under 3 year olds in your childcare centre. This discussion will be audio-taped to assist with the transcription of the data.

As part of the initial orientation visits, we will negotiate a set of ground rules for the video recording. I suggest we consider the following points:

- There will be opportunities for you to indicate situations prior to filming that you specifically do or do not want included.

- We will arrange a signal for you to indicate that filming should cease, eg: because of your comfort levels, your reading of children's comfort levels, your sense that a situation with/between children was escalating and you don't want to make the situation worse. 
- I will be able to stop video-taping if I sense that my presence is becoming disruptive (eg: children are getting excited by the video) and the situation is becoming less typical or "authentic".

- The video-tapes recorded from the raw data for the study, and as such copies are unable to be passed on to you to use for other purposes in the centre (such as use in parent-practitioner meetings) as this would breach the condition for ethical approval.

\section{Informed consent}

Participation in this project requires your informed consent. Attached to this information sheet is a consent form, which needs to be completed and returned to me, if you are willing to be a participant in the project.

The identity of each centre, participating practitioners and children will remain confidential in the written thesis and any papers that are prepared for presentation and /or publication. Pseudonyms will be used for the childcare centre, practitioners and children.

Because children will be in the video recordings during their interactions with peers, I will need to gain informed consent from the parents of each of the children attending the centre. I would appreciate your assistance with the distribution and return of these consent forms. I will be available to talk with any parents who wish to discuss the project further before signing the consent form. In addition to gaining informed consent from the parents during the data gathering, I will remain sensitive to children's reactions to the video camera and will cease filming if children become distressed with the camera operating. 


\section{Withdrawal from the project}

The centre has the right to withdraw from the project up until the data gathering phase is done. An individual practitioner or child (via the child's parents) also has the right to withdraw from the project up until the observation has been done.

This research has been approved by Victoria University of Wellington Human Ethics Committee. Video recording of children's peer interactions and audio recordings of interviews and focus group discussion will be electronically wiped within five years of the conclusion of the project. If you have further questions about the project, I am very happy to discuss these with you either at a meeting or by telephone. My contact details are:

Farhana Wan Yunus

Phone: +603-33935712

Email: Farhana.WanYunus@vuw.ac.nz

My supervisors, Professor Carmen Dalli and Professor Vanessa Green, are also available to discuss any questions you may have about the research project. Their contact details are:

Professor Carmen Dalli

Email: Carmen.Dalli@vuw.ac.nz
Professor Vanessa Green

Email:Vanessa.Green@vuw.ac.nz

Thank you for considering involvement in the project.

Yours sincerely,

Farhana Wan Yunus 


\section{PhD project: Peer interactions among under three year olds in Malaysian childcare centres: A case study approach.}

\section{Informed Consent Form - Practitioners}

- I agree to take part in this research

- I have been given and understood an explanation of this research project. I have had an opportunity to ask questions and have them answered to my satisfaction.

- I understand that I may withdraw myself (or any information I have provided) from this project (before data collection is complete) without having to give reasons or without penalty of any sort.

- I understand that the data collected will be kept confidential to the researcher and her supervisors. Any IT technicians who provide technical assistance with the editing of video tapes gathered for this project will be asked to sign confidentiality agreements.

- I understand that the published results will not use my name or the name of the centre, or include descriptions that in any way identify me or the centre.

- I understand that the video recording of children's peer interactions and audio recordings of interviews and focus group discussion will be electronically wiped within five years of the conclusion of the project.

- I understand that I will have an opportunity to review the transcripts of the personal and group interviews for errors before publication.

- I understand that the data I provide will not be used for any other purpose or released to others without my written consent.

Signed:

Name of participant:

Date: 


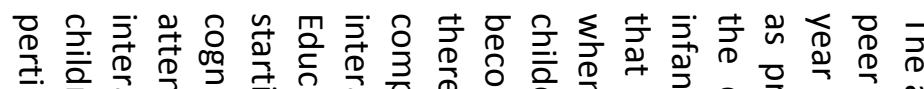

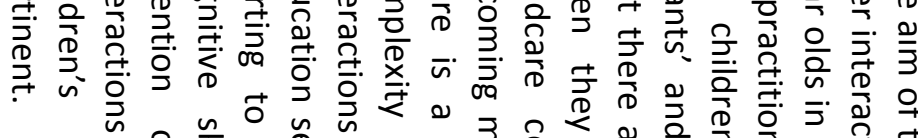

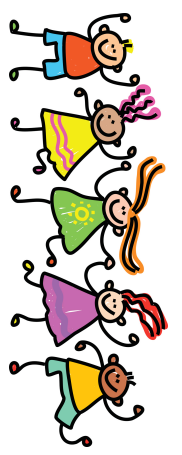

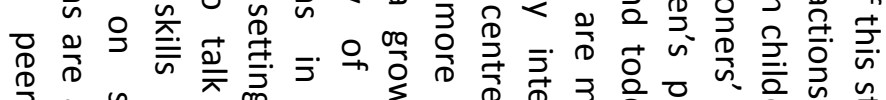

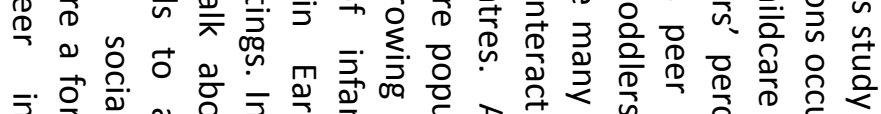

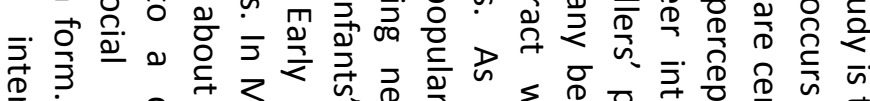

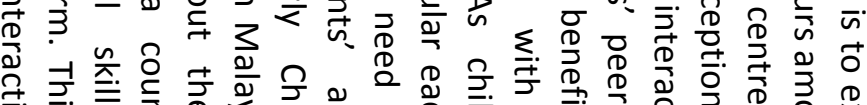

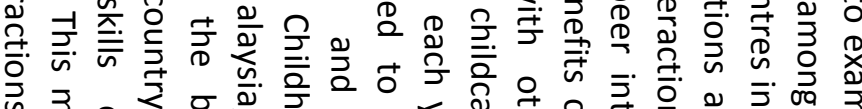

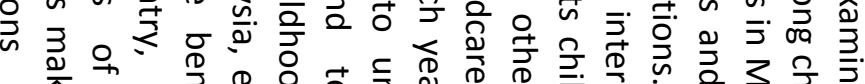
テ. 空

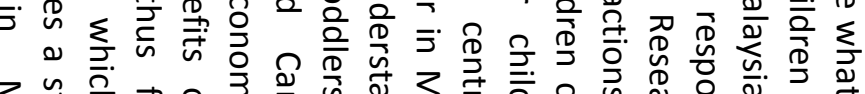

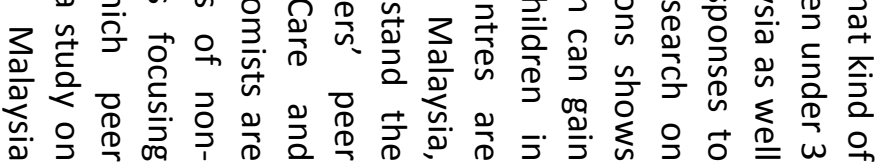
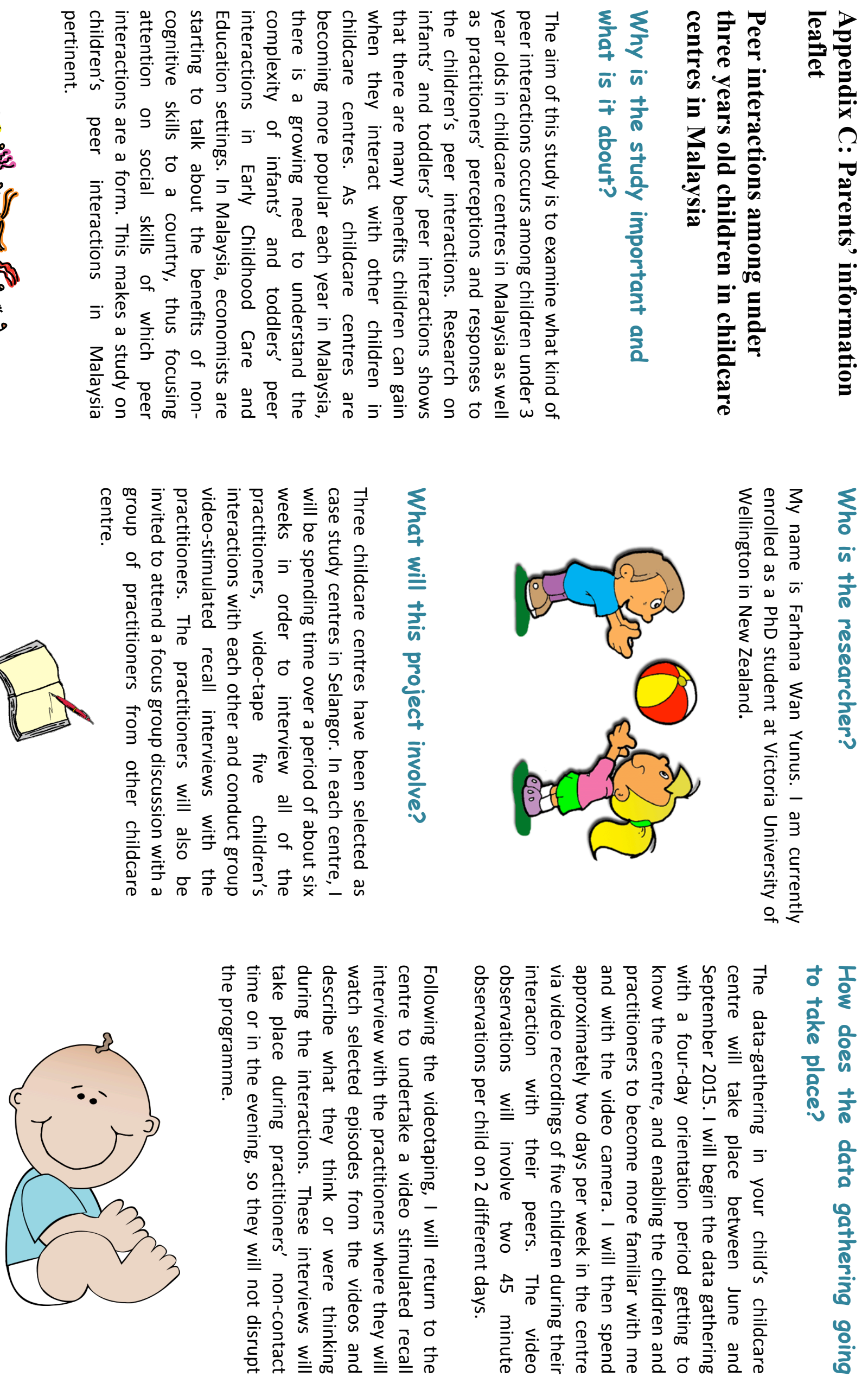

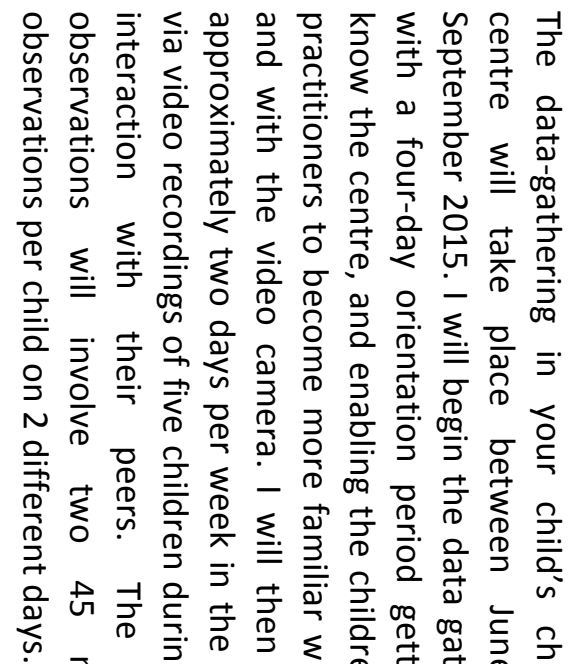

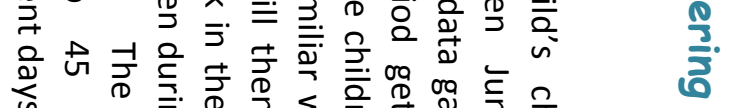

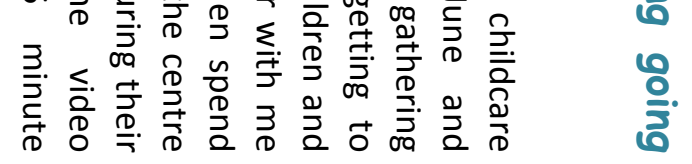



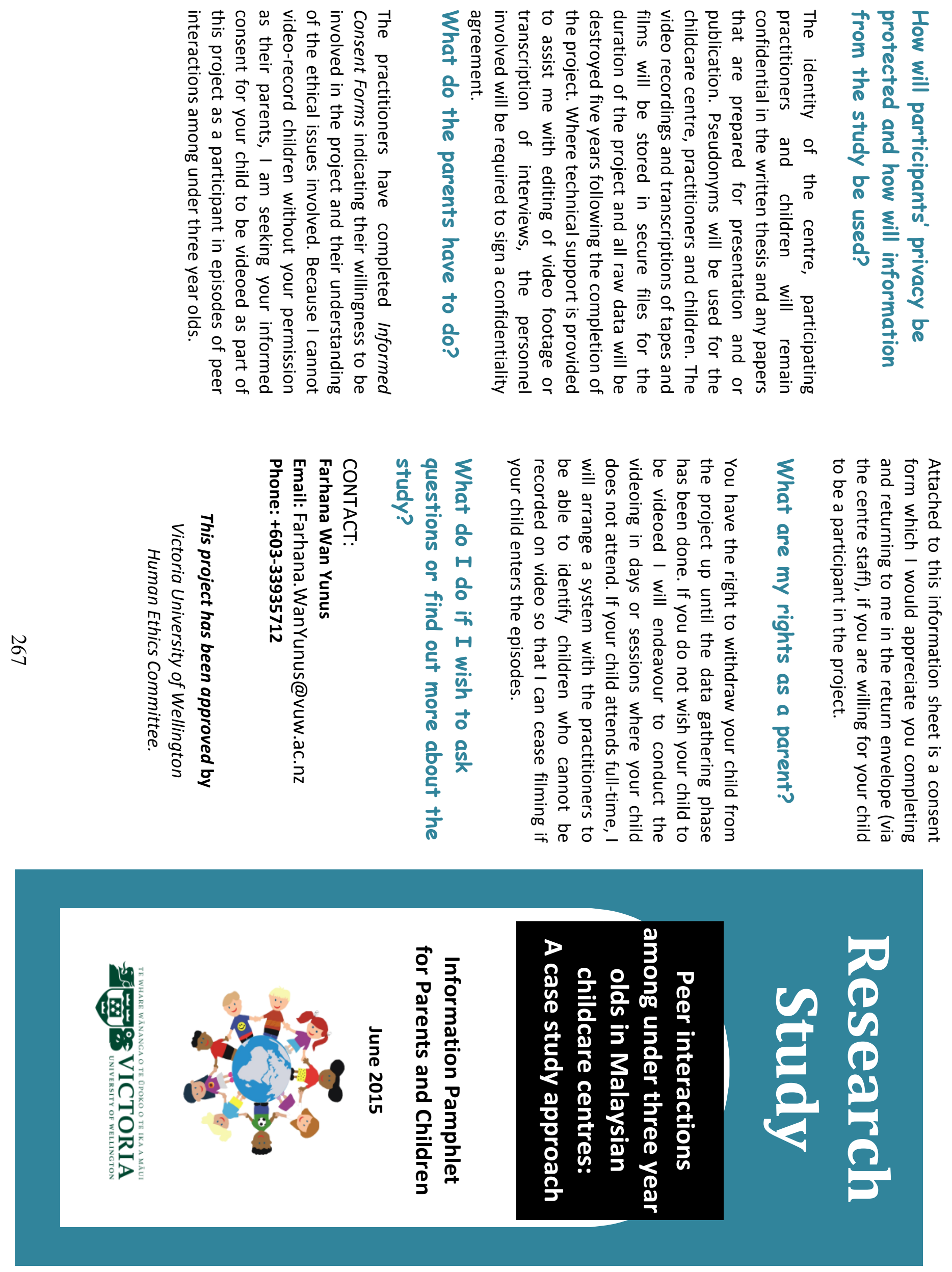


\section{Appendix D: Informed Consent Form - Parents / Guardians}

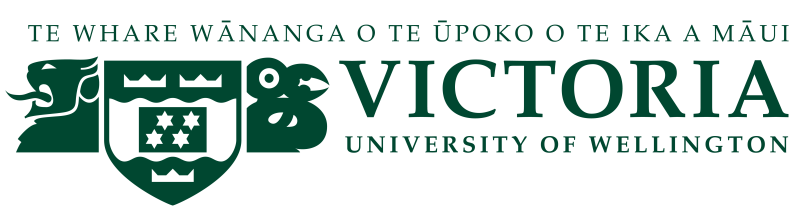

PhD project: Peer interactions among under three year olds in Malaysian childcare centres: A case study approach.

- I agree that (print name please), who is under my guardianship, may be video-recorded as part of this research.

- I have been given and have understood an explanation of this research project. I have had an opportunity to ask questions and have them answered to my satisfaction.

- I understand that the data collected will be kept confidential to the researcher and her supervisors. Any IT technicians who provide technical assistance with the editing of video tapes gathered for this project will be asked to sign confidentiality agreement.

- I understand that the published results will not use my name, my child's name or the name of the centre, or include descriptions that in any way identify my child, the centre or myself.

- I understand that the video recording of children's peer interactions and audio-tape recordings of interviews with the practitioners will be electronically wiped within five years of the conclusion of the project.

Signed:

Name of Parent / Guardian (please print clearly)

Date: 


\section{Appendix E: Semi-structured Interview Protocol with individual practitioners}

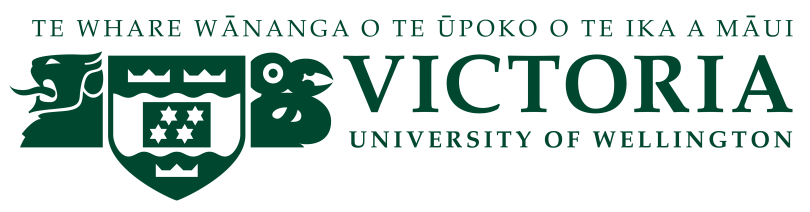

Schedule for semi-structured interview:

The purpose of the semi-structured interviews is to provide childcare centre practitioners with the opportunity to express their perception of peer interactions among under three year olds in their childcare centre. It is also to give opportunity to practitioners to talk about how they respond to peer interactions among under three year olds. This semi-structured interview will be done individually, one on one, with the researcher. Interviews will be scheduled during non-contact times or during the evenings to enable practitioners to participate and to avoid interruptions.

The interviews will use the following protocol:

1. Introduction and explanation of the interview process, including:

a. Overview of what the interview questions are about

2. Undertaking the interview, including:

b. Tape recording the interviews for future transcribing and analysis

c. Use of range of possible prompt questions to elicit deeper responses

3. Concluding the interview, including:

a. Letting the participant know that they will receive a copy of the transcribed interview so that they can check for accuracy. 


\section{Practitioner Semi-structured Interview Questions (Interview Protocol)}

\section{Practitioners' perceptions and responses to peer interactions among under three year olds in Malaysian childcare centres: A case study approach}

The questions are indicative. The questions are translated into the participants' home language by the researcher. The interview's open-ended questions are designed to answer the research questions of this study.

Time of interview:

Date:

Place:

Interviewer:

Interviewee $\&$ position of interviewee:

\section{Introduction}

As you know this interview is part of my PhD study on peer interactions among under three years old in Malaysian childcare centre.

I'm very grateful to you for your help so far. This interview should take us about an hour to get through. The questions in the interview are about:

- Your perception of peer interactions among children under three year olds

I hope you'll feel comfortable answering them all but please do feel free to pass on any one you wish not to answer. Also, please don't let the questions limit you in what you say; if you wish to elaborate on what I ask, please do. And if anything is unclear at any stage, please do ask me to clarify.

How does that sound to you? (If it's okay, then move on to the questions). 


\section{A. Background of Practitioner}

Can we start with a few questions about your background in early childhood work?

1. Could you tell me how long you have been working in the centre?

2. How long have you been working as an early childhood practitioner?

3. What other experience do you have that you think is relevant to your work as an early childhood practitioner?

4. What formal early childhood training / qualification do you have?

5. Are there other training/qualifications you have that you think are relevant to your job?

\section{B. Practitioners' views on peer interactions among under three year olds}

6. Could you tell me, what do you understand by the term peer interactions among under three years old in childcare centre?

7. Can you tell me your view about the importance of peer interactions among under three year olds?

8. Can you describe the kind of interactions you have observed among under three year olds in your centre?

9. In your view, what role do practitioners have in children's peer interactions?

10. What kind of support do you give when children interact with their peers?

11. What influences your decision to act as you do?

12. Are there particular cues/signals that you watch out for to guide your response?

13. In your view, how should practitioners support children's peer interactions?

The end. Thank you very much. 


\section{Appendix F: Video-Stimulated Recall Interview Protocol}

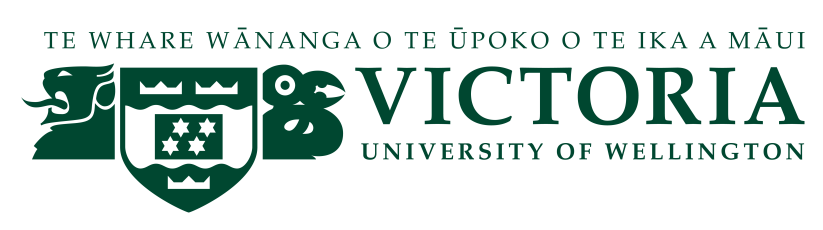

\section{Schedule for Video Stimulated Recall Interview}

The purpose of the video-SR interviews is to provide childcare centre practitioners with the opportunity to express their thoughts of peer interactions among under three year olds in their childcare centre.

Interviews will be scheduled during non-contact times or during the evenings to enable practitioners to participate and to avoid interruptions. I will provide refreshments and hope to establish a relaxed, yet focused tone for the interviews where practitioners are encouraged to openly discuss their thinking and reflections.

The interviews will use the following protocol:

1. Introduction and explanation of the interview process, including:

a. Overview of the episodes video-taped during previous visits to the centre

b. Explanation of how the selected episodes were chosen for discussion.

c. I will ask practitioners to comment about specific aspects of the episodes but also invite any other comments on the episodes.

d. Opportunities for clarification of the process and setting of further ground-rules.

2. Undertaking the interview, including:

a. Stopping the DVD to discuss elements of practitioners' thinking about each of the chosen episodes, prompted as necessary by my prepared questions. During the first playing of the DVD, practitioners will select when to stop the video for discussion. A subsequent playing of individual episodes may occur if there are aspects that I am interested in discussing further.

b. Have range of possible prompt questions to elicit deeper responses.

c. Tape recording the interviews for future transcribing and analysis

3. Concluding the interview, including:

b. Checking that all practitioners have been able to contribute.

c. If a follow-up meeting is necessary, arrange details for next meeting.

d. Inviting participants to signal particular episodes that they might want to focus on in the next round of vide-taping.

e. Checking for potential ethical considerations that may have arisen since the previous data collection round. 


\section{Possible prompts and questions to ask during video stimulated recall interview}

- I'm interested in what you think is happening here between these children?

- What do you think was happening for this child $\mathrm{A} / \mathrm{B} / \mathrm{C}$ ?

- Are there particular cues/signals that this child gives that made you think that way?

- Were there responses from the child that you found surprising/made you realise you weren't sure what he/she was thinking/trying to achieve?

- Can you describe the learning that is happening for the child - in terms of peer interactions?

- What was significant for you in this interaction? Why?

If a practitioner is involved in the video interaction, the following prompts can be used:

- Tell me about what was happening here? What were you thinking when you (intervene)?

- What were you trying to achieve when you (intervened)? Was the outcome as you expected?

- Tell me about other ways you could have responded. What outcomes could there have been? 


\section{Appendix G: Focus group ground rules}

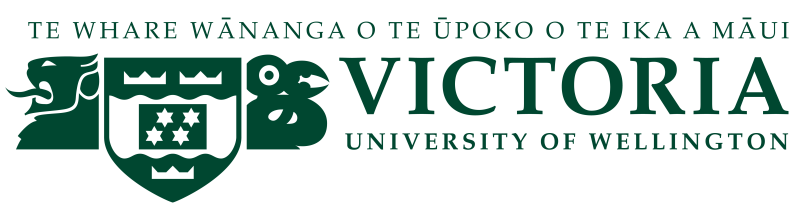

Purpose: The purpose of the focus group discussion is to provide childcare centre practitioners with the opportunity to stimulate and probe each other's memories so that indepth information on peer interactions among under three year olds in Malaysian childcare centres can be gained. The discussion will be structured around broad themes identified in the individual interviews and during observations.

Focus group discussion will be scheduled during non-contact times or during the evenings to enable practitioners to participate and to avoid interruptions. The practitioners from both childcare centres are required to come at a specific place and time for the focus group discussion. Travel expanses to and from the focus group meeting place can be reimbursed. I will also provide refreshments and aim to establish a relaxed, yet focused tone for the interviews where practitioners are encouraged to openly discuss their thinking and reflections.

\section{The focus group will use the following protocol:}

1. Introduction and explanation of the focus group, including:

e. Welcome and purpose of the focus group

f. Ground rules

- We want you to do the talking

- There are no right or wrong answers

- What is said in this room stays here

- I will be tape recording the group

g. Opportunities for clarification of the process and setting of further ground-rules.

h. Presentation of themes from observations and interviews

2. Undertaking the interview, including:

d. Tape recording the interviews for future transcribing and analysis

e. Use of range of possible prompt questions to elicit deeper responses

3. Concluding the interview, including:

4. Checking for potential ethical considerations that may have arisen during the data collection round. 


\section{Possible prompts for the focus group discussion}

1. As a start, let's go round the room and invite each practitioner to say something that was on top of their mind about broad themes.

2. Open up the contributions from practitioners (use Wh questions/tell me about...)

\section{Conclusion of discussion}

3. What do you think would strengthen interactions among children under three year olds?

4. What do you think constrains interactions among children under three year olds?

5. What are some learning moments for you?

6. What can you do to make parents and other practitioners aware of peer interactions?

7. What have you learned as participants?

8. Do you have any further ideas regarding this you would like to share?

9. This is our last meeting and so I thought it would be really good to share any insights about children's peer interactions or any questions you still have. 


\section{Appendix H: Informed Consent Form for Focus Group - Practitioners}

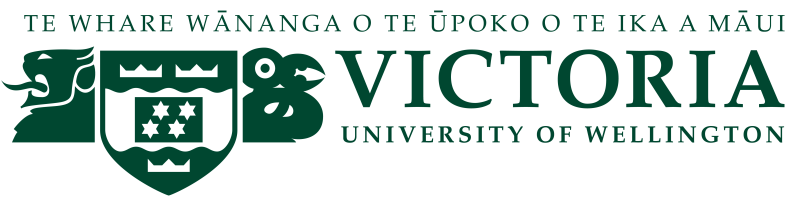

\section{PhD project: Peer interactions among under three year olds in Malaysian childcare centres: A case study approach.}

- I agree to take part in this focus group.

- I have been given and understood an explanation of this research project. I have had an opportunity to ask questions and have them answered to my satisfaction.

- I understand that the data collected will be kept confidential to the researcher and her supervisors. Any IT technicians who provide technical assistance with the editing of video tapes gathered for this project will be asked to sign confidentiality agreements.

- I understand that the published results will not use my name or the name of the centre, or include descriptions that in any way identify me or the centre.

- I understand that the audio recordings of this focus group discussion will be electronically wiped within five years of the conclusion of the project.

- I understand that I will have an opportunity to review the transcripts of the focus group for errors before publication.

- I understand that the data I provide will not be used for any other purpose or released to others without my written consent.

Signed:

Name of practitioner (please print clearly)

Date: 


\section{Appendix I: Ethics Approval from Victoria University of Wellington}

TE WHARE WĀNANGA O TE Ũ POKO O TE IKA A MĀUI

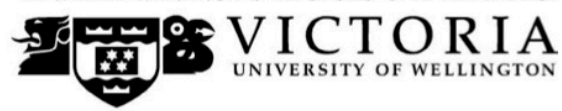

MEMORANDUM

Phone $\quad 0-4-4635480$

Email susan.corbett@vuw.ac.nz

\begin{tabular}{l|l}
\hline TO & Farhana Wan Yunus \\
\hline COPY TO & Carmen Dalli \\
\hline FROM & AProf Susan Corbett, Convener, Human Ethics Committee \\
\hline DATE & 25 June 2015 \\
\hline PAGES & 1 \\
\hline
\end{tabular}

SUBJECT Ethics Approval: 21808

Peer interactions among under three year olds in Malaysian childcare centres: A case study approach

Thank you for your application for ethical approval, which has now been considered by the Standing Committee of the Human Ethics Committee.

Your application has been approved from the above date and this approval continues until 1 February 2018. If your data collection is not completed by this date you should apply to the Human Ethics Committee for an extension to this approval.

Best wishes with the research.

Kind regards

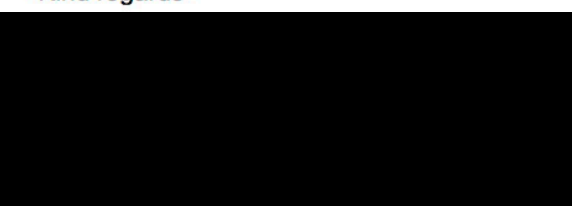

Susan Corbett

Convener, Victoria University Human Ethics Committee 


\title{
Appendix J: Ethics Approval from Economic Planning Unit, Malaysia
}$$
\text { (n) }
$$ \\ UNIT PERANCANG EKONOMI \\ Economic Planning Unit \\ Jabatan Perdana Menteri \\ Prime Minister's Department \\ Block B5 \& B6 \\ Pusat Pentadbiran Kerajaan Persekutuan \\ 62502 PUTRAJAYA \\ MALAYSIA

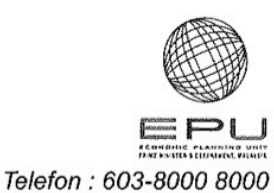 \\ Ruj. Tuan: \\ Your Ref:: \\ Ruj. Kami: UPE 40/200/19/3277 \\ FARHANA WAN YUNUS \\ Our Ref.: \\ (2) \\ 57 Lorong Lautan Samudera 9/3 \\ Tarikh: \\ Date: \\ 22 Oktober 2015 \\ Seksyen 9 \\ 42300 Puncak Aldin \\ SELANGOR \\ Email : p_hana83@yahoo.com
}

\section{APPLICATION TO CONDUCT RESEARCH IN MALAYSIA}

With reference to your application, I am pleased to inform you that your application to conduct research in Malaysia has been approved by the Research Promotion and CoOrdination Committee, Economic Planning Unit, Prime Minister's Department. The details of the approval are as follows:

Researcher's name

Passport No./ I.C No

Nationality

Title of Research

Period of Research Approved
FARHANA WAN YUNUS

830921715098

MALAYSIA

"Peer interactions among under three year olds in Malaysian childcare centres: A case study approach."

6 months

2. Please collect your Research Pass in person from the Economic Planning Unit, Prime Minister's Department, Parcel B, Level 4 Block B5, Federal Government Administrative Centre, 62502 Putrajaya, Malaysia. Bring along two (2) colour passport size photographs. Kindly, get an appointment date from us before you come to collect your research pass.

"Merancang Ke Arah Kecemerlangan" 
3. Please take note that the study should avoid sensitive issues pertaining to local values and norms as well as political elements while undertaking your research project in Malaysia. You are also required to comply with the rules and regulations stipulated from time to time by the agencies with which you have dealings in the conduct of your research.

4. I would like to draw your attention to the undertaking signed by you that you will submit without cost to the Economic Planning Unit the following documents:

a) A brief summary of your research findings on completion of your research and before you leave Malaysia; and

b) Three (3) copies of your final dissertation/publication.

5. Lastly, please submit a copy of your preliminary and final report directly to the State Government where you carried out your research. Thank you.

Yours sincerely,

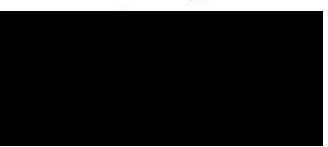

(MUNIRAH BT. ABD MANAN)

For Director General

Economic Planning Unit

E-mail: munirah@epu.gov.my

Tel : 0388882809

Fax: 0388883798

\section{ATTENTION}

This letter is only to inform you the status of your application and cannot be used as a research pass. 